CAMILA SEIÇO KATO

MÉTODO PARA ESTIMAR CUSTOS DIRETOS DA EXECUÇÃO DE EDIFÍCIOS: APLICAÇÃO À ALVENARIA ESTRUTURAL 
CAMILA SEIÇO KATO

\section{MÉTODO PARA ESTIMAR CUSTOS DIRETOS DA EXECUÇÃO DE EDIFÍCIOS: APLICAÇÃO À ALVENARIA ESTRUTURAL}

Dissertação apresentada à Escola Politécnica da Universidade de São Paulo para obtenção do título de Mestre em Engenharia

Área de Concentração:

Engenharia de Construção Civil e Urbana

Orientador: Prof. Livre-Docente

Ubiraci Espinelli Lemes de Souza 


\section{Este exemplar foi revisado e alterado em relação à versão original, sob responsabilidade única do autor e com a anuência de seu orientador.}

São Paulo, 07 de janeiro de 2013.

Assinatura do autor

Assinatura do orientador

FICHA CATALOGRÁFICA

Kato, Camila Seiço

Método para estimar custos diretos da execução de edifí -

cios: aplicação à alvenaria estrutural / C.S. Kato. -- ed.rev. -- São

Paulo, 2013.

$159 \mathrm{p}$.

Dissertação (Mestrado) - Escola Politécnica da Universidade de São Paulo. Departamento de Engenharia de Construção Civil.

1. Edifícios (Custos; Orçamentos) 2. Alvenaria estrutural I. Universidade de São Paulo. Escola Politécnica. Departamento de Engenharia de Construção Civil II. t. 


\section{DEDICATÓRIA}

A Deus e aos meus pais. 


\section{AGRADECIMENTOS}

Primeiramente, agradeço a Deus por me criar, guiar e proteger durante toda trajetória de minha vida.

Aos meus pais, José Koki Kato e Cremilda Coelho Mendes Seiço Kato, pessoas mais que amadas, são meus exemplos de vida, educadores, amigos e os meus maiores incentivadores.

Ao Ubiraci Espinelli Lemes de Souza, meu professor, chefe, orientador, amigo, pai. Agradeço por me escolher para fazer parte de seu time e por todos os ensinamentos que tem me transmitido.

Ao meu irmão José Rafael Seiço Kato, sua esposa, Telma Regina Andrade Kato e ao meu lindo e querido sobrinho Miguel Andrade Kato.

Ao meu namorado e a todos os meus amigos que têm me dado suporte durante a elaboração da dissertação, em especial os da graduação: os Poliamigos e os Civis.

Aos amigos do mestrado: Carol, Elaine, Ricardo, Renato, Adriana, Eliane, Fernanda Belizário, Paulo, Luciano, Flávia, Tathyana, Cinthia, Claudio, Maria, Jamil e Fernanda Marchiori.

A todos os Professores do curso de Engenharia Civil da Escola Politécnica, em especial à Professora Mércia Maria Semensato Bottura de Barros, por me apoiar durante a graduação e durante o mestrado; ao Professor Luiz Sérgio Franco, que me forneceu uma entrevista sobre alvenaria estrutural e, mais que isso, me autorizou a publicar indicadores que ele mesmo produziu na empresa Arco.

Aos Professores Silvio Burrattino Melhado e Khaled Ghoubar, por contribuírem com o trabalho através de críticas construtivas feitas durante o exame de Qualificação.

A todo time da Produtime: Felipe, Janaina, Débora, Edílvia, Aline, Matheus, Guilherme e, em especial, à Ellen, que tem me auxiliado nos últimos detalhes da dissertação. 
À contribuição da revisão de inglês feita por amigos da Austrália: Fernanda Maluly e Steve Gadzio.

À empresa Conx e ao Mestre Fabrício, por me fornecerem os projetos e orçamentos utilizados na dissertação.

À CAPES, pelo apoio financeiro, através da concessão de bolsa de estudos. 


\section{RESUMO}

O trabalho de mestrado propõe um método para estimar custos diretos de edificações, através da análise de fatores que comparam o edifício a ter o custo prognosticado com outro tomado como referência. Esta ferramenta é muito útil na medida em que a análise de custos durante estágios iniciais do empreendimento auxilia as empresas de Construção Civil a tomar decisões importantes, tais como a compra do terreno, o lançamento do empreendimento, a escolha da concepção arquitetônica da edificação, entre outras. O método utilizado para a elaboração desta ferramenta foi a modelagem, pois utilizou-se de análises paramétricas para descrever o funcionamento do prognóstico de custos. A simulação da ferramenta desenvolvida foi feita para o serviço de alvenaria estrutural, e envolveu levantamento bibliográfico para conhecer e quantificar os aspectos técnicos e arquitetônicos que influenciam o custo deste serviço. O método proposto, apesar de ter um desenvolvimento complexo, possui vantagens em relação a outros estudados na revisão bibliográfica, tais como: precisão, rapidez na utilização em alvenaria estrutural, entendimento de fatores influenciadores, possibilidade de atualização do método, utilização por diferentes empresas, comparação de diferentes projetos arquitetônicos.

Palavras-chave: Estimativa de custo. Edificações. Alvenaria estrutural. 


\begin{abstract}
This thesis proposes a method to forecast direct costs for multi-storey building construction. The costs are estimated by comparison to another building which costs were estimated before. The cost estimation this method provides can be very useful to improve important decisions including: land purchasing, timing to initiate marketing campaigns, and selecting architectural concepts.

The approach to develop this method was modelling; parametrical analyses were used to describe the cost prognosis. The conceptual model was tested for structural masonry direct cost estimate. To do so, bibliographical survey was used in order to identify and quantify the impact of technical and architectonic parameters on the cost of this service. The proposed method, although complex, presents many advantages when compared to existing methods including: its accuracy, speed when used for structural masonry estimates, the understanding of the trigger parameters, it is easy to include new information, allows diversity of users, and its ability to compare different architectural designs.
\end{abstract}

Keywords: Cost estimates. Building construction. Structural masonry. 


\section{LISTA DE ILUSTRAÇÕES}

Figura 1.1 - Impacto nos custos de mudanças feitas no empreendimento (adaptado de Flanagan e Tate, 1997) .5

Figura 1.2 - Diferentes abordagens de análise de custos de projetos (LOVE et al., 2002) 6

Figura 1.3 - Etapas da Metodologia de Pesquisa (PALIARI, 2008) .8

Figura 1.4 - Método de Pesquisa 12

Figura 2.1 - Classificação de gastos (OLIVEIRA; PEREZ JR, 2000) 18

Figura 2.2 - Planejamento tradicional de custos para edifícios (Adaptado de FERRY; BRANDON; FERRY, 1999) .20

Figura 2.3 - Fases do projeto e do prognóstico de custo (MARCHIORI, 2009) .21

Figura 2.4 - Diferentes desdobramentos de serviço de contrapiso sobre laje, em se variando o produto/ processo (MARCHIORI, 2009) 26

Figura 2.5 - Proposta para o processo de desenvolvimento(MELHADO,1994) 28

Figura 2.6 - Etapas do processo de análise de alternativas (ROCHA LIMA, 1985) ..31

Figura 2.7 - Cálculo do Custo Global de Construção, adaptado de ABNT NBR 12721 (2006) 37

Figura 2.8 - Fluxograma do tratamento dos dados, fonte: Losso, 1995 39

Figura 2.9 - Aplicação das Redes Neurais para prognóstico de estrutura de concreto, conforme Günaydm; Dogan, 2004

Figura 2.10 - Procedimentos de cálculos pelo CBR, conforme Kim, An e Kang (2004) 
Figura 3.1 - Desdobramento do produto e dos processos (MARCHIORI, 2009) .......53

Figura 3.2 - Custo de um edifício 54

Figura 3.3 - Fluxograma para determinação da quantidade de serviço .57

Figura 3.4 - Eficiências ligadas á transformação do recurso financeiro em físico e deste em serviço/produto

Figura 3.5 - Diferentes abordagens quanto à mão-de-obra contemplada (SILVA, 2003)

Figura 4.1 - Diferenças na quantidade de parede em uma mesma área .74

Figura 4.2 - Variação do custo de construção em função do índice de compacidade (Ic) do edifício (MASCARÓ, 1998) 75

Figura 4.3 - Amarração a) de canto com bloco especial de $35 \mathrm{~cm}$; b) de borda com blocos especiais de $55 \mathrm{~cm}$ de comprimento modular (MAMEDE, CORRÊA 2006)...81

Figura 4.4 - Amarração indireta: a) com barras de aço; b) com tela de aço (Grama, 2005) .83

Figura 4.5 - Ajuste na dimensão do vão da porta com blocos complementares (MAMEDE; CORRÊA, 2006)

Figura 4.6 - Uso de pré-moldados para acerto da altura da porta ( $A B C I, 1990) \ldots \ldots .87$

Figura 4.7 - Representação das medidas a serem utilizadas na Eq. 4.2 (TCPO, 2003) .88

Figura 4.8 - Furo vertical de bloco estrutural. .96

Figura 4.9 - Vazio do bloco canaleta .96

Figura 4.10 - Variação da quantidade de pontos de graute .99

Figura 4.11 - Variação das bitolas de armação vertical por andar 102 
Figura 4.12 - Variação da produtividade para execução de alvenaria estrutural

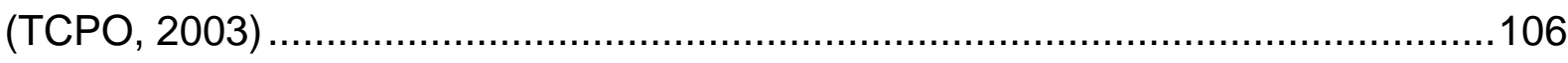

Figura 5.1 - Planta do ED1 (a ter custo prognosticado) ….................................109

Figura 5.2 - Planta do ED0 (referência) ……………..................................110

Figura 5.3 - Dimensões da seção de vazio da canaleta ......................................125

Figura 5.4 - Dimensões de furos verticais dos blocos estruturais .........................127 


\section{LISTA DE TABELAS}

Tabela 4.1 - Indicadores para estimar quantidade linear de paredes para apartamentos com até $70 \mathrm{~m}^{2}$. .76

Tabela 4.2 - Indicadores para estimar quantidade linear de paredes para apartamentos com, aproximadamente, $100 \mathrm{~m}^{2}$ 76

Tabela 4.3 - Indicadores para estimar quantidade linear de paredes para apartamentos com, aproximadamente, $250 \mathrm{~m}^{2}$ 76

Tabela 4.4 - Análise do custo de blocos com diferentes comprimentos 89

Tabela 5.1 - Curva ABC de edifício de alvenaria estrutural 108

Tabela 5.2 - Estimativa de quantidade de blocos 115

Tabela 5.3 - Custo de blocos estruturais com 4 MPa (ED1 - base out/2010) 118

Tabela 5.4 - Custo de blocos estruturais com 6 MPa (ED1 - base out/2010) 118

Tabela 5.5 - Custo de blocos estruturais com 8 MPa (ED1 - base de out/2010) ....118

Tabela 5.6 - Custo de blocos estruturais com 10 MPa (ED1 - base de out/2010) ..119

Tabela 5.7 - Custo de blocos estruturais com 12 MPa (ED1 - base de out/2010)..119

Tabela 5.8 - Custo de blocos estruturais com 14 MPa (ED1 - base de out/2010) ..119

Tabela 5.9 - Custos de blocos estruturais para ED1 (base de out/2010) 120

Tabela 5.10 - Quantidade de graute por andar 127

Tabela 5.11 - Custo de graute do ED1 128

Tabela 5.12 - Quantidade de aço vertical 130

Tabela 5.13 - Custo de armação do ED1 131 


\section{LISTA DE QUADROS}

Quadro 1.1 - Classificação da dissertação

Quadro 2.1 - Caracterização dos Projetos- padrão da norma ABNT NBR 12721 (Adaptado de SINDUSCON-MG, 2007)

Quadro 2.2 - Análise das estimativas de custo levantadas - continua .45

Quadro 3.1 - Serviços pertencentes às curvas $A$ e $B$ de uma curva $A B C$, conforme Gonçalves (2011) .56

Quadro 4.1 - Dimensões usuais de mercado para blocos de concreto M-15 e M-20 (MAMEDE, CORRÊA 2006) .82

Quadro 4.2 - Vãos modulares e esquadrias preferidas (LUCINI; 2001) - continua ...84 Quadro 4.3 - Dimensões nominais do vão de portas (ABNT NBR 15930-2:2011) ....86 Quadro 4.4 - Indicadores para estimar quantidade de blocos .89

Quadro 4.5 - Distribuição percentual de componentes de blocos estruturais, sem considerar as canaletas .90

Quadro 4.6 - Faixas de variação de perdas de blocos (SOUZA, 2001) 91

Quadro 4.7 - Pesos associados a outros fatores influenciadores (SOUZA, 2001) ....92 Quadro 4.8 - Pesos relativos a diferentes realizações dos fatores influenciadores (SOUZA; 2001) .94

Quadro 4.9 - Quantidade de juntas $\left(\mathrm{em} \mathrm{m} / \mathrm{m}^{2}\right.$ ) em função do tamanho do componente de alvenaria (SOUZA; 2001) .95

Quadro 4.10 - $\Delta$ perdas associadas a outros fatores (SOUZA; 2001)...... .95

Quadro 4.11 - Preenchimento vertical dos furos verticais: blocos (OLIVEIRA JUNIOR, 1992) 
Quadro 4.12 - Preenchimento horizontal dos vazios: canaletas (OLIVEIRA JUNIOR, 1992)

Quadro 4.13 - Indicadores de quantidade de graute vertical Q0 .98

Quadro 4.14 - Valores de RUP totais de referências 107

Quadro 5.1 - Principais características do ED1 109

Quadro 5.2 - Principais características do ED0 110

Quadro 5.3 - Quantidade de serviço (área líquida de paredes estruturais) do pavimento tipo para ED1

Quadro 5.4 - Custos dos insumos do ED0 (base de out/2010) 113

Quadro 5.5 - Distribuição percentual de componentes de blocos estruturais, sem considerar as canaletas

Quadro 5.6 - Faixas de variação de perdas de blocos (SOUZA, 2001) 116

Quadro 5.7 - Pesos associados a outros fatores influenciadores (SOUZA, 2001) ..117

Quadro 5.8 - Pesos relativos a diferentes realizações dos fatores influenciadores (SOUZA; 2001).

Quadro 5.9 - $\Delta$ perdas associadas a outros fatores (SOUZA; 2001) 122

Quadro 5.10 - Indicadores de quantidade de graute vertical Q0 125 


\section{SUMÁRIO}

1 INTRODUÇÃO

1.1 Construção Civil Brasileira: panorama atual, perspectivas e desafios 1

1.2 A importância do prognóstico de custos nas fases iniciais do empreendimento 3

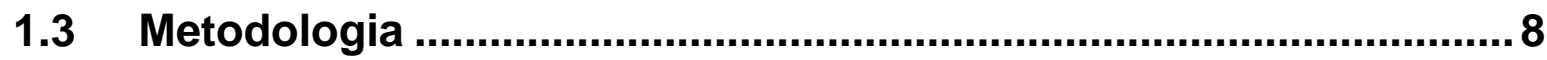

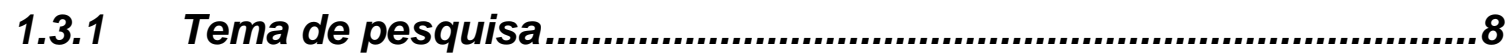

1.3.2 Formulação do problema de pesquisa .............................................

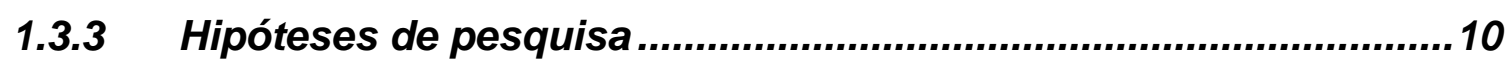

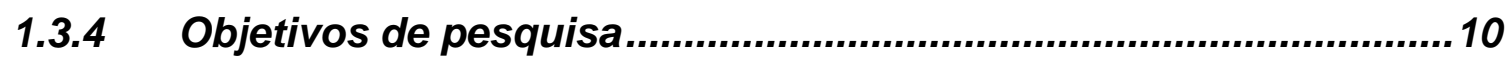

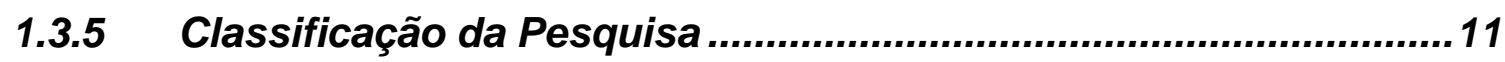

1.4 Método de Pesquisa......................................................................... 12

1.4.1 Levantamento Bibliográfico.........................................................12

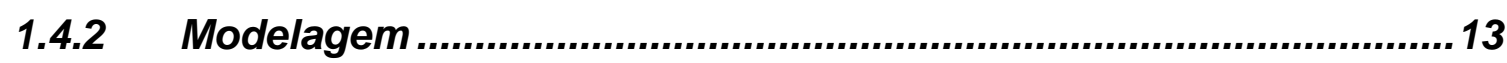

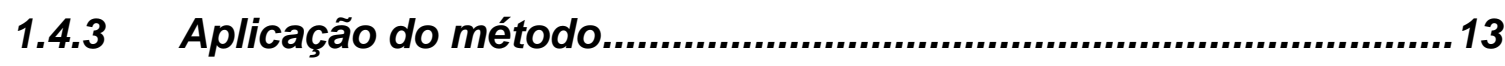

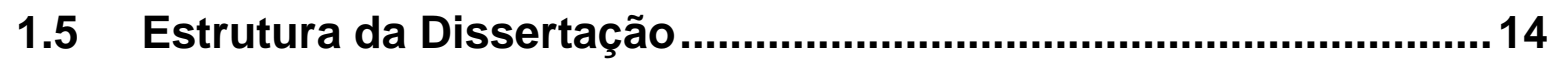

2 O ESTUDO DOS CUSTOS DE EDIFICAÇÕES ............................ 16

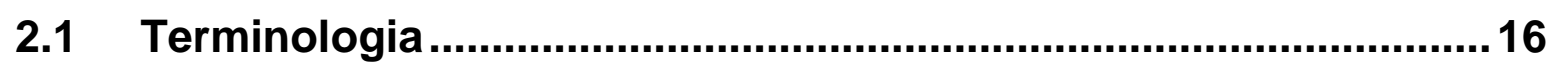

2.2 Considerações gerais para prognósticos de custo.......................18

2.3 Prognóstico de custo ao longo do desenvolvimento do empreendimento .................................................................................... 20

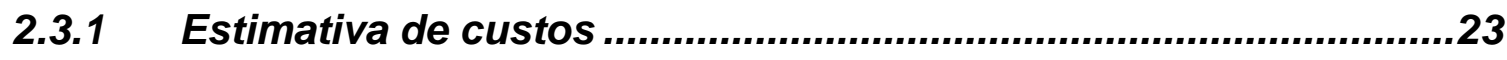

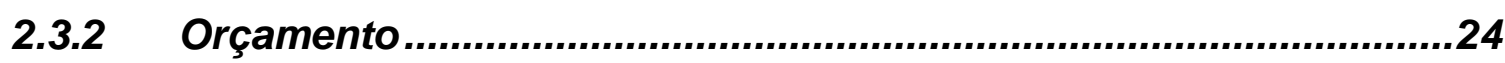

2.4 A estimativa de custo dentro do Processo de Projeto .................27

2.5 Métodos para estimativa de custo................................................... 32

2.5.1 CUB

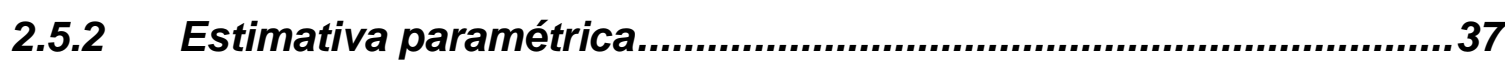

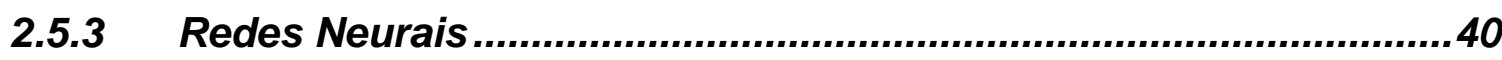

2.5.4 Raciocínio Baseado em Casos ("Case-based reasoning - CBR").42

2.5.5 Análise sobre as estimativas de custo ...........................................4 
3.1 Entendimento e premissas do método proposto..........................50

3.2 Desenvolvimento do método …..................................................52

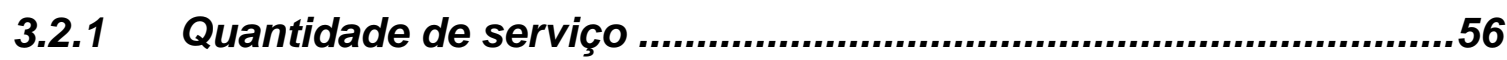

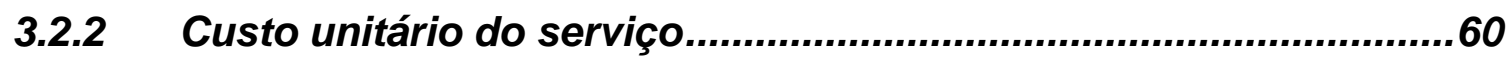

3.2.2.1 SUBFATOR DE CUSTO UNITÁRIO LIGADO AOS MATERIAIS .........................62

3.2.2.2 SUBFATOR DE CUSTO UNITÁRIO LIGADO À MÃO-DE-OBRA ........................66

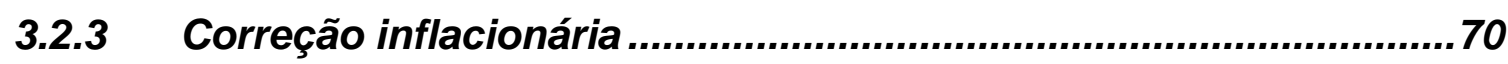

\section{DESENVOLVIMENTO DO MÉTODO PARA ALVENARIA}

ESTRUTURAL .............................................................................. 73

4.1 Quantidade de alvenaria estrutural (QServ) ................................73

4.2 Custo unitário ligado aos materiais ................................................77

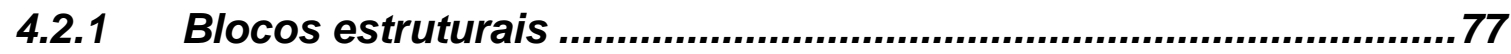

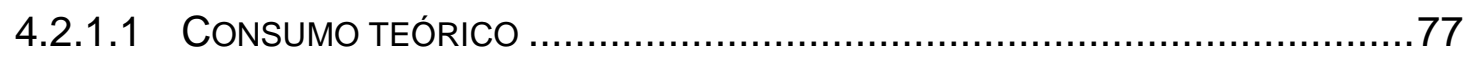

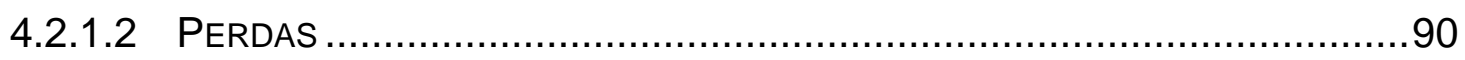

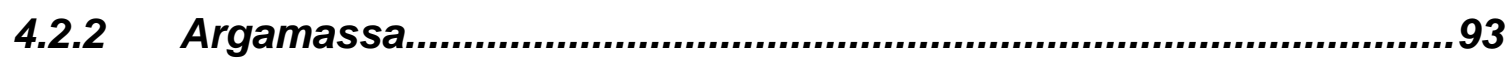

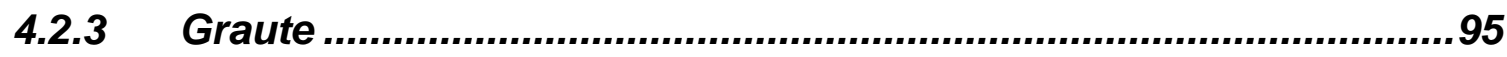

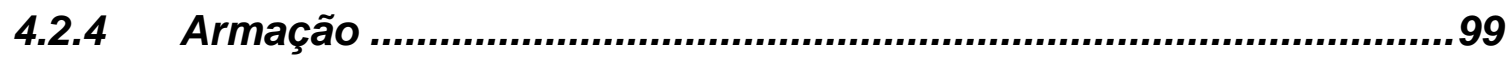

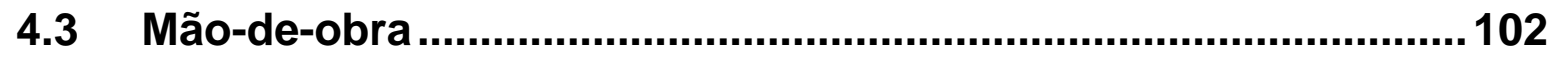

\section{APLICAÇÃO DO MÉTODO AO ESTUDO DE ALVENARIA}

\section{ESTRUTURAL ............................................................................. 108}

5.1 Quantidade de serviço .............................................................111

5.2 Custo unitário do serviço ............................................................112

5.2.1 Subfator de custo unitário ligado aos materiais ..........................113

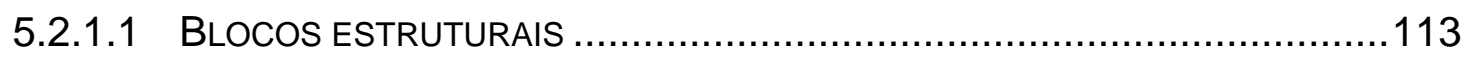

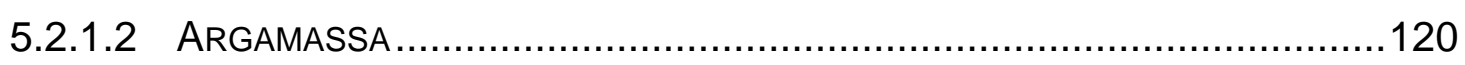

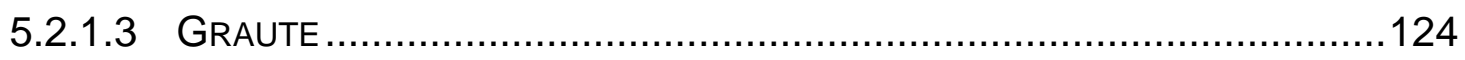

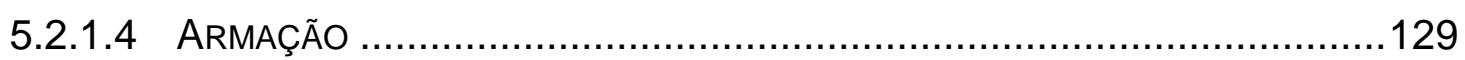

5.2.1.5 CÁLCULO DO SUBFATOR LIGADO AOS MATERIAIS ..............................131

5.2.2 Subfator de custo unitário ligado à mão-de-obra ..........................134

5.2.3 Cálculo do fator do custo unitário.............................................135 
5.3 Custo do serviço de alvenaria estrutural....................................136

5.4 Atualização dos valores para maio de 2012 .................................137

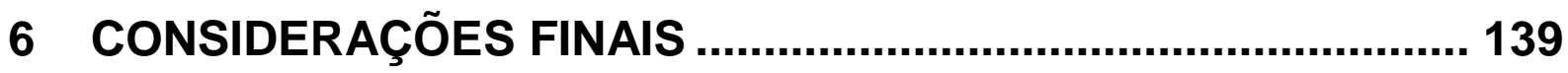

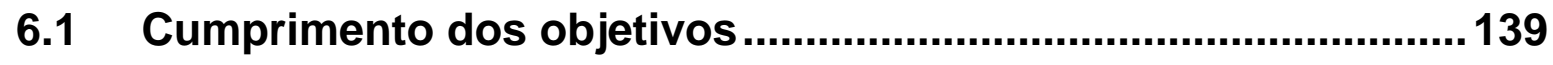

6.2 Avaliação crítica do método proposto …......................................140

6.3 Relevância do método apresentado.............................................141

6.4 Sugestões para próximos trabalhos sobre o tema......................142 REFERÊNCIAS BIBLIOGRÁFICAS .............................................. 143 APÊNDICE A - ENTREVISTA SEMI-ESTRUTURADA COM PROJETISTA DE ALVENARIA ESTRUTURAL .............................. 154

A.1 Estimativa e indicadores de blocos ….........................................155

A.2 Quantidade de graute ................................................................... 156

A.3 Quantidade de aço ...................................................................158 


\section{INTRODUÇÃO}

O trabalho de mestrado será apresentado através de sua contextualização, explicitando a importância de seu desenvolvimento. Em seguida, mostra-se a metodologia aplicada em sua elaboração e a estrutura que a dissertação possui.

\subsection{Construção Civil Brasileira: panorama atual, perspectivas e desafios}

A crise financeira mundial de 2008 atingiu o setor da construção a partir de agosto do mesmo ano. Com a crise, os exageros que aconteciam no mercado da construção foram evidenciados, pois os valores da oferta pública das ações de empresas que abriram seus mercados "foram pautados por valores muito além do razoável" deste modo, "as ações caíram mais do que o mercado" (ROCHA LIMA, 2008). De acordo com a consultora da FGV Projetos Ana Maria Castelo (CASTELO, GALA, 2009), este panorama resultou em "um momento de piora nas condições de crédito para capital de giro, queda nas vendas, redução do número de lançamentos, redução do emprego além da sazonalidade e desaceleração no setor e na cadeia produtiva".

A fim de minimizar os efeitos desta crise, foram tomadas as seguintes medidas no Brasil (MONTEIRO FILHA et al., 2011):

- desoneração tributária de alguns materiais de construção: esta medida consistiu na redução de tributos, tendo como o mais impactante, a redução do Imposto sobre Produtos Industrializados (IPI), levando à queda dos preços dos materiais de construção civil;

- expansão do crédito para habitação: com a implantação do Programa Minha Casa, Minha Vida e a expansão da atuação de bancos públicos o crédito imobiliário habitacional duplicou em 2009;

- aumento do aporte de recursos para investimentos no âmbito do PAC. 
Tais medidas, mais que atenuar os efeitos da crise, proporcionaram o crescimento da indústria da Construção Civil no país. Cabe ressaltar, ainda, que o país possui perspectivas futuras bem otimistas, já que sediará grandes eventos: a Copa do Mundo de futebol, em 2014, e os Jogos Olímpicos, em 2016. Deste modo, investimentos em diferentes áreas da construção estão sendo feitos, como a construção de estádios e hotéis, a ampliação e melhoria da infraestrutura, entre outros. Além disso, é importante verificar que, a exemplo dos outros países que receberam tais eventos, os investimentos que serão realizados provocarão efeitos diretos e indiretos sobre o crescimento da economia do país como um todo (MONTEIRO FILHA et al., 2011).

Porém, entrar neste mercado em expansão não é tarefa simples. Atuando na construção civil brasileira, em 2009, existiam cerca de 64 mil empresas (IBGE, 2009); assim, para sobreviver neste mercado, uma nova empresa deve oferecer produtos pelos quais os consumidores tenham preferência em relação a outros existentes, mantendo-se financeiramente estável ao longo do tempo (MCT; 2000).

Para Rocha Lima (1993), os atributos de uma habitação se concentram na relação entre preço/ qualidade, e é através desta análise que os consumidores escolhem os produtos de construção.

Para Neto, Fensterseifer e Formoso (2003), além do preço e da qualidade, são desejos dos clientes da construção: condições de pagamento facilitadas; bom desempenho do produto; possibilidade de alterações; introdução de inovações; bom atendimento ao cliente e disponibilização de assistência técnica eficaz após a entrega.

Com relação ao preço de uma habitação, seu valor é determinado pela soma do custo com o lucro. Como, atualmente, a concorrência tem se tornado cada vez mais acirrada, o preço de venda é um valor definido em mercado, considerado como o "valor máximo que o cliente está disposto a pagar". Assim, para que a margem de lucro atinja o resultado desejável para um empreendimento, é necessário que se reduza os custos (CARDOSO, 2009).

Como a população de baixa renda é o foco dos créditos habitacionais do Governo Federal, a redução de custos se torna um fator competitivo ainda mais valorizado. 
A fim de minimizar os efeitos da crise de 2008 e diminuir o déficit habitacional do Brasil (que, segundo a Fundação Pinheiro e o Centro de Estatística em Informação (2011), em 2008, era estimado em mais de 5,5 milhões de domicílios), o Governo Federal lançou o Programa Minha Casa Minha Vida, que promove a construção de novas unidades habitacionais para as camadas da população com menor renda, concebendo expressivos subsídios (Caixa Econômica Federal, 2011).

De acordo com Monteiro Filha et al. (2011) e Faria (2008), como lucro o imobiliário é baixo neste mercado, para poderem ser competitivas, as empresas devem buscar tecnologias que baixem seus custos de produção.

Obviamente, reduzir custos passa pela capacidade de prevê-lo, principalmente para que as ações visando tal redução possam ser implementadas. Assim, devido à importância do prognóstico de custo dentro do processo de empreender em Construção Civil, a sua avaliação deve ser feita em diferentes etapas deste processo, ou seja, desde a análise de viabilidade, passando pela definição do produto até o acompanhamento dos reais custos incorridos em obra, para compor dados históricos, que serão utilizados em novos orçamentos (ASSUMPÇÃO; FUGAZZA, 2000).

\subsection{A importância do prognóstico de custos nas fases iniciais do empreendimento}

O custo de uma edificação é definido por sua concepção; cada traçado projetado representa um elemento que, por sua vez, irá consumir diferentes tipos de insumos durante a construção (MASCARÓ, 1998).

Deste modo, fica claro que os custos de empreendimentos são mais afetados pelas decisões tomadas por projetistas que pelos executores (construtores); ou seja, os custos são mais determinados pelas decisões feitas no início de sua concepção que pelas decisões feitas em obra (ELHAG; BOUSSABAINE; BALLAL, 2005).

Melhado e Agopyan (1995) verificaram ainda que é durante as fases iniciais de um empreendimento que se podem fazer alterações de produto para se reduzir custos 
de execução com os menores gastos em sua elaboração, sem impactar na qualidade do produto, pois, se tais modificações forem feitas em fase adiantada de projeto ou, ainda, durante a execução da obra, ocorrerão retrabalhos dos serviços já realizados. Tal afirmação é compartilhada também por Flanagan e Tate (1997), os quais explicam no início do empreendimento, soluções de reduções de custos podem ser facilmente implementadas porque o produto ainda é flexível o bastante para incorporar mudanças. Uma vez definido o projeto e iniciada a construção, o potencial para redução de custos é pequeno.

De acordo com Isaac e Navon (2009), mudanças feitas em edificações, durante a elaboração de seus projetos finais ou sua execução, são as maiores causas de atrasos, excessos de custos e desvios nos requisitos de desempenho. Os autores constataram que, devido à falta de ferramentas para avaliação de mudanças em projeto, quando estas são implementadas, os projetistas não avaliam, integralmente, os impactos gerados nos custos, prazos e desempenho da edificação, o que pode impactar negativamente tanto na qualidade do empreendimento, quanto nas exigências do cliente.

A Figura 1.1, apresentada por Flanagan e Tate (1997), ilustra este raciocínio a partir de duas curvas traçadas em relação ao ciclo de vida de um empreendimento: a primeira mostra o potencial de redução de custos, enquanto a segunda mostra quanto se deve desembolsar para fazer mudanças no empreendimento. 


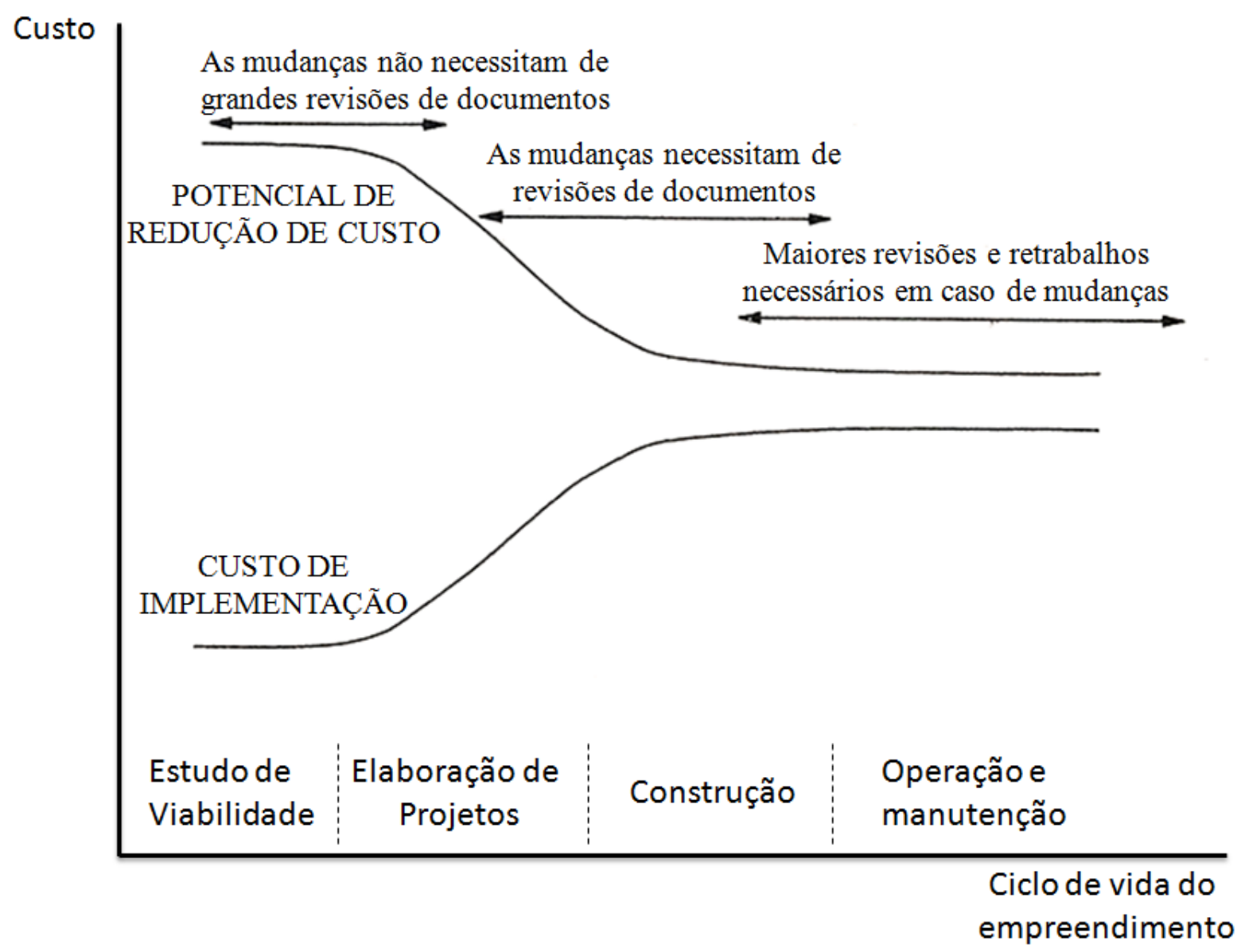

Figura 1.1 - Impacto nos custos de mudanças feitas no empreendimento (adaptado de Flanagan e Tate, 1997)

Karshenas (1984) aponta a estimativa de custos como uma análise importante para diferentes agentes da construção: para o empreendedor, a estimativa auxilia na verificação da viabilidade da execução da obra; para os projetistas, o estudo de custos pode auxiliar na escolha entre diferentes tipos de produtos; já para os construtores, é importante se fazer uma estimativa de custos de obras para auxiliálos em participações de licitações e na elaboração de seus orçamentos de contratos. Acrescenta-se, ainda, a este raciocínio, a importância da estimativa de custos para análise de inovações tecnológicas a serem utilizadas em um empreendimento (CARDOSO; ABIKO, 2000).

A análise de viabilidade financeira e econômica é feita pelo empreendedor para verificar se o negócio proposto é factível (com relação aos recursos disponíveis pela empresa) e rentável, ou seja, proporciona uma taxa de retorno atrativa (ROCHA 
LIMA, 1985). Esta análise envolve, principalmente, o estudo de quatro variáveis: preço de venda, distribuição de vendas, custos de construção e programação da obra. De acordo com Belchior et al. (2007), os preços de venda e custos representaram os fatores mais influentes sobre a rentabilidade do negócio; assim, pode-se concluir que desenvolver um produto com custo previsto neste estudo é um fator crucial para atingir o resultado esperado.

A determinação de um produto é feita pelo seu projeto que, por sua vez, determina o custo do produto. Assim, para Love et al. (2002) há dois modos que um projetista tem para conceber um empreendimento de construção civil: concepção de um produto que custe um valor pré-determinado ao empreendedor; ou a concepção de um produto sem esta limitação pré-estabelecida. No primeiro caso, o projetista deve ser capaz de analisar o custo de cada traço feito, para que possa atender às exigências do empreendedor. Já no segundo, apesar de o projetista possuir maior liberdade na concepção, é necessário estimar o custo do produto desenvolvido, de modo a analisar a viabilidade do empreendimento.

A Figura 1.2 ilustra as abordagens expostas por estes autores.

PROJETAR COM CUSTO LIMITE

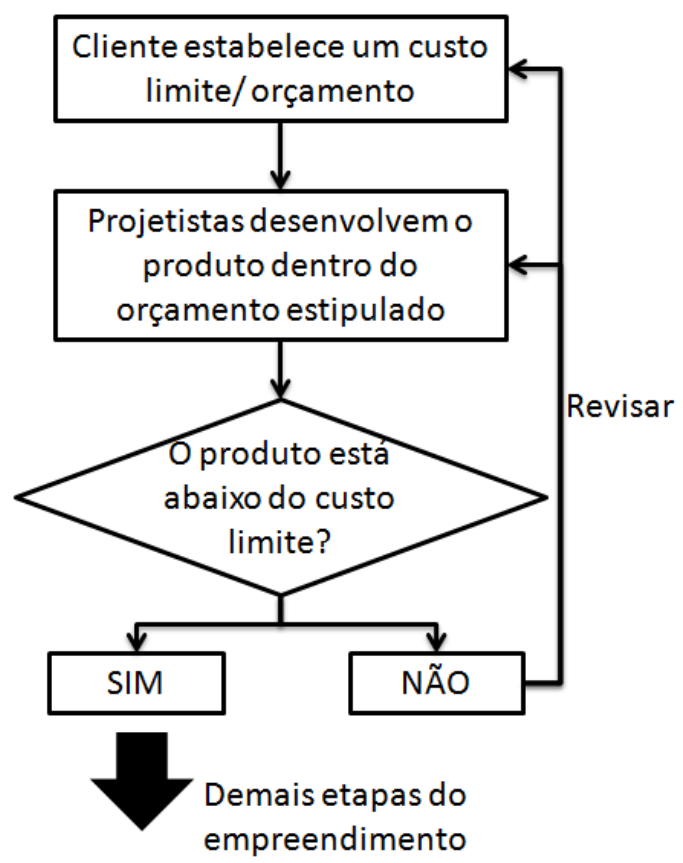

ORÇAR UM PROJETO

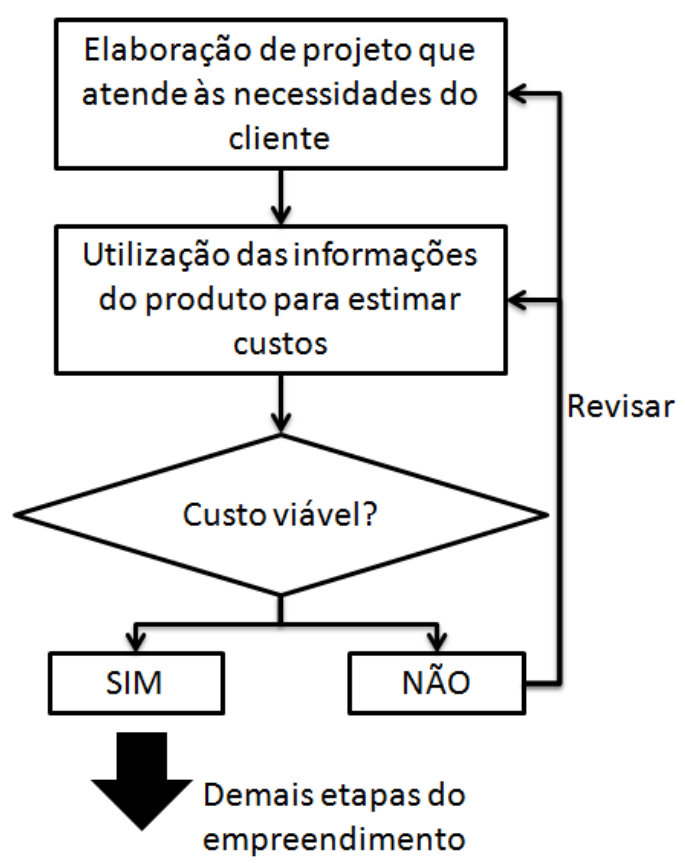

Figura 1.2 - Diferentes abordagens de análise de custos de projetos (LOVE et al., 2002) 
Outro fato que exige análise de custos é a seleção da tecnologia a ser adotada na construção. De acordo com Barros (1996), Cardoso e Abiko (2000) e Souza e Sabbatini (2004), a fim de melhorar a competitividade, as empresas têm buscado novas tecnologias que, principalmente, aumentem a qualidade e produtividade de suas obras. A adoção de uma inovação passa por uma análise das alternativas tecnológicas, que envolve a verificação do benefício econômico-financeiro que trarão, frente ao investimento necessário, desde que estas atendam o desempenho necessário e esperado. Portanto, para a seleção de uma nova tecnologia, entre outros critérios, o empreendedor deve avaliar os custos de sua execução, sendo necessário, para isto, que esta avaliação consiga comparar soluções diferentes, com variações de produtividade e consumo de materiais.

De acordo com o que foi exposto acima, verifica-se a grande importância da avaliação de custos nas fases iniciais de um empreendimento. Porém, durante este momento, poucas são as informações disponíveis acerca do produto a ser desenvolvido, já que os projetos ainda não foram totalmente definidos; assim, estimativas simplistas que apenas correlacionem o valor de um empreendimento a outro, sem entender os fatores influenciadores, podem gerar valores imprecisos de custos (STOY; SCHALCHER, 2007).

No entanto, mesmo em etapas iniciais do empreendimento, é importante que a definição dos custos tenha valores confiáveis; erros na sua definição podem acarretar em redução do lucro da empresa, na redução do padrão de acabamento da construção (que pode minimizar a qualidade do produto, insatisfazendo o usuário final), ou, ainda, em obra inacabada por falta de recursos (CARDOSO, 2009; GONÇALVES; 2011).

Portanto, um prognóstico preciso de custos, com base em informações preliminares do empreendimento, que consiga comparar diferentes concepções, avaliando, inclusive, a produtividade e consumo de materiais, pode ser uma ferramenta muito poderosa para diferentes tomadas de decisões garantindo rentabilidade a baixo custo, tornando o empreendedor mais competitivo frente ao mercado da Construção Civil. 
Dentro deste contexto, esta dissertação vai apresentar um método que prognostique custos com base em indicadores (relacionados não apenas à área de construção), na utilização de uma edificação de referência e na análise de parâmetros técnicos e arquitetônicos, tendo por inspiração o Modelo dos Fatores (THOMAS et al., 1990), que associa resultados às suas causas.

\subsection{Metodologia}

Gil (2008) definiu pesquisa como um procedimento racional e sistemático com objetivo de elaborar respostas aos problemas que são propostos. O autor considera que a pesquisa deve ser desenvolvida em diferentes etapas, que envolvem desde a formulação do problema até a apresentação dos resultados, utilizando, para isto, métodos, técnicas e outros procedimentos científicos.

De acordo com Paliari (2008), a Figura 1.3 representa o fluxograma que envolve as diferentes etapas de uma pesquisa.

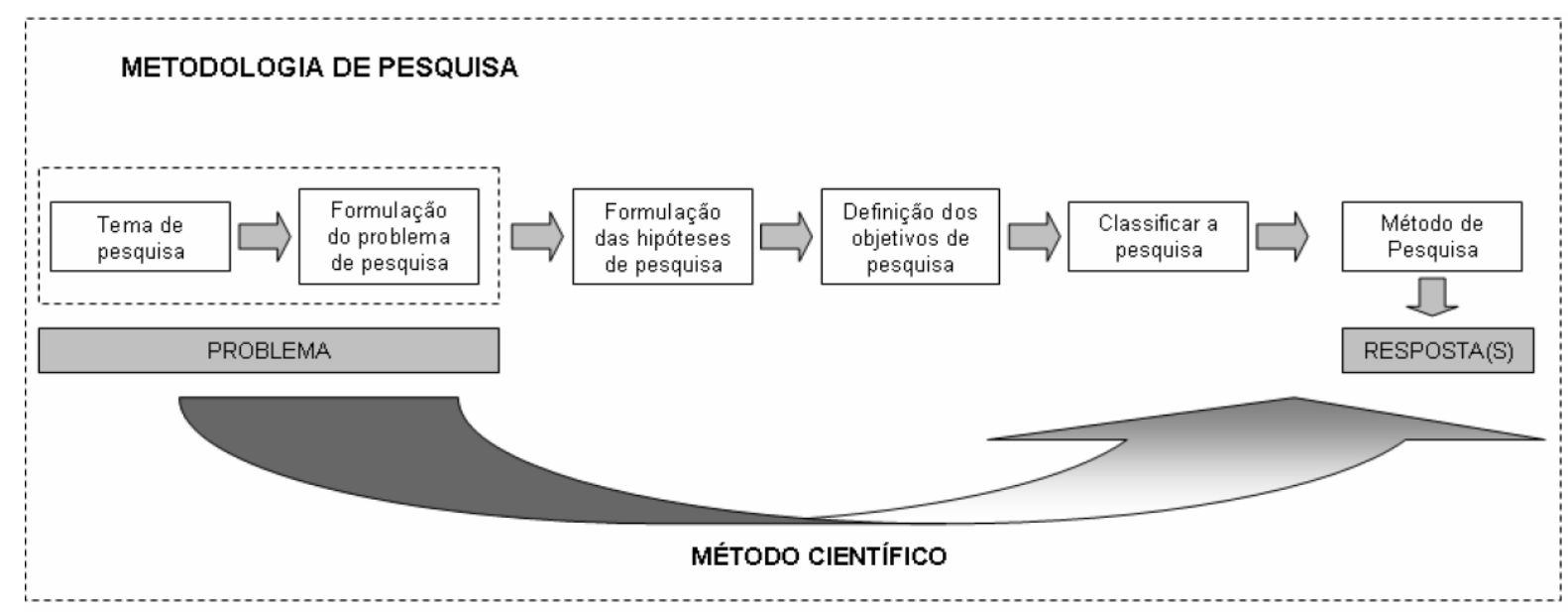

Figura 1.3 - Etapas da Metodologia de Pesquisa (PALIARI, 2008)

\subsubsection{Tema de pesquisa}

Marconi e Lakatos (2008) definem o tema de pesquisa como o assunto que se deseja estudar e pesquisar, o qual deverá ser preciso, bem determinado e específico. 
O tema adotado neste trabalho é:

Elaboração de um método para estimar o custo de empreendimentos da Construção Civil.

De acordo com Marconi e Lakatos (2008), delimitar a pesquisa á estabelecer limites para a investigação em relação ao assunto, extensão ou uma série de fatores. No caso da pesquisa desenvolvida no presente trabalho, foi dada uma delimitação em relação ao assunto; assim, a estimativa se refere a custos diretos de construção com enfoque em edificações. Além disso, a aplicação numérica do método de estimativa será feita apenas para alvenaria estrutural dos andares tipo, sem considerar a transição no térreo.

Deste modo, o tema delimitado é:

Elaboração de um método para estimar o custo direto de edificações, com aplicação à alvenaria estutural, desconsiderando a transição estrutural no térreo.

\subsubsection{Formulação do problema de pesquisa}

Gil (2008) define o problema de pesquisa como a questão não resolvida, objeto de discussão, em qualquer domínio do conhecimento. Para Marconi e Lakatos (2008), o problema é a dificuldade teórica ou prática no conhecimento de algo, para que se deva encontrar uma solução.

Marconi e Lakatos (2008) indicam, ainda, que a formulação do problema deve ser em forma interrogativa, clara, concisa e objetiva. Além disso, os autores consideram que a formulação de um problema é valorizada a partir de sua análise em relação à viabilidade, relevância, novidade, exeqüibilidade e oportunidade em atender a interesses particulares e gerais.

Com base nestas definições, o problema a ser estudado no presente trabalho é: 
Como estimar o custo direto de uma edificação com informações de estudo preliminar e quais são os parâmetros deste método no caso de sua aplicação à alvenaria estrutural?

\subsubsection{Hipóteses de pesquisa}

De acordo com Gil (2008), a hipótese é uma proposição para solucionar o problema de pesquisa, podendo ser declarada verdadeira ou falsa, de acordo com o teste a ser realizado pelo estudo. Sua elaboração envolve a criatividade do pesquisador, que pode utilizar sua experiência na área.

A hipótese do presente trabalho é:

A estimativa do custo direto de um empreendimento pode ser feita através do estudo do custo de cada serviço que o compõe que, por sua vez, pode ser prognosticado através da análise dos fatores que influenciam as variações nos custos de seus recursos, tais como: quantidade de serviço, materiais e mão-de-obra.

\subsubsection{Objetivos de pesquisa}

De acordo com Marconi e Lakatos (2008), o objetivo de uma pesquisa tem a função de informar o que se procura e o que será alcançado, explicitando o problema a ser estudado.

O objetivo principal do presente trabalho é:

Elaboração de um método para prognóstico de custos diretos de construção, com base no estudo preliminar de arquitetura, para dar apoio às tomadas de decisões visando atender o valor previsto no estudo de viabilidade de edificações.

Para a elaboração deste método, há a necessidade de desenvolver estudos que constituem os seguintes objetivos específicos: 
- revisão crítica quanto às metodologias empregadas em estimativas de custo;

- desenvolvimento do método proposto para estudo do serviço de alvenaria estrutural, verificando as variações técnicas e arquitetônicas que podem implicar no custo deste serviço e levantando os indicadores disponíveis na bibliografia que auxiliam a estimativa de quantidades de serviço e de custo unitários;

- aplicação do método proposto ao serviço de alvenaria estrutural, a fim de mostrar a utilização do método e os cálculos envolvidos para este serviço.

\subsubsection{Classificação da Pesquisa}

De acordo com as fontes pesquisadas (PALIARI, 2008; MARCONI e LAKATOS, 2008; GIL, 2008; BERTO e NAKANO, 1999), a pesquisa pode ter diferentes classificações.

Com base na tese de Paliari (2008), foi elaborado o Quadro 1.1, que mostra as classificações dadas à presente dissertação.

Quadro 1.1 - Classificação da dissertação

\begin{tabular}{|l|l|l|}
\hline Tipo & Classificação & Características \\
\hline $\begin{array}{l}\text { De acordo com a } \\
\text { natureza }\end{array}$ & Aplicada & $\begin{array}{l}\text { Resultados possuem interesses práticos e } \\
\text { podem ser utilizados em problemas reais }\end{array}$ \\
\hline $\begin{array}{l}\text { Forma de abordagem } \\
\text { do problema }\end{array}$ & Quantitativa & $\begin{array}{l}\text { As informações podem ser traduzidas em } \\
\text { números }\end{array}$ \\
\hline $\begin{array}{l}\text { Caráter sob o ponto de } \\
\text { vista dos objetivos a } \\
\text { serem alcançados }\end{array}$ & Exploratório & $\begin{array}{l}\text { Identifica os fatores que determinam ou } \\
\text { contribuem para ocorrência de fenômenos }\end{array}$ \\
\hline $\begin{array}{l}\text { Segundo as fontes de } \\
\text { informação }\end{array}$ & $\begin{array}{l}\text { Bibliográfica } \\
\text { entrevista }\end{array}$ & $\begin{array}{l}\text { Utiliza pesquisa em documentos e foi feita uma } \\
\text { entrevista. }\end{array}$ \\
\hline Método de Pesquisa & Modelagem & $\begin{array}{l}\text { Uso de técnicas matemáticas para descrever o } \\
\text { funcionamento de um sistema ou de parte dele. }\end{array}$ \\
\hline
\end{tabular}




\subsection{Método de Pesquisa}

O estudo desenvolvido neste trabalho foi realizado em três fases principais: levantamento bibliográfico, modelagem do prognóstico de custos e sua aplicação (Figura 1.4).

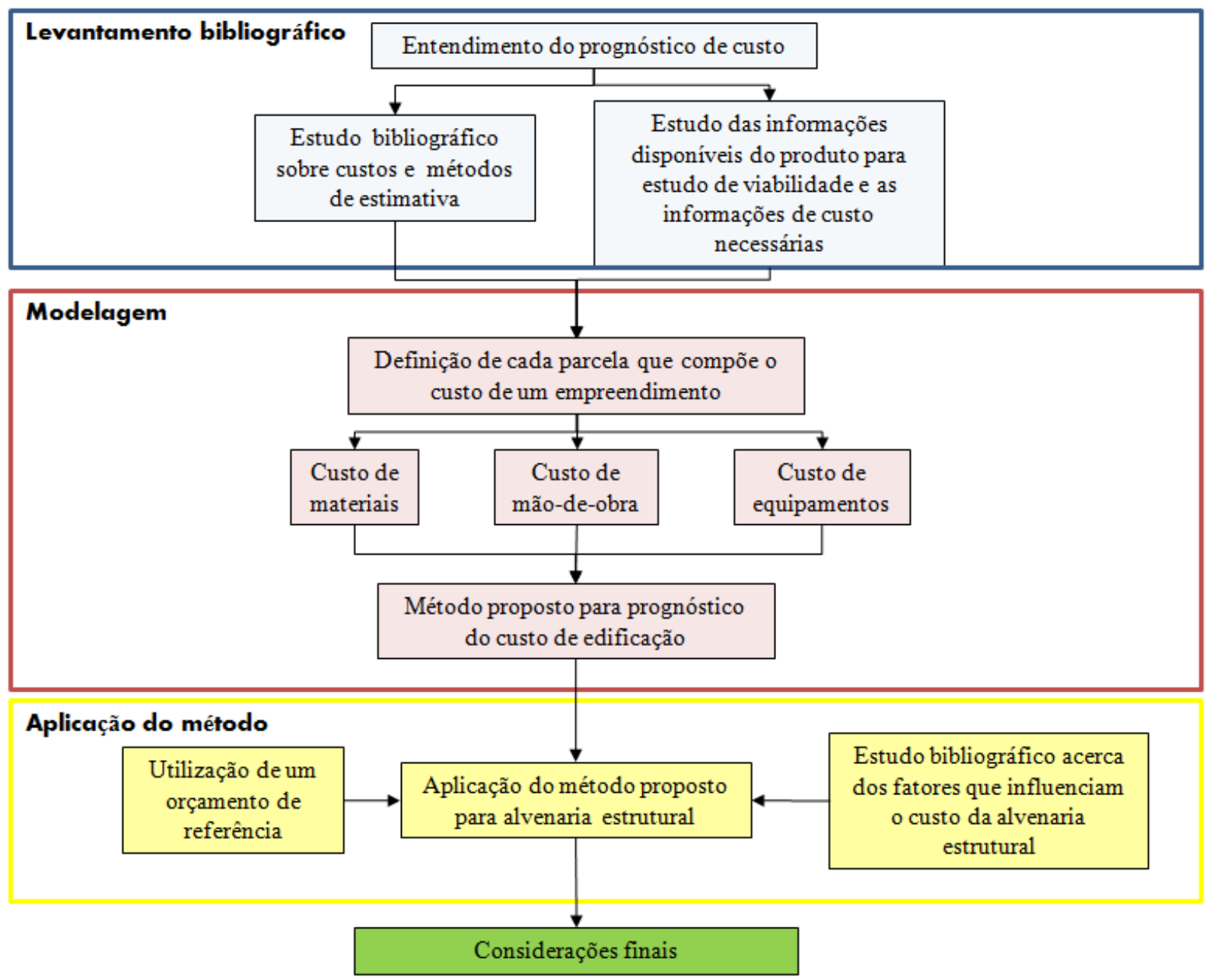

Figura 1.4 - Método de Pesquisa

\subsubsection{Levantamento Bibliográfico}

Apesar de acompanhar as fases posteriores da pesquisa, o levantamento bibliográfico foi o primeiro passo no entendimento e delimitação do tema proposto.

Inicialmente, foram levantadas informações a respeito de custos e seu estudo durante o ciclo de um empreendimento. A partir destas informações, buscaram-se 
na bibliografia os métodos de prognóstico de custo atuais, e se analisaram os pontos fortes e fracos de tais estimativas.

Como o objetivo deste trabalho é apresentar um método de estimativa, buscaram-se na bibliografia quais seriam as informações disponíveis para o prognóstico e quais seriam os dados de custo necessários para o gestor avaliar a concepção arquitetônica de modo a garantir a viabilidade de um empreendimento.

\subsubsection{Modelagem}

O método de estimativa proposto foi desenvolvido através da decomposição do custo direto de um empreendimento em produtos menores que, por sua vez, foram analisados através de sua quantidade e dos insumos que os compõem, quais sejam: materiais e mão-de-obra.

Através de levantamento bibliográfico, principalmente em trabalhos realizados pelo grupo de pesquisa ao qual este trabalho pertence, foram verificados os fatores que influenciam cada parcela do custo e o modo de mensuração para se obter o custo prognosticado.

Tal mensuração leva em conta um empreendimento tomado como referência, que terá o custo por área construída comparado com o empreendimento a ser estudado através dos fatores influenciadores, os quais determinarão pesos que qualificam as diferenças no custo dos dois empreendimentos. Com o valor destes pesos, é possível estimar o custo direto do empreendimento em estudo.

\subsubsection{Aplicação do método}

Não se pretende nesta dissertação apresentar todas as equações e cálculos utilizados para estimar o custo de um empreendimento inteiro, pois, como já foi apresentado no objetivo, pretende-se, com este estudo, apresentar o raciocínio para elaborar um método de prognóstico de custos diretos que possa ser aplicado a diferentes tipos de edificações. 
Deste modo, foi feita a aplicação do método às paredes de alvenaria estrutural.

Primeiramente, foram desenvolvidos os cálculos e levantados indicadores que estimam cada parcela do método proposto através da pesquisa bibliográfica sobre alvenaria estrutural. Para se obterem informações mais específicas e para complementar os dados pesquisados, foi feita, durante esta etapa, uma entrevista com um especialista em alvenaria estrutural do tipo não estruturada - focalizada, ou seja, apesar de o entrevistado ter liberdade para desenvolver o assunto, havia um roteiro de tópicos a ser seguido durante a entrevista (MARCONI; LAKATOS, 2008).

Tais cálculos foram utilizados, posteriormente, na aplicação a um caso real a fim de verificar a aplicabilidade do método.

\subsection{Estrutura da Dissertação}

A dissertação está dividida em seis Capítulos:

- Capítulo 1: mostra a importância de se prognosticarem custos no início da vida de um empreendimento; além disso, explica a metodologia utilizada no desenvolvimento da dissertação;

- Capítulo 2: faz a revisão bibliográfica sobre as definições de custo, a análise de custo em função do estágio de desenvolvimento de um empreendimento, mostra quais são as informações requeridas e disponíveis em um estudo preliminar, e é finalizado com a descrição dos métodos de estimativa de custos utilizados atualmente no Brasil e no mundo;

- Capítulo 3: apresenta o método elaborado para o prognóstico de custos diretos, definindo os vários influenciadores, os quais são calculados a partir de um empreendimento tomado como referência;

- Capítulo 4: a partir da apresentação geral do método proposto no Capítulo 3, foi feito o seu desenvolvimento para contemplar o serviço de alvenaria estrutural, através de uma pesquisa bibliográfica que identificou os fatores técnicos e arquitetônicos que influenciam tanto a quantidade de serviço, 
quanto o seu custo unitário; além disso, buscaram-se, na literatura e através de entrevista com especialista em alvenaria estrutural, quais os indicadores de referência utilizados para este serviço;

- Capítulo 5: é feita a aplicação do método proposto no Capítulo 3, utilizando as informações coletadas no Capítulo 4; pretende-se mostrar ao usuário do método como se calcula cada fator no prognóstico de custo, utilizando, para isto, um empreendimento de referência;

- Capítulo 6: avalia-se o método proposto para estimativa de custo, verificando se o mesmo atende aos objetivos listados no Capítulo 1 e sugerindo caminhos para seu aprimoramento. 


\section{O ESTUDO DOS CUSTOS DE EDIFICAÇÕES}

A elaboração de um método exige, primeiramente, o conhecimento dos conceitos envolvidos, das limitações existentes e do processo no qual se insere.

Além disso, pretende-se, neste capítulo, situar o momento em que a estimativa de custo é realizada e verificar quais são os métodos existentes, a fim de verificar os pontos fortes e fracos de cada um, e obter subsídios para a elaboração de um novo método.

\subsection{Terminologia}

De acordo com Cabral (1988), a palavra custos tem sido conceituada de formas divergentes na área da Construção Civil, sendo muitas vezes utilizada para se referir a gastos, despesas, desembolsos etc.

Para uniformizar a nomenclatura adotada nesta dissertação, foi feito um levantamento conceitual dos gastos que podem ocorrer em empreendimentos da Construção Civil, a partir da publicação de Oliveira e Perez Jr (2000).

Estes autores definiram gasto como um consumo genérico de bens e serviços por meio de desembolso passado, presente ou futuro. Para estes autores, os custos e despesas são tipos de gastos e podem ser definidos como:

- custo é o valor dos bens e serviços que são consumidos na produção de outros bens e serviços, e que pode ser relacionado a eles; como exemplos, têm-se o custo de materiais utilizados em uma obra e salários da gerência da fábrica;

- despesa é o valor dos bens e serviços consumidos no processo de geração de receitas e manutenção dos negócios da empresa, ou seja, são gastos ocorridos fora da fábrica, nas áreas administrativas, financeiras e comerciais; como exemplos, têm-se os impostos e aluguéis de prédios da administração. 
De acordo com as variações no volume das atividades produtivas e das vendas, para Oliveira e Perez Jr (2000), os gastos podem ser fixos ou variáveis. Deste modo, os conceitos relacionados a esta classificação são:

- custos fixos: custos que permanecem constantes dentro de determinada capacidade instalada, independentemente do volume de produção; assim, uma alteração no volume de produção não altera o valor dos custos fixos (exemplos: salários das chefias de departamentos e setores produtivos, aluguel de máquinas produtivas etc.);

- custos variáveis: custos que mantêm uma relação direta com o volume de produção ou serviço (exemplos: matéria-prima, mão-de-obra direta etc.);

- despesas fixas: despesas constantes dentro de determinada faixa de atividades geradores de receitas, independentemente do volume de vendas ou de prestação de serviços (exemplos: salários dos funcionários administrativos, despesas financeiras etc.);

- despesas variáveis: despesas que variam proporcionalmente às variações no volume de receitas (exemplos: impostos incidentes sobre o faturamento, comissões de vendedores sobre vendas etc.).

Quanto à forma de identificação e apropriação, os autores classificaram os custos e despesas em diretos ou indiretos, conforme as seguintes definições:

- custos diretos: custos que podem ser quantificados e identificados aos produtos e serviços (exemplos: materiais, mão-de-obra direta etc);

- custos indiretos: custos que não podem ser apropriados de forma direta com os produtos ou serviços, necessitando de critério de rateio para sua alocação (exemplos: equipamentos de uso geral, alimentação e transporte da mão-deobra, salários da equipe de planejamento e controle da produção etc.);

- despesas diretas: despesas que podem ser quantificadas e correlacionadas em relação às receitas de vendas e de prestação de serviços; 
- despesas indiretas: despesas que não podem ser identificadas com precisão com as receitas geradas (exemplo: despesas administrativas, despesas com imposto de renda etc).

A Figura 2.1 ilustra a classificação adotada por Oliveira e Perez Jr (2000).

\begin{tabular}{|c|c|c|c|}
\hline & \multicolumn{2}{|c|}{ Gastos } & \\
\hline & \multicolumn{2}{|c|}{ Consumo de bens e serviços } & \\
\hline \multicolumn{2}{|c|}{ Custos } & \multicolumn{2}{|c|}{ Despesas } \\
\hline \multicolumn{2}{|c|}{$\begin{array}{l}\text { Gastos incorridos na produção } \\
\text { de novos bens ou serviços }\end{array}$} & \multicolumn{2}{|c|}{$\begin{array}{c}\text { Gastos incorridos no processo } \\
\text { de geração de receitas }\end{array}$} \\
\hline Fixos & Variáveis & Fixas & Variáveis \\
\hline $\begin{array}{l}\text { Total constante } \\
\text { em relação ao } \\
\text { volume } \\
\text { produzido }\end{array}$ & $\begin{array}{c}\text { Total variável em } \\
\text { relação ao } \\
\text { volume } \\
\text { produzido }\end{array}$ & $\begin{array}{l}\text { Total constante } \\
\text { em relação ao } \\
\text { volume } \\
\text { de receitas }\end{array}$ & $\begin{array}{l}\text { Total variável em } \\
\text { relação ao } \\
\text { volume de } \\
\text { receitas }\end{array}$ \\
\hline $\begin{array}{c}\text { Aluguel } \\
\text { Depreciação }\end{array}$ & Material direto & $\begin{array}{c}\text { Despesas } \\
\text { administrativas }\end{array}$ & $\begin{array}{c}\text { Comissões sobre } \\
\text { vendas }\end{array}$ \\
\hline Indiretos & Diretos & Indiretas & Diretas \\
\hline $\begin{array}{c}\text { Alocados de } \\
\text { forma subjetiva } \\
\text { por critérios de } \\
\text { rateio }\end{array}$ & $\begin{array}{l}\text { Alocados de } \\
\text { forma objetiva } \\
\text { por meio de } \\
\text { controles }\end{array}$ & $\begin{array}{c}\text { Alocados de } \\
\text { forma subjetiva } \\
\text { por critérios de } \\
\text { rateio }\end{array}$ & $\begin{array}{l}\text { Alocados de } \\
\text { forma objetiva } \\
\text { por meio de } \\
\text { controles }\end{array}$ \\
\hline
\end{tabular}

Figura 2.1 - Classificação de gastos (OLIVEIRA; PEREZ JR, 2000)

Com base na sua importância para os gastos com edificações e sua correlação com o projeto do produto, o presente trabalho se restringirá ao prognóstico de custos diretos de construção (materiais e mão-de-obra).

\subsection{Considerações gerais para prognósticos de custo}

Um prognóstico de custo não é e nem tem pretensão de ser o valor exato do desembolso que o construtor terá no decorrer da obra. De acordo com Mattos (2007), o cálculo de um custo envolve incertezas pelo simples fato de ele ser feito em tempo anterior à realização da obra. Assim, diversas são as premissas adotadas e que devem ser acompanhadas em todo o processo. 
Este autor relacionou os atributos que o prognóstico de custo tem, e que devem ser adotados nas premissas: a aproximação, a especificidade e a temporalidade.

Por se tratar de uma previsão,o prognóstico de custo deve ser preciso enquanto técnica de gerar um valor de referência; mas é aproximado na medida em que os parâmetros usados para sua definição podem variar. Esta aproximação é feita em diversos itens, tais como: mão-de-obra (são adotados valores de produtividade prevista e percentuais de encargos que podem divergir do real praticado); material (os impostos e preços podem ser reajustados durante a obra); perda de materiais (pode variar mais do que foi previsto em orçamento); entre outros (MATTOS, 2007).

Com relação à especificidade, Mattos (2007) defende a idéia de que o valor de uma obra varia de acordo com a empresa (o orçamento contém custos ligados à administração da empresa, ao padrão de canteiro, ao número adotado para cargos de supervisão da obra etc.); e de acordo com as condições locais, já que o clima, relevo, vegetação, tipo de solo, oferta de mão-de-obra e equipamentos, legislação local, entre outros fatores, influenciam a determinação do custo de um empreendimento.

Como o orçamento é feito antes da execução da obra, seus valores não serão válidos na data de desembolso, se ele não for reajustado. Este reajuste deve ser feito devido a fatores como a flutuação no custo dos insumos ao longo do tempo; criação ou alteração de impostos e encargos sociais e trabalhistas; evolução dos métodos construtivos (que pode ser alterado em relação àquele que tinha sido adotado); ocorrência de diferentes cenários financeiros e gerenciais (MATTOS, 2007).

Diante do exposto, verifica-se que um prognóstico de custo tem limitações e especificidades que devem ser levadas em conta durante sua elaboração e durante a sua atualização ao longo do desenvolvimento do empreendimento. 


\subsection{Prognóstico de custo ao longo do desenvolvimento do empreendimento}

O prognóstico de custos demanda informações sobre o produto a ser executado. Para Assumpção e Fugazza (2000), a qualidade da informação para especificar o orçamento "melhora na medida em que o empreendimento avança e detalham-se os projetos, fornecendo quantidades que possam ser mensuradas com melhor qualidade, e os custos são também melhor apropriados".

A fim de verificar o planejamento de custos praticado na Inglaterra, Ferry, Brandon e Ferry (1999) elaboraram o esquema da Figura 2.2, que retrata a influência da concepção do produto na análise de seu custo.

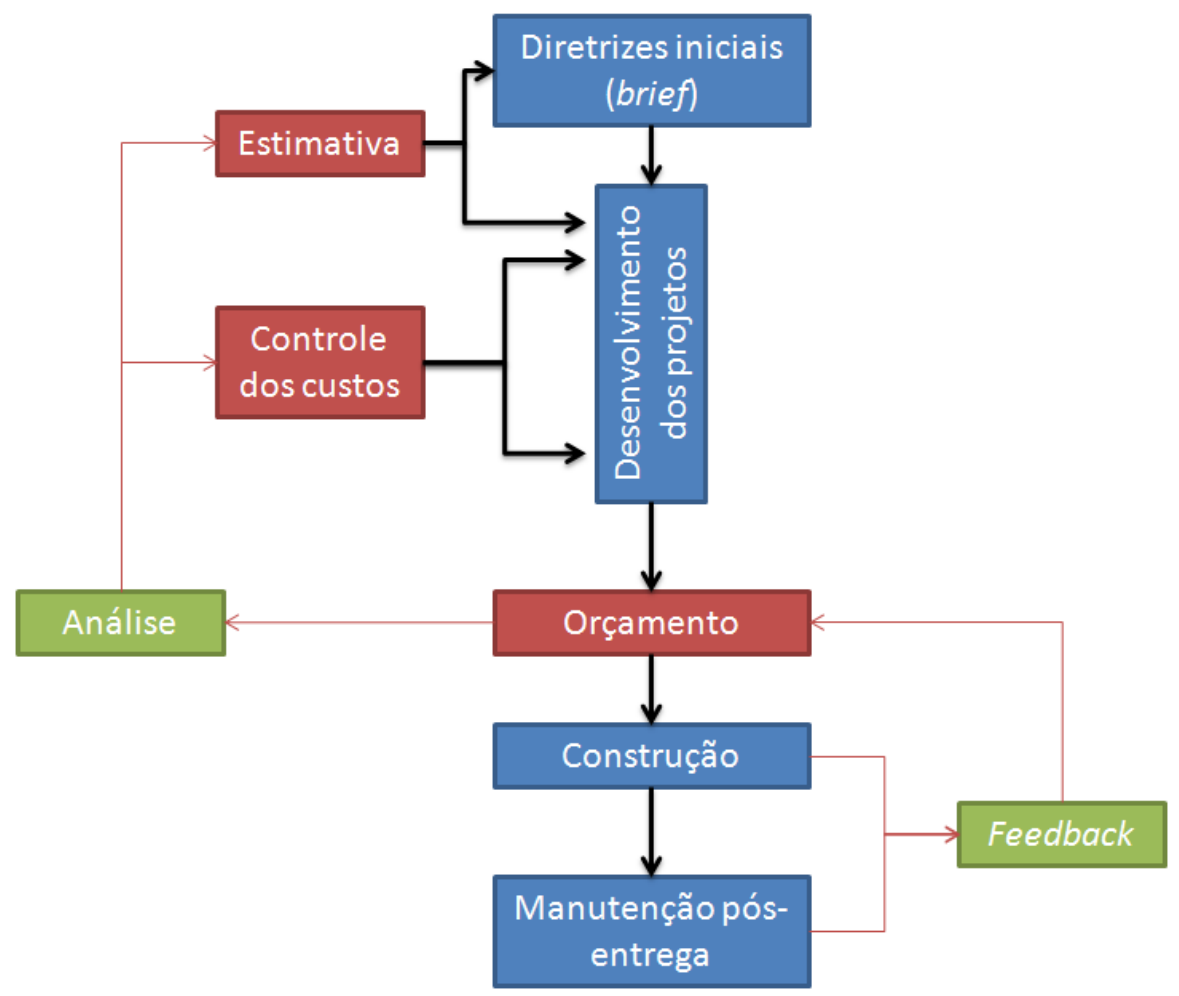

Figura 2.2 - Planejamento tradicional de custos para edifícios (Adaptado de FERRY; BRANDON; FERRY, 1999)

De acordo com estes autores, a partir das necessidades do cliente são definidas as diretrizes iniciais do produto, as quais devem ser base para a investigação preliminar do custo, a fim de analisar a viabilidade em se fazer o empreendimento. Para Kamara, Anumba e Evbuomwan (2001), as informações desta etapa devem ser claras o bastante para convencer o cliente de que o empreendimento é um bom 
negócio a se investir; assim, é usual a elaboração de esboços da edificação a ser construída nesta etapa.

Como as diretrizes iniciais são informações muito preliminares, tal estimativa deve ser revisada durante a concepção, para verificar se o produto atende aos custos prédeterminados. Deste modo, é importante que o desenvolvimento dos projetos seja feito com certo controle, por parte dos projetistas, para que sigam as diretrizes adotadas na elaboração das estimativas e não extrapolem os recursos previstos para sua execução. Logicamente, durante o detalhamento do produto, modificações podem ser sugeridas, mas, para serem incorporadas, as alterações de custo também devem ser investigadas para que se obtenha um real aprimoramento do produto (FERRY; BRANDON; FERRY, 1999).

Após a elaboração dos projetos, é possível realizar o orçamento detalhado da obra, indicando os quantitativos e os custos de todos os serviços que a compõem. Tais quantidades serão verificadas durante a obra, gerando informações que retroalimentem o planejamento de custos de um novo empreendimento (FERRY; BRANDON; FERRY, 1999).

A exemplo do esquema de planejamento de custos apresentados na Figura 2.2, a fim de melhor verificar a integração entre as fases de projeto e prognóstico de custo, Marchiori (2009) propôs a evolução do processo de orçamento, conforme mostra a Figura 2.3.

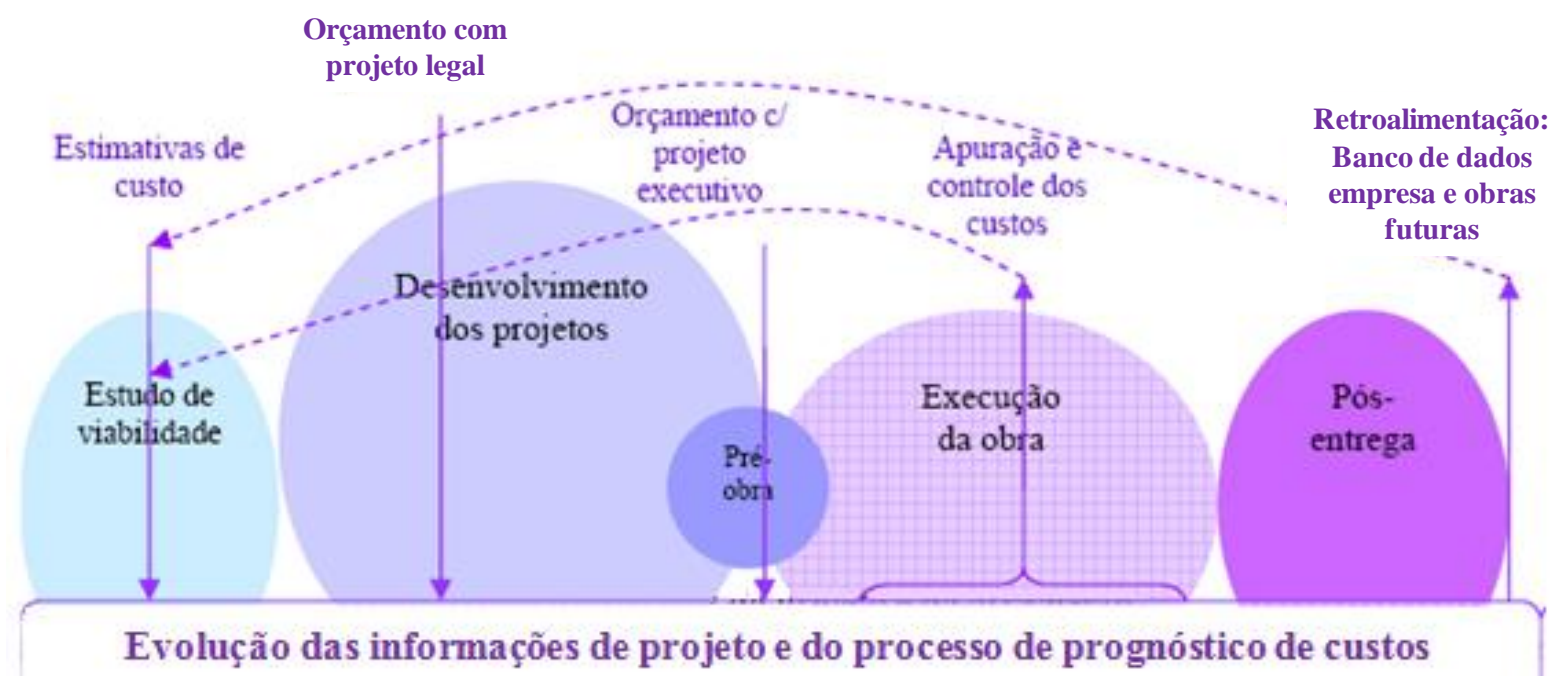

Figura 2.3 - Fases do projeto e do prognóstico de custo (MARCHIORI, 2009) 
De acordo com Ubiraci E. L. Souza, em entrevista à Revista Construção Mercado, (CARVALHO, 2003), "quanto mais especificado é um orçamento, mais útil ele se torna enquanto referência para a execução". Porém, conforme Assumpção e Fugazza (2000), "no mercado de incorporações é comum definir o produto e comercializá-lo sem ainda terem-se desenvolvido os projetos executivos”. Deste modo, durante seu estudo de viabilidade e no início da definição do produto, são realizadas estimativas com base em planta do terreno, seu levantamento planialtimétrico ou aerofotogramétrico, estudo de massa e quadro de áreas do edifício (Lyrio Filho e Amorim; 2005).

Definido o produto, pode-se elaborar um orçamento com base no projeto de prefeitura, que permite o levantamento inicial de quantitativos, além de possuir definições sobre os padrões de qualidade do empreendimento e de suas necessidades funcionais (MARCHIORI, 2009). De acordo com Goldman e Amorim (2007), este prognóstico de custo é chamado de orçamento preliminar e se baseia no projeto legal, memorial de especificações técnicas, de acabamentos e de equipamentos, nas informações básicas do projeto estrutural, instalações prediais e projetos especiais.

Conforme Marchiori (2009), a elaboração do orçamento executivo é feita na fase de pré-obra, onde os projetos possuem detalhamento completo das especificações. Deste modo, este orçamento será mais específico, contendo quantitativos completos, informações sobre o cronograma de execução e os critérios de medição dos serviços, auxiliando, essencialmente, a execução da obra. Como este tipo de prognóstico é feito com base nos projetos executivos, Goldmam e Amorin (2007) o chamam de orçamento executivo ou detalhado.

A última etapa do processo de entendimento dos custos em um empreendimento acontece durante o desenvolvimento da obra, na qual são levantados e medidos os custos ocorridos para retroalimentar o sistema de custos da empresa, possibilitar ajustes no orçamento e alimentar o banco de dados de custos para processos orçamentários de nova obra (MARCHIORI, 2009).

Com base no processo de orçamentação descrito, pode-se verificar que, dependendo da quantidade de informação disponível a respeito de um 
empreendimento, podem-se elaborar dois tipos de prognóstico de custo: a estimativa e o orçamento.

\subsubsection{Estimativa de custos}

De acordo com Losso (1995), a estimativa de custo é uma previsão para a implantação, ou não, de um determinado projeto.

Mais que um auxílio aos empreendedores para verificação da viabilidade econômico-financeira, a estimativa de custo pode, ainda, apoiar outras tomadas de decisões acerca do produto a ser desenvolvido, tais como: a definição da tecnologia a ser empregada e a concepção arquitetônica a ser projetada (KARSHENAS, 1984; CARDOSO; ABIKO, 2000).

Como este prognóstico é feito em uma etapa onde se possuem poucas informações acerca do empreendimento, conforme Marchiori (2009), para se elaborar estas estimativas, é necessário utilizar parâmetros vindos de projetos similares feitos anteriormente.

De acordo com Kim, An e Kang (2004), os atributos de uma estimativa de custo são:

- precisão;

- facilidade e rapidez na elaboração da ferramenta de prognóstico;

- oferecer o valor de custo rapidamente;

- poder se entender o processo utilizado, para verificar quais fatores podem variar e quais suas influências no custo prognosticado;

- $\quad$ poder atualizar facilmente os dados que basearam a elaboração do método.

O método mais tradicional para se estimar custo é a correlação direta entre o custo por $\mathrm{m}^{2}$ de um empreendimento, feito anteriormente, com a área do novo empreendimento. Porém, é sabido que tal correlação é muito fraca, e pode fornecer um valor impreciso de custo (GUNADYN; DOGAN, 2004; STOY; POLLALIS, 
SCHALCHER, 2008; MARCHIORI, 2009; GONÇALVES 2011). Assim, a busca por novos métodos que resultem em valores mais acurados, e possuam os atributos listados anteriormente, tem sido tema de muitos trabalhos na área de custos em todo o mundo.

Por ser objeto de pesquisa da presente dissertação, tal prognóstico de custo será melhor detalhado no item 2.4 (que verifica o momento durante o Processo de Projeto onde se elabora tal tipo de prognóstico) e no item 2.5 (que relaciona os métodos de estimativas mais adotados na atualidade).

\subsubsection{Orçamento}

De acordo com o PMBOK (2002), o orçamento engloba o custo da obra estimado alocado aos itens individuais de trabalho, a fim de estabelecer parâmetros de custo que possam medir o desempenho do empreendimento.

Para Cardoso (2009), a elaboração de um orçamento completo é feita seguindo-se o pressuposto de que, para se prognosticar o custo de um empreendimento de forma mais precisa, pode-se fracionar a obra em partes, desde que estas possam ter seus custos facilmente avaliados.

Deste modo, tendo-se projetos que permitam a divisão da obra em partes menores, ou seja, em serviços, é possível fazer o levantamento mais preciso dos recursos necessários à execução destes serviços (CARDOSO, 2009).

Assim, o valor global dos custos diretos de uma construção, gerado a partir de um orçamento, é dado pela somatória dos custos de todos os serviços da obra.

Para se prognosticar o custo de um dado serviço, o TCPO 2003 informa que são dados de entrada: os coeficientes de produtividade de mão-de-obra, de consumo de materiais e de consumo horário de equipamentos; os valores de preço unitário de cada insumo; e a quantidade de serviço.

De acordo com Marchiori (2009), a multiplicação do quantitativo de um serviço pelo seu custo unitário, resulta no custo deste serviço. O custo unitário, por sua vez, é 
dado pelo produto entre o indicador de consumo unitário (ou produtividade), de cada insumo que compõe o serviço, pelos correspondentes preços unitários. A Eq 2.1 mostra este cálculo.

$$
\text { Custo }_{i}=Q S_{i} \sum_{j}\left(C U_{j} \times P U_{j}\right)
$$

onde:

$$
\begin{aligned}
& \text { Custo }_{i}=\text { custo do serviço "i”; } \\
& Q S_{i}=\text { quantidade do serviço "i”; } \\
& C U_{j}=\text { consumo unitário ou produtividade do insumo "j" correspondente } \\
& \text { ao serviço "i”; } \\
& P U_{j}=\text { preço unitário do insumo "j" correspondente ao serviço "i”. }
\end{aligned}
$$

Marchiori (2009) informa, ainda, que durante o cálculo de custos dos serviços, é importante se saber o produto a ser realizado e o processo empregado, pois, dependendo da tecnologia utilizada em sua execução, podem-se ter diferentes consumos de mão-de-obra, equipamentos e materiais. Considerando o serviço de contrapiso sobre laje, por exemplo, o custo deste serviço, poderá variar, quando se consideram os diferentes processos utilizados: aderido x não-aderido; utilização de argamassa industrializada $x$ feita em obra que, por sua vez, pode utilizar diferentes dosagens (Figura 2.4). 


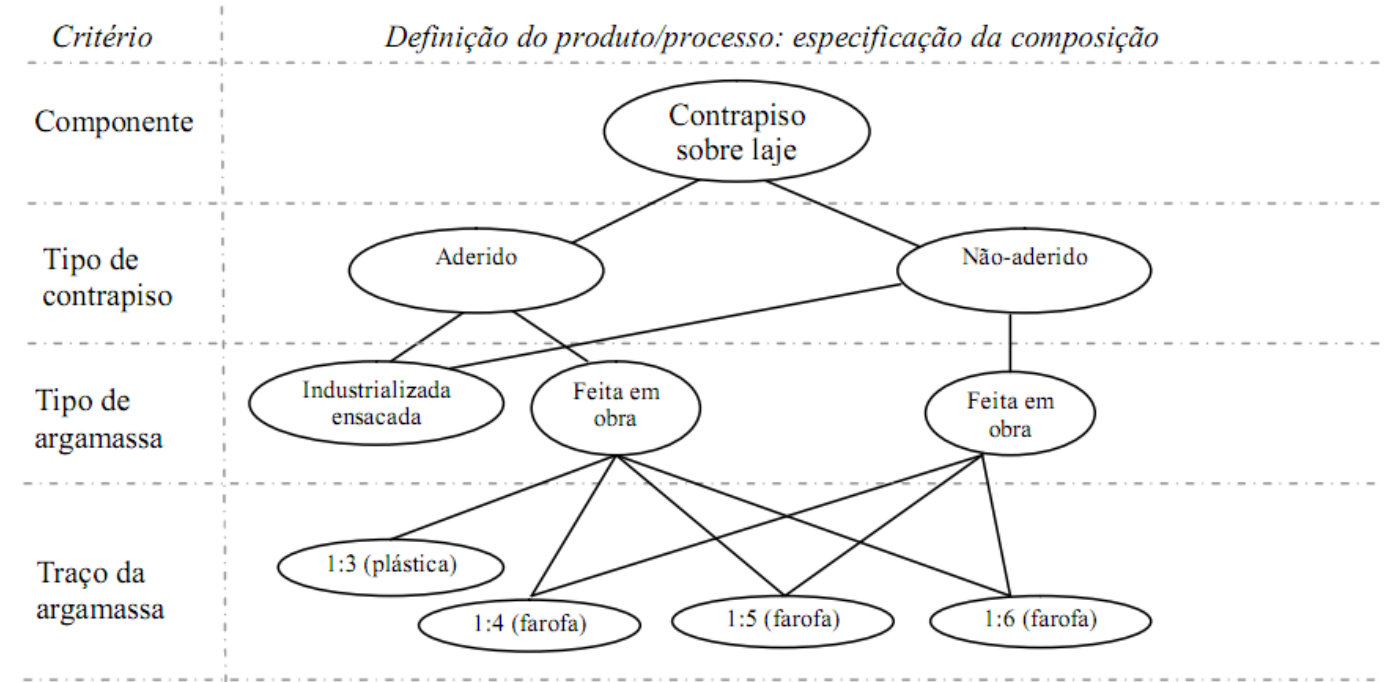

Figura 2.4 - Diferentes desdobramentos de serviço de contrapiso sobre laje, em se variando o produto/ processo (MARCHIORI, 2009)

Para Mattos (2007), mais que retratar o custo de uma obra, como um todo, o orçamento também possui as seguintes aplicações:

- informa os quantitativos de materiais e serviços, auxiliando o setor de suprimentos a planejar as compras, identificar fornecedores, estudar formas de pagamento e analisar metodologias executivas;

- fornece índices (produtividade da mão-de-obra, de equipamentos e consumo de material), que auxiliam tanto no acompanhamento dos custos durante a execução quanto na definição de metas de desempenho das equipes de campo;

- auxilia no dimensionamento das equipes, ao fornecer os indicadores de produtividade;

- pode ter os valores e índices revisados, a fim de se recalcular o custo da obra no caso de mudanças;

- permite a simulação de diferentes cenários, com utilização de outras tecnologias e materiais;

- fornece informações para a geração de cronogramas físicos e financeiros da obra; 
- fornece informações para analisar a situação da obra ao longo dos meses.

\subsection{A estimativa de custo dentro do Processo de Projeto}

Conforme discutido anteriormente, as informações utilizadas para se prognosticarem os custos diretos provêm dos parâmetros que se possui a respeito da concepção do produto, ou seja, as informações dos projetos.

Para se saber quais são as informações disponíveis para se elaborar uma estimativa de custo, deve-se analisar o processo de projeto e identificar em qual fase tal estudo é feito. Assim, os produtos da fase identificada serão aqueles que poderão ser utilizados como dados de entrada deste prognóstico.

De acordo com o RIBA, Royal Institute of British Architects, (2008), os processos envolvidos no gerenciamento e desenvolvimento de projetos de edifícios são:

- fase de preparação: nesta fase ocorre a identificação das necessidades do cliente, preparação do estudo de viabilidade e desenvolvimento de um esboço do projeto que contemple os requisitos chave do cliente (design brief);

- fase de elaboração de projetos: esta fase inicia com a finalização da concepção do produto, incluindo propostas preliminares de estrutura e sistemas prediais, e definição do custo; com a concepção elaborada, passase para a elaboração final dos projetos executivos;

- fase pré-obra: nesta fase é feita a preparação de toda a documentação do empreendimento e pedidos das aprovações legais;

- fase de construção: emissão de informações adicionais ao contratante, revisão de projetos, auxílio no gerenciamento do contrato para a conclusão prática da obra (Practical Completion);

- fase de uso: após a conclusão prática da obra (Practical Completion), auxíliar as inspeções finais, dar assistência ao usuário durante a ocupação e fazer possíveis revisões de projeto durante o uso. 
Semelhantemente ao praticado na Inglaterra, Melhado (1994) apresentou o fluxograma da Figura 2.5, que mostra as etapas do processo de projeto, desde a idealização do empreendimento até sua entrega ao usuário.

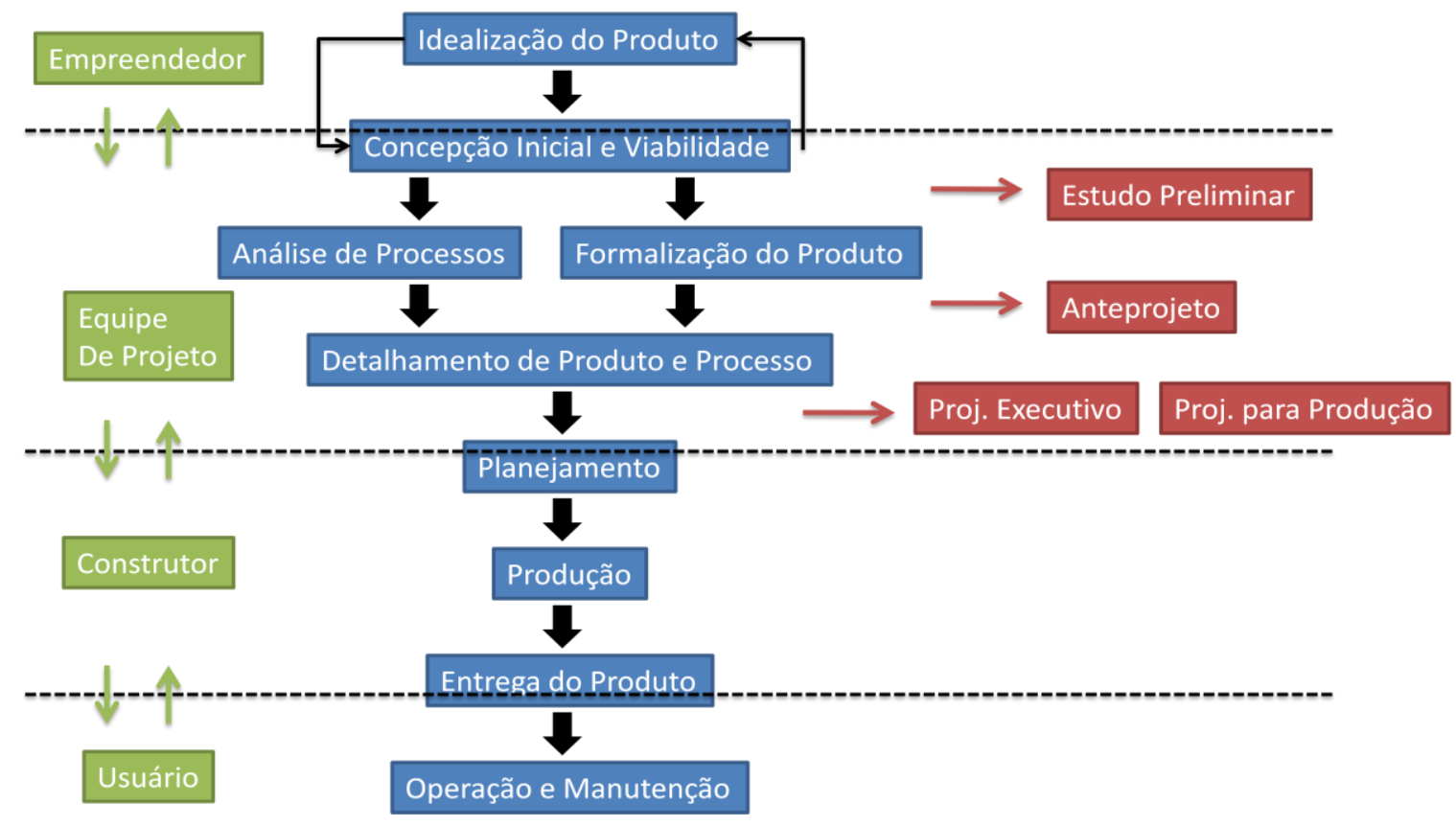

Figura 2.5 - Proposta para o processo de desenvolvimento(MELHADO,1994)

Conforme o autor, o processo de projeto passa por etapas conceitualmente progressivas, nas quais "a liberdade de decisão entre as alternativas vai sendo gradativamente substituída pelo detalhamento das soluções adotadas”. Assim, as etapas definidas por ele, no processo de projeto, são:

- idealização do produto: consiste na formulação inicial do produto, que deve atender a uma série de necessidades e restrições iniciais exigidas;

- análise de viabilidade: avaliação da solução segundo critérios estabelecidos previamente, contemplando aspectos de custo, tecnologia, adequação ao usuário e às restrições legais correspondentes; o processo é iterativo até que se encontre uma solução definitiva que será traduzida em um estudo preliminar;

- formalização: solução adotada resulta em anteprojeto; 
- detalhamento: elaboração, conjunta e iterativamente, do detalhamento final do produto (Projeto Executivo) e da análise de necessidades vinculadas aos processos de execução (Projeto para Produção);

- planejamento e execução: a partir do Projeto para Produção, faz-se o planejamento das etapas de execução da obra, a qual passa a ser conduzida dentro dos procedimentos da empresa e com assistência da equipe de projeto ao longo da mesma;

- entrega: o produto é passado às mãos do usuário, que terá a assistência técnica da construtora na fase inicial de uso, operação e manutenção, onde serão coletadas informações para a retroalimentação necessária à melhoria contínua do processo.

A Asbea (Associação Brasileira de Escritórios de Arquitetura), com a participação das entidades setoriais representativas dos contratantes de projetos do setor imobiliário e da construção, Secovi-SP, Sindinstalação e Sinduscon-SP, desenvolveu o Manual de Escopo de Projetos e Serviços de Arquitetura (2010). Este Manual estabelece parâmetros do que se espera dos projetistas, contribuindo para a elaboração e organização de seus serviços, desde a fase de proposta até o acompanhamento pós-entrega da obra, sendo a referência que mais se aproxima com o praticado no Brasil na atualidade. Assim, as fases definidas neste Manual são (ASBEA, 2010):

- fase A: concepção do produto - levantamento de informações sobre restrições e possibilidades que regem e limitam o produto imobiliário pretendido, para que se possa caracterizar o partido arquitetônico e urbanístico, e as possíveis soluções das edificações e de implantação; esta fase é subdividida em Levantamento de Dados, Programa de Necessidades e Estudo de Viabilidade;

- fase B: definição do produto - desenvolvimento do partido arquitetônico e dos demais elementos do empreendimento, definindo e consolidando todas informações necessárias a fim de verificar sua viabilidade física, legal e econômica, bem como possibilitar a elaboração dos Projetos Legais; esta fase é subdividida em Estudo Preliminar, Anteprojeto e Projeto Legal; 
- fase C: identificação e solução de interfaces - consolidação de todos ambientes, suas articulações e demais elementos do empreendimento, com as definições necessárias para o intercâmbio entre todos envolvidos no processo; o projeto resultante (Projeto Básico) deve ter todas as suas interfaces resolvidas, possibilitando uma avaliação preliminar dos custos, métodos construtivos e prazos de execução;

- fase D: projeto de detalhamento de especialidades - detalhamento de todos os elementos do empreendimento, de modo a gerar um conjunto de informações suficientes para a perfeita caracterização das obras/serviços a serem executadas, bem como a avaliação dos custos, métodos construtivos e prazos de execução; o produto gerado nesta fase será o Projeto Executivo;

- fase E: pós-entrega do projeto - deverá garantir a plena compreensão e utilização das informações de projeto, bem como sua aplicação correta nos trabalhos de campo;

- fase F: pós-entrega da obra - análise e avaliação do comportamento da edificação em uso para verificar e reafirmar se os condicionantes e pressupostos de projeto foram adequados e se eventuais alterações, realizadas em obra, estão compatíveis com as expectativas do empreendedor e de ocupação dos usuários.

De um modo geral, pode-se verificar que o ciclo de vida de empreendimento inicia por um estudo de viabilidade que definirá um custo a ser seguido e atingido durante a definição do produto.

De acordo com Rocha Lima (1985), o estudo de viabilidade passa, normalmente, pelas etapas mostradas na Figura 2.6. 


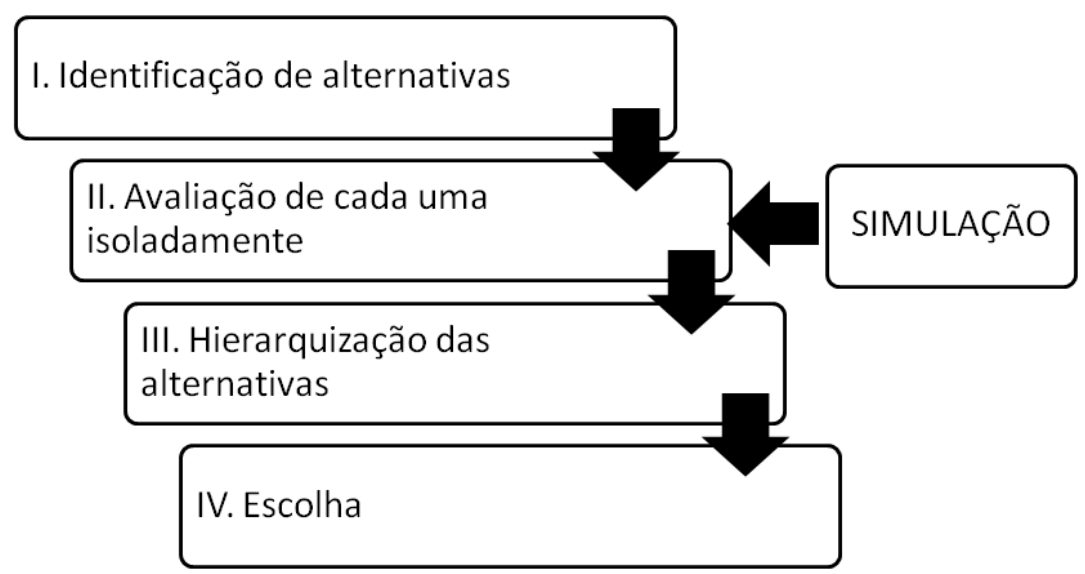

Figura 2.6 - Etapas do processo de análise de alternativas (ROCHA LIMA, 1985)

Primeiramente, o empreendedor busca alternativas para o empreendimento que se deseja executar; tal busca é orientada por informações de caráter financeiro (recursos disponíveis) e de caráter econômico, estabelecendo balizas operacionais (ROCHA LIMA, 1985).

A avaliação das alternativas é feita a partir da simulação de cada uma, a fim de analisar os prováveis resultados. Tal simulação inclui a construção de cenários que representem as expectativas quanto aos custos, ao programa de obras e aos preços e desempenho de vendas. Estes cenários são analisados através da avaliação da viabilidade financeira, ou seja, verificando se os recursos exigidos são compatíveis com os disponíveis e com a capacidade de endividamento da empresa; e através da avaliação da viabilidade econômica, na qual o empreendedor verifica se a taxa de retorno é maior que a taxa de atratividade. Além disso, é importante analisar o grau de risco de cada cenário, que será tanto maior quanto mais sensível for o comportamento da alternativa, em função de mudanças no cenário mais provável de cada alternativa (ROCHA LIMA, 1985).

Deste modo, a escolha da alternativa mais favorável será feita através da verificação da rentabilidade (escolha pelas maiores taxas de retorno) e do risco (escolha pelo menor risco). Porém, como normalmente as alternativas de maior rentabilidade envolvem os maiores riscos, é necessário que o empreendedor hierarquize suas alternativas e escolha aquela que alcance um resultado esperado, aceitando a condição de risco envolvida (ROCHA LIMA, 1985). 
Com base nas etapas propostas por Rocha Lima (1985), verifica-se que o produto a ser desenvolvido deve atender ao custo determinado na análise de viabilidade a fim de que se obtenha o resultado pretendido.

Deste modo, é importante que durante a definição do empreendimento se controle os custos para que o produto esteja dentro do valor previsto, ou seja, é importante que a elaboração dos projetos seja acompanhada de suas avaliações por meio de estimativas de custos para que se atendam os valores definidos na Análise de Viabilidade.

Dentro deste contexto, o método de prognóstico de custo a ser definido no presente trabalho pretende auxiliar planejadores e orçamentistas a verificarem as soluções de projeto de modo a se analisar os custos envolvidos. Este método pode ser utilizado nas etapas iniciais (antes da elaboração de projetos executivos), utilizando apenas esboços de arquiteturas nos quais se possam levantar quantidades simplificadamente.

Outro agente que pode utilizar o método proposto é o projetista, a fim de ele mesmo avaliar o custo de suas decisões durante a definição do produto.

\subsection{Métodos para estimativa de custo}

De acordo com o PMBOK (2002), as ferramentas e técnicas de estimativas de custo podem ser:

- Estimativas por analogias: são uma forma de avaliação especializada (necessita de conhecimento de grupo ou indivíduo especializado), pouco dispendiosas e, freqüentemente, menos precisas, que utilizam custos reais de projetos anteriores similares para basear o custo do empreendimento a ser estudado, sendo aplicada, principalmente, em prognósticos de custo totais de empreendimentos que realmente são semelhantes àqueles que serviram de base de estudo; apesar da menor precisão (o resultado é muito dependente da experiência do gestor e do banco de projetos para analisar a semelhança com o novo empreendimento) são, atualmente, o tipo de estimativa mais 
utilizada (KARSHENAS, 1984; STOY; SCHALCHER, 2007; STOY; POLLAIS; SCHALCHER, 2006)

- Modelagem paramétrica: utilização de modelos matemáticos que utilizam parâmetros de projetos para estimar custos, com base em informações históricas (este tipo de estimativa será melhor definido no item 2.4.2);

- Estimativas de baixo para cima: estimam-se, primeiramente, os custos de atividades individuais de pacotes de trabalho para, posteriormente, sumarizálos ou agregá-los à estimativa total do projeto;

- Ferramentas computadorizadas: são ferramentas que simplificam o uso daquelas descritas anteriormente, agilizando a análise entre várias alternativas de custo (estes tipos de ferramentas serão discutidos em $2.4 .3 \mathrm{e}$ 2.4.4);

- Outros métodos de estimativa de custos: por exemplo, o CUB, que será melhor explicado em 2.4.1.

Os métodos de estimativas mais amplamente disseminados na literatura nacional são o CUB e a estimativa paramétrica. Em outros países, têm sido desenvolvidas novas ferramentas utilizando inteligência artificial, através de ferramentas computadorizadas e cálculos numéricos.

\subsubsection{CUB}

Através do CUB (Custo Unitário Básico) pode-se calcular o custo global de uma construção a partir das áreas equivalentes em área de custo padrão e da semelhança do empreendimento com um projeto-padrão definido pela norma.

De acordo com a cartilha desenvolvida pelo Sindicato da Indústria da Construção Civil no Estado de Minas Gerais em 2007, o CUB teve origem através da Lei Federal $\mathrm{n}^{\circ} 4.591$ de 16 de dezembro de 1964. O principal objetivo do CUB/m², conforme esta publicação, é “...disciplinar o mercado de incorporação imobiliária, servindo como parâmetro na determinação dos custos dos imóveis"; porém, devido à credibilidade alcançada, "... a evolução relativa do $\quad C U B / m^{2}$ também tem sido utilizada como indicador macroeconômico dos custos do setor da construção civil'. 
A cartilha do SINDUSCON-MG afirma, ainda, que a norma que foi definida a partir desta Lei foi a ABNT NB 140:1965 "Avaliação de Custos Unitários e Preparo de Orçamento de Construção para Incorporação de Edifícios em Condomínios", sendo que sua última revisão ocorreu em 2006, com a introdução de novos projetos-padrão e novo lote básico.

A norma ABNT NBR 12721 (2006) estabelece o cálculo do custo de construção através do CUB, indicando os seguintes passos:

- seleção do projeto padrão que mais se assemelha ao do empreendimento;

- utilização do valor do custo unitário básico (CUB), para o projeto padrão selecionado, que é divulgado no Sindicato da Construção na região em que o empreendimento será construído;

- soma dos seguintes valores:

- $C U B \times \sum$ áreas equivalentes à área de custo padrão

- Valor de todas as demais despesas não incluídas no cálculo do custo unitário básico, com a inclusão, no mínimo, dos seguintes itens: fundações especiais, elevadores, equipamentos e instalações, playground, obras e serviços complementares e outros serviços.

Os projetos-padrão são aqueles selecionados para representar os diferentes tipos de edificações, variando o número de pavimentos, número de dependências por unidade, áreas equivalentes à área de custo padrão privativas das unidades autônomas, padrão de acabamento da construção e o número total de unidades. (ABNT NBR 12721, 2006). O Quadro 2.1 mostra os projetos-padrão utilizados no cálculo do CUB/m². 
Quadro 2.1 - Caracterização dos Projetos- padrão da norma ABNT NBR 12721 (Adaptado de SINDUSCON-MG, 2007)

\begin{tabular}{|c|c|c|c|c|c|}
\hline RESIDENCIAIS & Padrão & Sigla & Pavimentos & $\begin{array}{c}\mathrm{N} \\
\text { apart./tipo }\end{array}$ & Dormitórios \\
\hline \multirow{3}{*}{$\begin{array}{l}\text { Residência } \\
\text { unifamiliar }\end{array}$} & Baixo & $\mathrm{R} 1-\mathrm{B}$ & 1 & 1 & 2 \\
\hline & Normal & $\mathrm{R} 1-\mathrm{N}$ & 1 & 1 & 3 \\
\hline & Alto & R1-A & 1 & 1 & 4 \\
\hline \multicolumn{2}{|c|}{ Residência Popular } & $\mathrm{RP} 1 \mathrm{Q}$ & 1 & 1 & 1 \\
\hline \multicolumn{2}{|c|}{ Projeto de Interesse Social } & PIS & Térreo + 4 & 4 & 2 \\
\hline \multirow{2}{*}{ Prédio Popular } & Baixo & PP-B & Térreo + 3 & 4 & 2 \\
\hline & Normal & PP-N & Pilotis +4 & 4 & 3 \\
\hline \multirow{3}{*}{$\begin{array}{c}\text { Residência } \\
\text { Multifamiliar (R8) }\end{array}$} & Baixo & R8-B & Térreo+7 & 4 & 2 \\
\hline & Normal & $\mathrm{R} 8-\mathrm{N}$ & Garagem + Pilotis +8 & 4 & 3 \\
\hline & Alto & R8-A & Garagem + Pilotis +8 & 2 & 4 \\
\hline \multirow[b]{2}{*}{$\begin{array}{c}\text { Residência } \\
\text { Multifamiliar (R16) }\end{array}$} & Normal & $\begin{array}{l}\text { R16- } \\
N\end{array}$ & $\begin{array}{c}\text { Garagem + Pilotis + } \\
16\end{array}$ & 4 & 3 \\
\hline & Alto & $\begin{array}{l}\text { R16- } \\
\text { A }\end{array}$ & $\begin{array}{c}\text { Garagem + Pilotis + } \\
16\end{array}$ & 2 & 4 \\
\hline COMERCIAIS & Padrão & Sigla & Pavimentos & salas/tipo & \\
\hline \multirow{2}{*}{$\begin{array}{l}\text { Comercial: salas e } \\
\text { lojas (CSL-8) }\end{array}$} & Normal & $\begin{array}{l}\text { CSL- } \\
8\end{array}$ & Garagem + Pilotis + 8 & $\begin{array}{l}8 \text { salas/ } \\
\text { tipo }\end{array}$ & \\
\hline & Alto & $\begin{array}{c}\text { CSL- } \\
8\end{array}$ & Garagem + Pilotis +8 & $\begin{array}{l}8 \text { salas/ } \\
\text { tipo }\end{array}$ & \\
\hline \multirow{2}{*}{$\begin{array}{l}\text { Comercial: salas e } \\
\text { lojas (CSL-16) }\end{array}$} & Normal & $\begin{array}{c}\text { CSL- } \\
16\end{array}$ & $\begin{array}{c}\text { Garagem + Pilotis + } \\
16\end{array}$ & $\begin{array}{l}8 \text { salas/ } \\
\text { tipo }\end{array}$ & \\
\hline & Alto & $\begin{array}{c}\text { CSL- } \\
16\end{array}$ & $\begin{array}{c}\text { Garagem + Pilotis + } \\
16\end{array}$ & $\begin{array}{l}8 \text { salas/ } \\
\text { tipo }\end{array}$ & \\
\hline \multirow{2}{*}{$\begin{array}{c}\text { Comercial: andares } \\
\text { livres }\end{array}$} & Normal & $\begin{array}{c}\text { CAL- } \\
8 \\
\end{array}$ & Garagem + Pilotis +8 & Andar livre & \\
\hline & Alto & $\begin{array}{l}\text { CAL- } \\
8\end{array}$ & Garagem + Pilotis + 8 & Andar livre & \\
\hline \multicolumn{2}{|c|}{ Galpão Industrial } & $\mathrm{Gl}$ & 1 & - & \\
\hline
\end{tabular}

As áreas equivalentes à área de custo padrão são a soma das áreas cobertaspadrão e áreas equivalentes (ABNT NBR 12721, 2006).

As áreas cobertas-padrão são medidas de superfície de dependências cobertas, (incluindo as superfícies das projeções de paredes, de pilares e demais elementos construtivos), que possuem áreas de padrão de acabamento semelhantes às respectivas áreas de projetos-padrão (ABNT NBR 12721, 2006).

Já as áreas equivalentes são áreas virtuais cujo custo da construção é equivalente ao custo da respectiva área real, utilizada quando este custo é diferente do custo unitário básico da construção adotado como referência. Pode ser, conforme o caso, maior ou menor que a área real correspondente, utilizando, para a transformação, 
um coeficiente multiplicado pela área do ambiente, que não possua mesmo valor que a área coberta-padrão (ABNT NBR 12721, 2006).

Apesar de a norma recomendar que os coeficientes sejam calculados pelas empresas, com base em seus próprios projetos, ela indica, como referência, os seguintes coeficientes médios para o cálculo da equivalência (ABNT NBR 12721, 2006):

- $\quad$ garagem (subsolo)=0,50 a 0,75;

- área privativa (unidade autônoma padrão)=1,00;

- área privativa salas com acabamento=1,00;

- área privativa salas sem acabamento=0,75 a 0,90;

- $\quad$ área de loja sem acabamento=0,40 a 0,60;

- varandas $=0,75$ a 1,00 ;

- terraços ou áreas descobertas sobre lajes=0,30 a 0,60;

- estacionamento sobre terreno=0,05 a 0,10;

- área de projeção do terreno sem benfeitoria=0,00;

- área de serviço - residência unifamiliar padrão baixo (aberta)=0,50;

- barrilete=0,50 a 0,75;

- caixa d'água=0,50 a 0,75;

- $\quad$ casa de máquinas=0,50 a 0,75; e

- $\quad$ piscinas, quintais etc. $=0,50$ a 0,75 .

A Figura 2.7 ilustra a sequencia do cálculo do Custo Global de construção. 


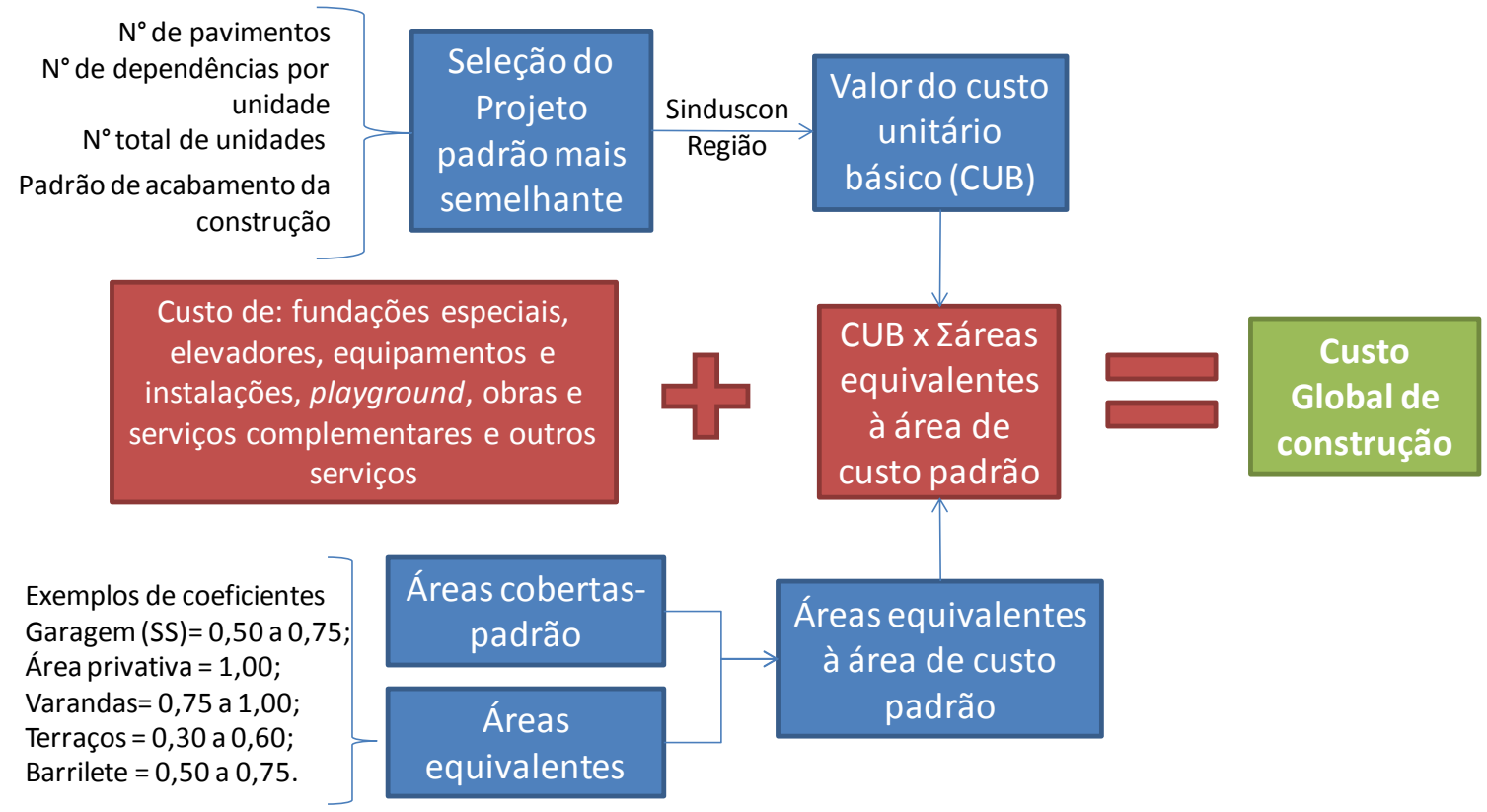

Figura 2.7 - Cálculo do Custo Global de Construção, adaptado de ABNT NBR 12721 (2006)

\subsubsection{Estimativa paramétrica}

Apesar de a maioria das estimativas de custo levar em conta apenas a área construída (área edificada ${ }^{1}$ ) do empreendimento, muitas outras variáveis interferem diretamente no custo. A fim de melhor avaliar estes demais fatores, são feitas análises paramétricas, envolvendo elaboração de equações com base em dados de projetos anteriores para refinar o prognóstico de custo (STOY; POLLALIS; SCHALCHER, 2008).

O método de estimativa paramétrica é uma "técnica que é usada por contratantes a fim de acelerar o processo de estimativa, no caso em que outra técnica exigisse maior tempo e recurso, sendo que os resultados entre elas seriam semelhantes" (UNITED STATES OF AMERICA, 1995).

\footnotetext{
${ }^{1}$ Área edificada: de acordo com a Lei 11.228, de 25 de junho de 1992 do Município de São Paulo, é definida como a "área total coberta de uma edificação. Serão excluídas da área edificada a área de poços e vazios em geral, e das saliências (detalhes de fachada)".
} 
Para Gonçalves (2011), "parametrizar é correlacionar por aproximação, serviços e preços dos principais itens da construção, com as poucas informações disponíveis".

$\mathrm{Na}$ área da construção, a aplicação deste método pode ocorrer relacionando o espaço do edifício com seu custo, excluindo o custo do terreno. Esta relação pode ser criada com base em uma regressão linear entre uma variável dependente, cujo valor se deseja obter, e outra independente, cujo valor é conhecido. A análise para verificar a confiabilidade da equação utiliza o valor de sua correlação $\left(R^{2}\right)$, sendo que os valores desejáveis de correlação são aqueles maiores ou iguais a 0,80; além disso, deve-se tomar cuidado com valores iguais a 1,00, pois pode indicar uma identidade entre as variáveis e levar a resultados redundantes. A partir das regressões lineares, novas variáveis dependentes podem ser incluídas (UNITED STATES OF AMERICA, 1995). Embora simplificadas, as recomendações citadas dão conta de que se pode, a partir de experiências anteriores e de uma análise estatística, gerar uma equação correlacionando o custo unitário com as características de uma edificação em processo de concepção.

No Brasil, a estimativa paramétrica é bastante difundida pela bibliografia existente. Mascaró (1998) propôs diferentes indicadores calculados parametricamente, considerando que as decisões de projeto estão diretamente relacionadas ao custo total da edificação.

A partir deste autor, publicações como Losso, 1995; Oliveira, 1990; Solano e Heineck, 2001; Andrade, 1996; Otero e Heineck, 2004; Gonçalves, 2011; entre outras, fizeram estudos com análises estatísticas a fim de estimar as quantidades de serviços a partir das geometrias dos edifícios. A Figura 2.8 representa a metodologia apresentada em Losso, 1995. 


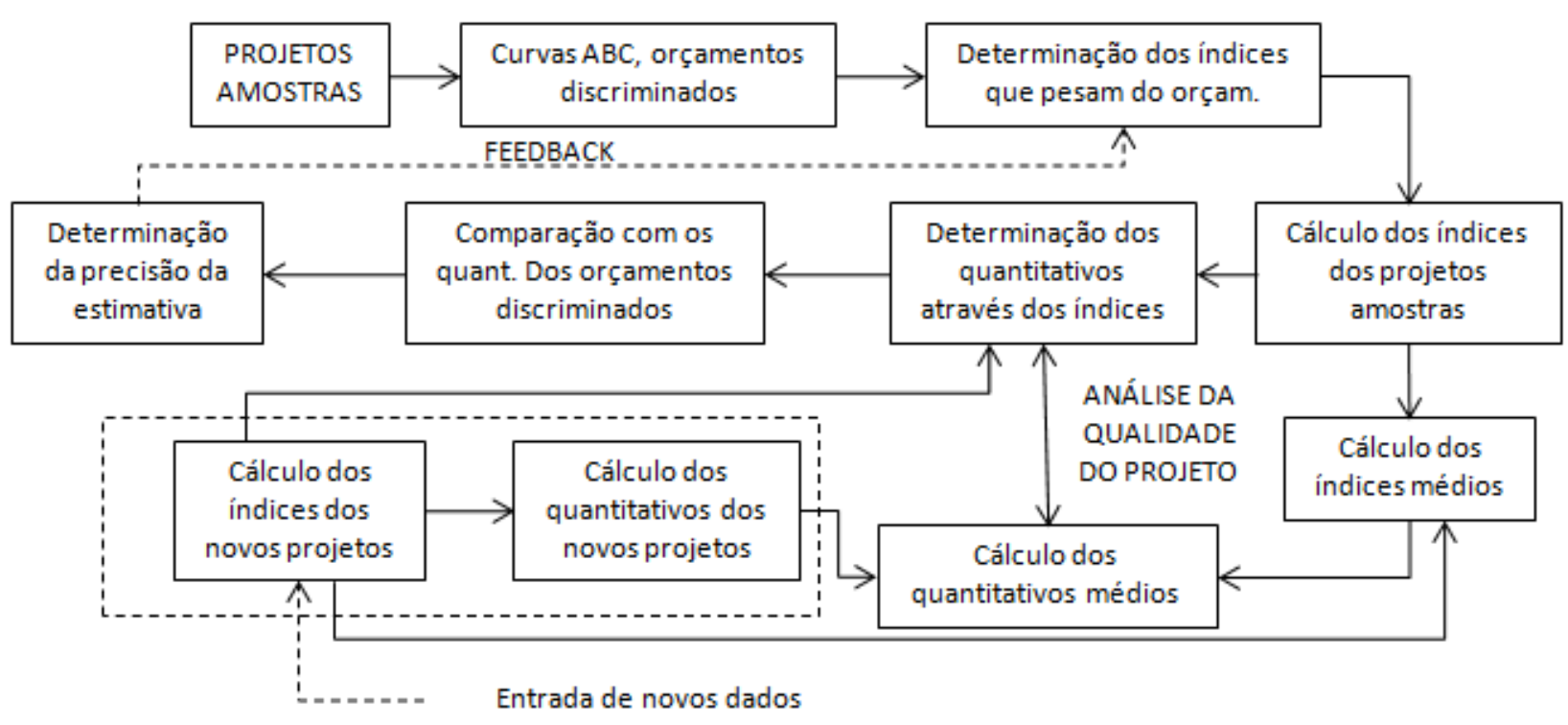

Figura 2.8 - Fluxograma do tratamento dos dados, fonte: Losso, 1995

De acordo com esta metodologia, a partir de uma base de dados formada por orçamentos e projetos utilizados por uma incorporadora, é feita uma $\mathrm{ABC}^{2}$.

Os insumos de maiores pesos nesta curva são escolhidos para se determinarem índices que relacionam a geometria dos projetos com as quantidades de insumos. Nos casos em que a correlação entre estas variáveis for satisfatória, adotam-se estes índices para quantificar os insumos de um novo empreendimento, a fim de utilizá-los no prognóstico de seu custo.

A estimativa paramétrica também pode ser feita de modo mais direto, ou seja, utilizando uma única equação para estimar o custo total de construção. Este tipo de cálculo envolve programas computacionais específicos para relacionar as variáveis, sendo usual a utilização do programa Statistical Package for Social Science (Pacote Estatístico para as Ciências Sociais). Este tipo de equação também é ajustado pelo valor da correlação $\left(R^{2}\right)$, e as fórmulas resultantes são, geralmente, representadas

\footnotetext{
${ }^{2}$ A análise por uma curva $A B C$, apresentada por Li, Xianyi e Xin (2012), consiste em distribuir elementos em três tipos de classes: A, B e C. Para elaborar tal curva, é necessário, primeiramente, organizar os custos de todos os serviços de uma edificação na ordem decrescente. Com estes serviços, é calculada tanto a proporção individual de seus custos em relação ao custo total da edificação, quanto a proporção cumulativa, de acordo com a ordem decrescente citada. No ponto em que a proporção cumulativa atingiu $80 \%$ do custo da obra, tem-se os serviços que serão classificados como pertencentes à classe $\mathrm{A}$. Os serviços que representam os percentuais cumulativos entre $80 \% \mathrm{e}$ $95 \%$ são considerados como os pertencentes à classe B; já o restante dos serviços (que representam apenas $5 \%$ do custo da obra), pertencem à classe $\mathrm{C}$.
} 
na seguinte forma: $Y=C+b_{1} \cdot X_{1}+b_{2} . X_{2}+\ldots b_{n} . X_{n}$, onde $Y$ é o resultado do custo total de construção; $X_{1}, X_{2}$ e $X_{n}$ são as variáveis que indicam, normalmente, as características geométricas das edificações; $C$ é a constante estimada; e $b_{1}, b_{2}, b_{n}$ são os coeficientes estimados pela análise de regressão (KIM; AN; KANG, 2004).

Com base em um banco de dados de 23 edificações, Li, Shen e Love (2005) desenvolveram uma equação com regressão múltipla na qual o custo de edifícios comerciais com estrutura metálica era estimado relacionando-o a três varáveis independentes: altura do edifício, área construída e área média dos pavimentos. De acordo com os autores, este tipo de estimativa é de fácil aplicação e tem precisão maior que o uso simples de regressão linear com base apenas em área construída.

$\mathrm{Li}$, Shen e Love (2005) salientam que, para atualizar o método paramétrico quando dados de novos empreendimentos são disponibilizados, devem ser revisadas todas as equações englobando as novas informações no cálculo.

Sabendo que são diversas as variáveis que influenciam o custo e que este pode não variar linearmente, cálculos mais avançados são desenvolvidos buscando uma maior precisão nos valores.

\subsubsection{Redes Neurais}

Como alternativa aos métodos paramétricos (com análises estatísticas), muitos autores têm utilizado as redes neurais para solucionar problemas de previsão que envolvam funções não lineares (PALIWAL; KUMAR, 2009; Yeh, 1998).

Carvalho (2011) explica que a técnica de Redes Neurais Artificiais é inspirada na estrutura neural de organismos inteligentes, que adquirem conhecimento através da experiência.

De acordo com Günaydm e Dogan (2004), o desenvolvimento do modelo passa por três fases: a modelagem, o treinamento e o teste. A modelagem envolve a análise dos dados, a identificação dos parâmetros de estimativa e a definição da estrutura da rede a ser feita, considerando o número de camadas de processamento e de neurônios, e o tipo de função a ser utilizada, conforme mostra a Figura 2.9. A fase 
de treinamento tem como objetivo elaborar as regras entre as variáveis, através de testes com dados históricos de custo, refinando o método toda vez que o erro entre a variável calculada e o valor de um dado histórico real de saída for muito alto. A fase de teste é aquela onde se verifica a acurácia do modelo, calculando o erro percentual do custo estimado, comparando os resultados do método com os dados históricos já obtidos.

\begin{tabular}{|l|l|}
\hline$x_{1}$ & Área total de construção \\
\hline$x_{2}$ & $\begin{array}{l}\text { Relação entre a área do tipo } \\
\text { pela área total de construção }\end{array}$ \\
\hline$x_{3}$ & $\begin{array}{l}\text { Relação entre a área do térreo } \\
\text { pela área total de construção }\end{array}$ \\
\hline$x_{4}$ & Número de andares \\
\hline$x_{5}$ & $\begin{array}{l}\text { A direção do contra- } \\
\text { ventamento do prédio }\end{array}$ \\
\hline$x_{6}$ & $\begin{array}{l}\text { Tipo de fundação utilizada } \\
\text { (estaca; sapata; radier) }\end{array}$ \\
\hline$x_{7}$ & $\begin{array}{l}\text { Concreto in loco ou pré- } \\
\text { fabricado }\end{array}$ \\
\hline$x_{8}$ & $\begin{array}{l}\text { Localização do núcleo do } \\
\text { edifício }\end{array}$ \\
\hline$y$ & $\begin{array}{l}\text { Custo do sistema estrutural por } \\
\mathrm{m}^{2}\end{array}$ \\
\hline
\end{tabular}

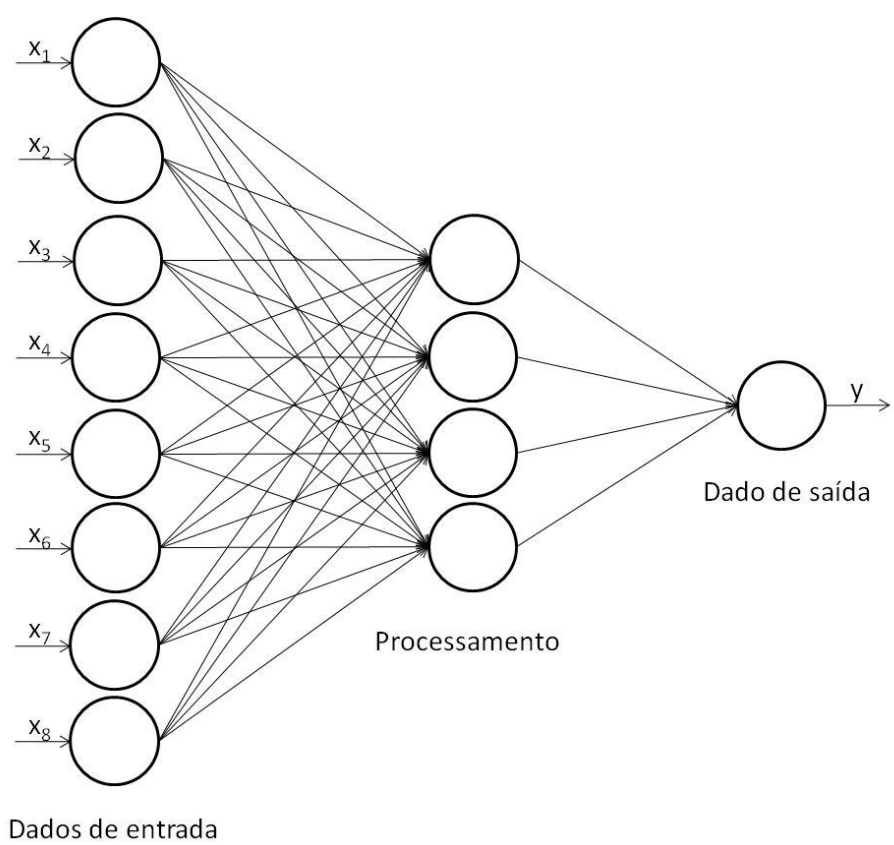

Figura 2.9 - Aplicação das Redes Neurais para prognóstico de estrutura de concreto, conforme Günaydm; Dogan, 2004

Carvalho (2011) explica que a fase de treinamento é composta por diversas unidades de processamento, cujo funcionamento inicia-se pelos sinais que chegam à entrada e que são multiplicados por um peso equivalente à influência na saída de cada unidade. É feita a soma ponderada destes sinais, que produzem um nível de atividade que, se maior que certo limite (threshold), faz com que a unidade produza uma determinada resposta de saída. Os modelos de redes neurais possuem a habilidade de aprendizado, pois os pesos são ajustados de forma iterativa e o aprendizado ocorre quando o modelo atinge uma solução generalizada para uma classe de problemas.

Como desvantagens deste método, podem-se citar: 
- dificuldade na elaboração da rede e demora para encontrar a configuração ideal do problema (KIM; AN; KANG, 2004; PALIWAL; KUMAR, 2009);

- falta de interpretação dos valores dos pesos, já que o modelo funciona como uma "caixa preta" no seu processamento (KIM; AN; KANG, 2004; PALIWAL; KUMAR, 2009);

- dificuldade na atualização do modelo para acrescentar mais projetos no banco de dados, pois requer que se faça novo processamento, o que demanda tempo e novos testes do modelo (KIM; AN; KANG, 2004, 2004).

A fim de agilizar o processamento das redes neurais, Kim, Seo e Kang (2005) formularam um modelo híbrido, com rede neural e algoritmos genéticos, para estimar custos de empreendimentos imobiliários. O princípio dos algoritmos genéticos é a evolução natural, ou seja, a contínua melhoria da população, a qual, após diversas gerações, atinge um estado mais otimizado. De acordo com este estudo, verificou-se que os algoritmos genéticos tornaram o modelo mais efetivo, pois melhoraram a resolução das unidades de processamento da rede neural.

\subsubsection{Raciocínio Baseado em Casos (“Case-based reasoning - CBR”)}

Outro método de estimativa de custos que utiliza métodos computacionais é o Raciocínio Baseado em Casos ("Case-based reasoning - CBR"). A ideia básica deste método é a hipótese de que problemas similares possuem soluções parecidas (JI; PARK; LEE, 2011).

De acordo com autores como Yau e Yang (1998) e Dorgan, Arditi e Günaydin (2006), este método tem obtido maiores benefícios que outros que utilizam princípios de inteligência artificial. Isto ocorre porque, através do CBR, a estimativa de um novo projeto é feita com recuperação de dados de um banco histórico, através de sua aprendizagem.

Inicialmente, a resolução de problemas através do método CBR envolve a definição dos atributos chave que caracterizam o empreendimento (tais como: área construída, altura da edificação, tempo de execução, entre outros); e, com base em 
dados históricos de projetos e orçamentos já feitos, são calculados os pesos que cada atributo tem em relação à definição do custo do empreendimento (KIM; AN; KANG; 2004).

Conforme mostra a Figura 2.10, o modelo CBR passa pelos seguintes processos (KIM; AN; KANG; 2004):

- casos de experiências anteriores são armazenados em uma base de dados;

- para se estimar o custo de um novo caso, o sistema CBR recupera um ou mais casos similares armazenados, a partir de cálculos de percentual de similaridade entre os atributos dos empreendimentos;

- o cálculo do custo do novo caso é feito pela adaptação entre ele e os casos recuperados; tal adaptação é feita aplicando os percentuais de similaridade no novo caso, adaptando a solução do custo;

- a nova solução é armazenada no base de dados.

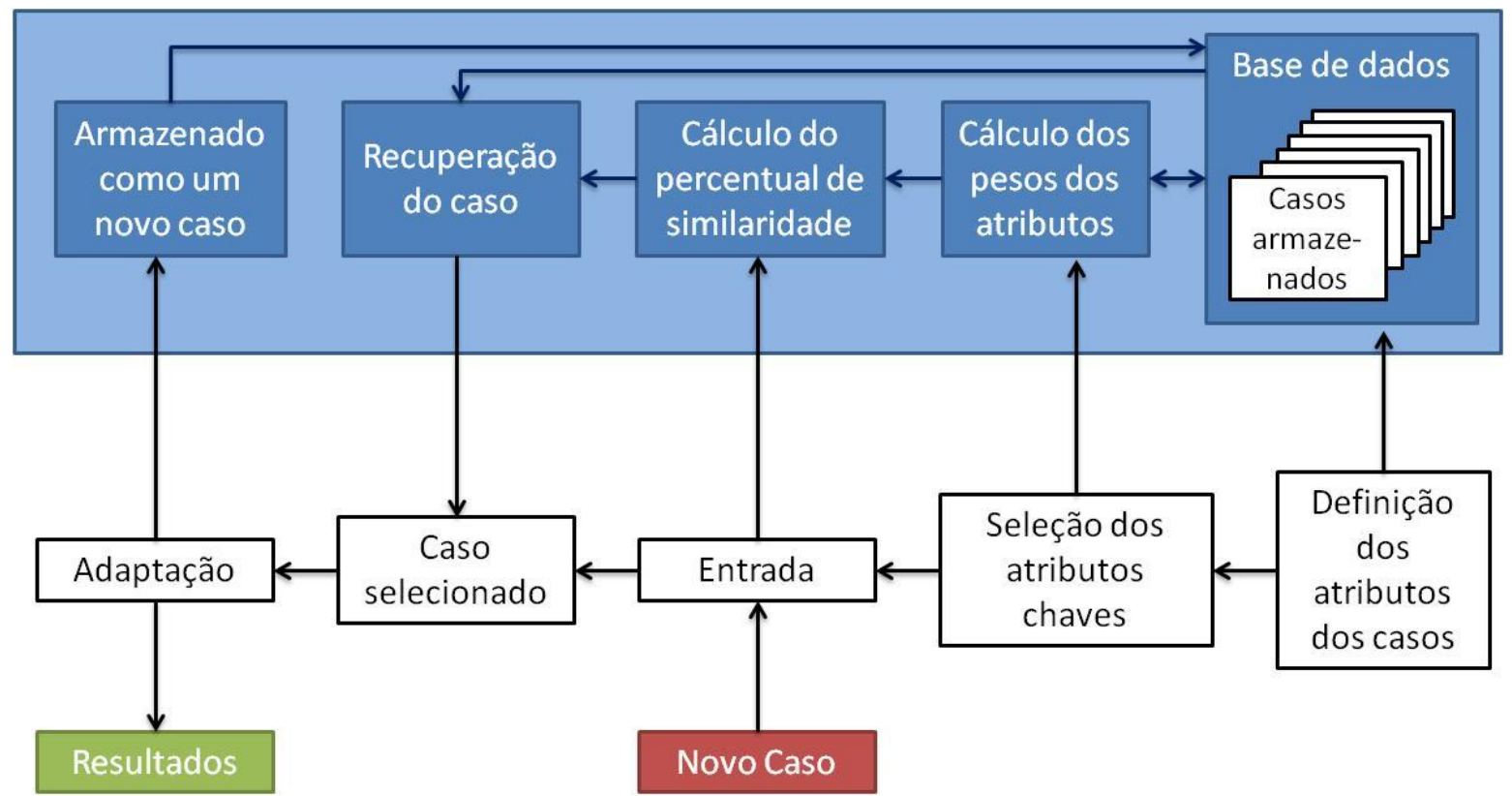

Figura 2.10 - Procedimentos de cálculos pelo CBR, conforme Kim, An e Kang (2004)

Por inserir novos casos à base de dados, esta estimativa permite a atualização do método. Além disso, o CBR tem a vantagem de mostrar numericamente as similaridades entre o projeto a ser estimado e os que serviram de base ao método, 
ou seja, não considera que os projetos do banco de dados possuem os mesmos atributos que o novo a ser estudado.

\subsubsection{Análise sobre as estimativas de custo}

A estimativa de custo pelo CUB pode não representar a realidade praticada por uma incorporadora. Isto ocorre devido aos índices adotados nos quantitativos de insumos e mão-de-obra, que são pré-determinados de acordo com o padrão de acabamento que a própria norma estabelece para os projetos-padrão e com um desempenho padrão de eficiência para o uso dos insumos. Assim, a empresa fica restrita a estes valores, sem poder refinar os dados com seus próprios índices, o que poderia fornecer um valor de custo mais próximo ao que ela pratica realmente.

Para levar em consideração estes índices, é comum a realização da parametrização de valores históricos de uma mesma incorporadora. Porém, neste tipo de modelagem, os projetos são homogeneizados, ou seja, diferentes geometrias são tomadas por suas médias a fim de se preverem os custos de um futuro edifício através de dados correlacionados entre áreas. Porém, tais médias podem não retratar a real quantidade; por exemplo, ao estudar a quantidade de alvenaria em relação à área do pavimento tipo, se a geometria dos ambientes for diferente, a quantidade de parede por $\mathrm{m}^{2}$ também não será a mesma, conforme mostra a Figura 2.11 .
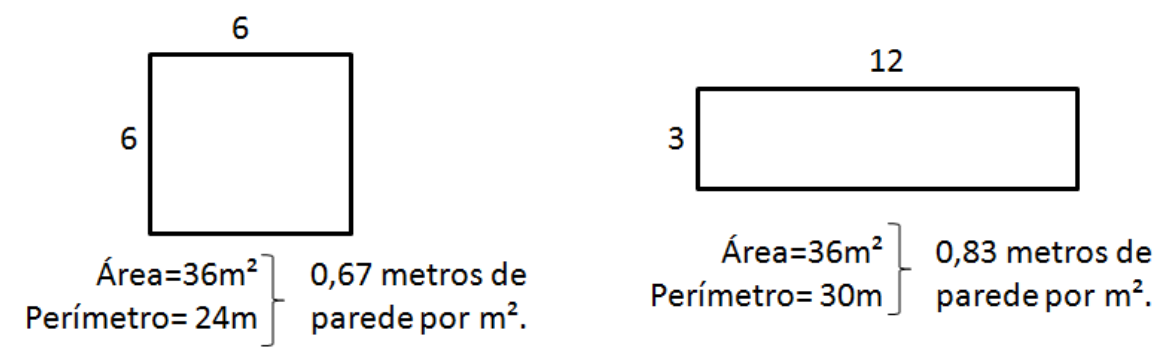

Figura 2.11 - Diferenças na quantidade de parede em uma mesma área

Com relação a esta limitação, Marchiori (2009) afirma que este tipo de estimativa depende do banco de dados no qual o modelo está embasado, pois "o novo projeto, que terá seu custo prognosticado com este método, deverá ter a mesma tipologia e características semelhantes àquelas dos projetos que geraram o modelo". Além 
disso, Otero e Heineck (2004) atentam ao fato de que o método de estimativa está restrito "à empresa e região do país estudadas. A extrapolação de tais dados para fora destes limites deve ser precedida por uma verificação de compatibilidade entre as informações presentes neste ambiente e as daquele novo universo que se deseja como objeto de estudo".

Já os métodos mais atuais utilizados em outros países são realizados através de princípios sobre inteligência artificial. Estes métodos, apesar de supostamente fornecerem maior precisão, necessitariam de um estudo mais focado em computação e análise matemática, mas indicam a possibilidade de trabalhar-se o aprendizado contínuo, no prognóstico, a cada novo caso estimado.

O Quadro 2.2 mostra a análise de cada método descrito, com base em atributos listados a partir de levantamentos bibliográficos.

\section{Quadro 2.2 - Análise das estimativas de custo levantadas - continua}

\begin{tabular}{|c|c|c|c|c|}
\hline Atributo & CUB & Parametrização & Redes Neurais & CBR \\
\hline 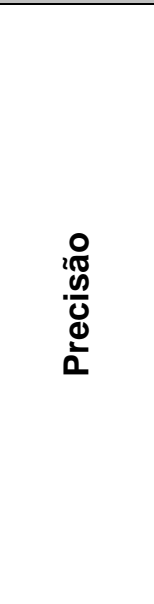 & $\begin{array}{l}\text { Possui cálculos de } \\
\text { quantidade de } \\
\text { insumos e de mão- } \\
\text { de-obra que } \\
\text { podem não retratar } \\
\text { as verdadeiras } \\
\text { eficiências de uma } \\
\text { empresa em } \\
\text { particular; assim, } \\
\text { podem ocorrer } \\
\text { discrepâncias entre } \\
\text { os valores } \\
\text { estimados e os } \\
\text { realmente } \\
\text { praticados. }\end{array}$ & $\begin{array}{l}\text { Por relacionar } \\
\text { informações } \\
\text { geométricas com as } \\
\text { quantidades de } \\
\text { serviço, pode sofrer } \\
\text { com variações de } \\
\text { tipologias. Seus } \\
\text { valores estão restritos } \\
\text { a projetos similares de } \\
\text { uma mesma empresa. }\end{array}$ & $\begin{array}{l}\text { De acordo com a } \\
\text { bibliografia, fornece } \\
\text { valores com erro } \\
\text { reduzido; porém, por } \\
\text { estimar o custo com } \\
\text { base em diferentes } \\
\text { projetos orçados, se } \\
\text { estes possuírem } \\
\text { erros, ou se o } \\
\text { prognóstico for feito } \\
\text { para projeto muito } \\
\text { diferente, pode-se } \\
\text { ter erro. }\end{array}$ & $\begin{array}{l}\text { De acordo com a } \\
\text { bibliografia, fornece } \\
\text { valores com erro } \\
\text { reduzido; porém, } \\
\text { por estimar o custo } \\
\text { com base em } \\
\text { diferentes projetos } \\
\text { orçados, se estes } \\
\text { possuírem erros, } \\
\text { ou se o prognóstico } \\
\text { for feito para } \\
\text { projeto muito } \\
\text { diferente, pode-se } \\
\text { ter erro. }\end{array}$ \\
\hline 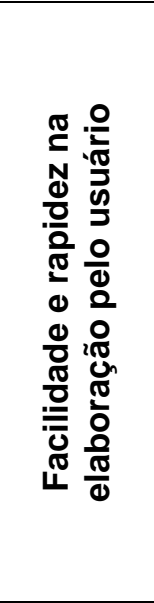 & $\begin{array}{l}\text { A elaboração já foi } \\
\text { definida em norma } \\
\text { (ABNT NBR } \\
\text { 12721); assim, o } \\
\text { usuário apenas } \\
\text { busca dados da } \\
\text { norma e valores do } \\
\text { SINDUSCON. }\end{array}$ & $\begin{array}{l}\text { Como os métodos } \\
\text { divulgados pela } \\
\text { bibliografia são } \\
\text { restritos às empresas } \\
\text { estudadas, as } \\
\text { extrapolações das } \\
\text { equações a obras de } \\
\text { outras empresas } \\
\text { podem gerar erros. } \\
\text { Assim, é necessário } \\
\text { que o usuário elabore } \\
\text { suas próprias } \\
\text { equações, o que pode } \\
\text { exigir tempo e } \\
\text { experiência. }\end{array}$ & $\begin{array}{l}\text { De acordo com a } \\
\text { bibliografia, sua } \\
\text { elaboração é } \\
\text { extremamente } \\
\text { dificultosa, exige } \\
\text { modelagem } \\
\text { computacional } \\
\text { complexa; além } \\
\text { disso, mesmo para } \\
\text { os especialistas, } \\
\text { demora-se muito } \\
\text { para encontrar a } \\
\text { configuração ideal } \\
\text { do problema. }\end{array}$ & $\begin{array}{l}\text { De acordo com a } \\
\text { bibliografia, sua } \\
\text { elaboração é } \\
\text { extremamente } \\
\text { dificultosa, exige } \\
\text { modelagem } \\
\text { computacional } \\
\text { complexa; porém, o } \\
\text { tempo exigido é } \\
\text { menor que o das } \\
\text { redes neurais. }\end{array}$ \\
\hline
\end{tabular}


Quadro 2.4 - Análise das estimativas de custo levantadas - continuação

\begin{tabular}{|c|c|c|c|c|}
\hline Atributo & CUB & Parametrização & Redes Neurais & CBR \\
\hline 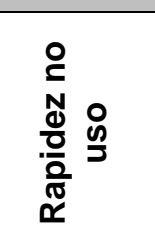 & $\begin{array}{l}\text { Possui facilidade } \\
\text { por ter orientações } \\
\text { para seu uso e } \\
\text { dados de entrada } \\
\text { amplamente } \\
\text { divulgados. }\end{array}$ & $\begin{array}{l}\text { Necessita utilizar } \\
\text { diferentes equações, } \\
\text { o que pode demandar } \\
\text { tempo. }\end{array}$ & $\begin{array}{l}\text { Por ser um } \\
\text { programa } \\
\text { computacional, } \\
\text { pode exigir pouco } \\
\text { tempo na } \\
\text { aplicação. }\end{array}$ & $\begin{array}{l}\text { Por ser um programa } \\
\text { computacional, pode } \\
\text { exigir pouco tempo } \\
\text { na aplicação. }\end{array}$ \\
\hline 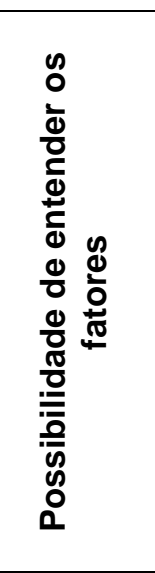 & $\begin{array}{l}\text { A norma não expõe } \\
\text { os cálculos } \\
\text { envolvidos de } \\
\text { maneira clara. } \\
\text { Assim, não se } \\
\text { consegue verificar } \\
\text { quais fatores } \\
\text { influenciam o custo, } \\
\text { podendo-se apenas } \\
\text { analisar áreas e } \\
\text { padrões. }\end{array}$ & $\begin{array}{l}\text { As equações mostram } \\
\text { a relação entre as } \\
\text { variáveis. Porém, não } \\
\text { há explicação técnica } \\
\text { explícita para as } \\
\text { variações. }\end{array}$ & $\begin{array}{l}\text { O método } \\
\text { funciona como } \\
\text { uma "caixa preta"; } \\
\text { não se consegue } \\
\text { saber o motivo } \\
\text { das variações. }\end{array}$ & $\begin{array}{l}\text { O cálculo do custo do } \\
\text { novo caso é feito } \\
\text { pela adaptação entre } \\
\text { ele e os casos } \\
\text { recuperados; tal } \\
\text { adaptação é feita } \\
\text { aplicando os } \\
\text { percentuais de } \\
\text { similaridade no novo } \\
\text { caso. Porém, não há } \\
\text { explicação técnica } \\
\text { explícita para as } \\
\text { variações destes } \\
\text { percentuais. }\end{array}$ \\
\hline 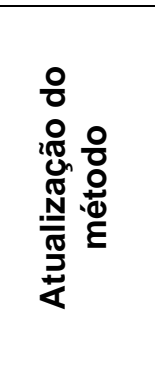 & $\begin{array}{l}\text { Atualização dos } \\
\text { custos dos insumos } \\
\text { feito pelos } \\
\text { SINDUSCONs; } \\
\text { porém não se } \\
\text { consegue atualizar } \\
\text { os projetos e } \\
\text { insumos (estes são } \\
\text { dados da norma). }\end{array}$ & $\begin{array}{l}\text { Pode-se atualizar o } \\
\text { método com a } \\
\text { inclusão de dados de } \\
\text { novo projeto, mas isto } \\
\text { não é automático, } \\
\text { necessita de } \\
\text { reelaboração das } \\
\text { equações. }\end{array}$ & $\begin{array}{l}\text { Dificuldade de } \\
\text { inclusão de novos } \\
\text { dados, pois a } \\
\text { reelaboração da } \\
\text { modelagem é } \\
\text { dificultosa. }\end{array}$ & $\begin{array}{l}\text { Esta estimativa } \\
\text { permite a atualização } \\
\text { do método com } \\
\text { inclusão de projetos } \\
\text { novos. }\end{array}$ \\
\hline 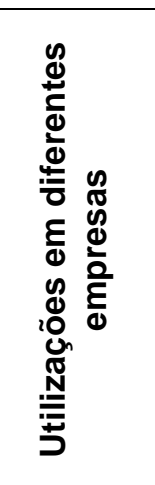 & $\begin{array}{l}\text { O CUB foi } \\
\text { elaborado para ser } \\
\text { utilizado por } \\
\text { diferentes } \\
\text { empresas, com } \\
\text { valores distintos por } \\
\text { região do Brasil e } \\
\text { por tipo de projeto- } \\
\text { padrão. Assim, sua } \\
\text { aplicação pode ser } \\
\text { feita nas diferentes } \\
\text { regiões brasileiras. }\end{array}$ & $\begin{array}{l}\text { A extrapolação do } \\
\text { método paramétrico a } \\
\text { obras com geometrias } \\
\text { diferenciadas e de } \\
\text { empresas diferentes } \\
\text { pode gerar erros. O } \\
\text { melhor modo de uma } \\
\text { empresa utilizar este } \\
\text { método seria } \\
\text { desenvolvendo suas } \\
\text { próprias equações. }\end{array}$ & $\begin{array}{l}\text { O melhor modo de } \\
\text { uma empresa } \\
\text { utilizar este } \\
\text { método seria } \\
\text { desenvolvendo } \\
\text { seu próprio } \\
\text { modelo, com base } \\
\text { nos projetos e } \\
\text { orçamentos já } \\
\text { realizados. }\end{array}$ & $\begin{array}{l}\text { O melhor modo de } \\
\text { uma empresa utilizar } \\
\text { este método seria } \\
\text { desenvolvendo seu } \\
\text { próprio modelo, com } \\
\text { base nos projetos e } \\
\text { orçamentos já } \\
\text { realizados. }\end{array}$ \\
\hline
\end{tabular}


Quadro 2.4 - Análise das estimativas de custo levantadas - conclusão

\begin{tabular}{|c|c|c|c|c|}
\hline Atributo & CUB & Parametrização & Redes Neurais & CBR \\
\hline 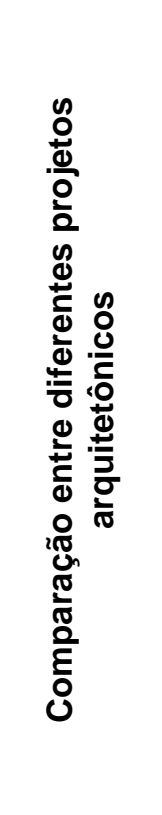 & $\begin{array}{l}\text { A comparação } \\
\text { que este método } \\
\text { pode fazer, em } \\
\text { relação ao partido } \\
\text { arquitetônico, é } \\
\text { apenas com } \\
\text { relação às } \\
\text { diferenças } \\
\text { apresentadas } \\
\text { pelos projetos- } \\
\text { padrões e áreas } \\
\text { medidas. Deste } \\
\text { modo, diferentes } \\
\text { formatos e } \\
\text { variação nas } \\
\text { quantidades são } \\
\text { avaliados. }\end{array}$ & $\begin{array}{l}\text { A análise de arquitetura } \\
\text { pode ser feita através } \\
\text { de indicadores } \\
\text { resultantes de } \\
\text { correlações entre } \\
\text { fatores relacionados a } \\
\text { áreas, formatos, altura, } \\
\text { número de ambientes. } \\
\text { Porém, como as } \\
\text { equações devem ser } \\
\text { utilizadas para projetos } \\
\text { similares, a análise de } \\
\text { custo de projetos } \\
\text { distintos, pode gerar } \\
\text { dados imprecisos. Além } \\
\text { disso, por não } \\
\text { quantificar o projeto, a } \\
\text { avaliação pode não } \\
\text { retratar o real valor de } \\
\text { quantidades. }\end{array}$ & $\begin{array}{l}\text { Não se consegue } \\
\text { avaliar os partidos } \\
\text { arquitetônicos, pois } \\
\text { atua como uma } \\
\text { "caixa preta". Se } \\
\text { não tiver dados de } \\
\text { quantitativos como } \\
\text { entrada, a avaliação } \\
\text { pode não retratar o } \\
\text { real valor de } \\
\text { quantidades. }\end{array}$ & $\begin{array}{l}\text { Avaliam diferentes } \\
\text { partidos } \\
\text { arquitetônicos } \\
\text { através dos } \\
\text { resultados de } \\
\text { percentuais de } \\
\text { similaridade. Se } \\
\text { não tiver dados de } \\
\text { quantitativos como } \\
\text { entrada, a } \\
\text { avaliação pode não } \\
\text { retratar o real valor } \\
\text { de quantidades. }\end{array}$ \\
\hline 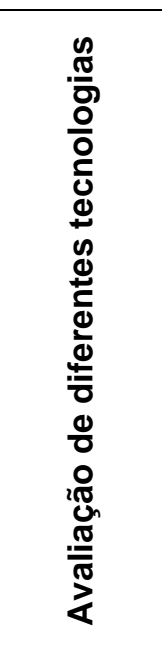 & $\begin{array}{l}\text { O método não } \\
\text { avalia tecnologia, } \\
\text { pois esta já é pré- } \\
\text { definida, de } \\
\text { acordo com os } \\
\text { projetos-padrões } \\
\text { constantes na } \\
\text { norma. }\end{array}$ & $\begin{array}{l}\text { Por gerar equações } \\
\text { que homogeneízam } \\
\text { soluções adotadas } \\
\text { anteriormente, não } \\
\text { avalia a tecnologia, (a } \\
\text { não ser que se façam } \\
\text { equações distintas por } \\
\text { tecnologia adotada). } \\
\text { Não se consegue } \\
\text { analisar uma inovação, } \\
\text { pois não constará no } \\
\text { banco de dados. }\end{array}$ & $\begin{array}{l}\text { A modelagem deve } \\
\text { prever, como } \\
\text { entrada, o tipo de } \\
\text { tecnologia a ser } \\
\text { utilizada e, para } \\
\text { isto, o modelo deve } \\
\text { ter sido gerado por } \\
\text { banco de projetos } \\
\text { que utilizaram as } \\
\text { diferentes } \\
\text { tecnologias. Assim, } \\
\text { não se consegue } \\
\text { analisar o custo de } \\
\text { uma inovação, pois } \\
\text { esta não constará } \\
\text { no banco de dados. }\end{array}$ & $\begin{array}{l}\text { A modelagem deve } \\
\text { prever, como } \\
\text { entrada, o tipo de } \\
\text { tecnologia a ser } \\
\text { utilizada e, para } \\
\text { isto, o modelo deve } \\
\text { ter sido gerado por } \\
\text { banco de projetos } \\
\text { que utilizaram as } \\
\text { diferentes } \\
\text { tecnologias. Assim, } \\
\text { não se consegue } \\
\text { analisar o custo de } \\
\text { uma inovação, pois } \\
\text { esta não constará } \\
\text { no banco de dados. }\end{array}$ \\
\hline
\end{tabular}

Com base na revisão bibliográfica, um caminho que parece ser indicado para a melhoria do prognóstico de custos é o de usar um pouco de cada um dos métodos citados.

Mesmo nas fases iniciais do empreendimento, são disponíveis representações arquitetônicas que permitem uma incipiente orçamentação, na medida em que alguns serviços podem ser quantificados, tanto em termos de quantidades, quanto dos fatores que influenciam a eficiência no consumo de materiais e mão-de-obra, levando em conta o padrão de acabamento. 
A comparação com estudos anteriores permitiria a geração de indicadores para estimar o custo relativo de um novo caso em relação a um empreendimento tomado como referência, analisando-se os fatores que poderiam tornar o custo diferenciado. 


\section{MÉTODO PROPOSTO}

Foi discutida, no Capítulo 1, a importância do prognóstico de custos na tomada de decisões, tanto por parte do empreendedor (para compra de terreno, escolha de tecnologia, entre outros), como por parte dos projetistas, na medida em que a análise de custos sobre os projetos os auxilia a conceber empreendimentos coerentes com o orçamento previsto.

No Capítulo 2 verificou-se que a elaboração de um orçamento completo durante o estudo preliminar não é possível devido a pouca informação disponível e, também, devido ao fato de que tal tipo de orçamento demanda muito tempo para ser concluído. Deste modo, a solução para prognosticar custos, para muitos empreendedores, é baseada em correlações de quantidades de serviços com área construída; porém, tais métodos podem gerar um valor de custo por área construída pouco preciso.

A presente dissertação pretende elaborar método de estimativa de custo que forneça valor acurado para verificar a análise de viabilidade, auxiliando a elaboração da concepção do empreendimento, na medida em que possibilita comparar os custos de construção de diferentes projetos.

De acordo com Cardoso (2009), a avaliação do custo de uma obra como um todo é menos precisa que a avaliação de suas partes, já que estas podem ter seus custos melhor entendidos e determinados. Para o autor, tal fracionamento só ocorre quando se tem os projetos detalhados; porém, se os croquis existentes durante o estudo preliminar possibilitam a quantificação de diversos serviços, por que não utilizar tal informação para estimar o custo?

Com base nesta indagação foi proposto o método a ser apresentado nesta dissertação, buscando mesclar a determinação de custos pelos métodos de orçamentação e parametrização (com uso de indicadores).

De um modo geral, o método apresentado compara custos entre um empreendimento, orçado anteriormente, com outro, a ser desenvolvido, através da aplicação do Modelo dos Fatores a custos. Este Modelo, definido em Thomas et al. 
(1990), nasceu do entendimento da produtividade da mão-de-obra através da análise dos fatores que a influenciam. Através da quantificação de tais fatores, foi possível obter subsídios para a previsão de produtividade em nova obra.

Ainda com base neste Modelo, para os serviços que não poderiam ser quantificados, o método proposto utiliza indicadores, já definidos em bibliografia, que relacionam os fatores de variação das quantidades de serviço ou dos consumos de insumo com as informações disponíveis em estudo preliminar, a fim de se preverem seus valores.

O presente capítulo pretende mostrar o raciocínio envolvido na elaboração do método e as equações a serem utilizadas para a sua utilização.

\subsection{Entendimento e premissas do método proposto}

Com base nos produtos gerados em fases iniciais do empreendimento, pode-se considerar as seguintes informações disponíveis para a estimativa de custo (MELHADO, 1994; ABNT NBR 6492, 1994; ASBEA, 2010),

- quadro de áreas das unidades e totais do empreendimento;

- croquis de implantação;

- planta do andar tipo;

- cortes típicos;

- fachada;

- condicionantes locais;

- relação das atividades exercidas no empreendimento, contendo as descrições, características, áreas e dimensionamentos preliminares de todos os itens abordados;

- prazo para execução. 
Desta forma, muitos são os elementos que podem ser quantificados para elaboração de composições: paredes; pisos; fachada; esquadrias; quantidades e tipos de ambientes; infraestrutura, com base na implantação; entre outros.

Para se determinarem os demais fatores que impactam no custo, o Método utilizará a parametrização, com uso de indicadores de consumo. De acordo com a revisão bibliográfica, muitas são as publicações que defendem o uso de indicadores como auxílio em análise de projetos e estimativa de custos.

Para verificar a constituição de um edifício, Mascaró (1998) o subdividiu em planos horizontais em interseção com outro conjunto de planos verticais, formando os espaços projetados que, por sua vez, devem possuir "mecanismos de chegada" como acessos. Para o autor, a análise destes conjuntos de formas possibilita a compreensão de custos e do desempenho do edifício.

Analisando os custos de uma maneira geral, Mascaró verificou que, do total do custo de construção de uma edificação, os planos horizontais (formados por planos horizontais da estrutura e fundações, telhado, pisos e parte horizontal dos revestimentos) representam 25\%; os planos verticais (parte vertical da estrutura e das fundações, alvenarias, aberturas, revestimentos interno e externo verticais) abrangem 45\%; as instalações, $25 \%$; e o canteiro de obras, outros $5 \%$.

Em relação aos planos horizontais, a redução de custo é mais restringida às modificações arquitetônicas, podendo-se, de uma forma geral, variar os pisos e contrapisos e telhado. Já em relação aos planos verticais, apresentam-se inúmeras alternativas, tanto na concepção geométrica quanto na escolha de materiais. As modificações em instalações, por sua vez, dependem de decisões arquitetônicas dicotômicas (sim ou não).

Com base nestes estudos, Mascaró elaborou diversos indicadores que influenciam o custo da edificação, estudando diferentes indicadores geométricos, tais como: tamanho médio dos ambientes, a compacidade, densidade de paredes, altura do edifício, entre outros.

A análise de custos de edifícios, em particular, da estrutura, através de indicadores, foi feita, também, por Neto (2003). Este autor compartilha a opinião de que os 
traçados arquitetônicos têm o maior peso no custo estrutural de um edifício e que a análise de empreendimentos com base em indicadores é um modo simples e prático para suportar o empreendedor na escolha de alternativas economicamente mais viáveis, junto a modificações feitas na arquitetura do edifício.

Neto (2003) afirma ainda que o uso de indicadores (incluindo os de produtividade) permite estimar o custo da estrutura desde o início do projeto. Além disso, para o autor, os indicadores permitem que o empreendedor possa avaliar diferentes métodos construtivos, verificando aquele com maior produtividade e menor custo, auxiliando-o na tomada de decisões, a fim de tornar-se mais competitivo.

Com relação ao uso de indicadores para estimar custos de mão-de-obra, Proverbs, Holt e Olomolaiye (1999) apresentaram um método para prognosticar o custo de mão-de-obra de estrutura de concreto armado através de taxas definidas para um empreendimento, considerado como típico. Para este estudo, os autores multiplicaram a quantidade de homens-hora $(\mathrm{Hh})$ necessários para se fazer uma dada unidade de serviço ( $\mathrm{m}^{3}$ para concreto, por exemplo) pela taxa desse serviço em relação a área do empreendimento (ou seja, a taxa de $\mathrm{m}^{3}$ de concreto por $\mathrm{m}^{2} \mathrm{de}$ pavimento). Assim, os autores obtiveram a quantidade de $\mathrm{Hh}$ por $\mathrm{m}^{2}$ de pavimento. Sabendo a área total do edifício, pôde-se estimar a quantidade de Hh necessária, em um estágio preliminar de projetos.

Nota-se que o uso de indicadores não é uma inovação; porém, a elaboração de um método que os relacione pode apoiar o empreendedor a melhor organizar as informações e poder extrair valores de custo estimado com precisão.

\subsection{Desenvolvimento do método}

O método proposto irá tratar apenas da estimativa de custos diretos, propriamente ditos, ou seja, se desenvolverá ferramenta para prognosticar custos relacionados a gastos com materiais e mão-de-obra utilizados na construção da edificação a ter custo estimado. Este método utilizará a técnica de estimativa de "baixo para cima", decompondo o edifício em atividades menores (PMBOK 2002), além de realizar cálculos paramétricos. 
O PMBOK (2002) propõe a decomposição de um empreendimento a partir de uma estrutura analítica do projeto (EAP). Uma EAP deve organizar e definir o escopo total de um projeto através de seu detalhamento em diferentes níveis que deverão se referir a identificadores únicos, sendo que os níveis mais baixos de um EAP serão referenciados como pacote de trabalho.

De acordo com Marchiori (2009), um empreendimento de edificação pode ser subdividido em partes menores, a fim de se estudar mais especificadamente cada atividade que compõe tal edificação, conforme mostra a Figura 3.1.

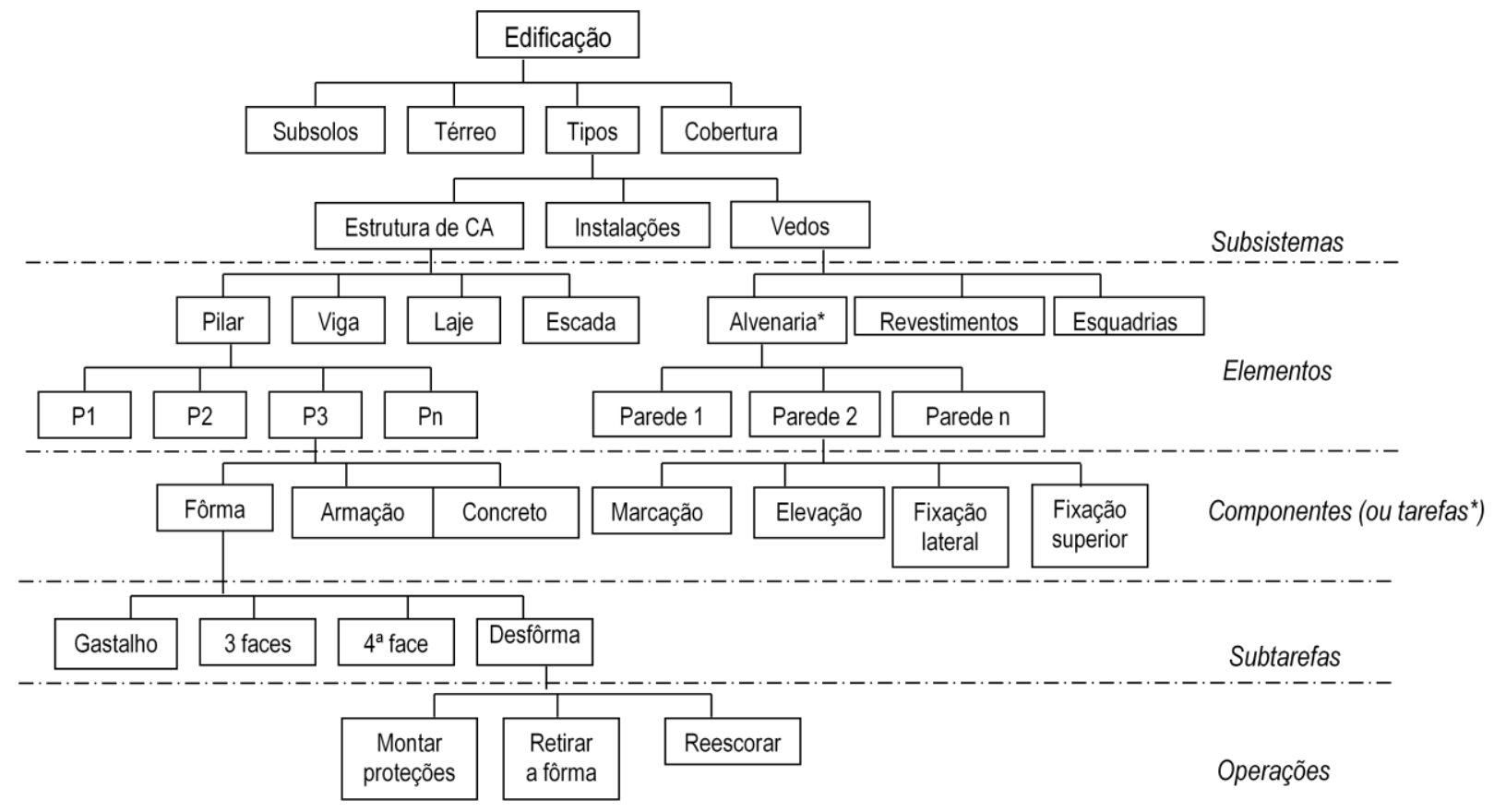

Figura 3.1 - Desdobramento do produto e dos processos (MARCHIORI, 2009)

Dada a visão analítica da Figura 3.1, o método proposto, em função das informações disponíveis e da maior ou menor precisão requerida, pode ter suas parcelas alocadas em níveis mais ou menos abrangentes. Por exemplo, poder-se-iam entender as fôrmas como um todo ou ir-se na direção de distinção de pilares, vigas e lajes.

A fim de homogeneizar a terminologia, será adotada, nesta dissertação, a quebra do edifício em serviços de obra, que, conforme Cardoso e Haito (2011), são definidos como serviços de natureza física, relacionados com a execução de parte(s) de uma obra, como, por exemplo, terraplenagem, fundações, estrutura metálica, impermeabilização, revestimentos, entre outros. 
Deste modo, o custo de uma edificação é a soma dos custos dos serviços que a compõem (Figura 3.2).

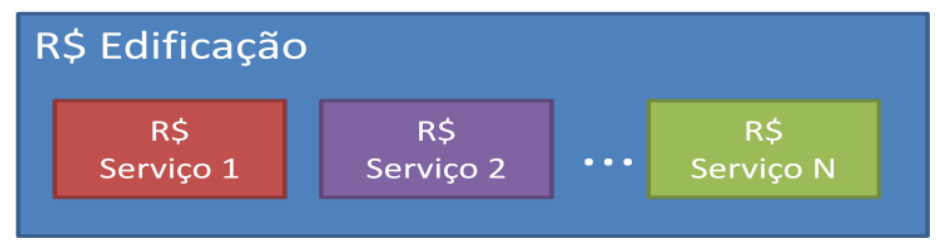

Figura 3.2 - Custo de um edifício

Como o estudo de viabilidade fornece valores de custo por área de construção, o valor referente à somatória dos custos de cada serviço também deve ser dividido pela área total da edificação, como mostra a Eq. 3.1.

$$
\frac{\text { CustoT }}{A}=\frac{\text { CustoServ }_{1}}{A}+\frac{\text { CustoServ }_{2}}{A}+\ldots+\frac{\text { CustoServ }_{n}}{A}
$$

onde:

CustoT = Custo total de construção da edificação;

A = área de construção;

CustoServ $_{n}=$ Custo do serviço " $n$ ".

Analisando o custo de cada serviço, tem-se que seu valor pode ser calculado através de seu custo unitário multiplicado pela sua quantidade, conforme mostra a Eq. 3.2.

$$
\frac{\text { CustoServ }_{i}}{A}=\frac{\text { QServ }_{i}}{A} \times \frac{\text { CustoServ }_{i}}{Q \text { Serv }_{i}}
$$

onde:

CustoServ $_{\mathrm{i}}=$ Custo do serviço $\mathrm{i}$; 
$A$ = área de construção;

QServ $_{\mathrm{i}}=$ Quantidade de serviço para o serviço i;

CustoServ ${ }_{\mathrm{i}} / \mathrm{QServ}_{\mathrm{i}}=$ Custo unitário do serviço i.

O método analisa as duas parcelas da Eq. 3.2 através de uma comparação da edificação a ter seu custo prognosticado com uma edificação similar, com custos de serviços conhecidos. Esta comparação é feita através do cálculo de fatores que relacionam os valores de quantidade de serviço e de custo unitário entre os dois empreendimentos.

O empreendimento a ter o custo da edificação prognosticado será chamado, nesta dissertação, como ED-1. Já a edificação de referência, ou seja, aquela com custo já conhecido, com função de subsidiar informações ao empreendimento em estudo, será denominada de ED-0. O valor do custo prognosticado deve ser atualizado, pois deve-se levar em conta o tempo transcorrido entre os custos definidos para ED0 e aqueles utilizados para ED1.

A Eq. 3.3 mostra como será obtido o custo por $\mathrm{m}^{2}$ de cada serviço do empreendimento, utilizando os fatores.

$$
\left(\frac{\text { CustoServ }}{A}\right)_{E D 1}=\left(\frac{\text { CustoServ }}{A}\right)_{E D 0} \times F Q \operatorname{Ser} v \times F C U n \times F \text { inf }
$$

onde:

$(\text { CustoServ/A })_{E D 1}=$ custo de serviço por área de construção da edificação a ter custo prognosticado;

$(\text { CustoServ/A })_{\text {EDO }}=$ custo de serviço por área de construção da edificação com custo já definido e tomado como referência;

FQServ = fator de conversão relacionado com a quantidade de serviço; 
FCUn = fator de conversão relacionado ao custo unitário do serviço;

Finf=fator de correção inflacionária para o período.

Como o estudo de todos os serviços de uma edificação demandaria muito tempo, a análise pode ser feita priorizando aqueles que possuem maior peso na curva $A B C$, analisada com base no ED0.

De acordo com Gonçalves (2011), os serviços mais comuns a terem custos mais impactantes, ou seja, que pertencem às curvas $A$ e $B$ de uma curva $A B C$, são os listados no Quadro 3.1.

Quadro 3.1 - Serviços pertencentes às curvas A e B de uma curva $A B C$, conforme Gonçalves (2011)

\begin{tabular}{|c|c|c|}
\hline Tipo de edificação & Curva A & Curva B \\
\hline Residencial & $\begin{array}{ll}\text { - } & \text { estrutura; } \\
\text { - } & \text { instalações elétricas } \\
& \text { e hidráulicas; } \\
\text { - } & \text { vedações; } \\
\text { - } & \text { esquadrias. }\end{array}$ & $\begin{array}{l}\text { - } \text { elevadores; } \\
\text { - } \quad \text { revestimento de fachada; } \\
\text { - } \quad \text { revestimentos internos; } \\
\text { - } \quad \text { fundação; } \\
\text { - } \quad \text { contenção; } \\
\text { - impermeabilização. }\end{array}$ \\
\hline Comercial & $\begin{array}{ll}\text { - } & \text { estrutura; } \\
\text { - } & \text { ar condicionado; } \\
\text { - } & \text { instalações elétricas; } \\
\text { - } & \text { revestimento de fachada. }\end{array}$ & $\begin{array}{ll}\text { - } & \text { instalações hidráulicas; } \\
\text { - } & \text { elevadores; } \\
\text { - } & \text { revestimentos de piso; } \\
\text { - } & \text { forro e painéis. }\end{array}$ \\
\hline
\end{tabular}

A seguir são mostrados os raciocínios para a determinação dos fatores.

\subsubsection{Quantidade de serviço}

A quantidade de um dado serviço pode ser calculada ou estimada dependendo das informações disponíveis e do serviço em estudo. 
Com base nas informações disponíveis, a Figura 3.3 mostra os passos para se determinar a quantidade de serviço, através de um fluxograma.

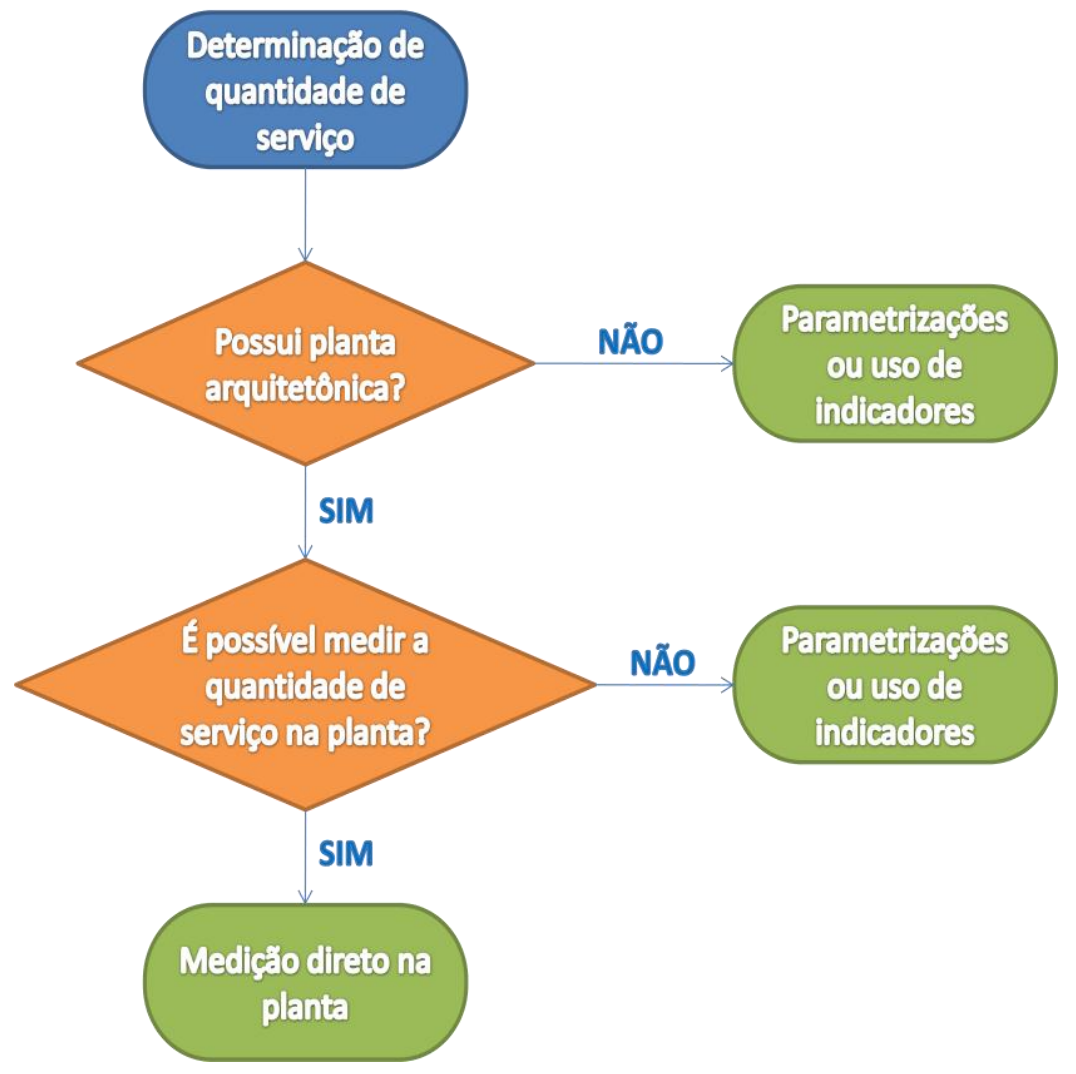

Figura 3.3 - Fluxograma para determinação da quantidade de serviço

A medição de quantidades de serviço diretamente em plantas (2D) pode gerar valores de áreas, volumes, perímetros ou outras unidades (TCPO, 2003).

Assim, no caso de se ter a planta arquitetônica, o método prevê que os seguintes serviços podem ter suas quantidades medidas diretamente na mesma:

- laje: área dada pelo pavimento menos os vazios;

- alvenaria: através do levantamento da quantidade de paredes;

- revestimento: através da quantidade de paredes a revestir e da área dos pisos dos ambientes;

- impermeabilização: com base nas áreas de ambientes molháveis e de terraços;

- esquadrias: contagem; 
- elevadores: contagem.

Atualmente, novas ferramentas de informática, utilizando o sistema CAD e, até mesmo, sistemas de informação geográfica, estão sendo desenvolvidas para auxiliar a quantificação de serviços. Estes programas possibilitam tanto a realização de levantamento de quantidades em projetos de arquitetura (BANSAL; PAL, 2007) quanto em projetos de estrutura (JADID; IDREES, 2007).

De acordo com Eastman et al. (2011), a utilização do BIM (Building Information Modeling ou Modelagem de Informações para a Construção), durante a concepção de um empreendimento, permite extrair automaticamente informações sobre quantidades de componentes (e suas especificações), áreas, volumes e quantitativos de materiais dos elementos modelados, permitindo, inclusive, exportar tais informações para planilhas. Comparando o levantamento de quantitativos feitos manualmente em projetos 2D com os gerados pelo BIM, Shen e Issa (2010) constataram que este último fornece valores com maior precisão, consumindo menos tempo que o levantamento manual.

Para os serviços que não podem ter suas quantidades levantadas nos croquis existentes em estudo preliminar, ou no caso de não se ter tais projetos, deve-se fazer uma estimativa com base em análises paramétricas ou através de indicadores. A seguir, são mostradas formas de se estimarem estes valores:

- cobertura: a área de sua superfície pode ser correlacionada com a área do pavimento;

- esquadrias: pode-se correlacionar a quantidade e tipo de esquadria por quantidade e tipo de ambientes existentes no andar;

- estrutura de concreto armado:

- Botelho e Marchetti (2004) definiram indicadores que relacionam a quantidade de concreto com a área de construção; e as fôrmas e armaduras com a quantidade de concreto;

- Neto (2003), a fim de estimar o volume de concreto, correlacionou a espessura média (relação entre o volume do concreto e área efetiva de 
estrutura do pavimento) com a área de influencia de pilares (área do pavimento dividida pelo número de pilares) e com a altura do prédio; além disso, o autor determinou indicadores de quantidade de fôrmas por volume de concreto;

- alvenarias: diversos estudos correlacionam a quantidade de paredes com a área do pavimento e seu formato, sendo que o precursor desta sondagem foi Mascaró (1998); tal estudo será retomado no Capítulo 4, onde se verificará a quantidade paredes para alvenaria estrutural;

- sistemas elétricos: pode-se criar um banco de informações a respeito de quantidade de eletroduto por $\mathrm{m}^{2}$ e fazer uma suposição de número de fios inseridos, sendo tais números atrelados a um determinado padrão de construção;

- sistemas hidráulicos: Paliari (2008) determinou diferentes indicadores para sistemas hidráulicos e, com base neles, nas áreas e quantidades de apartamentos, áreas e quantidades de ambientes molháveis, número de prumadas, número de pontos de consumo de água, desenvolveu um método para prognosticar quantidade de serviço para este subsistema;

- urbanização: em Kelly (2008) há diversos indicadores de urbanização, determinados para conjuntos habitacionais horizontais, para os seguintes serviços: terraplenagem, rede de drenagem, rede de esgoto, rede de abastecimento de água, paisagismo e pavimentação.

Com relação a parametrizações para se determinarem quantidades de serviços, citam-se, também, trabalhos desta temática já realizados: Losso, 1995; Oliveira, 1990; Solano e Heineck, 2001; Andrade, 1996; Otero e Heineck, 2004; Gonçalves, 2011; entre outros.

Com os valores de quantidades de serviço determinadas, para se obter o fator FQServ, mostrado na Eq. 3.4, deve-se relacionar o valor da quantidade de serviço em relação à área de construção do ED1 com o do ED0. 


$$
F Q \operatorname{Ser} v=\frac{\left(\frac{Q S e r v}{A}\right)_{E D 1}}{\left(\frac{Q S e r v}{A}\right)_{E D 0}}
$$

onde:

FQServ = fator de conversão relacionado com a quantidade de serviço;

$(\mathrm{QServ} / \mathrm{A})_{\mathrm{ED} 1}=$ quantidade de serviço por área de construção da edificação a ter custo prognosticado;

$(Q S e r v / A)_{E D O}=$ quantidade serviço por área de construção da edificação com custo já definido e tomado como referência.

\subsubsection{Custo unitário do serviço}

A análise do custo unitário é feita para os serviços que podem ter custos de mão-deobra e materiais variados, devido a variações de consumo/ produtividade, a diferentes especificações técnicas e/ou arquitetônicas, ou, ainda, devido à variação regional.

Deste modo, no caso de não haver tais variações, pode-se estimar o valor do serviço apenas através da multiplicação do custo do serviço por $\mathrm{m}^{2}$ de área de construção por seu fator de quantidade de serviço. Por exemplo, este raciocínio pode ser empregado para um dado revestimento interno de um edifício (ED1) que terá a mesma especificação daquele tomado como referência (ED0), a mesma tecnologia a ser empregada e para o qual não se prevê variações na produtividade (tanto devido à regionalização quanto devido às semelhanças no conteúdo que não implicam em maiores ou menores dificuldades de execução).

O estudo do custo unitário leva em conta que este valor é definido pela soma dos custos dos recursos que compõem o serviço, ou seja, custo de material, de mão-deobra e de equipamento, conforme mostra a Eq. 3.5. 


$$
\frac{\text { CustoServ }}{Q \operatorname{Serv}}=\frac{\text { CustoMO }}{Q \operatorname{Serv}}+\frac{\text { CustoMAT }}{Q \operatorname{Serv}}+\frac{\text { CustoEQ }}{Q \operatorname{Serv}}
$$

onde:
CustoServ/QServ = custo unitário do serviço;
CustoMO/QServ = custo de mão-de-obra por quantidade de serviço;
CustoMAT/QServ = custo de material por quantidade de serviço;
CustoEQ/QServ = custo de equipamento por quantidade de serviço.

O custo de dado recurso pode ser descrito através de duas parcelas: uma ligada ao ônus de sua aquisição; e outra associada à eficiência na transformação física deste recurso em produto. A Figura 3.4 representa estas relações.

\section{M.O.}
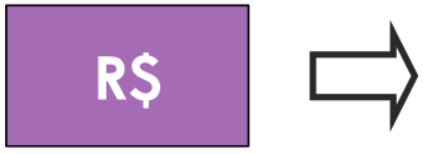

\section{MAT.}

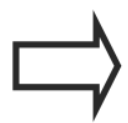

Processo

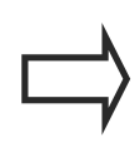

\section{EQUIP.}
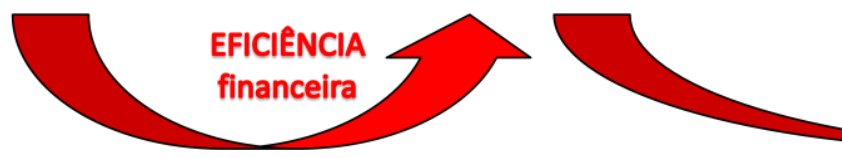

EFICIÊNCIA física

Figura 3.4 - Eficiências ligadas á transformação do recurso financeiro em físico e deste em serviço/produto

A eficiência financeira é aquela ligada à comparação da demanda de recursos financeiros para a aquisição de uma unidade de recurso físico.

Já a eficiência em transformar os recursos físicos em serviços/produtos (eficiência física) pode ser calculada em função de cada recurso. 
Como a determinação do custo de equipamentos não é objeto desta dissertação, pois não é custo direto, os recursos a serem avaliados no método são materiais e mão-de-obra.

Deste modo, o cálculo do fator do custo unitário é aquele mostrado na Eq. 3.6, a qual leva em conta o peso associado ao custo de cada um dos recursos, com base na edificação de referência; e subfatores que analisam as variações de especificações e de eficiência dos recursos.

$$
F C U n=\frac{f M A T \times\left(\frac{\text { CustoMAT }}{Q S e r v}\right)_{E D 0}+f M O \times\left(\frac{\text { CustoMO }}{Q S e r v}\right)_{E D 0}}{\left(\frac{\text { CustoMAT }}{Q S e r v}\right)_{E D 0}+\left(\frac{\text { CustoMO }}{Q S e r v}\right)_{E D 0}}
$$

onde:

FCUn = fator do custo unitário;

fMAT = subfator ligado ao custo de materiais;

CustoMAT/QServ = Custo de material por quantidade de serviço;

$\mathrm{fMO}=$ subfator ligado ao custo de mão-de-obra;

CustoMO/QServ = Custo de mão-de-obra por quantidade de serviço;

EDO = edificação de referência.

\subsubsection{SUBFATOR DE CUSTO UNITÁRIO LIGADO AOS MATERIAIS}

Sabendo que cada serviço é formado pela composição de diferentes materiais, o custo referente a este recurso é a soma de todas as composições que formam o serviço. 
Deste modo, conforme a Eq. 3.7, o cálculo do custo de material para um dado serviço é igual à soma dos custos unitários de cada material multiplicados pelos seus respectivos consumos unitários, que indicam a eficiência de transformar 0 recurso físico material em serviços/ produtos de construção (SOUZA, 2001).

$$
\frac{\text { CustoMAT }_{n}}{Q \operatorname{Serv}}=\frac{\text { CustoMAT }_{n}}{Q M A T_{n}} \times \frac{Q M A T_{n}}{Q \operatorname{Serv}}
$$

onde:

CustoMAT $_{n} /$ Qserv = custo do material n para um dado serviço;

CustoMAT $_{n} / \mathrm{QMAt}_{\mathrm{n}}=$ custo unitário do material $\mathrm{n}$;

$\mathrm{QMAT}_{\mathrm{n}} /$ Qserv = consumo unitário do material $\mathrm{n}$ referente a um dado serviço.

Verificando as parcelas da Eq. 3.7, nos casos em que o ED1 terá os mesmos processos construtivos utilizados na ED0, as variações que podem ocorrer ao se compararem duas edificações diferentes são:

- custo unitário do material: este valor pode variar, principalmente, devido às especificações, como, por exemplo, o custo de concreto poder ser diferente de acordo com a resistência, os tipos de blocos de alvenaria poderem variar de acordo com a modulação, entre outros;

- consumo unitário do material: é um valor influenciado, principalmente, pela eficiência do processo, medida através do indicador de perdas.

A perda é um conceito relativo que associa uma quantidade de material teoricamente necessária com a realmente utilizada, podendo ocorrer em diferentes momentos, tais como no recebimento, na estocagem, no processamento intermediário e no processamento final. Além disso, as perdas se apresentam de diferentes formas: como entulho, incorporadas na construção ou através de roubo do material (SOUZA, 2001). 
Souza (2001) definiu o indicador de perdas através da Eq. 3.8.

$$
I P=\left(\frac{Q M A T_{\text {real }}-Q M A T_{\text {teórico }}}{Q M A T_{\text {teórico }}}\right) \times 100
$$

onde:

$\mathrm{IP}=$ indicador de perdas (em \%);

$\mathrm{QMAT}_{\text {real }}=$ quantidade de material realmente consumido;

$\mathrm{QMAT}_{\text {teórico }}=$ quantidade de material teoricamente necessária, calculada com base nos projetos.

A partir do valor adotado para as perdas de determinado material, o consumo unitário real de um material, ou seja, aquele que realmente ocorre na obra, será dado pela Eq. 3.9.

$$
\frac{Q M A T_{\text {real }}}{Q S e r v}=\frac{Q M A T_{\text {teórico }}}{Q S e r v} \times\left(1+\frac{I P}{100}\right)
$$

onde:

$\mathrm{QMAT}_{\text {real }} /$ Qserv = consumo unitário de material;

IP = indicador de perdas (em \%);

$\mathrm{QMAT}_{\text {real }}$ = quantidade de material realmente consumido;

$\mathrm{QMAT}_{\text {teórico }}=$ quantidade de material teoricamente necessária, calculada com base nos projetos. 
O subfator relacionado aos materiais será composto por todas as variações que possam ocorrer em suas composições, ou seja, diferenças no custo e consumo unitários.

As variações de acordo com as especificações podem ser medidas de acordo com as considerações técnicas e arquitetônicas. Porém, as perdas devem ser analisadas de acordo com um estudo baseado em banco de dados, associando perdas aos fatores influenciadores (SOUZA, 2001) como, por exemplo, verificando a qualidade do material, o tipo de transporte e equipamentos utilizados no processamento final, entre outros.

O valor do subfator referente às comparações entre todos os materiais que compõe um dado serviço é determinado a partir do cálculo da Eq. 3.10. Este cálculo leva em conta uma ponderação entre os custos dos insumos, pois um dado serviço é formado por diferentes materiais que influenciam distintamente o custo total deste serviço.

$$
f M A T=\frac{\sum_{n}\left[\left(\frac{\text { CustoMAT }_{n}}{Q \operatorname{serv}}\right)_{E D 0} \times \frac{\left(\frac{\text { CustoMAT }_{n}}{Q M A T_{n}}\right)_{E D 1}}{\left(\frac{\text { CustoMAT }_{n}}{Q M A T_{n}}\right)_{E D 0}} \times \frac{\left(\frac{Q M A T_{n-\text { real }}}{Q S e r v}\right)_{E D 1}}{\left(\frac{Q M A T_{n-\text { real }}}{Q S e r v}\right)_{E D 0}}\right]}{\sum_{n}\left(\frac{\text { CustoMAT }}{Q \text { serv }}\right)_{E D 0}}
$$

onde:

CustoMAT $_{n} /$ Qserv = custo do material n para um dado serviço;

CustoMAT $n / \mathrm{QMAt}_{n}=$ custo unitário do material $\mathrm{n}$;

$\mathrm{QMAT}_{\mathrm{n} \text {-real }} /$ Qserv = consumo unitário de material $\mathrm{n}$ referente à quantidade de serviço;

ED1 = empreendimento a ter o custo da edificação prognosticado;

ED0 = edificação de referência. 
Nota-se que o subfator pode ser 1 no caso de não se variar a composição de materiais para o serviço (ou seja, não variam os tipos de materiais, seus custos unitários e consumos unitários) entre o ED1 e ED0.

Assim, deve-se fazer a verificação apenas dos materiais que tiverem valores diferenciados, levando em conta seu peso em relação ao custo total do serviço, dado pela ponderação feita com base no edifício de referência.

No caso de o ED1 ter materiais diferenciados do ED0 (por exemplo, a fachada do primeiro foi especificada como pastilha, enquanto, a do segundo, é argamassada), deve-se buscar nova composição, cotar os valores e determinar o fator relacionado a esta modificação. Os custos dos materiais diferenciados cotados devem ser somados ao numerador da Eq. 3.10, para comparação com o custo total relacionado a materiais do empreendimento de referência.

\subsubsection{SUBFATOR DE CUSTO UNITÁRIO LIGADO À MÃO-DE-OBRA}

O custo da mão-de-obra deve ser analisado verificando o tipo de contratação adotado.

Se a obra utilizar mão-de-obra terceirizada, o preço fornecido pelo subcontratado será o valor do CustoMO/QSub, ou seja, custo por quantidade de serviço feita. Deve-se verificar que tal valor pode variar de região para região e também de acordo com a tecnologia a ser empregada; por isso, é importante fazer a comparação destas variações nestes casos, obtendo o subfator de mão-de-obra através da relação entre seus valores, conforme mostra a Eq. 3.11.

$$
\left.f M O_{\text {terceirizada }}=\frac{\left(\frac{\text { CustoMO }}{\text { terceirizada }}\right)}{\left(\frac{\text { Customo }}{\text { terceirizada }}\right)}\right)_{E D 1}
$$

onde: 
$\mathrm{fMO}_{\text {terceirizada }}=$ subfator de mão-de-obra para o caso de terceirização;

$(\text { CustoMO } \text { terceirizada } / Q S e r v)_{\text {ED1 }}=$ custo de mão-de-obra por quantidade de serviço verificado para o empreendimento a ter o custo da edificação prognosticado;

$(\text { CustoMO } \text { terceirizada } / \text { QServ })_{\text {EDO }}=$ custo de mão-de-obra por quantidade de serviço da edificação de referência.

No caso de se utilizar mão-de-obra própria, deve-se analisar o custo de acordo com a variação do custo unitário da mão-de-obra e com a sua eficiência, ou seja, deve-se verificar o valor da produtividade, que pode ser obtido em manuais de orçamentação e softwares de orçamento, ou através de valor medido em obra anterior.

Variações no custo unitário ocorrem, principalmente, devido à regionalização, ou seja, o preço de um operário pode variar de região para região.

Já a produtividade pode ser analisada, primeiramente, verificando quais condições podem alterar seu valor, com base em seu cálculo, definido por Souza (2001), através da razão unitária de produção (RUP), que relaciona o esforço humano com as quantidades de serviço realizadas, conforme indicado na Eq. 3.12.

$$
R U P=\frac{H h}{Q S e r v}
$$

onde:

$$
\begin{aligned}
& \text { RUP = razão unitária de produção; } \\
& \text { Hh = Homem-hora; } \\
& \text { QServ = quantidade de serviço. }
\end{aligned}
$$

Deste modo, quanto menor for a RUP, melhor é a produtividade da mão-de-obra. 
Para se calcular este indicador, com base em uma obra similar, devem-se entender os valores de entrada, ou seja, o cálculo de Hh, e os de saída do processo, no caso, a QServ.

Para se apropriar a quantidade de Homens-horas demandados, deve-se analisar quais operários serão considerados no cálculo e qual o tempo de serviço que será utilizado.

Souza (2001) definiu três possibilidades principais para analisar a quantidade de operários; deste modo, pode-se calcular a produtividade apenas dos oficiais diretamente envolvidos; da equipe direta, ou seja, dos oficiais acrescidos dos seus ajudantes diretos; e global, acrescentando a quantidade de ajudantes de apoio. A Figura 3.5 mostra um exemplo de quais operários são considerados em cada cálculo.

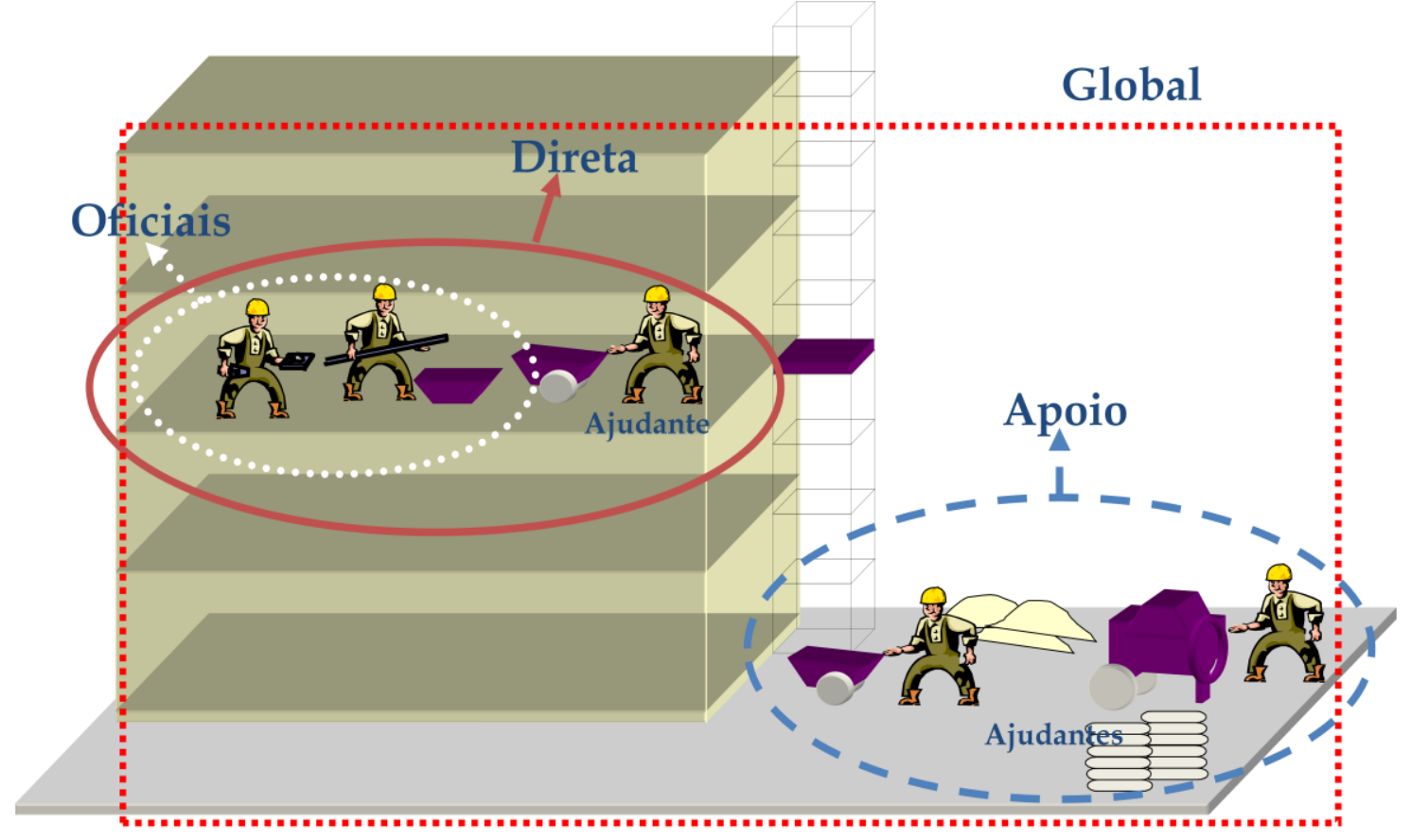

Figura 3.5 - Diferentes abordagens quanto à mão-de-obra contemplada (SILVA, 2003)

O tempo de serviço considerado no cálculo da RUP diz respeito às horas disponíveis para o trabalho, ou seja, o tempo total que o operário está presente no canteiro e pronto para trabalhar, sem descontar horas de paralisações (SOUZA, 2001).

A RUP pode, ainda, ser calculada em relação a diferentes períodos de coleta. Assim, podem-se obter (SOUZA, 2001): 
- a RUP diária calculada a cada dia de trabalho;

- a RUP do ciclo, calculada a cada ciclo, por exemplo, no caso da concretagem em edifício com repetição do pavimento tipo, calcula-se a RUP de todo o período de tempo envolvido na concretagem de um pavimento;

- a RUP cumulativa, que considera as quantidades de entradas e saídas acumuladas desde o primeiro dia do estudo até a data de sua avaliação.

No caso de a empresa possuir indicadores históricos, a RUP cumulativa final seria aquela que deveria ser adotada, pois seu valor final sintetiza o serviço feito durante todo o período de coleta.

Para definir a influência da produtividade no subfator de custo unitário, devem-se analisar variações que a RUP a ser utilizada pode possuir em relação à do caso de referência. Tal análise é feita verificando os fatores que a influenciam, de acordo com o Modelo dos Fatores. Thomas et al. (1990) definiram o Modelo dos Fatores com uma ferramenta que estuda as causas das variações da produtividade e seu peso relativo em relação aos valores de RUP.

De acordo com Thomas (1987) e Souza (2001), os fatores que interferem na produtividade podem estar ligados ao conteúdo e ao contexto. Conforme Araújo e Souza (2001) os fatores associados ao conteúdo são os relacionados a componentes físicos do trabalho, especificações exigidas e detalhes de projeto entre outros; já os associados ao contexto são aqueles relacionados ao ambiente de trabalho e a como ele é organizado e gerenciado, incluindo também condições atmosféricas, disponibilidade de materiais e equipamentos, seqüência de trabalho etc. Além destes fatores, os autores definiram ainda as anormalidades como fatores que causam distúrbios na produtividade, como chuva torrencial, quebra da grua etc.

Deste modo, para prognosticar a produtividade de um empreendimento deve-se utilizar um valor como referência, e avaliá-lo através dos fatores diferenciados em relação à obra de referência e a que terá o custo estimado.

O cálculo para se determinar o subfator de custo de mão-de-obra própria para um dado serviço é apresentado na Eq. 3.13. 


$$
f M O_{\text {própria }}=\frac{\left(\frac{\text { CustoMO }_{\text {própria }}}{H h} \times R U P\right)_{E D 1}}{\left(\frac{\text { CustoMO } O_{\text {própria }}}{H h} \times R U P\right)_{E D 0}}
$$

onde:

$$
\begin{aligned}
& \mathrm{fMO}_{\text {própria }}=\text { subfator de mão-de-obra (própria); } \\
& \mathrm{RUP}=\text { razão unitária de produção; } \\
& \text { CustoMO própria/ } \mathrm{Hh} \text { = Custo horário da mão-de-obra. }
\end{aligned}
$$

\subsubsection{Correção inflacionária}

De acordo com o método apresentado, o orçamento do empreendimento de referência (ED0) foi elaborado em tempo anterior à análise de custo do empreendimento ED1. Assim, já que se utilizam os custos do ED0 como referência, tais valores devem ser atualizados por número-índice ou taxa.

De acordo com SINDUSCON-MG (2009), o número-índice é um valor adimensional, determinado por análises estatísticas, que indica as oscilações de uma ou mais variáveis (neste caso, custos) em datas ou locais diferentes. Já a taxa percentual expressa a evolução de uma série de índices.

Marchiori (2009) apontou, como principais índices do mercado da construção civil: o CUB (Custo Unitário Básico), o SINAPI (Sistema Nacional de Custos de Construção Civil da Caixa Econômica Federal), o IPCE (Índice Pini de Custo de Edificações da Editora Pini) e o INCC (Índice Nacional de Custos de Construção, da Fundação Getúlio Vargas).

O CUB, além de ser utilizado como estimativa de custo (vide item 2.5.1 do Capítulo 2 desta dissertação), também representa um índice que avalia o custo de construções de edificações. Criado em 1964 e divulgado no dia 5 de cada mês pelos Sindicatos da Indústria da Construção Civil, o CUB representa a evolução de custo por metro 
quadrado de construção de um projeto-padrão considerado (SINDUSCON-MG, 2007; ABNT NBR 12721, 2007).

Criado em 1969 pelo BNH (Banco Nacional da Habitação), o SINAPI tem como objetivo informar custos e índices da construção, mensalmente, de forma sistematizada e com abrangência nacional. A base técnica do SINAPI, ou seja, a determinação de serviços/quantitativos, especificações e composições, é feita pela CAIXA (Caixa Econômica Federal); já a coleta de preços e salários é de responsabilidade do IBGE (Instituto Brasileiro de Geografia e Estatística). A divulgação é feita pelo site do IBGE no início do mês seguinte ao de referência da coleta (IBGE, 2012).

O IPCE é um índice desenvolvido pela editora PINI em 1957 para acompanhar a evolução de custos de empreendimento habitacional na grande São Paulo e no Grande Rio de Janeiro (OLIVEIRA, 2006).

Configurando-se como o primeiro índice oficial de custo da construção civil do Brasil, - INCC é, ainda, um dos índices mais utilizados no país. O INCC tem como abrangência geográfica atual sete municípios: Belo Horizonte, Brasília, Porto Alegre, Recife, Salvador, Rio de Janeiro e São Paulo. Este índice possui diferentes versões relativas aos períodos de coletas: INCC-DI, pesquisado do dia $1^{\circ}$ ao último do mês de referência; INCC-M, pesquisado entre os dias 21 do mês anterior e 20 do mês de referência; INCC-10, pesquisado entre os dias 11 do mês anterior e 10 do mês de referência (FGV-IBRE, 2012; FGV-IBRE, 2010).

De acordo com o SINDUSCON-MG (2009), o cálculo da variação percentual de custos, de acordo com um certo período, utilizando índices, é feito como mostrado na Eq 3.14.

$$
\text { var iação\% }{ }_{\text {periodo } i-f}=\left[\left(\begin{array}{ll}
\text { número }- \text { indice } & \text { mêsf } \\
\hline \text { número-indice } & \text { mêsi }
\end{array}\right)-1\right] \times 100
$$

onde:

variação\% período i-f = variação em \% do valor do índice entre os meses i (início do período) e f (mês final do período); 
número-índice mêsf= número índice relativo ao mês final do período;

número-índice mêsi= número índice relativo ao mês inicial do período.

Esta publicação prevê, ainda, o cálculo da variação percentual de custos, utilizando a acumulação de taxas para um dado período, conforme mostra a Eq. 3.15.

$$
\text { var iação } \%_{\text {período } i-f}=\left(\text { multiplicador }_{i-f}-1\right) \times 100
$$

onde:

variação\% período i-f = variação em \% do valor do índice entre os meses i (início do período) e f (mês final do período);

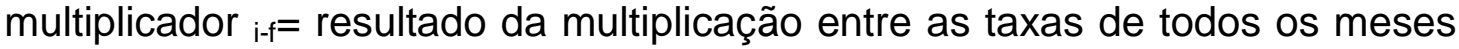
do período, ou seja: taxa mês i $x$ taxa $a_{\text {mês } i+1} \times$ taxa $a_{\text {mês } i+2} \ldots$ taxa $a_{\text {mês } f-1} \times$ taxamês $f$

A partir dos valores da variação percentual entre o período que corresponde ao mês em que foi elaborado o orçamento do ED0 (mês i) e o mês em que se fará o prognóstico do ED1 (mês f), calcula-se o fator de correção inflacionária pela Eq. 3.16.

$$
F \inf =1+\text { variação\% } \%_{\text {período } i-f}
$$

onde:

Finf=fator de correção inflacionária para o período i a f;

variação\% período i-f = variação em \% do valor do índice entre os meses i (início do período, ED1) e f (mês final do período, ED0). 


\section{DESENVOLVIMENTO DO MÉTODO PARA ALVENARIA ESTRUTURAL}

Este capítulo pretende mostrar o desenvolvimento do raciocínio apresentado no Capítulo 3 para a alvenaria estrutural.

Deste modo, serão mostrados quais fatores influenciam o custo deste serviço, analisando seus valores de acordo com diferenças geométricas e/ou de tecnologia entre a edificação a ter o custo prognosticado (ED1) e aquela tomada como referência (ED0).

\subsection{Quantidade de alvenaria estrutural (QServ)}

A quantidade de alvenaria estrutural será considerada como o total da área líquida das paredes que empregam esta tecnologia.

No caso em que o gestor possui um esboço do pavimento tipo, podem-se quantificar as paredes através de medição direta. Assim, mede-se o comprimento total das paredes, multiplica-se pelo valor do pé-direito e subtrai-se a área de todos os vãos de esquadrias.

No caso em que o gestor não possui uma planta arquitetônica, deve-se parametrizar o valor, considerando não apenas a área de construção, mas, também, o padrão do apartamento e a quantidade de ambientes.

Segundo Kato e Souza (2009), a extrapolação da parametrização de quantidade de paredes em relação à área para obras com geometrias diferenciadas pode gerar erros, de acordo com os parâmetros analisados. Por exemplo, ao estudar a quantidade de alvenaria em relação à área do pavimento tipo, se a geometria dos ambientes for diferente, a quantidade de paredes por $\mathrm{m}^{2}$ também não será a mesma, conforme mostra a Figura 4.1. 

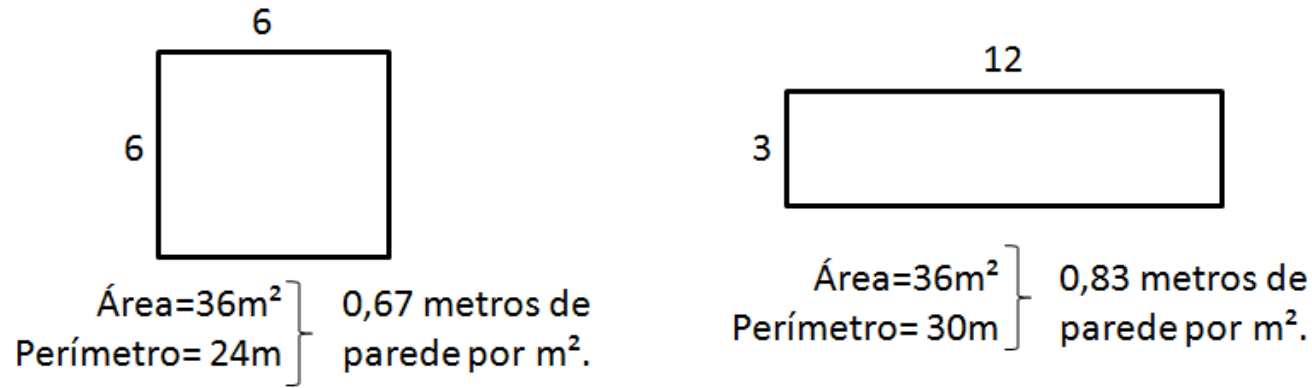

Figura 4.1 - Diferenças na quantidade de parede em uma mesma área

De acordo com Mascaró (1998), para medir e avaliar com certa objetividade a relação entre paredes que envolvem o edifício e sua superfície foi estudado o que se conhece como "índice de compacidade" dos edifícios, que é definido como a relação percentual que existe entre o perímetro de um círculo de igual área do projeto e o perímetro das paredes exteriores do mesmo (Eq.4.1).

$$
I c=\frac{P c}{P p} \times 100
$$

onde:

Ic: índice de compacidade;

Pc: perímetro de um círculo de área igual à do projeto;

Pp: perímetro das paredes exteriores, em planta, do projeto.

Mascaró (1998) estudou diferentes tipologias de edifício e verificou as diferenças nos custos em relação ao índice de compacidade, que chegaram a $24 \%$, conforme mostra a Figura 4.2. 


\begin{tabular}{|c|c|c|c|c|}
\hline Forma da planta & $\begin{array}{c}\text { Superficie da } \\
\text { Planta (indice) }\end{array}$ & $\begin{array}{c}\text { Índice de } \\
\text { Compacidade } \\
\text { (Ic) }\end{array}$ & $\begin{array}{c}\text { Custo de } \\
\text { Construção } \\
\left.\text { (Libras } / \mathrm{m}^{2}\right)\end{array}$ & $\begin{array}{c}\text { Variações de } \\
\text { custo (\%) }\end{array}$ \\
\hline 100 & $88,5 \%$ & 90 & 100 \\
\hline & 100 & $49,2 \%$ & 108 & 114 \\
\hline
\end{tabular}

Figura 4.2 - Variação do custo de construção em função do índice de compacidade (Ic) do edifício (MASCARÓ, 1998)

Como no estudo preliminar, se não se tiver a planta arquitetônica fica difícil calcular a compacidade, foi proposto pelo orientador da presente dissertação um estudo da variação da quantidade de alvenaria estudando diferentes concepções arquitetônicas com base na área do apartamento e na quantidade de ambientes.

Este estudo foi feito em uma Iniciação Científica com bolsa CNPq da estudante Thatiany Tiemi Silva Koza, sob co-orientação da autora da presente dissertação.

Gerou-se um banco de dados através de projetos disponíveis na internet sobre empreendimentos em São Paulo, fazendo-se um levantamento de indicadores para 36 tipos de apartamentos com até $70 \mathrm{~m}^{2} ; 4$ tipos de apartamentos com área de, aproximadamente $100 \mathrm{~m}^{2}$; e 4 apartamentos com área de aproximadamente $250 \mathrm{~m}^{2}$.

De acordo com o Gráfico 4.1, que mostra a variação da quantidade de paredes em função da área do apartamento, quanto maior o apartamento, menos alvenaria por $\mathrm{m}^{2}$ de pavimento ele terá. Isto ocorre porque, quanto maior o apartamento, maior a tendência de ele ter ambientes maiores (sala, dormitório, banheiros etc. maiores), para maior conforto do usuário. 


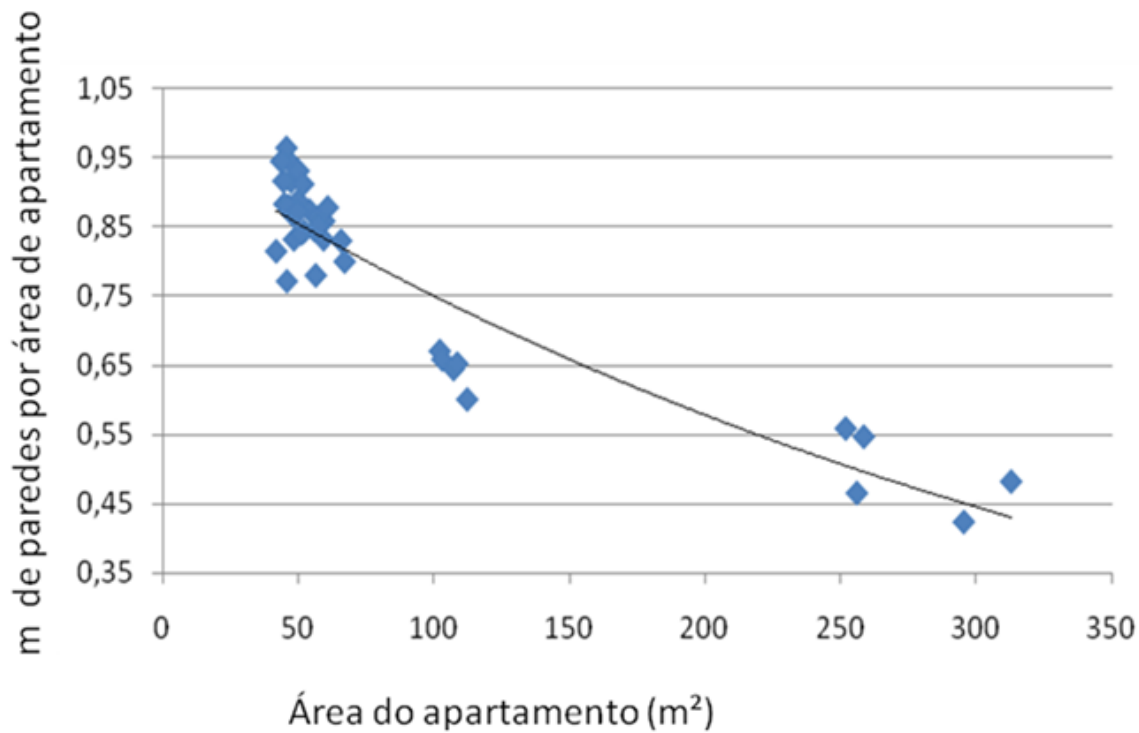

Gráfico 4.1 - Densidade de paredes x Área construída de um apartamento

As Tabelas 4.1, 4.2 e 4.3 mostram os indicadores gerados por este estudo.

Tabela 4.1 - Indicadores para estimar quantidade linear de paredes para apartamentos com até $70 \mathrm{~m}^{2}$

\begin{tabular}{|l|c|c|c|c|c|c|c|c|c|}
\hline \multicolumn{1}{c|}{} & \multicolumn{3}{c|}{$2 \mathrm{D}+1 \mathrm{~B}$} & \multicolumn{3}{c|}{$3 \mathrm{D}+1 \mathrm{~B}$} & \multicolumn{3}{c|}{ 3D+2B } \\
\cline { 2 - 11 } & min & médio & máx & min & médio & máx & min & Médio & máx \\
\hline $\mathrm{m}$ de parede total $/ \mathrm{m}^{2}$ & 0,77 & 0,88 & 0,96 & 0,78 & 0,83 & 0,86 & 0,80 & 0,83 & 0,88 \\
\hline
\end{tabular}

Tabela 4.2 - Indicadores para estimar quantidade linear de paredes para apartamentos com, aproximadamente, $100 \mathrm{~m}^{2}$

\begin{tabular}{|l|l|l|l|}
\cline { 2 - 4 } \multicolumn{1}{c|}{} & \multicolumn{3}{c|}{$3 \mathrm{D}+4 \mathrm{~B}$} \\
\cline { 2 - 4 } & min & médio & máx \\
\hline $\mathrm{m}$ de parede total $/ \mathrm{m}^{2}$ & 0,60 & 0,64 & 0,67 \\
\hline
\end{tabular}

Tabela 4.3 - Indicadores para estimar quantidade linear de paredes para apartamentos com, aproximadamente, $250 \mathrm{~m}^{2}$

\begin{tabular}{|l|l|l|l|}
\cline { 2 - 4 } \multicolumn{1}{c|}{} & \multicolumn{3}{|c|}{$4 \mathrm{D}+5 \mathrm{~B}$} \\
\cline { 2 - 4 } & min & médio & máx \\
\hline $\mathrm{m}$ de parede total $/ \mathrm{m}^{2}$ & 0,42 & 0,49 & 0,56 \\
\hline
\end{tabular}


Assim, para mesmo padrão de acabamento e mesma quantidade de ambientes, apartamentos com maior área tendem a ter maior custo por $\mathrm{m}^{2}$, por aumentar tanto a demanda por blocos (supondo mesmo preço unitário), quanto por revestimentos.

\subsection{Custo unitário ligado aos materiais}

Esta parcela que compõe o custo da alvenaria estrutural é analisada subdividindo-a em todos os materiais que a compõem: blocos estruturais, argamassa de assentamento, graute e armadura.

\subsubsection{Blocos estruturais}

Para a alvenaria estrutural, o presente trabalho irá estudar a previsão da quantidade de blocos de concreto devido a três principais vantagens deste tipo de bloco: maior oferta no mercado, regularidade dimensional e cálculo estrutural definido há mais tempo que o da alvenaria de blocos cerâmicos.

O estudo para prognóstico da quantidade de blocos estruturais será feito, primeiramente, avaliando-se o consumo teórico de material, e, em seguida, as perdas.

\subsubsection{CONSUMO TEÓRICO}

Para prognosticar o consumo teórico de um material, primeiro devem ser verificados os fatores que induzem a adoção de quantidade e especificação diferentes.

No caso dos blocos, são dois os fatores que devem ser estudados:

- resistência do bloco: que influencia as especificações do material em relação ao comportamento estrutural do edifício; 
- geometria do bloco: que influencia a quantidade de blocos por área de alvenaria.

A norma ABNT NBR 6136 (2006) prevê quatro classes para os blocos. Em termos do papel estrutural e localização dos blocos, a norma faz as seguintes denominações:

- classe A: função estrutural, para uso em elementos de alvenaria acima ou abaixo do nível do solo;

- classes B e C: função estrutural, para uso em elementos de alvenaria acima do nível do solo;

- classe D: sem função estrutural, para uso em elementos de alvenaria acima do nível do solo.

Para especificar as dimensões nominais de blocos, os módulos indicados são múltiplos de $M=10 \mathrm{~cm}$. Assim, para blocos estruturais da classe $C$, a norma recomenda que aqueles de módulo M10 (originam paredes com $10 \mathrm{~cm}$ de espessura) devem ser utilizados em edificações de no máximo um pavimento; aqueles de módulo M12,5, em edificações de no máximo dois pavimentos; e os de módulo M15 e M20, em edificações maiores.

Os limites para a resistência à compressão dos blocos estruturais, de acordo com a ABNT NBR 6136 (2006), são:

- classe A: maior ou igual a $6 \mathrm{MPa}$;

- classe B: maior ou igual a $4 \mathrm{MPa}$;

- classe C: maior ou igual a $3 \mathrm{MPa}$;

- classe D: maior ou igual a $2 \mathrm{MPa}$.

O cálculo da resistência dos blocos $\left(f_{b k}\right)$ deve atender às definições da norma ABNT NBR 15961 (2011), prevendo todas as ações atuantes, tais como: permanentes, variáveis, acidentais, do vento e excepcionais (impactos e explosões). 
Porém, para estimar o valor do $\mathrm{f}_{\mathrm{bk}}$ de forma rápida e consistente, duas publicações (ACETTI, 1998; FREIRE, 2007) apresentam uma regra empírica utilizada por projetistas e embasada em indicadores levantados com base em banco de projetos. De acordo com esta regra, o $f_{b k}$ pode ser relacionado com os números de andares da edificação; assim, para cada andar, $1 \mathrm{MPa}$ é acrescido no valor do $\mathrm{f}_{\mathrm{bk}}$ dos pavimentos abaixo.

Devido às limitações impostas pela norma ABNT NBR 6136 (2006), para blocos da classe $B$, nos quatro últimos andares de um edifício, a resistência dos blocos será de pelo menos $4 \mathrm{MPa}$, aumentando $1 \mathrm{MPa}$ a cada pavimento imediatamente abaixo ou utilizando $f_{b k}$ maior ou igual ao estimado, de acordo com a oferta de blocos por fabricantes no local de execução.

Além da resistência, as geometrias dos blocos também variam de projeto para projeto. Assim, três aspectos devem ser analisados com relação ao formato dos blocos:

- canaleta ou vazado;

- variação da espessura;

- variação no comprimento.

Freire (2007) definiu cintas como elementos compostos por blocos do tipo canaleta preenchidos com graute e, possivelmente, armadura. Este autor indica, ainda, que em prédios com alvenaria estrutural, é usual a utilização de dois tipos de cintas: a de respaldo e a cinta a meia altura.

De acordo com a ABNT NBR 10837 (1989), as paredes devem ter cintas de respaldo ligadas às lajes, ou vergas de janelas, pois atuarão como um diafragma rígido, transferindo os esforços horizontais.

Já as cintas a meia altura, conforme Freire (2007), situam-se na altura da 5 $5^{\text {a }}$ fiada, para coincidir com a contra-verga, e são utilizadas para minimizar o aparecimento de fissuras devido a deformações internas na alvenaria, causadas pelos efeitos de retração ou pela variação de temperatura. $O$ autor verificou que a adoção de cintas a meia altura depende da opção do projetista estrutural e do número de pavimentos do 
edifício. Assim, em 120 projetos que estudou, 71\% deles possuíam cinta a meia altura nas paredes externas, sendo que 13\% dos projetos possuíam este tipo de cinta também nas paredes internas por terem mais que 10 pavimentos.

De acordo com a entrevista feita com o projetista estrutural Dr. Luiz Sérgio Franco (Apêndice A), o uso de cinta a meia altura é opcional, sendo que em seu escritório não é usual sua adoção. Em seus projetos, Franco adota blocos canaletas apenas em cintas superiores, em vergas e em contravergas. Para estimar a quantidade deste tipo de bloco, o projetista sugere a medição linear dos locais onde serão assentadas as canaletas, e a quantidade será dada pela divisão deste comprimento por $40 \mathrm{~cm}$ (correspondente ao bloco inteiro, imaginando que o projeto utilize coordenação modular M20).

Com relação à especificação da espessura das paredes, a ABNT NBR 15961 (2011) determina que as espessuras efetivas das paredes resistentes armadas devem ser no mínimo 1/30 da altura livre ou da largura, mas não menor que $14 \mathrm{~cm}$.

Após definir a utilização de cintas, especificando blocos canaletas, e a espessura das paredes, deve-se verificar outra variação na geometria do bloco: seu comprimento, o qual depende da modulação do projeto.

Conforme o documento do Convênio POLI-ENCOL (1991), para modular a alvenaria, é interessante projetar as paredes com um sistema coordenado dimensionalmente formado por valores múltiplos ou submúltiplos das medidas dos componentes utilizados. O documento ressalta que a coordenação modular racionaliza o projeto e a execução da alvenaria, na medida em que traz diversos benefícios, tais como: o aumento da produtividade, redução de falhas de projeto e de execução, diminuição de índices unitários de consumo, redução dos custos habitacionais, incremento no desempenho dos subsistemas que compõem a alvenaria e aumento nos padrões de qualidade do produto final.

Assim, de acordo com Camacho (2006), devem-se prever, na modulação, os encontros das paredes, aberturas, caixas de passagem, colocação de pré-moldados e de instalações e, no caso da alvenaria estrutural, os pontos de graute e ferragem, ligações entre a parede e a laje. 
Nos encontros de paredes deve-se compatibilizar a espessura com os comprimentos do bloco. Camacho (2006) relata que, no início da alvenaria estrutural, eram utilizados blocos com dimensões nominais de $(20 \times 40) \mathrm{cm}$; porém, com a evolução dos materiais, foi possível executar paredes com menor espessura e passou-se a utilizar blocos com dimensões nominais de $(15 \times 40) \mathrm{cm}$. Devido a esta mudança, surgiram problemas na coordenação modular, já que nos encontros de paredes surgiu a necessidade de utilizar blocos especiais: $(15 \times 55) \mathrm{cm}$ no encontro em "T" e $(15 \times 35) \mathrm{cm}$ em encontros em “L”, conforme mostra a Figura 4.3.

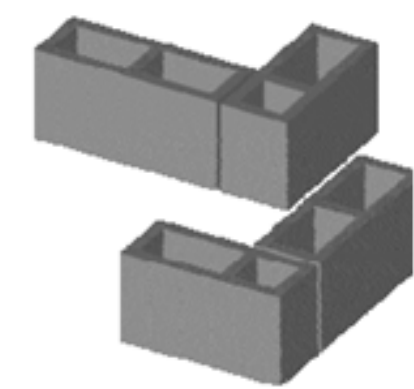

a) Amarração de canto com bloco especial de $35 \mathrm{~cm}$.

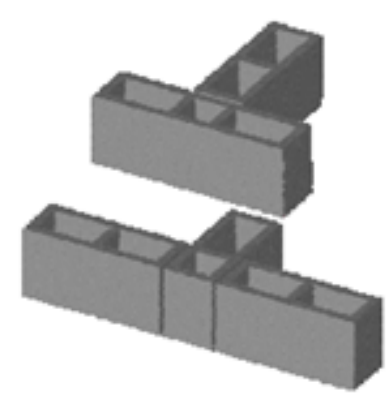

b) Amarração de borda com blocos especiais de $55 \mathrm{~cm}$ de comprimento modular

Figura 4.3 - Amarração a) de canto com bloco especial de $35 \mathrm{~cm}$; b) de borda com blocos especiais de $55 \mathrm{~cm}$ de comprimento modular (MAMEDE, CORRÊA 2006)

Para reduzir o número de peças em obra, foram desenvolvidos blocos com dimensões de $15 \times 30 \mathrm{~cm}$, ou seja, o comprimento possui o dobro da espessura, facilitando a coordenação modular do projeto (POLI-ENCOL, 1991).

O Quadro 4.1 mostra as dimensões coordenadas de diferentes blocos para os valores de referência na coordenação modular de 15 e 20 cm. 
Quadro 4.1 - Dimensões usuais de mercado para blocos de concreto M-15 e M-20 (MAMEDE, CORRÊA 2006)

\begin{tabular}{|c|c|c|c|c|}
\hline \multirow{2}{*}{$\begin{array}{c}\text { Dimensões } \\
(\mathrm{cm})\end{array}$} & \multirow{3}{*}{20} & \multicolumn{3}{|c|}{ Dimensões coordenadas (mm) } \\
\cline { 3 - 5 } & \multirow{3}{*}{$\mathrm{M}-20$} & 190 & 190 & 190 \\
\cline { 3 - 5 } & & 190 & 190 & 390 \\
\hline \multirow{3}{*}{15} & \multirow{3}{*}{$\mathrm{M}-15$} & 140 & 190 & 190 \\
\cline { 3 - 5 } & & 140 & 190 & 290 \\
\cline { 3 - 5 } & & 140 & 190 & 340 \\
\cline { 3 - 5 } & & 140 & 190 & 390 \\
\cline { 3 - 5 } & & 140 & 190 & 540 \\
\hline
\end{tabular}

Os encontros de paredes na alvenaria estrutural devem ser amarrados de forma a que as combinações das intersecções entre painéis resultem em uma rigidez relativa, entre as paredes amarradas, eficaz na distribuição das tensões entre esses elementos (POLI-ENCOL, 1991).

Deste modo, a união e solidarização entre paredes podem ocorrer através de amarração direta ou indireta. De acordo com a ABNT NBR 15961 (2011), a amarração direta ocorre em paredes com 50\% dos blocos penetrando alternadamente na parede interceptada; já a amarração indireta ocorre no encontro de paredes com junta vertical a prumo, sendo que a ligação entre as paredes se dá através de grampos metálicos ancorados em furos verticais adjacentes ou de telas metálicas ancoradas em juntas de assentamento.

Com relação à amarração indireta definida pela norma, Grama (2005) indica, ainda, que para promover a amarração indireta, podem-se utilizar vergalhões de aço CA-50 ou CA-60 dobrados em forma de "U" e colocados nos furos dos blocos, que serão preenchidos por graute (Figura 4.4 a). A Figura 4.4 b) ilustra a opção de utilização de telas de aço. 

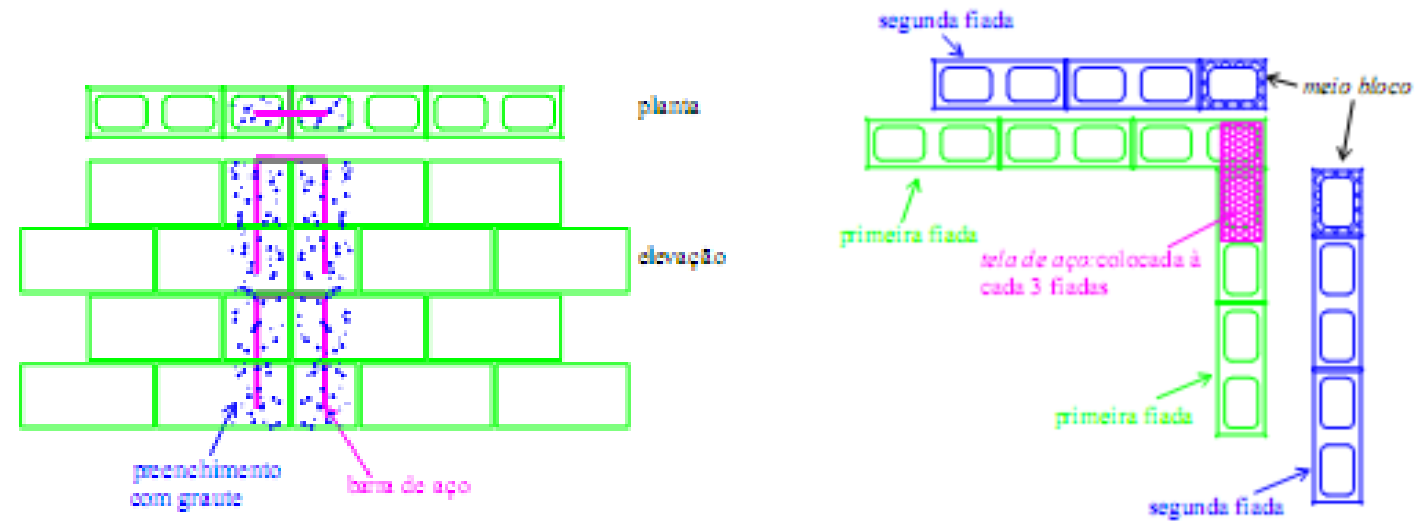

Figura 4.4 - Amarração indireta: a) com barras de aço; b) com tela de aço (Grama, 2005)

Acceti (1998) destaca que, apesar de a amarração direta ser comprovadamente melhor em relação à uniformização de tensões e monolitismo da edificação, a execução é facilitada com o uso de amarrações indiretas, pois as paredes podem ser executadas independentemente uma das outras.

Além dos blocos, a modulação deve prever as esquadrias, que interferem na posição e na escolha dos tipos de blocos. Assim, para racionalizar a alvenaria, é preferível a utilização de elementos que compensem as diferentes medidas de blocos e esquadrias, como uso de vergas que garantam a correta modulação vertical e de blocos compensadores na modulação horizontal (POLI-ENCOL, 1991).

De acordo com Lucini (2001), a modulação de vãos permite uma delimitação qualitativa, econômica, dimensional e produtiva do sistema de fechamentos de vãos; assim, com a definição de dimensões preferenciais por tipologias de esquadrias, há a padronização dos vãos e, conseqüente, racionalização da construção. Esta padronização é feita com base em estudos de fabricantes, construtoras e projetistas, que analisam diversas variáveis, como as econômicas, produtivas, mercadológicas e de desempenho.

O Quadro 4.2 mostra as dimensões mais utilizadas para vãos, conforme Lucini (2001). 
Quadro 4.2 - Vãos modulares e esquadrias preferidas (LUCINI; 2001) - continua

\begin{tabular}{|c|c|c|c|}
\hline Tipologias & $\begin{array}{l}\text { Vão modular } \\
(\mathrm{m})\end{array}$ & $\begin{array}{l}\text { Esquadria } \\
\text { dimensão } \\
(\mathrm{m})\end{array}$ & $\begin{array}{l}\text { Vão vedação } \\
(\mathrm{m})\end{array}$ \\
\hline \multirow{2}{*}{$\begin{array}{l}\text { JC-2F } \\
\text { Janela de Correr } 2 \text { Folhas }\end{array}$} & $1,2 \times 1,2$ & $1,15 \times 1,15$ & $1,21 \times 1,21$ \\
\hline & $1,5 \times 1,2$ & $1,45 \times 1,15$ & $1,51 \times 1,21$ \\
\hline \multirow{3}{*}{$\begin{array}{l}\text { JC-3F/V } \\
\text { Janela Correr } 3 \text { Folhas } \\
\text { com Veneziana }\end{array}$} & $1,2 \times 1,2$ & $1,15 \times 1,15$ & $1,21 \times 1,21$ \\
\hline & $1,5 \times 1,2$ & $1,45 \times 1,15$ & $1,51 \times 1,21$ \\
\hline & & & \\
\hline & $1,5 \times 2,2$ & $1,45 \times 2,15$ & $1,51 \times 2,21$ \\
\hline & $2,0 \times 2,2$ & $1,95 \times 2,15$ & $2,01 \times 2,21$ \\
\hline Porta de Correr 2 Folhas & $2,4 \times 2,2$ & $2,35 \times 2,15$ & $2,41 \times 2,21$ \\
\hline \multirow{3}{*}{$\begin{array}{l}\text { PC-3F/V } \\
\text { Porta Correr } 3 \text { Folhas } \\
\text { com Veneziana }\end{array}$} & $1,5 \times 2,2$ & $1,45 \times 2,15$ & $1,51 \times 2,21$ \\
\hline & $2,0 \times 2,2$ & $1,95 \times 2,15$ & $2,01 \times 2,21$ \\
\hline & & & \\
\hline \multirow{3}{*}{ 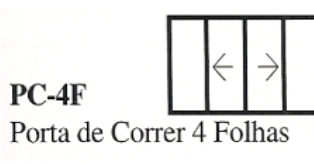 } & $3,0 \times 2,2$ & $2,95 \times 2,15$ & $3,01 \times 2,21$ \\
\hline & & & \\
\hline & & & \\
\hline \multirow{2}{*}{$\begin{array}{l}\text { JC-2F/P } \\
\text { Janela de Correr 2 Folhas } \\
\text { com Persiana de Enrolar }\end{array}$} & $1,2 \times 1,2$ & $1,15 \times 1,15$ & $1,21 \times 1,21$ \\
\hline & $1,5 \times 1,2$ & $1,45 \times 1,15$ & $1,51 \times 1,21$ \\
\hline \multirow{3}{*}{$\begin{array}{l}\text { PC-2F/P } \\
\text { Porta de Correr 2 Folhas } \\
\text { com Persiana de Enrolar }\end{array}$} & $1,2 \times 2,3$ & $1,15 \times 2,25$ & $1,21 \times 2,31$ \\
\hline & $1,5 \times 2,3$ & $1,45 \times 2,25$ & $1,51 \times 2,31$ \\
\hline & & & \\
\hline \multirow{3}{*}{$\begin{array}{l}\text { PA-1F } \\
\text { Porta Pivotante } \\
\text { Vertical de 1 Folha }\end{array}$} & $0,9 \times 2,2$ & $0,85 \times 2,15$ & $0,91 \times 2,21$ \\
\hline & & & \\
\hline & & & \\
\hline \multirow[b]{2}{*}{$\begin{array}{l}\text { PA-2F } \\
\text { Porta de Abrir } 2 \text { Folhas }\end{array}$} & $1,5 \times 2,2$ & $1,45 \times 2,15$ & $1,51 \times 2,21$ \\
\hline & & & \\
\hline
\end{tabular}


Quadro 4.2 - Vãos modulares e esquadrias preferidas (LUCINI; 2001) - conclusão

\begin{tabular}{|c|c|c|c|}
\hline Tipologia & $\begin{array}{c}\text { Vão modular } \\
(\mathrm{m})\end{array}$ & $\begin{array}{c}\text { Esquadria } \\
\text { dimensão } \\
(\mathrm{m})\end{array}$ & $\begin{array}{c}\text { Vão vedação } \\
(\mathrm{m})\end{array}$ \\
\hline \multirow{3}{*}{$\begin{array}{l}\text { JC- 2F/C } \quad \| L|| C|| \\
\text { Janela de Correr } \\
\text { 2 Folhas Camarão } \\
\end{array}$} & $1,2 \times 1,2$ & $1,15 \times 1,15$ & $1,21 \times 1,21$ \\
\hline & $1,5 \times 1,2$ & $1,45 \times 1,15$ & $1,51 \times 1,21$ \\
\hline & & & \\
\hline \multirow{3}{*}{$\begin{array}{l}\mathbf{P C}-\mathbf{2} \mathbf{F} / \mathbf{C} \\
\text { Porta de Correr } \\
2 \text { Folhas Camarão }\end{array}$} & $1,5 \times 2,2$ & $1,45 \times 2,15$ & $1,51 \times 2,21$ \\
\hline & $2,0 \times 2,2$ & $1,95 \times 2,15$ & $2,01 \times 2,21$ \\
\hline & & & \\
\hline \multirow{3}{*}{$\begin{array}{l}\text { RF-1F } \\
\text { Requadro Fixo } 1 \text { Folha }\end{array}$} & $0,6 \times 0,6$ & $0,55 \times 0,55$ & $0,61 \times 0,61$ \\
\hline & $0,8 \times 0,6$ & $0,75 \times 0,55$ & $0,81 \times 0,61$ \\
\hline & & & \\
\hline \multirow{3}{*}{$\begin{array}{l}\text { Mx-1F } \\
\text { Maxim-ar 1 Folha } \\
\end{array}$} & $0,6 \times 0,6$ & $0,55 \times 0,55$ & $0,61 \times 0,61$ \\
\hline & $0,8 \times 0,6$ & $0,75 \times 0,55$ & $0,81 \times 0,61$ \\
\hline & $1,0 \times 0,6$ & $0,95 \times 0,55$ & $1,01 \times 0,61$ \\
\hline \multirow{3}{*}{$\begin{array}{l}\text { VP-2F } \\
\text { Ventilação } \\
\text { Permanente 2 Folhas }\end{array}$} & $1,2 \times 1,2$ & $1,15 \times 1,15$ & $1,21 \times 1,21$ \\
\hline & & & \\
\hline & & & \\
\hline \multirow{3}{*}{$\begin{array}{l}\text { PC-1F/AS } \\
\text { Porta Correr para } \\
\text { área de serviço }\end{array}$} & $1,5 \times 2,2$ & $1,45 \times 2,15$ & $1,51 \times 2,21$ \\
\hline & & & \\
\hline & & & \\
\hline
\end{tabular}

Porém, a norma de requisitos para portas de madeira (ABNT NBR 15930, 2011) indica diferentes dimensões, as quais são bastante difundidas entre os fornecedores, podendo dificultar a modulação da alvenaria; os valores de vãos para diferentes tipos de fixação de portas de madeira são apresentados no Quadro 4.3. 
Quadro 4.3 - Dimensões nominais do vão de portas (ABNT NBR 15930-2:2011)

\begin{tabular}{|c|c|c|c|c|c|c|c|c|c|}
\hline $\begin{array}{l}\text { Tipo de } \\
\text { porta }\end{array}$ & \multicolumn{3}{|c|}{ Kit porta-pronta } & \multicolumn{3}{|c|}{$\begin{array}{c}\text { Porta fixada com espuma } \\
\text { PU }\end{array}$} & \multicolumn{3}{|c|}{$\begin{array}{l}\text { Porta fixada com parafusos ou } \\
\text { grapa }\end{array}$} \\
\hline \multirow[b]{2}{*}{$\begin{array}{l}\text { Tipo de } \\
\text { madeira }\end{array}$} & Leve & Médio & $\begin{array}{l}\text { Pesado } \\
\text { e super- } \\
\text { pesado }\end{array}$ & Leve & Médio & $\begin{array}{l}\text { Pesado } \\
\text { e super- } \\
\text { pesado }\end{array}$ & Leve & Médio & $\begin{array}{c}\text { Pesado e } \\
\text { super- } \\
\text { pesado }\end{array}$ \\
\hline & $\begin{array}{l}\text { de } 6 \\
\text { a } 10 \\
\mathrm{~kg} / \mathrm{m}^{2}\end{array}$ & $\begin{array}{c}\text { de } 10 \\
\text { a } 20 \\
\mathrm{~kg} / \mathrm{m}^{2}\end{array}$ & $\begin{array}{l}\text { acima } \\
\text { de } 20 \\
\mathrm{~kg} / \mathrm{m}^{2}\end{array}$ & $\begin{array}{c}\text { de } 6 \\
\text { a } 10 \\
\mathrm{~kg} / \mathrm{m}\end{array}$ & $\begin{array}{c}\text { de } 10 \\
\text { a } 20 \\
\mathrm{~kg} / \mathrm{m}^{2}\end{array}$ & $\begin{array}{l}\text { acima de } \\
20 \mathrm{~kg} / \mathrm{m}^{2}\end{array}$ & $\begin{array}{c}\text { de } 6 \text { a } \\
10 \\
\mathrm{~kg} / \mathrm{m}^{2}\end{array}$ & $\begin{array}{c}\text { de } 10 \text { a } \\
20 \\
\mathrm{~kg} / \mathrm{m}^{2}\end{array}$ & $\begin{array}{l}\text { acima de } \\
20 \mathrm{~kg} / \mathrm{m}^{2}\end{array}$ \\
\hline $\begin{array}{l}\text { Altura } \\
\text { folha } \\
(\mathrm{mm})\end{array}$ & 2100 & 2100 & $\begin{array}{l}2100 \\
2400\end{array}$ & 2100 & 2100 & $\begin{array}{l}2100 \\
2400\end{array}$ & 2100 & 2100 & $\begin{array}{l}2100 \\
2400\end{array}$ \\
\hline $\begin{array}{c}\text { Altura } \\
\text { vão }(\mathrm{mm})\end{array}$ & 2128 & 2133 & $\begin{array}{c}2138 \text { ou } \\
2143 \\
2443\end{array}$ & 2140 & 2145 & $\begin{array}{c}2150 \text { ou } \\
2155 \\
2455\end{array}$ & 2135 & 2140 & $\begin{array}{c}2145 ; 2150 \\
2450\end{array}$ \\
\hline $\begin{array}{l}\text { Largura } \\
\text { folha } \\
(\mathrm{mm})\end{array}$ & $\begin{array}{l}600 \\
700 \\
800 \\
900\end{array}$ & $\begin{array}{c}600 \\
700 \\
800 \\
900 \\
1000 \\
1100\end{array}$ & $\begin{array}{c}600 \\
700 \\
800 \\
900 \\
1000 \\
1100\end{array}$ & $\begin{array}{l}600 \\
700 \\
800 \\
900\end{array}$ & $\begin{array}{c}600 \\
700 \\
800 \\
900 \\
1000 \\
1100\end{array}$ & $\begin{array}{c}600 \\
700 \\
800 \\
900 \\
1000 \\
1100\end{array}$ & $\begin{array}{l}600 \\
700 \\
800 \\
900\end{array}$ & $\begin{array}{c}600 \\
700 \\
800 \\
900 \\
1000 \\
1100\end{array}$ & $\begin{array}{c}600 \\
700 \\
800 \\
900 \\
1000 \\
1100\end{array}$ \\
\hline $\begin{array}{l}\text { Largura } \\
\text { vão (mm) }\end{array}$ & $\begin{array}{l}645 \\
745 \\
845 \\
945\end{array}$ & $\begin{array}{c}655 \\
755 \\
855 \\
955 \\
1055 \\
1155\end{array}$ & $\begin{array}{c}666 ; 676 \\
766 ; 776 \\
866 ; 876 \\
966 ; 976 \\
1066 ; \\
1076 \\
1166 ; \\
1176\end{array}$ & $\begin{array}{l}670 \\
770 \\
870 \\
970\end{array}$ & $\begin{array}{c}680 \\
780 \\
880 \\
980 \\
1080 \\
1180\end{array}$ & $\begin{array}{c}690 ; 700 \\
790 ; 800 \\
890 ; 900 \\
990 ; \\
1000 \\
1090 ; \\
1100 \\
1190 ; \\
1200 \\
\end{array}$ & $\begin{array}{l}655 \\
755 \\
855 \\
955\end{array}$ & $\begin{array}{c}665 \\
765 \\
865 \\
965 \\
1065 \\
1165\end{array}$ & $\begin{array}{r}675 ; 685 \\
775 ; 785 \\
875 ; 885 \\
975 ; 985 \\
1075 ; 1085 \\
1175 ; 1185\end{array}$ \\
\hline
\end{tabular}

Lucini (2001) afirma ainda que, para garantir os níveis de modulação desejados, as dimensões dos vãos pretendidos devem ser compatibilizadas com os vãos originados utilizando complementos de 5 ou $10 \mathrm{~cm}$ na horizontal, através de compensadores (Figura 4.5), e de $10 \mathrm{~cm}$ na vertical, através de enchimento com argamassa ou uso de vergas pré-moldadas (Figura 4.6). 


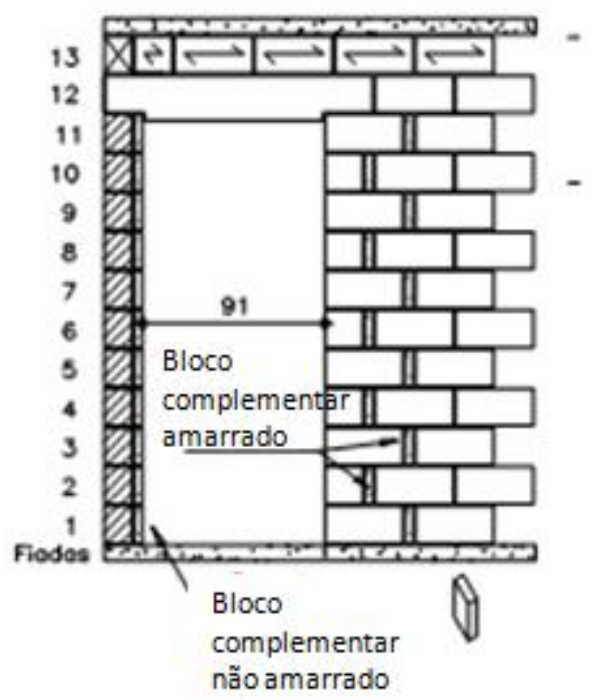

Figura 4.5 - Ajuste na dimensão do vão da porta com blocos complementares (MAMEDE; CORRÊA, 2006)

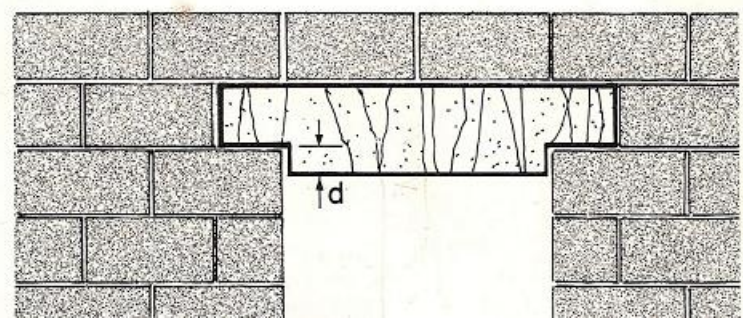

Figura 4.6 - Uso de pré-moldados para acerto da altura da porta $(A B C I, 1990)$

A utilização de vergas pré-moldadas torna a obra mais racionalizada, pois, além de evitar a moldagem do complemento durante a execução, substitui a verga feita com blocos canaleta, que exige escoramento, armação e grauteamento durante a elevação da parede.

No caso de não se estimar a quantidade de blocos através do estudo da modulação, podem-se utilizar, como referência, valores indicados no TCPO (2003), que consideram como critério de medição a área da parede, descontando os vãos superiores a $2 \mathrm{~m}^{2}$, além de considerar perda igual a $5 \%$. Deste modo, a estimativa de blocos pelo manual é:

- blocos com dimensões $(14 \times 19 \times 39) \mathrm{cm}$ e $(19 \times 19 \times 39) \mathrm{cm}: 13,10 \mathrm{blocos} / \mathrm{m}^{2} \mathrm{de}$ parede estrutural; 
Souza (2001) apresentou um método para prognosticar a quantidade de blocos através da Eq. 4.2.

$$
\frac{\text { Nblo } \cos _{t}}{m^{2}}=\frac{A_{\text {líquida }}}{\left(b+e_{h}\right) \times(a+e v)}
$$

onde:

Nblocost $/ \mathrm{m}^{2}=$ número de blocos teoricamente necessários por área líquida de parede;

$\mathrm{A}_{\text {líquida }}$ área líquida de paredes;

$\mathrm{b} ; \mathrm{e}_{\mathrm{h}} ; \mathrm{a} ; \mathrm{e}_{\mathrm{v}}$ : dependem da geometria do bloco e da junta argamassada, como mostra a Figura 4.7.
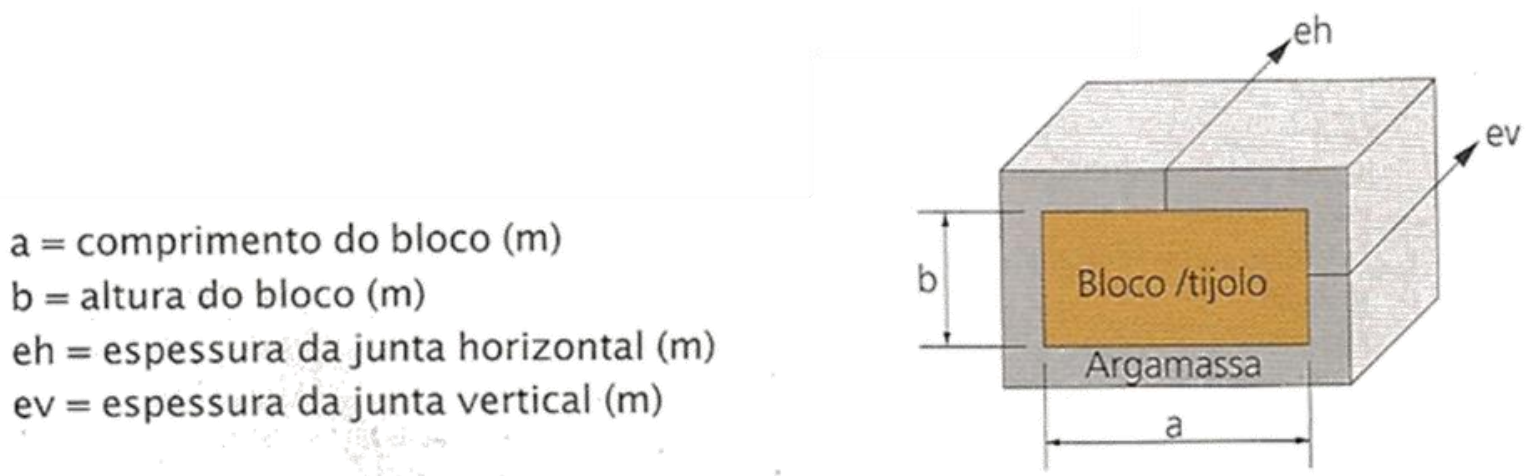

Figura 4.7 - Representação das medidas a serem utilizadas na Eq. 4.2 (TCPO, 2003)

As propostas de estimativa de blocos, com base no TCPO e em Souza (2001), contemplam apenas a quantificação de blocos inteiros, o que pode causar divergências no custo unitário.

Analisando os preços dos blocos, com diferentes geometrias, em relação à área da superfície do bloco, pode-se concluir que a utilização de blocos especiais tem maior custo que a utilização de bloco inteiro ou meio bloco, conforme mostra a Tabela 4.1. 
Tabela 4.4 - Análise do custo de blocos com diferentes comprimentos

\begin{tabular}{|l|r|r|}
\hline $\begin{array}{l}\text { Dimensões dos blocos } \\
{[\mathrm{cm}]}\end{array}$ & $\begin{array}{l}\text { Custo unitário } \\
{[\mathrm{R} \$ / \text { unid. }]}\end{array}$ & $\begin{array}{l}\text { Custo equivalente } \\
{\left[\mathrm{R} \$ / \mathrm{m}^{2} \text { de alvenaria }\right]}\end{array}$ \\
\hline $14 \times 19 \times 39$ (bloco inteiro) & $2,1^{*}$ & 28,34 \\
\hline $14 \times 19 \times 19$ (meio bloco) & $1,22^{*}$ & 33,80 \\
\hline $14 \times 19 \times 34$ (especial) & $2,19^{*}$ & 33,90 \\
\hline $14 \times 19 \times 54$ (especial) & $3,66^{*}$ & 35,67 \\
\hline $14 \times 19 \times 9$ (especial) & $0,84^{*}$ & 49,12 \\
\hline
\end{tabular}

Deste modo, o estudo de modulação, além de prever a quantidade de blocos a serem utilizados, auxilia a minimizar a quantidade de blocos especiais, reduzindo custos de construção.

Porém, se não há tal estudo ou se não existir o projeto preliminar, pode-se utilizar a quantificação de um empreendimento anterior, adotando a porcentagem de cada tipo de bloco que será extrapolada para o empreendimento em estudo, fazendo, se possível, uma correlação com a quantidade de paredes.

Freire (2007) apresentou em sua dissertação os indicadores presentes no Quadro 4.4, com base em 120 edifícios, estimando quantidades de blocos inteiros, meiosblocos, especiais e canaletas.

Quadro 4.4 - Indicadores para estimar quantidade de blocos

\begin{tabular}{|c|c|c|}
\hline Indicador & $\begin{array}{c}\text { Modulação } \\
\text { de } 30 \mathrm{~cm}\end{array}$ & $\begin{array}{c}\text { Modulação } \\
\text { de } 40 \mathrm{~cm}\end{array}$ \\
\hline Qtd de bloco inteiro por área do pav. tipo $\left(\mathrm{un} / \mathrm{m}^{2}\right)$ & 24,4 & 18 \\
\hline Qtd de meio-bloco por área do pav. tipo $\left(\mathrm{un} / \mathrm{m}^{2}\right)$ & 2,3 & 1,8 \\
\hline Qtd de bloco especial por área do pav. tipo $\left(\mathrm{un} / \mathrm{m}^{2}\right)$ & 0,8 & 4,6 \\
\hline Qtd de bloco canaleta por área do pav. tipo $\left(\mathrm{un} / \mathrm{m}^{2}\right)$ & 3,9 & 2,7 \\
\hline $\begin{array}{c}\text { Qtd de bloco meia-canaleta por área do pav. tipo } \\
\text { (un/m²) }\end{array}$ & 0,4 & 0,5 \\
\hline
\end{tabular}


Com base nos projetos de sua empresa, Franco (Apêndice A) informou a distribuição percentual de tipos de blocos mostrada no Quadro 4.5.

Quadro 4.5 - Distribuição percentual de componentes de blocos estruturais, sem considerar as canaletas

\begin{tabular}{|c|c|c|c|c|c|c|}
\hline Componente & Bloco 39 & $\begin{array}{c}\text { Meio } \\
\text { Bloco }\end{array}$ & $\begin{array}{c}\text { Bloco 34 } \\
\mathrm{cm}\end{array}$ & $\begin{array}{c}\text { bloco } 54 \\
\mathrm{~cm}\end{array}$ & $\begin{array}{c}\text { com } 4 \\
\mathrm{~cm}\end{array}$ & $\begin{array}{c}\text { comp } 9 \\
\mathrm{~cm}\end{array}$ \\
\hline Dimensões & $\begin{array}{c}14 \times 39 \times 19 \\
\mathrm{~cm}\end{array}$ & $\begin{array}{c}14 \times 19 \times 19 \\
\mathrm{~cm}\end{array}$ & $\begin{array}{c}14 \times 34 \times 19 \\
\mathrm{~cm}\end{array}$ & $\begin{array}{c}14 \times 54 \times 19 \\
\mathrm{~cm}\end{array}$ & $\begin{array}{c}14 \times 4 \times 19 \\
\mathrm{~cm}\end{array}$ & $\begin{array}{c}14 \times 9 \times 19 \\
\mathrm{~cm}\end{array}$ \\
\hline Área de um bloco & 0,08 & 0,04 & 0,07 & 0,11 & 0,01 & 0,02 \\
\hline $\begin{array}{c}\% \text { na alvenaria } \\
\text { estrutural }\end{array}$ & $81,8 \%$ & $5,7 \%$ & $6,8 \%$ & $4,6 \%$ & $0,8 \%$ & $0,3 \%$ \\
\hline
\end{tabular}

De acordo com o projetista, um método para estimar a quantidade de blocos seria:

- cálculo da área líquida de paredes;

- cálculo da área total dos blocos canaletas;

- determinação da área de paredes sem canaletas, dada pela subtração da área de canaletas da área líquida de paredes;

- determinação da área total de cada tipo de bloco dada pela multiplicação da área de paredes sem canaletas pelo percentual de distribuição do Quadro 4.5;

- estimativa da quantidade de blocos através da divisão da área total de cada tipo de bloco pela área de um único bloco (Quadro 4.5).

\subsubsection{PERDAS}

Conforme Souza (2001), os fatores que influenciam as perdas de blocos na obra são:

- resistência do bloco: quanto maior, menor índice de perdas;

- formato: canaletas são mais frágeis;

- tamanho das paredes: quanto maiores, menores perdas; 
- fornecimento e transporte: os blocos acondicionados em páletes e transportados paletizados possuem menor incidência de perdas;

- espessura dos blocos: os de menor espessura quebram mais facilmente;

- política de quantificação de blocos necessários por pavimento ou parte da obra: atitude que reduz perdas;

- existência de projeto: minimiza retrabalhos;

- procedimentos para corte dos blocos: equipamentos mecanizados reduzem perdas;

- controle de recebimento: reduz perdas;

- adoção de peças auxiliares para modulação: minimiza necessidade de cortar componentes;

- procedimentos para execução e seu controle: minimiza problemas de execução.

Este autor desenvolveu um método para estimar a perda de blocos em obra com base no Quadro 4.6, que apresenta a variação de perdas com base no formato, tamanho das paredes e forma de transporte; e Quadro 4.7, que associa demais aspectos que influenciam a perda com pesos.

Quadro 4.6 - Faixas de variação de perdas de blocos (SOUZA, 2001)

\begin{tabular}{|c|c|c|c|c|c|c|}
\hline \multirow{2}{*}{$\begin{array}{c}\text { Função } \\
\text { da } \\
\text { alvenaria }\end{array}$} & \multirow{2}{*}{$\begin{array}{l}\text { Formato } \\
\text { do bloco }\end{array}$} & \multirow{2}{*}{$\begin{array}{c}\text { Tamanho } \\
\text { das } \\
\text { paredes }\end{array}$} & \multirow{2}{*}{$\begin{array}{l}\text { Forma de } \\
\text { transporte }\end{array}$} & \multicolumn{3}{|c|}{ Faixa de variação } \\
\hline & & & & mínimo & mediana & máxima \\
\hline \multirow{6}{*}{$\begin{array}{l}\text { Parade } \\
\text { Estrutural }\end{array}$} & \multirow{3}{*}{ Canaleta } & \multicolumn{2}{|c|}{ páletes } & 8 & 18 & 20 \\
\hline & & \multirow{2}{*}{$\begin{array}{c}\text { unidades } \\
\text { soltas }\end{array}$} & $\begin{array}{l}\text { carrinho } \\
\text { específico }\end{array}$ & 10 & 20 & 23 \\
\hline & & & outras & 15 & 25 & 40 \\
\hline & \multirow{3}{*}{$\begin{array}{c}1 / 2 \\
\text { bloco; } \\
\text { inteiros }\end{array}$} & \multicolumn{2}{|c|}{ páletes } & 0 & 1 & 3 \\
\hline & & \multirow{2}{*}{$\begin{array}{c}\text { unidades } \\
\text { soltas }\end{array}$} & $\begin{array}{l}\text { carrinho } \\
\text { específico }\end{array}$ & 1 & 3 & 5 \\
\hline & & & outras & 2 & 5 & 8 \\
\hline
\end{tabular}


Quadro 4.7 - Pesos associados a outros fatores influenciadores (SOUZA, 2001)

\begin{tabular}{|c|c|c|}
\hline \multicolumn{2}{|l|}{ Fatores } & Pesos \\
\hline \multirow{2}{*}{$\begin{array}{l}\text { A espessura é superior a } 10 \\
\mathrm{~cm} \text { ? }\end{array}$} & Sim & 0,0 \\
\hline & Não & 1,0 \\
\hline \multirow{2}{*}{$\begin{array}{l}\text { É feita a quantificação de } \\
\text { blocos necessários por } \\
\text { pavimento? }\end{array}$} & Sim & 0,0 \\
\hline & Não & 1,5 \\
\hline \multirow{2}{*}{ Existe Projeto de alvenaria? } & Sim & 0,0 \\
\hline & Não & 1,5 \\
\hline \multirow{2}{*}{$\begin{array}{l}\text { Os blocos são cortados } \\
\text { mecanicamente? }\end{array}$} & Sim & 0,0 \\
\hline & Não & 1,5 \\
\hline \multirow{2}{*}{$\begin{array}{l}\text { Existe controle de } \\
\text { recebimento? }\end{array}$} & Sim & 0,0 \\
\hline & Não & 1,0 \\
\hline \multirow{2}{*}{$\begin{array}{l}\text { Existem peças auxiliares para } \\
\text { modulação? }\end{array}$} & Sim & 0,0 \\
\hline & Não & 1,5 \\
\hline \multirow{2}{*}{$\begin{array}{l}\text { Existem procedimentos de } \\
\text { execução/ controle? }\end{array}$} & Sim & 0,0 \\
\hline & Não & 1,0 \\
\hline \multirow{2}{*}{$\begin{array}{l}\text { Pedaços de blocos (cacos) } \\
\text { são utilizados em outras } \\
\text { atividades? }\end{array}$} & Sim & 1,0 \\
\hline & Não & 0,0 \\
\hline
\end{tabular}

Utilizando os dois quadros, calcula-se a perda através da Eq. 4.3.

Perda $\operatorname{Pr}$ evista $=$ Min $_{\text {faixa }}+\frac{\sum \text { Pesos }}{10} \times\left(\right.$ Máx $_{\text {faixa }}-$ Mín $\left._{\text {faixa }}\right)$

onde:

Perda prevista $=$ valor da perda $($ em \%);

Mín ${ }_{\text {faixa }}=$ valor mínimo da faixa, conforme Quadro 4.6;

Máx ${ }_{\text {faixa }}=$ valor máximo da faixa, conforme Quadro 4.6;

$\Sigma$ Pesos = somatória de todos os pesos, conforme Quadro 4.7. 


\subsubsection{Argamassa}

De acordo com a ABNT NBR 10837 (1989), a resistência à compressão da argamassa de assentamento $\left(f_{a k}\right)$ deve ser maior ou igual a $5 \mathrm{MPa}$ e menor ou igual a $17 \mathrm{MPa}$. Já a nova norma (ABNT NBR 15961, 2011), define que a resistência à compressão da argamassa deve atender ao valor máximo limitado a 0,7 da resistência característica especificada para o bloco.

Com relação ao consumo de argamassa, a norma NBR ABNT 15961 (2011) especifica que as espessuras das juntas verticais e horizontais devem ser consideradas com $10 \mathrm{~mm}$ (variação máxima de $3 \mathrm{~mm}$ ), com exceção da junta horizontal da primeira fiada, a qual pode ter espessura mínima de $5 \mathrm{~mm}$ e máxima de $20 \mathrm{~mm}$.

Os fatores que influenciam o consumo de argamassa de assentamento são (SOUZA, 2001):

- tamanho dos blocos;

- ferramentas utilizadas para assentamento;

- fabricação da argamassa;

- tamanho das paredes: as inferiores a $2 \mathrm{~m}$ tendem a consumir mais argamassa, pois a incidência do comprimento de juntas verticais preenchidas sobre a quantidade total de juntas é maior;

- utilização de componentes especiais: como estes blocos possuem menor tamanho, o consumo de argamassa será maior;

- dosagem da argamassa;

- transporte da argamassa.

Souza (2001) apresentou método para cálculo de consumo de argamassa, incluindo a previsão de perdas, através da Eq. 4.4. 


$$
\frac{Q \arg \text { amassa }}{\text { Qparedes }}=\frac{\text { Qjuntas }_{\text {pparedes }}}{\text { Qponsumo }} \underset{\text { aplicação }}{\text { Qjuntas }} \times\left(1+\frac{\Delta \text { Perdas }_{(\%)}}{100}\right)
$$

onde:

Qargamassa/Qparedes = consumo unitário de argamassa $\left(\mathrm{l} / \mathrm{m}^{2}\right)$;

Qjuntas/Qparedes $=$ quantidades de juntas $(\mathrm{em} \mathrm{m})$ em relação a área de paredes;

Consumoaplicação/Qjuntas = consumo de argamassa em I/m;

$\Delta$ Perdas $=$ perdas em porcentagem.

Para o cálculo do consumo na aplicação, o autor propôs a Eq. 4.5, que prevê uma faixa de consumo, com base nos fatores que determinam pesos diferenciados (Quadro 4.8). O valor deste consumo pode variar dentro desta faixa devido a fatores como incidência relevante de paredes pequenas e utilizações de peças pequenas para acerto de modulação.

$$
\frac{\text { consumo }_{\text {aplicaşão }}}{\text { Qjuntas }}=0,7+0,18 \times \text { Peso } \pm 0,18
$$

onde:

Peso é o valor referente à análise de fatores do Quadro 4.8.

Quadro 4.8 - Pesos relativos a diferentes realizações dos fatores influenciadores (SOUZA; 2001)

\begin{tabular}{|r|c|c|c|c|}
\hline Juntas verticais preenchidas & \multicolumn{2}{|c|}{ Todas } & \multicolumn{2}{c|}{ Não todas } \\
\hline $\begin{array}{r}\text { Ferramenta de } \\
\text { aplicação } \\
\text { Direção dos } \\
\text { furos dos blocos }\end{array}$ & Colher & $\begin{array}{r}\text { Tabuinha/ } \\
\text { Bisnaga/ } \\
\text { meia-cana }\end{array}$ & Colher & $\begin{array}{c}\text { Tabuinha/ } \\
\text { Bisnaga/ } \\
\text { meia-cana }\end{array}$ \\
\hline Vertical & 12 & 6 & 11 & 5 \\
\hline Horizontal & 10 & 4 & 9 & 3 \\
\hline Sem furos & 8 & 2 & 7 & 1 \\
\hline
\end{tabular}


Souza (2001) propôs, ainda, os valores de consumo unitário presentes no Quadro 4.9 , nos casos em que não se tem o valor de quantidade de juntas, facilitando a estimativa.

Quadro 4.9 - Quantidade de juntas (em $\mathrm{m} / \mathrm{m}^{2}$ ) em função do tamanho do componente de alvenaria (SOUZA; 2001)

\begin{tabular}{|c|c|c|c|c|}
\hline \multicolumn{2}{|c|}{ Dimensão nominal da face componente $(\mathrm{cm} \times \mathrm{cm})$} & $25 \times 25$ & $20 \times 40$ & $40 \times 60$ \\
\hline \multirow{2}{*}{ Junta $\left(\mathrm{m} / \mathrm{m}^{2}\right)$} & Horizontal & 4,0 & 5,0 & 2,5 \\
\cline { 2 - 5 } & Vertical & 4,0 & 2,5 & 1,7 \\
\hline
\end{tabular}

Com relação ao valor de perdas, Souza (2001) apresentou o Quadro 4.10, que indica os valores a serem utilizados na Eq. 4.4 para cálculo do consumo real.

Quadro 4.10 - $\Delta$ perdas associadas a outros fatores (SOUZA; 2001)

\begin{tabular}{|c|c|c|}
\hline \multirow{2}{*}{ Fatores } & \multicolumn{1}{c|}{} \\
\multirow{2}{*}{ Dosagem na obra? } & Não & Perdas \\
\cline { 2 - 3 } & Sim, com procedimento & 0,0 \\
\cline { 2 - 3 } & adequado & 5,0 \\
\cline { 2 - 3 } & Sim, sem procedimento & \multirow{2}{*}{ adequado } \\
\hline \multirow{2}{*}{ Transporte com equipamento inadequado? } & Não & 0,0 \\
\cline { 2 - 3 } & Sim & 20,0 \\
\hline \multirow{2}{*}{ Projeto arquitetônico completamente definido? } & Não & 15,0 \\
\cline { 2 - 3 } & Sim & 0,0 \\
\hline
\end{tabular}

No caso de se analisar a quantidade de argamassa em relação à massa de argamassa ensacada ou em silo, a transformação em $\mathrm{kg} / \mathrm{m}^{2}$ a partir de $\mathrm{I} / \mathrm{m}^{2}$ de parede pode ser feita através da Eq. 4.6 (SOUZA; 2001).

$$
\text { Cmassa }=\text { Cvolume } \times 1,7 \mathrm{~kg} / \mathrm{l}
$$

\subsubsection{Graute}

O valor mínimo para a resistência característica do graute $\left(f_{g k}\right)$, conforme a ABNT NBR 15961 (2011), é de 15 MPa. 
A norma ABNT NBR 10837 (1989) afirma que a tensão característica do graute deve atender à seguinte relação:

- $f_{g k} \geq 2 f_{b k}$

O graute é previsto em todos os pontos que terão armadura vertical e nas cintas, que são fiadas compostas por blocos canaleta com função de dar travamento ao prédio como um todo, transmitir a reação da laje à alvenaria e combater efeitos das variações volumétricas. As cintas são previstas abaixo da laje e a meia altura da parede, em especial nas externas devido à exposição a intempéries (Acceti, 1998).

A quantidade de graute pode ser medida através da geometria do bloco, considerando, no caso de graute vertical, o volume do furo do bloco (Figura 4.8); e, no caso do graute nas cintas horizontais, o volume do vazio na canaleta (Figura 4.9).

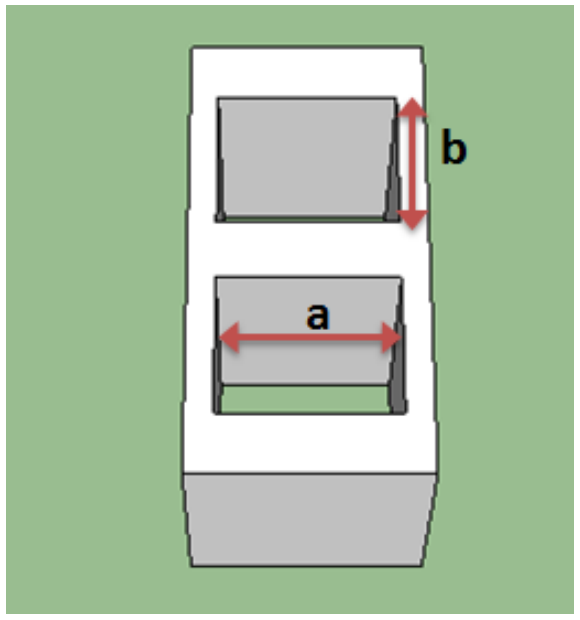

Figura 4.8 - Furo vertical de bloco estrutural

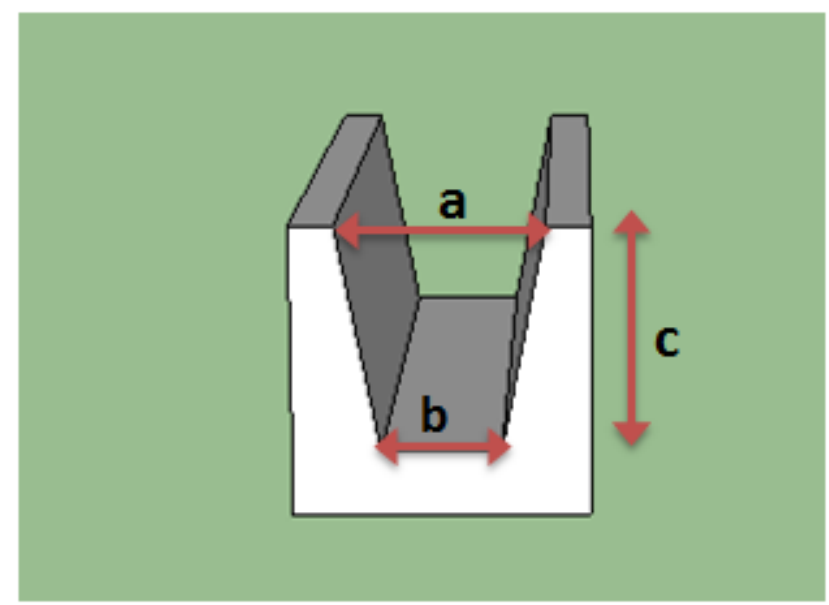

Figura 4.9 - Vazio do bloco canaleta 
Oliveira Junior (1992) forneceu os valores de volume de graute, em função da altura (para grautes verticais) e do comprimento (para grautes horizontais), conforme mostram o Quadro 4.11 e o Quadro 4.12.

Quadro 4.11 - Preenchimento vertical dos furos verticais: blocos (OLIVEIRA JUNIOR, 1992)

\begin{tabular}{|c|c|c|}
\hline \multirow{2}{*}{ Bloco } & \multicolumn{2}{|c|}{ Seções do furo } \\
\cline { 2 - 3 } & $\begin{array}{c}\text { Dimensões } \\
\mathrm{a} \times \mathrm{b}(\mathrm{cm})\end{array}$ & $\begin{array}{c}\text { Área furo } \\
(\mathrm{a} \times \mathrm{b})\left(\mathrm{m}^{2}\right)\end{array}$ \\
\hline $19 \times 19 \times 39$ & $12,25 \times 15,25$ & 0,0187 \\
\hline $14 \times 19 \times 39$ & $8,72 \times 15,35$ & 0,0134 \\
\hline $12 \times 19 \times 39$ & $6,5 \times 15,3$ & 0,0099 \\
\hline $9 \times 19 \times 39$ & $4,5 \times 15,95$ & 0,0072 \\
\hline
\end{tabular}

Quadro 4.12 - Preenchimento horizontal dos vazios: canaletas (OLIVEIRA JUNIOR, 1992)

\begin{tabular}{|c|c|c|}
\hline \multirow{2}{*}{ Canaleta } & \multicolumn{2}{|c|}{ Seções do vazio } \\
\cline { 2 - 3 } & $\begin{array}{c}\text { Dimensões } \\
\mathrm{a} \times \mathrm{b} \times \mathrm{c}(\mathrm{cm})\end{array}$ & $\begin{array}{c}\text { Área Vazio } \\
(\mathrm{c} \times(\mathrm{a}+\mathrm{b}) / 2)\left(\mathrm{m}^{2}\right)\end{array}$ \\
\hline $19 \times 19 \times 19$ & $13,3 \times 7,7 \times 14,65$ & 0,0154 \\
\hline $14 \times 19 \times 19$ & $9,3 \times 6,3 \times 14,65$ & 0,0114 \\
\hline $9 \times 19 \times 39$ & $4,3 \times 4 \times 15,65$ & 0,0065 \\
\hline
\end{tabular}

A previsão de quantidade de graute $\left(\mathrm{m}^{3}\right.$ por $\mathrm{m}^{2}$ de parede) pode ser adotada como a mesma quantidade do projeto de referência, ou, ainda, utilizar indicadores que estimem tal consumo.

Freire (2007) considera que os valores indicados para estimativa de graute são:

- $35 \mathrm{l} / \mathrm{m}^{2}$ de pavimento tipo, para edificação com mais de dois pavimentos;

- $64 \mathrm{l} / \mathrm{m}^{2}$ de pavimento tipo, para sobrados.

De acordo com a entrevista feita com o projetista Franco (Apêndice A), a estimativa de graute horizontal pode ser feita multiplicando a quantidade linear de canaletas pela área de furo de sua seção vertical (Quadro 4.12).

O projetista informou ainda que o grauteamento vertical é realizado, principalmente, devido a dois fatores: 
- fator construtivo: há um mínimo de grauteamento para maior resistência do conjunto estrutural, que depende, principalmente, da quantidade de ligações entre paredes, esforços localizados e da altura da edificação;

- fator ligado a esforços horizontais de vento.

No primeiro caso, Franco forneceu indicadores de quantidades mínimas de pontos de graute, aqui chamados de Q0, apresentados no Quadro 4.13.

\section{Quadro 4.13 - Indicadores de quantidade de graute vertical Q0}

\begin{tabular}{|c|c|}
\hline Pavimentos & $\begin{array}{c}\text { Q0 - Quantidade de grautes por } \\
\text { área construída }\left(\mathrm{un} / \mathrm{m}^{2}\right)\end{array}$ \\
\hline de 4 a 8 pavimentos & 0,065 \\
\hline de 9 a 12 pavimentos & 0,100 \\
\hline de 13 a 16 pavimentos & 0,120 \\
\hline
\end{tabular}

Para estimar a quantidade de graute devido a esforços de vento (Qv), o projetista desenvolveu a Eq. 4.7, que relaciona o vento, a rigidez do prédio (definida pelo projeto), a largura da fachada e altura da edificação. Esta quantidade deve ser aplicada apenas aos pavimentos abaixo de 8 andares (onde os esforços de vento serão significativos).

$$
Q_{v}=\frac{0,000007 \times V_{0}^{2} \times H^{3} \times L_{\text {Fachada }}}{\sum I}
$$

onde:

$Q_{v}=$ quantidade de grautes verticais devido a esforços de vento (em und.);

$\mathrm{V}_{0}=$ velocidade básica do vento em $\mathrm{m} / \mathrm{s}$ na região onde será implantado o edifício;

$\mathrm{H}=$ altura dos pavimentos acima do pavimento em questão, excluindo o ático do prédio (em m); 
$\Sigma I$ = somatória do momento de inércia das paredes estruturais para a direção principal do vento $\left(\mathrm{em} \mathrm{m}^{4}\right)$.

A Figura 4.10 mostra, graficamente, a variação da quantidade de graute em edifícios. Nota-se que nos últimos 8 andares, há apenas Q0 pontos de graute e que nos andares abaixo, a quantidade de pontos de graute muda conforme o cálculo de Qv.

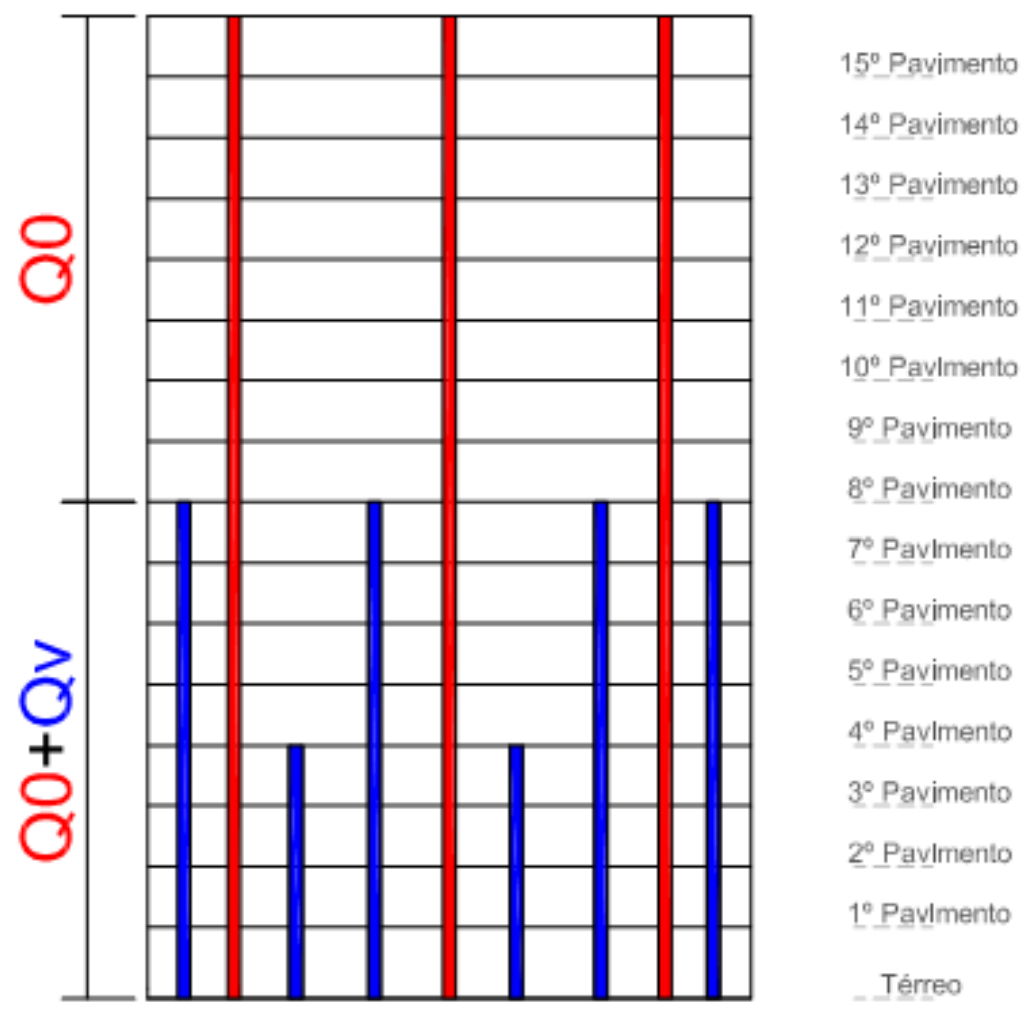

Figura 4.10 - Variação da quantidade de pontos de graute

\subsubsection{Armação}

A alvenaria estrutural pode ser classificada de acordo com o processo construtivo utilizado (Camacho, 2006) em:

- alvenaria Estrutural Armada: possui armadura passiva de aço, disposta nas cavidades dos blocos; 
- alvenaria Estrutural Não Armada: possui apenas armaduras com finalidades construtivas, a fim de evitar problemas patológicos;

- alvenaria Estrutural Parcialmente Armada: possui elementos resistentes projetados como armados e outros como não armados (termo empregado somente no Brasil);

- alvenaria Estrutural Protendida: alvenaria na qual é empregada uma armadura ativa de aço.

Analisando a quantidade de armação, há pontos que, tanto na alvenaria estrutural armada quanto na não armada, terão tal material. São eles (ABCl, 1990):

- perímetro das aberturas;

- amarração de paredes.

Acceti (1998) afirma que, no caso do dimensionamento de vergas e das cintas, as armaduras construtivas de $1 \phi 10 \mathrm{~mm}$ ou $2 \phi 8 \mathrm{~mm}$ são suficientes para atender os requisitos de resistência para esses elementos estruturais.

$\mathrm{Na}$ alvenaria estrutural armada, a armadura longitudinal principal, conforme a ABNT NBR 15961 (2011), não é menor que 0,10\% da área da seção transversal. Além disso, a alvenaria armada deve possuir uma armadura secundária mínima, perpendicular à principal, de $0,05 \%$ da seção transversal correspondente. A área da seção transversal da armadura máxima alojada em um mesmo espaço grauteado (furo vertical ou canaleta horizontal), definida pela norma, é de $8 \%$ da área correspondente à seção do graute envolvente.

De acordo com Gomes (1983), a taxa mínima indicada pela norma não é suficiente para garantir uma ruptura avisada, o que seria possível com uma taxa igual ou superior a $0,4 \%$.

Conforme a ABNT NBR 15961 (2011), o diâmetro máximo das barras de armaduras é de 6,3 mm, quando localizadas em juntas de assentamento e $25 \mathrm{~mm}$ em qualquer outro caso. 
A ancoragem definida pela norma deve ser de pelo menos 12 vezes o diâmetro da barra; além disso,as emendas para as armaduras devem ter comprimento superior a, no mínimo, $40 \phi$, ou $15 \mathrm{~cm}$ (quando as barras possuem saliências), ou $30 \mathrm{~cm}$ (quando os fios são lisos).

Para estimativa de quantidade de armação total, Freire (2007) levantou, com base em diferentes projetos, o valor médio de $1,5 \mathrm{~kg} / \mathrm{m}^{2}$ de pavimento.

De acordo com Franco (Apêndice A), o graute horizontal deve ser armado com 0,28 $\mathrm{Kg}$ / bloco canaleta (armação de uma barra de $10 \mathrm{~mm}$ nos blocos), o que, para o projetista, é adequado na maior parte das situações.

Com relação à armação vertical, Franco prevê que todos os pontos grauteados verticalmente tenham armação. A estimativa feita por ele, considera os seguintes indicadores, para um edifício de 16 andares:

- 4 primeiros andares: 1 barra de $16 \mathrm{~mm}(1,6 \mathrm{Kg} / \mathrm{m})$; comprimento igual ao do pavimento $+60 \mathrm{~cm}$ de transpasse;

- 5 pavimentos acima: 1 barra de $12,5 \mathrm{~mm}(1 \mathrm{Kg} / \mathrm{m})$; comprimento igual ao do pavimento $+60 \mathrm{~cm}$ de transpasse;

- restante (do $10^{\circ}$ ao $16^{\circ}$ andar): 1 barra de $10 \mathrm{~mm}(0,63 \mathrm{Kg} / \mathrm{m})$; comprimento igual ao do pavimento $+60 \mathrm{~cm}$ de transpasse;

A Figura 4.11 mostra, esquematicamente, a variação das bitolas das armações em relação à quantidade de pavimentos que o edifício possuir. 


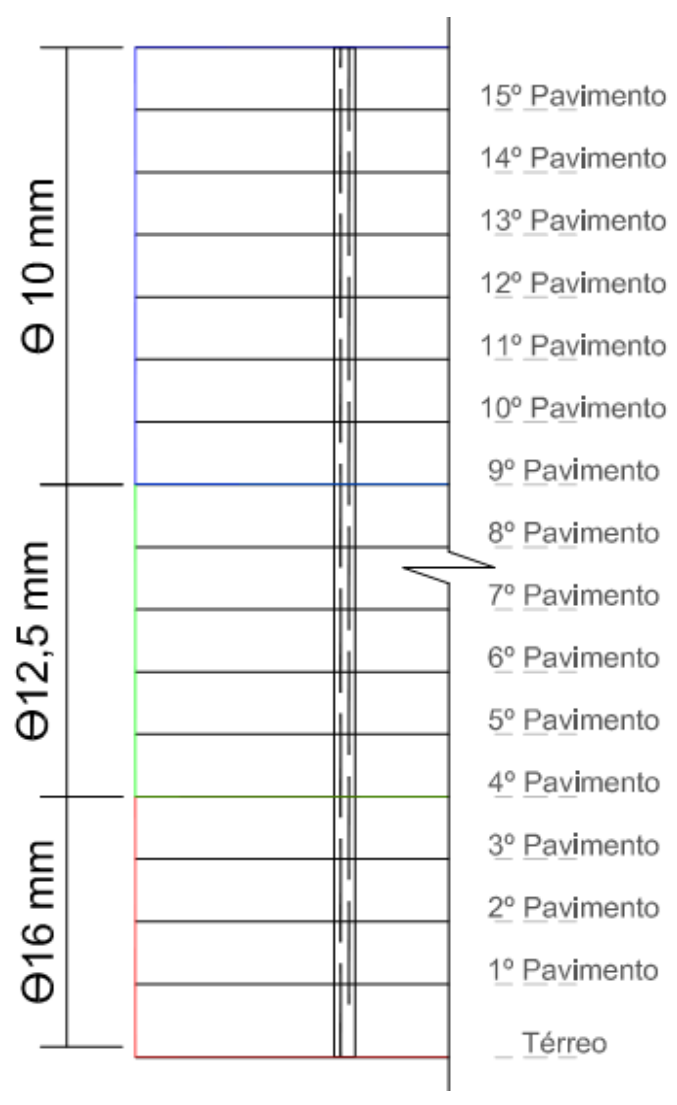

Figura 4.11 - Variação das bitolas de armação vertical por andar

\subsection{Mão-de-obra}

Nos casos em que a mão-de-obra é subcontratada, o estudo da RUP para avaliar o custo pode não ser realizado, pois a subempreiteira será contratada pelo custo da mão-de-obra em relação à quantidade de serviço que será feita, e é esta empresa que irá controlar a produtividade de seus operários e verificar se é condizente com o valor pago e com o próprio serviço. Ainda assim, o entendimento da melhor ou pior produtividade esperada pode ser útil para balizar a expectativa do preço a ser cobrado por subempreiteiros.

O custo da mão-de-obra de alvenaria estrutural empreitada $\left(R \$ / m^{2}\right)$ pode ser estimado com base em valores de mercado, presentes em revistas de construção ou adotado com base em obra similar feita anteriormente. 
Porém, para uma verificação do custo de mão-de-obra própria para este serviço, é importante verificar as variações que podem resultar em diferentes valores de produtividade para o serviço.

Conforme o Capítulo 3, o valor a ser adotado para a produtividade (RUP) pode ser baseado em manuais de orçamentação, em pesquisas anteriores ou em valores da própria empresa.

Com base em Araújo e Souza (2001), foram levantados os fatores que influenciam a produtividade da alvenaria estrutural:

- Características do produto:

- localização e geometria das paredes: as paredes internas e aquelas com maior comprimento e de altura não superior à alcançável por um andaime normal são as mais fáceis de se executar;

- formas de fixação vertical da alvenaria: os encontros de paredes através da intercalação de blocos entre as fiadas é mais dificultosa que a ligação feita por peças metálicas;

- modulação: quanto menor a quantidade de diversidade de blocos, melhor será a produtividade;

- cintas de armação: há projetos que possuem cintas de armação em toda a fiada localizada abaixo das janelas; nestes casos, o andar será realizado em duas etapas para o grauteamento destas cintas, este fato influencia a produtividade e deve ser considerado no dimensionamento das equipes e no planejamento da obra;

- graute: quanto maior a quantidade de pontos de graute, mais tempo será demandado para sua execução;

- armação: quanto mais aço a obra possuir, maior a interferência com a equipe de alvenaria e pior será a produtividade;

- Materiais e componentes: 
o variedades nos blocos: quanto maior a variedade em relação à geometria e resistência, pior será a produtividade;

- geometria dos blocos: os blocos com menor espessura são mais leves, e, conseqüentemente, mais fáceis de serem assentados;

- argamassas: pode ser industrializada ou produzida no canteiro; no segundo caso podem ocorrer mais anormalidades.

- Equipamentos e ferramentas:

- o transporte dos blocos pode ser feito por elevador de obras ou por grua, sendo que este último facilita a execução, pois transporta maior número de blocos;

- o transporte do material para o grauteamento pode ser feita por jerica, bomba ou grua, sendo que os dois últimos apresentam maior agilidade para abastecer as frentes de trabalho;

- a argamassa pode ser aplicada com colher de pedreiro, palheta ou bisnaga; a segunda opção tem mostrado melhores resultados quanto à produtividade de mão-de-obra;

- há ainda outras ferramentas que facilitam a execução da alvenaria estrutural, tais como: bancada para execução das últimas fiadas, caixas de argamassa que possuem altura adequada para a fiada em execução, entre outros;

- Mão-de-obra:

- dimensionamento das equipes: é necessário um número mínimo de serventes por pedreiro, para não comprometer a produtividade do oficial; além disso, deve-se atentar ao fato de que muitos operários em um mesmo ambiente pode resultar em alta RUP, pois é possível a ocorrência de interferências na execução;

- motivação dos funcionários: operários que recebem por produção tendem a ter melhor produtividade que os que trabalham por hora. 
Além disso, outros tipos de motivação da mão-de-obra podem melhorar a RUP, tais como: prêmios, boas condições de trabalho etc.

- Organização da produção:

- logística: o estudo do canteiro deve ser realizado para verificar a localização de equipamentos, ferramentas e materiais e da própria mão-de-obra, a fim de que, em cada fase da obra, os materiais possam ser transportados aos operários sem atrasos e sem subutilizar os equipamentos;

- suprimentos: a falta de material é um dos grandes problemas durante a execução da obra, influenciando diretamente a produtividade;

o projetos: projetos que melhor especificam as paredes e a organização do serviço, facilitam a execução e minimizam a ocorrência de improvisações em obra.

Apesar de a verificação do atendimento do estudo de viabilidade ocorrer em estágios iniciais do empreendimento, é importante que o gestor saiba qual a faixa de produtividade em que sua mão-de-obra é capaz de atuar, principalmente para analisar a mão-de-obra própria, verificando quais fatores, como os listados anteriormente, são praticados pela construtora, podendo, assim, prognosticar um valor próximo ao real. De acordo com o TCPO (2003), a execução da alvenaria estrutural pode ter produtividade variando de $0,51 \mathrm{Hh} / \mathrm{m}^{2}$ a $0,98 \mathrm{Hh} / \mathrm{m}^{2}$, como mostra a Figura 4.12. 


\section{TIPO 3: ALVENARIA DE BLOCOS PARA ALVENARIA ESTRUTURAL}

$$
\operatorname{Min}=0,51
$$

Med $=0,74 \quad$ Máx $=0,98$

\section{Pedreiro $\left(\mathrm{Hh} / \mathrm{m}^{2}\right)$}

\begin{tabular}{|l|l|}
\hline Não-preenchimento de juntas verticais & Preenchimento das juntas verticais \\
\hline $\begin{array}{l}\text { Densidade média de alvenaria- } \\
\mathrm{m}^{2} \text { de parede/m² de piso }\end{array}$ & $\begin{array}{l}\text { Densidade alta ou baixa de } \\
\text { alvenaria- } \mathrm{m}^{2} \text { de parede } / \mathrm{m}^{2} \text { de piso }\end{array}$ \\
\hline $\begin{array}{l}\text { Presença quase que exclusiva } \\
\text { de paredes na altura usual }\end{array}$ & $\begin{array}{l}\text { Presença significativa de } \\
\text { paredes altas ou baixas demais }\end{array}$ \\
\hline $\begin{array}{l}\text { Pouco tempo para executar } \\
\text { um pavimento (prazos enxutos) }\end{array}$ & $\begin{array}{l}\text { Muito tempo para executar um } \\
\text { pavimento (prazos extensos) }\end{array}$ \\
\hline Paredes de espessuras pequenas & Paredes de espessuras grandes \\
\hline Baixa rotatividade & Alta rotatividade \\
\hline Pagamento conforme acordado & Falhas no pagamento dos operários \\
\hline Material disponível & Falta de material \\
\hline Equipamento de transporte vertical disponível & $\begin{array}{l}\text { Quebras ou indisponibilidade do } \\
\text { equipamento de transporte vertical }\end{array}$ \\
\hline
\end{tabular}

Figura 4.12 - Variação da produtividade para execução de alvenaria estrutural (TCPO, 2003)

O valor deste manual pode ser adotado no estudo do custo de um novo empreendimento, desde que o gestor realmente saiba a faixa que sua empresa é capaz de atender. Porém, um valor mais apurado seria aquele baseado em uma obra anterior, no caso de a empresa possuir banco de dados de produtividade.

A bibliografia mostra os valores presentes no Quadro 4.14, como referência para a produtividade de alvenaria estrutural. A RUP considerada é a total, ou seja, considerou-se como entrada a equipe direta (marcação+elevação), o encarregado, os operários indiretos que atuam no transporte dos materiais (somente quando era exclusivo para o serviço de alvenaria) e o $\mathrm{Hh}$ despendido com a limpeza do pavimento. 
Quadro 4.14 - Valores de RUP totais de referências

\begin{tabular}{|c|c|c|}
\hline Fonte & $R U P_{\text {total }}\left(\mathrm{Hh} / \mathrm{m}^{2}\right)$ & Descrição da obra \\
\hline \multirow{3}{*}{$\begin{array}{c}\text { CARRARO, } \\
1998\end{array}$} & 1,74 & $\begin{array}{l}\text { Edifício em Goiás com } 3 \text { pavimentos, padrão } \\
\text { popular. Estrutura em alvenaria estrutural com } \\
\text { blocos de concreto }(19 \times 39) \mathrm{cm} \text { e vedação em } \\
\text { blocos de concreto com face igual a }(17 \times 39) \mathrm{cm}\end{array}$ \\
\hline & 1,21 & $\begin{array}{l}\text { Edifício em Goiás com } 3 \text { pavimentos, padrão } \\
\text { popular. Estrutura em alvenaria estrutural com } \\
\text { blocos de concreto }(19 \times 39) \mathrm{cm} \text { e vedação em } \\
\text { blocos de concreto com face igual a }(17 \times 39) \mathrm{cm}\end{array}$ \\
\hline & 1,25 & $\begin{array}{l}\text { Edifício em Jundiaí com } 12 \text { pavimentos, } 4 \\
\text { apartamentos por andar. Estrutura em alvenaria } \\
\text { estrutural com blocos de concreto (19×39). }\end{array}$ \\
\hline \multirow{2}{*}{$\begin{array}{c}\text { ARAÚJO; } \\
\text { SOUZA, } 2001\end{array}$} & 0,88 & $\begin{array}{l}\text { Alvenaria estrutural em blocos de concreto } \\
(14 \times 19 \times 39) \mathrm{cm} \text {; supervisão por mestre de obras; } \\
\text { transporte com grua exclusivo ao serviço; } \\
\text { produção mecanizada de argamassa. }\end{array}$ \\
\hline & 1,10 & $\begin{array}{c}\text { Alvenaria estrutural em blocos de concreto } \\
(14 \times 19 \times 39) \mathrm{cm} \text {; argamassa industrializada } \\
\text { misturada no pavimento; transporte por elevador } \\
\text { de obras }\end{array}$ \\
\hline
\end{tabular}




\section{APLICAÇÃO DO MÉTODO AO ESTUDO DE ALVENARIA ESTRUTURAL}

O presente capítulo pretende mostrar a aplicação do método definido no Capítulo 3 para o serviço de alvenaria estrutural, considerando os estudos feitos no Capítulo 4.

Este serviço foi escolhido para ser analisado por representar o item mais caro de um dado edifício que utiliza este método de construção, conforme mostra a Tabela 5.1. A alvenaria estrutural tem custo representativo por atuar tanto como estrutura portante como por atuar como vedação da edificação.

Tabela 5.1 - Curva ABC de edifício de alvenaria estrutural

\begin{tabular}{|c|c|c|c|c|}
\hline SERVIÇO & $\begin{array}{l}\text { PREÇO TOTAL em reais } \\
(10 / 2010)\end{array}$ & $\%$ & $\%$ CUM & Curva \\
\hline ALVENARIA ESTRUTURAL & $901.190,99$ & $19,43 \%$ & $19,43 \%$ & \multirow{6}{*}{ A } \\
\hline $\begin{array}{l}\text { ESTRUTURA CONCRETO ARMADO } \\
\text { (LAJES - TRANSIÇÃO) }\end{array}$ & $685.290,97$ & $14,78 \%$ & $34,21 \%$ & \\
\hline REVESTIMENTOS INTERNOS & $641.455,22$ & $13,83 \%$ & $48,05 \%$ & \\
\hline $\begin{array}{l}\text { INSTALAÇÕES HIDRÁULICAS, LOUÇAS } \\
\text { E METAIS, INCENDIO }\end{array}$ & $500.658,79$ & $10,80 \%$ & $58,84 \%$ & \\
\hline INSTALAÇÕES ELÉTRICAS E EXAUSTÃO & $494.407,22$ & $10,66 \%$ & $69,51 \%$ & \\
\hline FUNDAÇÕES & $442.228,71$ & $9,54 \%$ & $79,04 \%$ & \\
\hline ESQUADRIAS & $382.178,79$ & $8,24 \%$ & $87,28 \%$ & \multirow{3}{*}{ B } \\
\hline FACHADA & $241.430,96$ & $5,21 \%$ & $92,49 \%$ & \\
\hline ELEVADORES & $174.360,00$ & $3,76 \%$ & $96,25 \%$ & \\
\hline VEDAÇÃO (GESSO ACARTONADO) & $104.700,25$ & $2,26 \%$ & $98,51 \%$ & \multirow{3}{*}{ C } \\
\hline IMPERMEABILIZAÇÃO & $53.532,73$ & $1,15 \%$ & $99,66 \%$ & \\
\hline COBERTURA & $15.631,94$ & $0,34 \%$ & $100,00 \%$ & \\
\hline
\end{tabular}

O edifício a ter o custo de alvenaria estrutural estimado (ED1) possui as características presentes no Quadro 5.1. 
Quadro 5.1 - Principais características do ED1

\begin{tabular}{|l|r|}
\hline Características & Valor \\
\hline Número de andares & 14 \\
\hline Número de apartamentos por andar & 8 \\
\hline Número de dormitórios de cada apartamento & 2 \\
\hline Número total de apartamentos & 112 \\
\hline Principais áreas & Valor (m²) \\
\hline Apartamento meio (4 apartamentos/ andar) & 45,88 \\
\hline $\begin{array}{l}\text { Apartamento de extremos (4 apartamentos/ } \\
\text { andar) }\end{array}$ & 44,02 \\
\hline Área privativa tipo & 359,6 \\
\hline Área total privativa (térreo com 8 apartamentos) & $5.034,4$ \\
\hline Área bruta pavimento tipo & 430,18 \\
\hline Área vazios & 10,26 \\
\hline Área líquida pavimento tipo (área construída) & 419,92 \\
\hline Área coletiva por pavimento & 60,32 \\
\hline Área coletiva por apartamento & 7,54 \\
\hline Área total edificação (área construída) & $5.878,88$ \\
\hline
\end{tabular}

A Figura 5.1 mostra a planta da ED1.

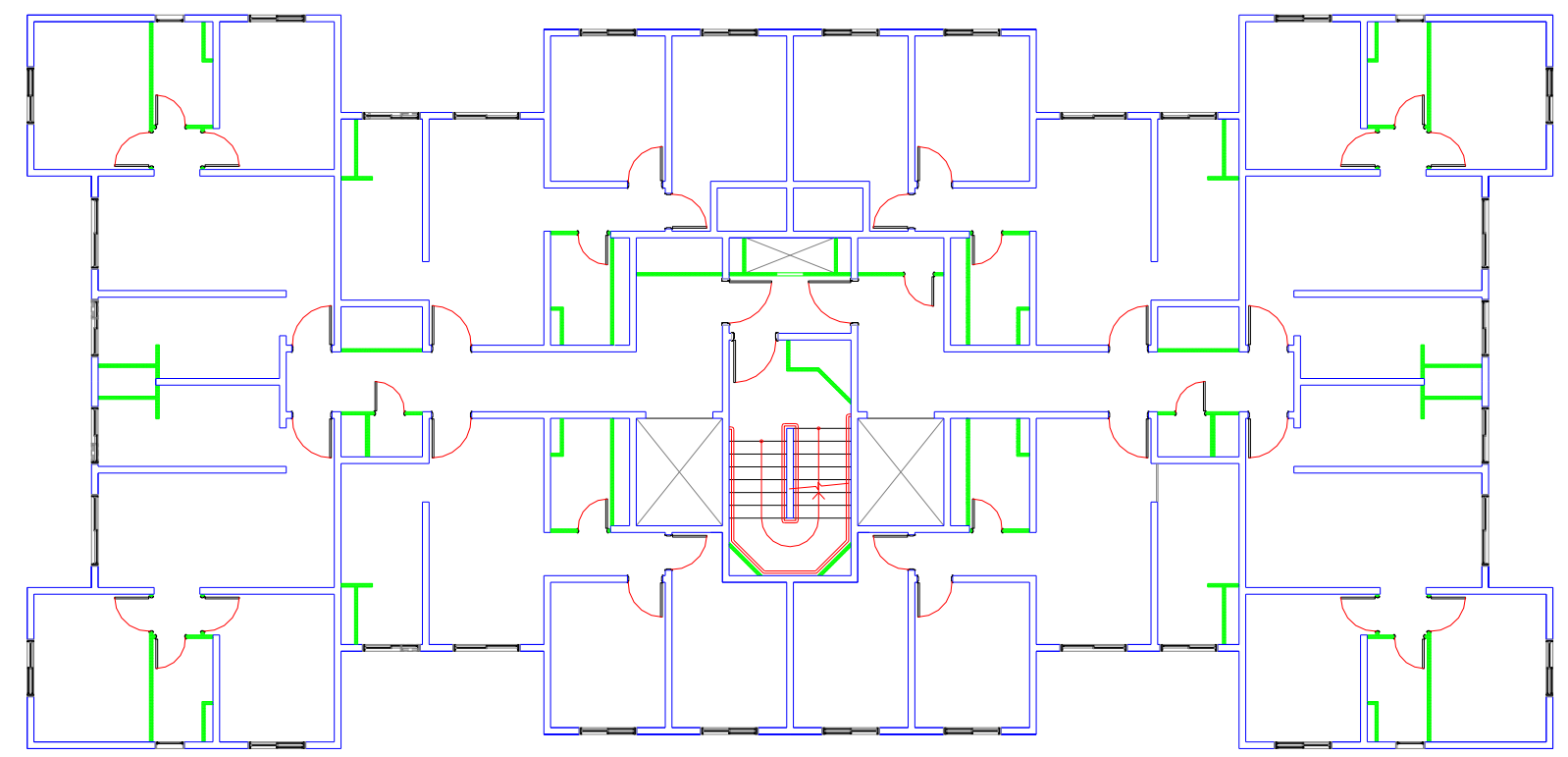

Figura 5.1 - Planta do ED1 (a ter custo prognosticado)

Conforme o método do Capítulo 3, é necessário que uma edificação com os custos já orçados anteriormente seja tomada como referência de custo para o cálculo dos fatores que indicam a diferença de custo entre os dois edifícios. Deste modo, o edifício de referência possui as características mostradas no Quadro 5.2. 
Quadro 5.2 - Principais características do ED0

\begin{tabular}{|l|r|}
\hline Características & \multicolumn{1}{|l|}{ Valor } \\
\hline Número de andares & 9 \\
\hline Número de apartamentos por andar & 6 \\
\hline Número de dormitórios de cada apartamento & 2 \\
\hline Número total de apartamentos & 54 \\
\hline Principais áreas & Valor $\left(\mathrm{m}^{2}\right)$ \\
\hline Apartamento meio (2 apartamentos/ andar) & 43,76 \\
\hline Apartamento de extremos (4 apartamentos/ andar) & 44,36 \\
\hline Área privativa tipo & 264,96 \\
\hline Área total privativa (térreo com 6 apartamentos) & $2.384,64$ \\
\hline Área bruta pavimento tipo & 303,08 \\
\hline Área vazios & 4,3 \\
\hline Área líquida pavimento tipo (área construída) & 298,78 \\
\hline Área coletiva por pavimento & 60,32 \\
\hline Área coletiva por apartamento & 7,54 \\
\hline Área total edificação (área construída) & $2.689,00$ \\
\hline Alvenaria estrutural & \\
\hline Área líquida de paredes estruturais para pavimento tipo $\left(\mathrm{m}^{2}\right)$ & 507,04 \\
\hline Área líquida de paredes estruturais para edificação $\left(\mathrm{m}^{2}\right)$ & $4.563,36$ \\
\hline Indicador área líquida de alvenaria estrutural/ área da edificação & 1,70 \\
\hline Custo do serviço de alvenaria estrutural em out/2010 (R\$) & $283.306,12$ \\
\hline Custo da alvenaria estrutural/A construída em out/2010 (R\$/m²) & 105,36 \\
\hline
\end{tabular}

A planta do ED0 é mostrada na Figura 5.2.

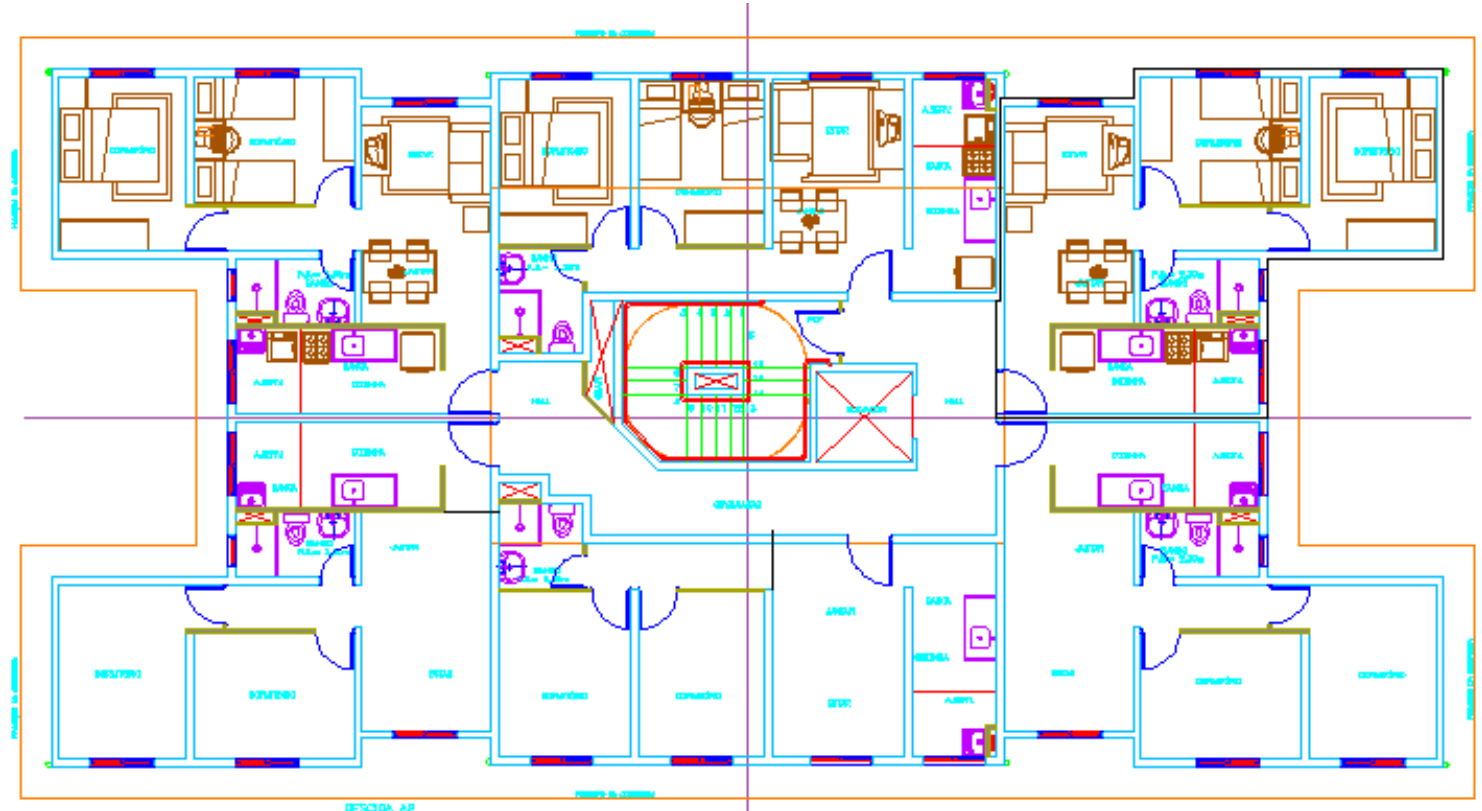

Figura 5.2 - Planta do ED0 (referência) 


\subsection{Quantidade de serviço}

A quantidade de alvenaria do ED1 foi medida no projeto através de ferramenta CAD, considerando a altura do pé-direito como 2,6 m. Além disso, para se obter a área líquida de alvenaria, foram descontadas as áreas de vãos das esquadrias com base nas seguintes dimensões:

- janela dos banheiros: $0(0,6 \times 0,6) \mathrm{m}$;

- janela das cozinhas: $(1,2 \times 1,2) \mathrm{m}$;

- janela dos dormitórios: $(1,2 \times 1,2) \mathrm{m}$;

- janela das salas: $(1,5 \times 1,2) \mathrm{m}$;

- porta dos banheiros: $(0,7 \times 2,1) \mathrm{m}$;

- porta dos dormitórios: $(0,8 \times 2,1) \mathrm{m}$;

- porta das salas: $(0,9 \times 2,1) \mathrm{m}$;

- porta dos elevadores: $(1,0 \times 2,1) \mathrm{m}$.

É importante salientar que, de acordo com a concepção feita para o ED1, há paredes de gesso acartonado que não foram contabilizadas como quantidade de serviço, por não serem de alvenaria estrutural. Tais paredes podem ser identificadas na planta da Figura 5.1 pela cor verde que possuem.

O Quadro 5.3 mostra a área líquida total de paredes de alvenaria estrutural do ED1, bom como a relação deste valor com a área do pavimento.

Quadro 5.3 - Quantidade de serviço (área líquida de paredes estruturais) do pavimento tipo para ED1

\begin{tabular}{|c|c|c|c|}
\hline $\begin{array}{c}\text { Área líquida de paredes } \\
\text { estruturais para } \\
\text { pavimento tipo - QS } \\
\left(\mathrm{m}^{2}\right)\end{array}$ & $\begin{array}{c}\text { Área líquida de } \\
\text { paredes } \\
\text { estruturais para o } \\
\text { edifício - QS }\left(\mathrm{m}^{2}\right)\end{array}$ & $\begin{array}{c}\text { Área da } \\
\text { edificação } \\
\mathrm{A}\left(\mathrm{m}^{2}\right)\end{array}$ & $\begin{array}{c}\text { Quantidade de } \\
\text { paredes estruturais } \\
\text { pela área construída - } \\
\text { QS } / \mathrm{A}\left(\mathrm{m}^{2} / \mathrm{m}^{2}\right)\end{array}$ \\
\hline 745,34 & $10.434,76$ & $5.878,88$ & 1,78 \\
\hline
\end{tabular}


De acordo com o Capítulo 3, o fator que compara a quantidade de paredes estruturais, do edifício a ser analisado com o tomado como referência, é calculado a partir da Eq. 5.1.

$$
F Q \operatorname{Ser} v=\frac{\left(\frac{Q S e r v}{A}\right)_{E D 1}}{\left(\frac{Q S e r v}{A}\right)_{E D 0}}
$$

onde:

FQServ = fator de conversão relacionado com a quantidade de serviço;

$(\text { QServ/A })_{E D 1}=$ quantidade de serviço por área de construção da edificação a ter custo prognosticado;

$(\text { QServ/A })_{\text {EDo }}=$ quantidade serviço por área de construção da edificação com custo já definido e tomado como referência.

Como $(\mathrm{QS} / \mathrm{A})_{\mathrm{ED} 1}=1,78$ e $(\mathrm{QS} / \mathrm{A})_{\mathrm{ED} 0}=1,70$ (Quadro 5.2):

- $F Q S e r v=1,05$

O fator de quantidade de serviço indica que o edifício a ter o custo estimado (ED1) possui $5 \%$ de paredes estruturais por $\mathrm{m}^{2}$ de pavimento a mais que 0 empreendimento de referência (ED0).

\subsection{Custo unitário do serviço}

Esta parcela é composta pelos recursos:

- materiais: blocos estruturais, argamassa, graute e armação;

- mão-de-obra. 
De acordo com o orçamento de ED0, os custos de materiais e mão-de-obra são aqueles apresentados no Quadro 5.4.

Quadro 5.4 - Custos dos insumos do ED0 (base de out/2010)

\begin{tabular}{|l|c|}
\hline \multicolumn{1}{|c|}{ Insumos } & $\begin{array}{c}\text { Custo } \\
\left(\mathrm{R} \$ / \mathrm{m}^{2} \text { parede estrutural }\right)\end{array}$ \\
\hline Blocos & 29,38 \\
\hline Argamassa & 2,27 \\
\hline Graute & 2,95 \\
\hline Armação & 2,48 \\
\hline Total materiais & $\mathbf{3 7 , 0 8}$ \\
\hline Mão-de-obra terceirizada & $\mathbf{2 5 , 0 0}$ \\
\hline
\end{tabular}

\subsubsection{Subfator de custo unitário ligado aos materiais}

Este subfator leva em conta os seguintes materiais que compõem a alvenaria estrutural:

- blocos estruturais;

- $\quad$ argamassa de assentamento;

- graute;

- armação.

\subsubsection{BLOCOS ESTRUTURAIS}

Com base na estimativa proposta por Franco (Apêndice A), primeiramente se estimou a quantidade de blocos canaletas para, posteriormente se estimar a quantidade de blocos, por tipo.

A quantidade de blocos canaletas foi definida a partir dos locais com graute horizontal. De acordo com Franco (Apêndice A), são previstas canaletas na última 
fiada das paredes, como ligação entre estas e a laje; e em vergas de portas e janelas e contravergas de janelas.

Assim, para um pavimento, medindo-se linearmente as paredes estruturais, obtevese o comprimento total de $319,46 \mathrm{~m}$ de blocos canaletas atuando como cinta superior. Com relação às vergas e contravergas, somando-se o comprimento de portas (verga) e 2 vezes o comprimento de janelas (verga e contraverga) e, considerando que cada verga/contraverga possua $20 \mathrm{~cm}$ do elemento inserido na parede (para se ter obter maior resistência do elemento), estimou-se comprimento de canaletas para estes elementos igual a 139,4 m.

Somando-se os comprimentos de canaleta, têm-se 458,86m. Considerando, ainda, que estes elementos possuam comprimento unitário de $40 \mathrm{~cm}$, obtém-se uma quantidade de 1.148 unidades de blocos canaletas inteiras $(39 \times 19) \mathrm{cm}$ por andar.

Para estimar a quantidade dos blocos, utilizou-se a distribuição de quantidades de blocos apresentadas por Franco (Apêndice A), como mostra o Quadro 5.5.

Quadro 5.5 - Distribuição percentual de componentes de blocos estruturais, sem considerar as canaletas

\begin{tabular}{|c|c|c|c|c|c|c|}
\hline Componente & Bloco 39 & $\begin{array}{c}\text { Meio } \\
\text { Bloco }\end{array}$ & $\begin{array}{c}\text { Bloco } 34 \\
\mathrm{~cm}\end{array}$ & $\begin{array}{c}\text { bloco } 54 \\
\mathrm{~cm}\end{array}$ & $\begin{array}{c}\text { com } 4 \\
\mathrm{~cm}\end{array}$ & $\begin{array}{c}\text { comp } 9 \\
\mathrm{~cm}\end{array}$ \\
\hline Dimensões & $\begin{array}{c}14 \times 39 \times 19 \\
\mathrm{~cm}\end{array}$ & $\begin{array}{c}14 \times 19 \times 19 \\
\mathrm{~cm}\end{array}$ & $\begin{array}{c}14 \times 34 \times 19 \\
\mathrm{~cm}\end{array}$ & $\begin{array}{c}14 \times 54 \times 19 \\
\mathrm{~cm}\end{array}$ & $\begin{array}{c}14 \times 4 \times 19 \\
\mathrm{~cm}\end{array}$ & $\begin{array}{c}14 \times 9 \times 19 \\
\mathrm{~cm}\end{array}$ \\
\hline $\begin{array}{c}\% \text { na alvenaria } \\
\text { estrutural }\end{array}$ & $81,8 \%$ & $5,7 \%$ & $6,8 \%$ & $4,6 \%$ & $0,8 \%$ & $0,3 \%$ \\
\hline $\begin{array}{c}\text { Área de um bloco } \\
\left(\mathrm{m}^{2}\right)\end{array}$ & 0,08 & 0,04 & 0,07 & 0,11 & 0,01 & 0,02 \\
\hline
\end{tabular}

Sabendo-se que a área líquida de paredes estruturais em um pavimento é de $745,34 \mathrm{~m}^{2}$, e que a área dos blocos canaletas é de $91,84 \mathrm{~m}^{2}$ (igual a 1.148 blocos canaleta multiplicados pela área de uma canaleta de 0,08 $\left.\mathrm{m}^{2}\right)$, tem-se que a área dos demais blocos é de $653,5 \mathrm{~m}^{2}$ em um pavimento.

Multiplicando o valor da distribuição percentual do Quadro 5.5 de cada bloco pela área de $653,5 \mathrm{~m}^{2}$, obteve-se a área destinada a cada elemento. Para se estimar a quantidade de blocos por tipo, dividiu-se tais áreas pela seção longitudinal de cada bloco (altura x comprimento). Os resultados são mostrados na Tabela 5.2. 
Tabela 5.2 - Estimativa de quantidade de blocos

\begin{tabular}{|c|c|c|c|c|c|c|}
\hline Componente & $\begin{array}{c}\text { Bloco } \\
39\end{array}$ & $\begin{array}{c}\text { Meio } \\
\text { Bloco }\end{array}$ & $\begin{array}{c}\text { Bloco } \\
34 \mathrm{~cm}\end{array}$ & $\begin{array}{c}\text { bloco } 54 \\
\mathrm{~cm}\end{array}$ & $\begin{array}{c}\text { com } 4 \\
\mathrm{~cm}\end{array}$ & $\begin{array}{c}\text { comp } 9 \\
\mathrm{~cm}\end{array}$ \\
\hline Dimensões & $\begin{array}{c}14 \times 39 \times 1 \\
9 \mathrm{~cm}\end{array}$ & $\begin{array}{c}14 \times 19 \times 1 \\
9 \mathrm{~cm}\end{array}$ & $\begin{array}{c}14 \times 34 \times 1 \\
9 \mathrm{~cm}\end{array}$ & $\begin{array}{c}14 \times 54 \times 1 \\
9 \mathrm{~cm}\end{array}$ & $\begin{array}{c}14 \times 4 \times 1 \\
9 \mathrm{~cm}\end{array}$ & $\begin{array}{c}14 \times 9 \times 1 \\
9 \mathrm{~cm}\end{array}$ \\
\hline$\%$ na alvenaria estrutural & $81,8 \%$ & $5,7 \%$ & $6,8 \%$ & $4,6 \%$ & $0,8 \%$ & $0,3 \%$ \\
\hline Área de um bloco $\left(\mathrm{m}^{2}\right)$ & 0,08 & 0,04 & 0,07 & 0,11 & 0,01 & 0,02 \\
\hline $\begin{array}{c}\text { Área estimada para cada tipo } \\
\text { de bloco }\left(\mathrm{m}^{2}\right)\end{array}$ & 534,56 & 37,25 & 44,44 & 30,06 & 5,23 & 1,96 \\
\hline $\begin{array}{c}\text { Quantidade de blocos por } \\
\text { andar (unidades) }\end{array}$ & $\mathbf{6 6 8 2}$ & $\mathbf{9 3 1}$ & $\mathbf{6 3 4}$ & $\mathbf{2 7 3}$ & $\mathbf{5 2 2}$ & $\mathbf{9 8}$ \\
\hline
\end{tabular}

Para se calcular o custo dos blocos, deve-se, ainda, verificar a sua resistência. Foi verificado no Capítulo 4 que, nos quatro últimos andares de um edifício, a resistência dos blocos será de $4 \mathrm{MPa}$ (limitação da norma ABNT NBR 15961, 2011), aumentando $1 \mathrm{MPa}$ a cada pavimento imediatamente abaixo ou utilizando $\mathrm{f}_{\mathrm{bk}}$ maior ou igual ao estimado, de acordo com a oferta de blocos por fabricantes no local de execução.

Como o ED1 possui apenas 14 pavimentos, o $\mathrm{f}_{\mathrm{bk}}$ varia do seguinte modo:

- $1^{\circ}$ ao $2^{\circ}$ andares: $f_{b k}=14 \mathrm{MPa}$;

- $3^{\circ}$ ao $4^{\circ}$ andares: $f_{b k}=12 \mathrm{MPa}$;

- $5^{\circ}$ ao $6^{\circ}$ andares: $\mathrm{f}_{\mathrm{bk}}=10 \mathrm{MPa}$;

- $7^{\circ}$ ao $8^{\circ}$ andares: $\mathrm{f}_{\mathrm{bk}}=8 \mathrm{MPa}$;

- $9^{\circ}$ ao $10^{\circ}$ andares: $\mathrm{f}_{\mathrm{bk}}=6 \mathrm{MPa}$;

- $11^{\circ}$ ao $14^{\circ}$ andares: $\mathrm{f}_{\mathrm{bk}}=4 \mathrm{MPa}$.

Para o cálculo de perdas de blocos, foram considerados os seguintes fatores:

- espessura do bloco $=14 \mathrm{~cm}$;

- não será feita quantificação de blocos necessários por pavimento;

- existe projeto de alvenaria; 
- os blocos não serão cortados;

- existirá controle de recebimento;

- são utilizadas peças auxiliares para modulação;

- existência de procedimentos de controle e execução;

- não serão utilizados pedaços de blocos para outras atividades;

- o transporte será feito com páletes.

De acordo com a metodologia de Souza (2001), a perda prevista para os blocos é calculada pela Eq. 5.2.

Perda Pr evista $=$ Min $_{\text {faixa }}+\frac{\sum \text { Pesos }}{10} \times\left(\right.$ Máx $_{\text {faixa }}-$ Mín $\left._{\text {faixa }}\right)$

onde:

Perda prevista $=$ valor da perda $(\mathrm{em} \%)$;

Mín $_{\text {faixa }}=$ valor mínimo da faixa, conforme Quadro 5.6;

Máx faixa $_{\text {= }}$ valor máximo da faixa, conforme Quadro 5.6;

$\Sigma$ Pesos = somatória de todos os pesos, conforme Quadro 5.7.

Quadro 5.6 - Faixas de variação de perdas de blocos (SOUZA, 2001)

\begin{tabular}{|c|c|c|c|c|c|c|}
\hline \multirow{2}{*}{$\begin{array}{l}\text { Função } \\
\text { da } \\
\text { alvenaria }\end{array}$} & \multirow{2}{*}{$\begin{array}{l}\text { Formato } \\
\text { do bloco }\end{array}$} & \multirow{2}{*}{\multicolumn{2}{|c|}{ Forma de transporte }} & \multicolumn{3}{|c|}{ Faixa de variação } \\
\hline & & & & mínimo & mediana & máxima \\
\hline \multirow{6}{*}{$\begin{array}{c}\text { Parade } \\
\text { Estrutural }\end{array}$} & \multirow{3}{*}{ Canaleta } & \multicolumn{2}{|r|}{ páletes } & 8 & 18 & 20 \\
\hline & & \multirow{2}{*}{$\begin{array}{c}\text { unidades } \\
\text { soltas }\end{array}$} & carrinho específico & 10 & 20 & 23 \\
\hline & & & outras & 15 & 25 & 40 \\
\hline & \multirow{3}{*}{$\begin{array}{c}1 / 2 \\
\text { bloco; } \\
\text { inteiros }\end{array}$} & \multirow{3}{*}{$\begin{array}{l}\text { unidades } \\
\text { soltas }\end{array}$} & páletes & 0 & 1 & 3 \\
\hline & & & carrinho específico & 1 & 3 & 5 \\
\hline & & & outras & 2 & 5 & 8 \\
\hline
\end{tabular}


Quadro 5.7 - Pesos associados a outros fatores influenciadores (SOUZA, 2001)

\begin{tabular}{|c|c|c|}
\hline \multicolumn{2}{|l|}{ Fatores } & Pesos \\
\hline \multirow{2}{*}{$\begin{array}{l}\text { A espessura é superior a } 10 \\
\mathrm{~cm} \text { ? }\end{array}$} & Sim & 0,0 \\
\hline & Não & 1,0 \\
\hline \multirow{2}{*}{$\begin{array}{l}\text { É feita a quantificação de } \\
\text { blocos necessários por } \\
\text { pavimento? }\end{array}$} & Sim & 0,0 \\
\hline & Não & 1,5 \\
\hline \multirow{2}{*}{ Existe Projeto de alvenaria? } & Sim & 0,0 \\
\hline & Não & 1,5 \\
\hline \multirow{2}{*}{$\begin{array}{l}\text { Os blocos são cortados } \\
\text { mecanicamente? }\end{array}$} & Sim & 0,0 \\
\hline & Não & 1,5 \\
\hline \multirow{2}{*}{$\begin{array}{l}\text { Existe controle de } \\
\text { recebimento? }\end{array}$} & Sim & 0,0 \\
\hline & Não & 1,0 \\
\hline \multirow{2}{*}{$\begin{array}{l}\text { Existem peças auxiliares para } \\
\text { modulação? }\end{array}$} & Sim & 0,0 \\
\hline & Não & 1,5 \\
\hline \multirow{2}{*}{$\begin{array}{l}\text { Existem procedimentos de } \\
\text { execução/ controle? }\end{array}$} & Sim & 0,0 \\
\hline & Não & 1,0 \\
\hline \multirow{2}{*}{$\begin{array}{l}\text { Pedaços de blocos (cacos) } \\
\text { são utilizados em outras } \\
\text { atividades? }\end{array}$} & Sim & 1,0 \\
\hline & Não & 0,0 \\
\hline
\end{tabular}

Nota-se que a soma dos pesos para o empreendimento em estudo resulta em 1,5, pois considerou-se que não é feita a quantificação de blocos por pavimento.

Para os blocos canaleta, o valor de perda é dado por:

- Perda prevista $=8+1,5 / 10 \times(20-8)=9,80 \%$

Para os blocos inteiros e complementares, o valor de perda é dado por:

- Perda prevista $=0+1,5 / 10 \times(3-0)=0,45 \%$

Foram utilizados os custos unitários dos blocos, a partir do orçamento de ED0; as Tabelas 5.3 a 5.8 mostram o custo deste material para blocos do ED1 com resistência de $4 \mathrm{MPa}, 6 \mathrm{MPa}, 8 \mathrm{MPa}, 10 \mathrm{MPa}, 12 \mathrm{MPa}$ e $14 \mathrm{MPa}$. 
Tabela 5.3 - Custo de blocos estruturais com 4 MPa (ED1 - base out/2010)

\begin{tabular}{|c|c|c|c|c|c|}
\hline $\begin{array}{l}\text { BLOCOS DE CONCRETO } \\
\text { ESTRUTURAL 4MPa }\end{array}$ & Perdas & $\begin{array}{r}\text { Custo } \\
\text { Unitário } \\
\text { (R\$) }\end{array}$ & $\begin{array}{r}\text { Quantidade } \\
\text { blocos sem } \\
\text { perdas (unid) }\end{array}$ & $\begin{array}{r}\text { Quantidade } \\
\text { blocos com } \\
\text { perdas (unid) }\end{array}$ & $\begin{array}{r}\text { Custo } \\
\text { blocos }(\mathbf{R} \$)\end{array}$ \\
\hline Bloco-14 x $19 \times 19$ & $0,45 \%$ & 1,05 & $3.724,00$ & $3.740,76$ & $3.927,80$ \\
\hline Bloco-14 x $19 \times 34$ & $0,45 \%$ & 1,92 & $2.536,00$ & $2.547,41$ & $4.891,03$ \\
\hline Bloco-14 x $19 \times 39$ & $0,45 \%$ & 2,00 & $26.728,00$ & $26.848,28$ & $53.696,55$ \\
\hline Bloco-14 x $19 \times 54$ & $0,45 \%$ & 3,55 & $1.092,00$ & $1.096,91$ & $3.894,04$ \\
\hline Bloco-14 x $19 \times 9$ & $0,45 \%$ & 1,20 & 392,00 & 393,76 & 472,52 \\
\hline Bloco- $14 \times 19 \times 4$ & $0,45 \%$ & 0,60 & $2.088,00$ & $2.097,40$ & $1.258,44$ \\
\hline Canaleta- $14 \times 19 \times 39$ & $9,80 \%$ & 2,22 & $4.592,00$ & $5.042,02$ & $11.193,28$ \\
\hline \multicolumn{3}{|l|}{$\begin{aligned} \text { Total } \\
\end{aligned}$} & $41.152,00$ & $41.766,54$ & $79.333,65$ \\
\hline
\end{tabular}

Tabela 5.4 - Custo de blocos estruturais com 6 MPa (ED1 - base out/2010)

\begin{tabular}{|c|c|c|c|c|c|}
\hline $\begin{array}{l}\text { BLOCOS DE CONCRETO } \\
\text { ESTRUTURAL 6MPa }\end{array}$ & Perdas & $\begin{array}{r}\text { Custo } \\
\text { Unitário } \\
\text { (R\$) }\end{array}$ & $\begin{array}{r}\text { Quantidade } \\
\text { blocos sem } \\
\text { perdas (unid) }\end{array}$ & $\begin{array}{r}\text { Quantidade } \\
\text { blocos com } \\
\text { perdas (unid) }\end{array}$ & $\begin{array}{r}\text { Custo } \\
\text { blocos (R\$) }\end{array}$ \\
\hline Bloco-14 x $19 \times 19$ & $0,45 \%$ & 1,06 & $1.862,00$ & $1.870,38$ & $1.982,60$ \\
\hline Bloco-14 x $19 \times 34$ & $0,45 \%$ & 1,95 & $1.268,00$ & $1.273,71$ & $2.483,73$ \\
\hline Bloco-14 x $19 \times 39$ & $0,45 \%$ & 2,08 & $13.364,00$ & $13.424,14$ & $27.922,21$ \\
\hline Bloco-14 x $19 \times 54$ & $0,45 \%$ & 3,61 & 546,00 & 548,46 & $1.979,93$ \\
\hline Bloco-14 x $19 \times 9$ & $0,45 \%$ & 1,26 & 196,00 & 196,88 & 248,07 \\
\hline Bloco-14 x $19 \times 4$ & $0,45 \%$ & 0,63 & $1.044,00$ & $1.048,70$ & 660,68 \\
\hline Canaleta-14 x $19 \times 39$ & $9,80 \%$ & 2,23 & $2.296,00$ & $2.521,01$ & $5.621,85$ \\
\hline \multicolumn{3}{|l|}{ to } & $20.576,00$ & $20.883,27$ & $40.899,06$ \\
\hline
\end{tabular}

Tabela 5.5 - Custo de blocos estruturais com 8 MPa (ED1 - base de out/2010)

\begin{tabular}{|c|c|c|c|c|c|}
\hline $\begin{array}{c}\text { BLOCOS DE CONCRETO } \\
\text { ESTRUTURAL 8MPa }\end{array}$ & Perdas & $\begin{array}{r}\text { Custo } \\
\text { Unitário } \\
(\mathbf{R} \$) \\
\end{array}$ & $\begin{array}{r}\text { Quantidade } \\
\text { blocos sem } \\
\text { perdas (unid) }\end{array}$ & $\begin{array}{r}\text { Quantidade } \\
\text { blocos com } \\
\text { perdas (unid) }\end{array}$ & $\begin{array}{r}\text { Custo } \\
\text { blocos }(R \$)\end{array}$ \\
\hline Bloco-14 x $19 \times 19$ & $0,45 \%$ & 1,21 & $1.862,00$ & $1.870,38$ & $2.263,16$ \\
\hline Bloco-14 x $19 \times 34$ & $0,45 \%$ & 2,20 & $1.268,00$ & $1.273,71$ & $2.802,15$ \\
\hline Bloco-14 x $19 \times 39$ & $0,45 \%$ & 2,39 & $13.364,00$ & $13.424,14$ & $32.083,69$ \\
\hline Bloco-14 x $19 \times 54$ & $0,45 \%$ & 4,02 & 546,00 & 548,46 & $2.204,80$ \\
\hline Bloco-14 x $19 \times 9$ & $0,45 \%$ & 1,32 & 196,00 & 196,88 & 259,88 \\
\hline Bloco-14 x $19 \times 4$ & $0,45 \%$ & 0,66 & $1.044,00$ & $1.048,70$ & 692,14 \\
\hline Canaleta- 14 x 19 × 39 & $9,80 \%$ & 2,50 & $2.296,00$ & $2.521,01$ & $6.302,52$ \\
\hline \multicolumn{3}{|l|}{ Total } & $20.576,00$ & $20.883,27$ & $46.608,34$ \\
\hline
\end{tabular}


Tabela 5.6 - Custo de blocos estruturais com $10 \mathrm{MPa}$ (ED1 - base de out/2010)

\begin{tabular}{|c|c|c|c|c|c|}
\hline $\begin{array}{l}\text { BLOCOS DE CONCRETO } \\
\text { ESTRUTURAL 10MPa }\end{array}$ & Perdas & $\begin{array}{r}\text { Custo } \\
\text { Unitário } \\
\text { (R\$) }\end{array}$ & $\begin{array}{r}\text { Quantidade } \\
\text { blocos sem } \\
\text { perdas (unid) }\end{array}$ & $\begin{array}{r}\text { Quantidade } \\
\text { blocos com } \\
\text { perdas (unid) }\end{array}$ & $\begin{array}{r}\text { Custo } \\
\text { blocos }(R \$)\end{array}$ \\
\hline Bloco-14 x $19 \times 19$ & $0,45 \%$ & 1,35 & $1.862,00$ & $1.870,38$ & $2.525,01$ \\
\hline Bloco-14 x $19 \times 34$ & $0,45 \%$ & 2,43 & $1.268,00$ & $1.273,71$ & $3.095,11$ \\
\hline Bloco-14 x $19 \times 39$ & $0,45 \%$ & 2,66 & $13.364,00$ & $13.424,14$ & $35.708,21$ \\
\hline Bloco-14 x $19 \times 54$ & $0,45 \%$ & 4,46 & 546,00 & 548,46 & $2.446,12$ \\
\hline Bloco-14 x $19 \times 9$ & $0,45 \%$ & 1,38 & 196,00 & 196,88 & 271,70 \\
\hline Bloco-14 x $19 \times 4$ & $0,45 \%$ & 0,69 & $1.044,00$ & $1.048,70$ & 723,60 \\
\hline Canaleta- $14 \times 19 \times 39$ & $9,80 \%$ & 2,78 & $2.296,00$ & $2.521,01$ & $7.008,40$ \\
\hline \multicolumn{3}{|l|}{$\begin{array}{ll}\text { Total } \\
\end{array}$} & $20.576,00$ & $20.883,27$ & $51.778,14$ \\
\hline
\end{tabular}

Tabela 5.7 - Custo de blocos estruturais com 12 MPa (ED1 - base de out/2010)

\begin{tabular}{|c|c|c|c|c|c|}
\hline $\begin{array}{l}\text { BLOCOS DE CONCRETO } \\
\text { ESTRUTURAL 12MPa }\end{array}$ & Perdas & $\begin{array}{r}\text { Custo } \\
\text { Unitário } \\
\text { (R\$) }\end{array}$ & $\begin{array}{r}\text { Quantidade } \\
\text { blocos sem } \\
\text { perdas (unid) }\end{array}$ & $\begin{array}{r}\text { Quantidade } \\
\text { blocos com } \\
\text { perdas (unid) }\end{array}$ & $\begin{array}{r}\text { Custo } \\
\text { blocos }(R \$)\end{array}$ \\
\hline Bloco-14 x $19 \times 19$ & $0,45 \%$ & 1,41 & $1.862,00$ & $1.870,38$ & $2.637,23$ \\
\hline Bloco-14 x $19 \times 34$ & $0,45 \%$ & 2,63 & $1.268,00$ & $1.273,71$ & $3.349,85$ \\
\hline Bloco-14 x $19 \times 39$ & $0,45 \%$ & 2,98 & $13.364,00$ & $13.424,14$ & $40.003,93$ \\
\hline Bloco- $14 \times 19 \times 54$ & $0,45 \%$ & 4,95 & 546,00 & 548,46 & $2.714,86$ \\
\hline Bloco-14 x $19 \times 9$ & $0,45 \%$ & 1,68 & 196,00 & 196,88 & 330,76 \\
\hline Bloco- $14 \times 19 \times 4$ & $0,45 \%$ & 0,84 & $1.044,00$ & $1.048,70$ & 880,91 \\
\hline Canaleta- $14 \times 19 \times 39$ & $9,80 \%$ & 3,35 & $2.296,00$ & $2.521,01$ & $8.445,38$ \\
\hline \multicolumn{3}{|l|}{$\begin{array}{ll}\text { Total } \\
\end{array}$} & $20.576,00$ & $20.883,27$ & $58.362,92$ \\
\hline
\end{tabular}

Tabela 5.8 - Custo de blocos estruturais com 14 MPa (ED1 - base de out/2010)

\begin{tabular}{|c|c|c|c|c|c|}
\hline $\begin{array}{c}\text { BLOCOS DE CONCRETO } \\
\text { ESTRUTURAL } 14 \mathrm{MPa}\end{array}$ & Perdas & $\begin{array}{r}\text { Custo } \\
\text { Unitário } \\
\text { (R\$) } \\
\end{array}$ & $\begin{array}{r}\text { Quantidade } \\
\text { blocos sem } \\
\text { perdas (unid) }\end{array}$ & $\begin{array}{r}\text { Quantidade } \\
\text { blocos com } \\
\text { perdas (unid) }\end{array}$ & $\begin{array}{r}\text { Custo } \\
\text { blocos }(R \$)\end{array}$ \\
\hline Bloco-14 x $19 \times 19$ & $0,45 \%$ & 1,66 & $1.862,00$ & $1.870,38$ & $3.104,83$ \\
\hline Bloco-14 x $19 \times 34$ & $0,45 \%$ & 2,94 & $1.268,00$ & $1.273,71$ & $3.744,70$ \\
\hline Bloco-14 x $19 \times 39$ & $0,45 \%$ & 3,25 & $13.364,00$ & $13.424,14$ & $43.628,45$ \\
\hline Bloco-14 x $19 \times 54$ & $0,45 \%$ & 5,24 & 546,00 & 548,46 & $2.873,91$ \\
\hline Bloco-14 x $19 \times 9$ & $0,45 \%$ & 1,84 & 196,00 & 196,88 & 362,26 \\
\hline Bloco-14 x $19 \times 4$ & $0,45 \%$ & 0,92 & $1.044,00$ & $1.048,70$ & 964,80 \\
\hline Canaleta-14 x $19 \times 39$ & $9,80 \%$ & 3,40 & $2.296,00$ & $2.521,01$ & $8.571,43$ \\
\hline \multicolumn{3}{|l|}{ Total } & $20.576,00$ & $20.883,27$ & $63.250,38$ \\
\hline
\end{tabular}


A Tabela 5.9 resume o custo total de blocos, bem como mostra o custo por $\mathrm{m}^{2}$ de alvenaria, sabendo-se que, de acordo com o Quadro 5.3, há $10.434,76 \mathrm{~m}^{2}$ de paredes de alvenaria.

Tabela 5.9 - Custos de blocos estruturais para ED1 (base de out/2010)

\begin{tabular}{|c|c|}
\hline Custo blocos $4 \mathrm{MPa}(\mathrm{R} \$)$ & $79.333,65$ \\
\hline Custo blocos $6 \mathrm{MPa}(\mathrm{R} \$)$ & $40.899,06$ \\
\hline Custo blocos 8MPa $(\mathrm{R} \$)$ & $46.608,34$ \\
\hline Custo blocos 10MPa $(\mathrm{R} \$)$ & $51.778,14$ \\
\hline Custo blocos 12MPa (R\$) & $58.362,92$ \\
\hline Custo blocos 14MPa $(\mathrm{R} \$)$ & $63.250,38$ \\
\hline Custo blocos (R\$) & $340.232,49$ \\
\hline Área alvenaria $\left(\mathrm{m}^{2}\right)$ & $10.434,76$ \\
\hline Custo blocos/ A alvenaria $\left(\mathrm{R} \$ / \mathrm{m}^{2}\right)$ & 32,61 \\
\hline
\end{tabular}

Como o custo de blocos estruturais do ED0 é de $\mathrm{R} \$ 29,38 / \mathrm{m}^{2}$ (Quadro 5.4), a relação (CustoMAT blocos $/ Q S e r v)_{\text {ED1 }}$ ( (CustoMAT $\left.T_{\text {blocos }} / Q S e r v\right)_{\text {EDo }}$ é igual:

- $32,61 / 29,38=1,11$

O valor de 1,11 indica que o custo de blocos $/ \mathrm{m}^{2}$ de parede estrutural do edifício a ter o custo estimado (ED0) é 11\% mais caro que o do empreendimento de referência (ED1). Esta variação se deve, principalmente, a:

- custo de componentes maiores com a elevação da resistência do bloco que, por sua vez, é tanto maior quanto mais alto é o edifício e, como o ED1 é mais alto que o EDO, seu custo por parede estrutural é maior.

\subsubsection{ARGAMASSA}

De acordo com a ABNT NBR 10837 (1989), a resistência à compressão mínima da argamassa de assentamento $\left(f_{a k}\right)$ é de $5 \mathrm{MPa}$. A norma atual de cálculo de alvenaria estrutural (ABNT NBR 15961, 2011) indica que o valor máximo para argamassa de assentamento é de 0,7 o valor de $f_{b k}$. 
Como o orçamento disponível do ED0 possui custos de argamassa com 5 e $7 \mathrm{MPa}$, as especificações de argamassa por andar, considerando as resistências de blocos, são:

- $\quad$ andares com blocos de 4 a $8 \mathrm{MPa}: \mathrm{f}_{\mathrm{ak}}=5 \mathrm{MPa}$;

- $\quad$ andares com blocos de 10 a $14 \mathrm{MPa}: \mathrm{f}_{\mathrm{ak}}=7 \mathrm{MPa}$;

O consumo de argamassa, considerando as perdas, foi estimado a partir da Eq. 5.3 (SOUZA, 2001).

$$
\frac{Q \arg \text { amassa }}{\text { Qparedes }}=\frac{\text { Qjuntas }_{\text {Qparedes }}}{\text { Qponsumo }} \times \frac{\text { aplicaşão }_{\text {Qjuntas }}}{\text { Qje }} \times\left(1+\frac{\Delta \text { Perdas }_{(\%)}}{100}\right)
$$

onde:

Qargamassa/Qalvenaria $=$ consumo unitário de argamassa $\left(1 / \mathrm{m}^{2}\right)$;

Qjuntas/Qalvenaria $=$ quantidades de juntas $(\mathrm{em} \mathrm{m})$ em relação a área de paredes estruturais;

Consumoaplicação/Qjuntas = consumo de argamassa em I/m;

$\Delta$ Perdas $=$ perdas em porcentagem.

A junta é a ligação entre dois blocos, nas quatro laterais. Sabendo-se que a junta é a mesma para os blocos justapostos, o comprimento deste filete argamassado é igual a soma dos perimetrais das superfícies argamassadas dos blocos dividido por dois. Utilizando a estimativa da quantidade de cada tipo de bloco feito no item 5.2.1.1, calculou-se um total de $80.972,5 \mathrm{~m}$ de juntas. Porém, como a especificação da argamassa varia de acordo com a resistência dos blocos, estimaram-se:

- $46.270 \mathrm{~m}$ de juntas argamassadas de $5 \mathrm{MPa}$;

- $\quad 34.702,5 \mathrm{~m}$ de juntas argamassadas de $7 \mathrm{MPa}$; 
Sabendo que a aplicação de argamassa em ED1 será feita com colher de pedreiro (Peso $=11$, Quadro 5.8), o valor do consumo na aplicação foi calculado utilizando a Eq. 5.4.

Quadro 5.8 - Pesos relativos a diferentes realizações dos fatores influenciadores (SOUZA; 2001)

\begin{tabular}{|r|c|c|c|c|}
\hline Juntas verticais preenchidas & \multicolumn{2}{|c|}{ Todas } & \multicolumn{2}{c|}{ Não todas } \\
\hline $\begin{array}{r}\text { Ferramenta de } \\
\text { aplicação }\end{array}$ & Colher & $\begin{array}{r}\text { Tabuinha/ } \\
\text { Bisnaga/ } \\
\text { Direção dos } \\
\text { furos dos blocos }\end{array}$ & Colher & $\begin{array}{c}\text { Tabuinha/ } \\
\text { Bisnaga/ } \\
\text { meia-cana }\end{array}$ \\
\hline Vertical & 12 & 6 & 11 & 5 \\
\hline Horizontal & 10 & 4 & 9 & 3 \\
\hline Sem furos & 8 & 2 & 7 & 1 \\
\hline
\end{tabular}

$$
\frac{\text { consumo }_{\text {aplicą̧ão }}}{\text { Qjuntas }}=0,7+0,18 \times \text { Peso } \pm 0,18=0,7+0,18 \times 11+0,18=2,86 \mathrm{l} / \mathrm{m}
$$

O cálculo de perdas foi feito considerando as seguintes premissas:

- dosagem em obra com procedimento adequado;

- transporte com equipamento adequado;

- projeto arquitetônico completamente definido.

Deste modo, somando o $\Delta$ Perdas do Quadro 5.9, tem-se o valor de 5.

Quadro 5.9 - $\Delta$ perdas associadas a outros fatores (SOUZA; 2001)

\begin{tabular}{|c|c|c|}
\hline \multicolumn{2}{|c|}{ Fatores } & $\begin{array}{c}\Delta \\
\text { Perdas }\end{array}$ \\
\hline \multirow{2}{*}{ Dosagem na obra? } & Não & 0,0 \\
\cline { 2 - 3 } & $\begin{array}{c}\text { Sim, com procedimento } \\
\text { adequado }\end{array}$ & 5,0 \\
\cline { 2 - 3 } & Sim, sem procedimento & 10,0 \\
\hline \multirow{2}{*}{ Transporte com equipamento inadequado? } & adequado & 0,0 \\
\cline { 2 - 3 } & Não & 20,0 \\
\hline Projeto arquitetônico completamente & Sim & 15,0 \\
\cline { 2 - 3 } definido? & Não & 0,0 \\
\hline
\end{tabular}


Para o cálculo do custo de argamassa, utilizou-se o custo unitário deste insumo baseado no orçamento de ED0 (out/2010), sendo que os valores são:

- custo unitário de argamassa com $5 \mathrm{MPa}=157,24$ reais $/ \mathrm{m}^{3}$ de argamassa;

- custo unitário de argamassa com $7 \mathrm{MPa}=166,89$ reais $/ \mathrm{m}^{3}$ de argamassa;

Com base nestes dados, o custo de argamassa por área de parede estrutural é:

- $\frac{\text { CustoMAT arg }}{\text { QServ }}=\frac{(\text { CustoMAT arg })_{5 M P a}+(\text { CustoMAT arg })_{7 M P a}}{\text { Qparedes }}$

Sabendo que o custo unitário é dado por $\mathrm{m}^{3}$ e que a Eq. 5.3 fornece consumo em I, os cálculos de custos de argamassa para cada resistência levaram em consideração a transformação de I para $\mathrm{m}^{3}$ (divisão por 1000), obtendo-se os seguintes valores:

- CustoMAT arg $=\frac{\text { CustoMAT } \arg }{Q \arg \text { amassa }} \times \frac{\left(\text { Qjuntas } \times \frac{\text { consumo }_{\text {aplicas̆äo }}}{\text { Qjuntas }} \times\left(1+\frac{\Delta \text { Perdas }_{(\%)}}{100}\right)\right)}{1000}$

- para a argamassa com 5MPa:

$$
\text { - CustoMAT } \arg _{5 M P a}=157,24 \times \frac{46.270,00 \times 2,86 \times\left(1+\frac{5}{100}\right)}{1000}=21.848,31 \text { reais }
$$

- para a argamassa com 7MPa:

$$
\text { ○CustoMAT } \arg _{7 M P a}=166,89 \times \frac{34.702,50 \times 2,86 \times\left(1+\frac{5}{100}\right)}{1000}=17.391,88 \text { reais }
$$

Deste modo, o custo deste insumo por área de alvenaria estrutural é dado por:

- $\quad \frac{\text { CustoMAT arg }}{\text { QServ }}=\frac{21.848,31+17.391,88}{10.434,76}=3,76$ reais $/ \mathrm{m}^{2}$ de alvenaria estrutural 
Sabendo que o custo de argamassa por $\mathrm{m}^{2}$ de alvenaria do ED0 é de 2,27 reais por

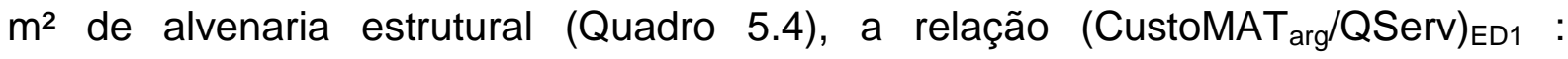
(CustoMAT $_{\text {arg }} /$ QServ $)_{\text {EDo }}$ é igual:

\section{- $3,76 / 2,27=1,65$}

O valor de 1,65 indica que o custo de argamassa $/ \mathrm{m}^{2}$ de parede estrutural do edifício a ter o custo estimado (ED1) é $65 \%$ maior que o do empreendimento de referência (ED0). Esta variação se deve, principalmente a:

- custo maior de argamassa com a elevação de sua resistência, que varia com a resistência dos blocos, que, por sua vez, é tanto maior quanto mais alto é o edifício e, como o ED1 é mais alto que o ED0, seu custo por parede estrutural é maior;

- maior consumo de argamassa por área de alvenaria do ED1, que pode ser explicada pelo tipo de ferramenta utilizada no assentamento, já que o ED0 especificou assentamento com bisnaga que, de acordo com Quadro 4.8, resulta em menor consumo na aplicação.

\subsubsection{GRAUTE}

A especificação de resistência para graute, de acordo com a ABNT NBR 10837 (1989), é que o $f_{g k} \geq 2 f_{b k}$. Porém, a ABNT NBR 15961 (2011) estabelece $15 \mathrm{MPa}$ como o valor mínimo de resistência de graute. Deste modo, o $\mathrm{f}_{\mathrm{gk}}$ do projeto ED1 varia do seguinte modo:

- $1^{\circ}$ ao $2^{\circ}$ andar: $\mathrm{f}_{\mathrm{gk}}=30 \mathrm{MPa}$;

- $3^{\circ}$ ao $4^{\circ}$ andar: $\mathrm{f}_{\mathrm{gk}}=25 \mathrm{MPa}$;

- $5^{\circ}$ ao $8^{\circ}$ andar: $\mathrm{f}_{\mathrm{gk}}=20 \mathrm{MPa}$;

- $9^{\circ}$ ao $14^{\circ}$ andar: $f_{g k}=15 \mathrm{MPa}$. 
O consumo de graute horizontal foi estimado a partir da quantidade de canaletas definida no item 5.2.1.1, igual a 1.148 unidades por piso, com dimensões de

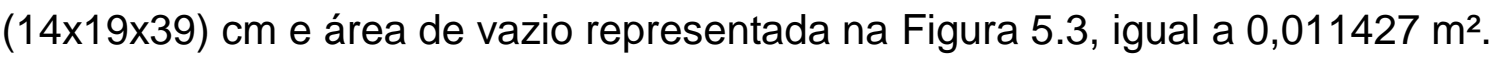

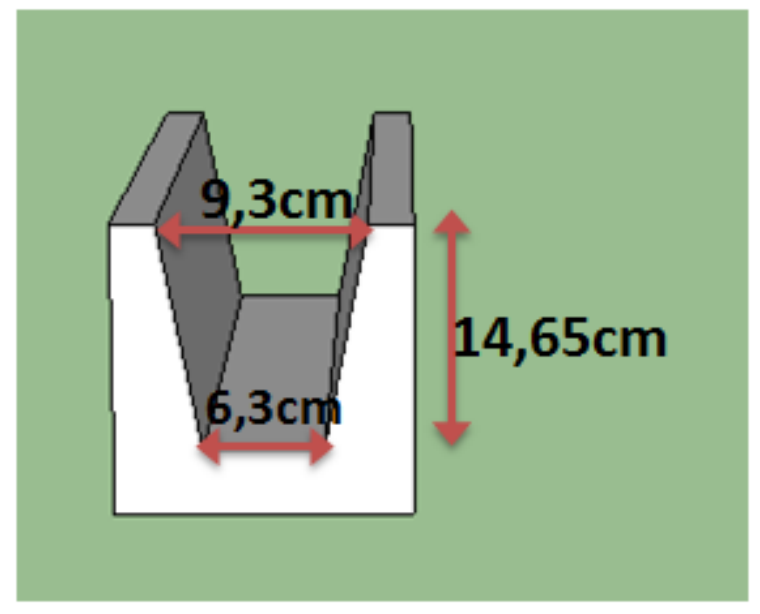

Figura 5.3 - Dimensões da seção de vazio da canaleta

Sabendo que o comprimento de cada bloco é de $40 \mathrm{~cm}$, o volume de graute horizontal para um piso é:

- Vol graute horizontal/ piso $=0,011427 \times 0,4 \times 1.148,0=5,25 \mathrm{~m}^{3} /$ piso

De acordo com Franco (Apêndice A), a quantidade de pontos de graute verticais é dada pela soma de pontos ligados ao fator construtivo $(\mathrm{Q} 0)$ e de pontos ligados a esforços horizontais de vento $(\mathrm{Qv})$.

Como o edifício analisado possui 14 andares, de acordo com o Quadro 5.10, a quantidade de Q0 é dada por 0,12 x área construída do andar, ou seja, Q0 por andar é igual a $0,12 \times 419,92=50,39$ pontos de graute.

Quadro 5.10 - Indicadores de quantidade de graute vertical Q0

\begin{tabular}{|c|c|}
\hline Pavimentos & $\begin{array}{c}\text { Q0 - Quantidade de grautes por } \\
\text { área construída }\left(\mathrm{un} / \mathrm{m}^{2}\right)\end{array}$ \\
\hline de 4 a 8 pavimentos & 0,065 \\
\hline de 9 a 12 pavimentos & 0,100 \\
\hline de 13 a 16 pavimentos & 0,120 \\
\hline
\end{tabular}


A quantidade de pontos de graute devido ao vento $(Q v)$ é estimada por pavimento, apenas do $1^{\circ}$ ao $6^{\circ}$ andar, pois, de acordo com Franco (Apêndice A), nos últimos 8 andares considera-se apenas o Q0.

De acordo com o projetista, Qv é dada pelo cálculo da Eq. 5.5.

$$
Q_{v}=\frac{0,000007 \times V_{0}{ }^{2} \times H^{3} \times L_{\text {Fachada }}}{\sum I}
$$

onde:

$Q_{v}=$ quantidade de grautes verticais devido a esforços de vento (em und.);

$\mathrm{V}_{0}=$ velocidade básica do vento em $\mathrm{m} / \mathrm{s}$ na região onde será implantado o edifício;

$\mathrm{H}=$ altura dos pavimentos acima do pavimento em questão, excluindo o ático do prédio (em m);

$\mathrm{L}_{\text {fachada }}=$ largura da fachada principal;

$\Sigma I$ = somatória do momento de inércia das paredes estruturais para a direção principal do vento (em $\left.\mathrm{m}^{4}\right)$.

Sabendo-se que:

- $\mathrm{V}_{0}=40 \mathrm{~m} / \mathrm{s}$ (São Paulo);

- $\mathrm{H}=2,7$ (pé-direito $+10 \mathrm{~cm}$ de laje) x número de andares acima do pavimento em estudo;

- $\mathrm{L}_{\text {fachada }}=32 \mathrm{~m}$;

- $\quad \Sigma \mathrm{I}=65,99 \mathrm{~m}^{4}$. 
Para se calcular o volume de graute em cada ponto, consideraram-se as dimensões de furo do bloco estrutural apresentadas na Figura 5.4.

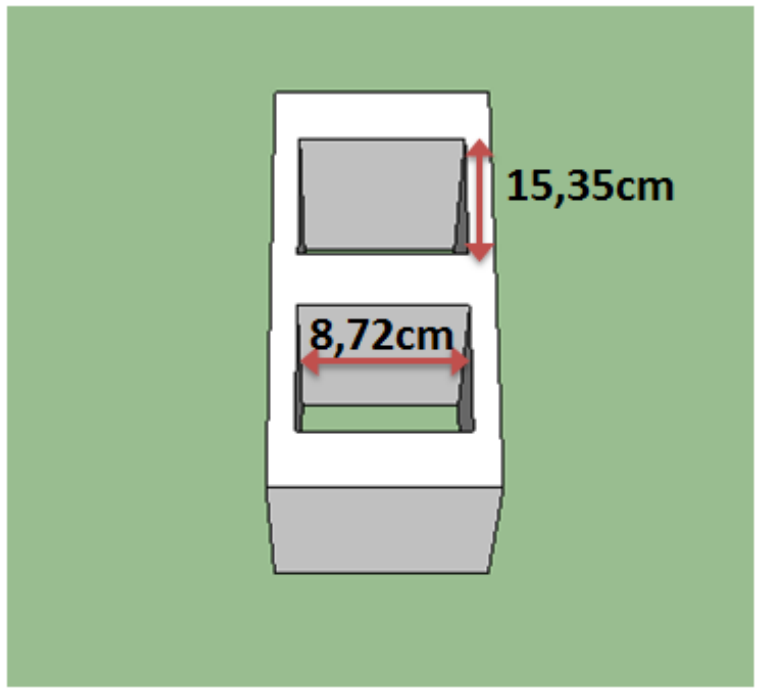

Figura 5.4 - Dimensões de furos verticais dos blocos estruturais

Como o pé-direito da edificação é de $2,6 \mathrm{~m}$, o volume de cada ponto de graute é dado por: $0,1535 \times 0,0872 \times 2,6=0,348 \mathrm{~m}^{3}$.

Os resultados de quantidade de graute por andar são mostrados na Tabela 5.10.

Tabela 5.10 - Quantidade de graute por andar

\begin{tabular}{|c|c|c|c|c|c|c|c|}
\hline Andar & $\begin{array}{c}\text { Fgk } \\
(\mathrm{MPa})\end{array}$ & $\begin{array}{c}\mathrm{Q} 0 \\
\text { (pontos) }\end{array}$ & $\begin{array}{c}\mathrm{QV} \\
\text { (pontos) }\end{array}$ & $\begin{array}{l}\text { Pontos } \\
\text { graute } \\
\text { vertical }\end{array}$ & $\begin{array}{c}\text { Graute } \\
\text { vertical } \\
\left(\mathrm{m}^{3}\right)\end{array}$ & $\begin{array}{c}\text { Graute } \\
\text { horizontal } \\
\left(\mathrm{m}^{3}\right)\end{array}$ & $\begin{array}{c}\text { VOLUME } \\
\text { GRAUTE } \\
\left(\mathrm{m}^{3}\right)\end{array}$ \\
\hline 14 & 15 & 50,39 & 0,00 & 51,00 & 4,80 & 5,25 & 10,04 \\
\hline 13 & 15 & 50,39 & 0,00 & 51,00 & 1,78 & 5,25 & 7,02 \\
\hline 12 & 15 & 50,39 & 0,00 & 51,00 & 1,78 & 5,25 & 7,02 \\
\hline 11 & 15 & 50,39 & 0,00 & 51,00 & 1,78 & 5,25 & 7,02 \\
\hline 10 & 15 & 50,39 & 0,00 & 51,00 & 1,78 & 5,25 & 7,02 \\
\hline 9 & 15 & 50,39 & 0,00 & 51,00 & 1,78 & 5,25 & 7,02 \\
\hline 8 & 20 & 50,39 & 0,00 & 51,00 & 1,78 & 5,25 & 7,02 \\
\hline 7 & 20 & 50,39 & 0,00 & 51,00 & 1,78 & 5,25 & 7,02 \\
\hline 6 & 20 & 50,39 & 77,93 & 129,00 & 4,49 & 5,25 & 9,74 \\
\hline 5 & 20 & 50,39 & 106,91 & 158,00 & 5,50 & 5,25 & 10,75 \\
\hline 4 & 25 & 50,39 & 142,29 & 193,00 & 6,72 & 5,25 & 11,97 \\
\hline 3 & 25 & 50,39 & 184,73 & 236,00 & 8,22 & 5,25 & 13,47 \\
\hline 2 & 30 & 50,39 & 234,87 & 286,00 & 9,96 & 5,25 & 15,21 \\
\hline 1 & 30 & 50,39 & 293,35 & 344,00 & 11,98 & 5,25 & 17,23 \\
\hline \multicolumn{5}{|c|}{ Total } & 64,13 & 73,46 & 137,59 \\
\hline
\end{tabular}


De acordo com o orçamento de referência (base de out/2010), os custos unitários de graute são:

- Graute $\mathrm{f}_{\mathrm{gk}}=30 \mathrm{MPa}: 229,40$ reais $/ \mathrm{m}^{3}$

- Graute $\mathrm{f}_{\mathrm{gk}}=25 \mathrm{MPa}: 199,77$ reais $/ \mathrm{m}^{3}$

- Graute $\mathrm{f}_{\mathrm{gk}}=20 \mathrm{MPa}: 189,52$ reais $/ \mathrm{m}^{3}$

- Graute $\mathrm{f}_{\mathrm{gk}}=15 \mathrm{MPa}: 182,94$ reais $/ \mathrm{m}^{3}$

Considerando a mesma perda do ED0 (de 30\%), as quantidades calculadas e os custos unitários, o custo total de graute do ED1 é de $R \$ 35.534,01$, conforme mostra a Tabela 5.11.

Tabela 5.11 - Custo de graute do ED1

\begin{tabular}{|c|c|c|c|c|c|c|}
\hline Graute & $\begin{array}{c}\text { Uni- } \\
\text { dade }\end{array}$ & $\begin{array}{c}\text { Custo } \\
\text { unitário } \\
\left(\mathrm{R} \$ / \mathrm{m}^{3}-\right. \\
\text { out } / 2010)\end{array}$ & $\begin{array}{c}\text { Volume } \\
\text { sem } \\
\text { perda } \\
\left(\mathrm{m}^{3}\right)\end{array}$ & $\begin{array}{c}\text { Perda } \\
(\%)\end{array}$ & $\begin{array}{c}\text { Volume } \\
\text { com perda } \\
\left(\mathrm{m}^{3}\right)\end{array}$ & $\begin{array}{c}\text { Custo } \\
(\text { out/2010) }\end{array}$ \\
\hline GRAUTE 30 MPA & $\mathrm{m}^{3}$ & 229,40 & 32,44 & $30 \%$ & 42,18 & $9.675,38$ \\
\hline GRAUTE 25 MPA & $\mathrm{m}^{3}$ & 199,77 & 25,44 & $30 \%$ & 33,07 & $6.607,03$ \\
\hline GRAUTE 20 MPA & $\mathrm{m}^{3}$ & 189,52 & 34,54 & $30 \%$ & 44,90 & $8.510,29$ \\
\hline GRAUTE 15 MPA & $\mathrm{m}^{3}$ & 182,94 & 45,17 & $30 \%$ & 58,71 & $10.741,31$ \\
\hline \multicolumn{2}{|r|}{ TOTAL } & & $\mathbf{1 3 7 , 5 9}$ & & $\mathbf{1 7 8 , 8 7}$ & $\mathbf{3 5 . 5 3 4 , 0 1}$ \\
\hline
\end{tabular}

Sabendo que o edifício tem 10.434,76 $\mathrm{m}^{2}$ de área de alvenaria, o custo de graute para ED1 é:

- $35.534,01 / 10.434,76=3,41$ reais $/ \mathrm{m}^{2}$ de paredes estruturais .

Como o custo de graute do ED0 é de $\mathrm{R} \$ 2,95 / \mathrm{m}^{2}$ de alvenaria (Quadro 5.4), a relação (CustoMAT graute/QServ) ED1 : (CustoMAT graute/QServ) $)_{\text {EDo }}$ é igual:

- $3,41 / 2,95=1,16$

O valor de 1,16 indica que o custo de graute $/ \mathrm{m}^{2}$ de parede estrutural do edifício a ter o custo estimado (ED1) é $16 \%$ mais caro que o do empreendimento de referência (ED0). Esta variação se deve, principalmente, a: 
- custo de graute mais caro com a elevação da resistência do bloco, que, por sua vez, é tanto maior quanto mais alto é o edifício e, como o ED1 é mais alto que o ED0, seu custo por parede estrutural é maior;

- maior quantidade de graute por área de alvenaria do ED1, já que este possui $0,0132 \mathrm{~m}^{3}$ de graute/ $\mathrm{m}^{2}$ de alvenaria; enquanto que o ED0 possui $0,0123 \mathrm{~m}^{3}$ de graute/ $\mathrm{m}^{2}$ de alvenaria. Este maior consumo pode ser explicado pela maior altura do ED1, tornando necessários mais pontos de graute devido a esforços de vento.

\subsubsection{ARMAÇÃO}

Com base na estimativa fornecida por Franco (Apêndice A), todos os grautes horizontais serão armados com uma barra de $10 \mathrm{~mm}$. Com base neste indicador e sabendo que a barra de $10 \mathrm{~mm}$ possui taxa de aço igual a $0,63 \mathrm{Kg} / \mathrm{m}$, a quantidade de aço horizontal, por pavimento, é:

- Aço horizontal/ andar = número de canaletas $\times$ comprimento canaleta $\times 0,63$ $\mathrm{kg} / \mathrm{m}$;

- Aço horizontal/ andar $=1.148 \times 0,4 \times 0,63=289,3 \mathrm{Kg} /$ andar $(\Theta=10 \mathrm{~mm})$.

Como o ED1 possui 14 andares, o consumo teórico de aço horizontal com $\Theta=10 \mathrm{~mm}$ é de $4.050,14 \mathrm{Kg}$.

Para estimar a quantidade de armadura vertical, Franco (Apêndice A) apresentou os seguintes consumos de aço por ponto vertical grauteado:

- 4 primeiros andares: 1 barra de $16 \mathrm{~mm}(1,6 \mathrm{Kg} / \mathrm{m})$; comprimento igual ao do pavimento $+60 \mathrm{~cm}$ de transpasse;

- 5 pavimentos acima: 1 barra de $12,5 \mathrm{~mm}(1 \mathrm{Kg} / \mathrm{m})$; comprimento igual ao do pavimento $+60 \mathrm{~cm}$ de transpasse;

- restante (do $10^{\circ}$ ao $16^{\circ}$ andar): 1 barra de $10 \mathrm{~mm}(0,63 \mathrm{Kg} / \mathrm{m})$; comprimento igual ao do pavimento $+60 \mathrm{~cm}$ de transpasse; 
Com base nestes valores e na quantidade de pontos de graute calculados no item 5.2.1.3, o consumo de aço vertical, por pavimento, é mostrado na Tabela 5.12.

Tabela 5.12 - Quantidade de aço vertical

\begin{tabular}{|c|c|c|c|c|c|c|}
\hline Andar & $\begin{array}{c}\ominus \\
(\mathrm{mm})\end{array}$ & $\begin{array}{c}\text { Peso } \\
\text { teórico } \\
(\mathrm{kg} / \mathrm{m})\end{array}$ & $\begin{array}{c}\text { Pontos } \\
\text { graute } \\
\text { vertical }\end{array}$ & $\begin{array}{c}\text { Comprimen- } \\
\text { to barra }(\mathrm{m})\end{array}$ & $\begin{array}{c}\text { Peso aço/ ponto } \\
\text { de graute vertical } \\
(\mathrm{kg} / \text { ponto })\end{array}$ & $\begin{array}{c}\text { Peso de } \\
\text { aço vertical } \\
(\mathrm{Kg})\end{array}$ \\
\hline 14 & 10 & 0,6 & 51 & 3,2 & 2,0 & 102,8 \\
\hline 13 & 10 & 0,6 & 51 & 3,2 & 2,0 & 102,8 \\
\hline 12 & 10 & 0,6 & 51 & 3,2 & 2,0 & 102,8 \\
\hline 11 & 10 & 0,6 & 51 & 3,2 & 2,0 & 102,8 \\
\hline 10 & 10 & 0,6 & 51 & 3,2 & 2,0 & 102,8 \\
\hline 9 & 10 & 0,6 & 51 & 3,2 & 2,0 & 102,8 \\
\hline 8 & 10 & 0,6 & 51 & 3,2 & 2,0 & 102,8 \\
\hline 7 & 12,5 & 1,0 & 51 & 3,2 & 3,2 & 163,2 \\
\hline 6 & 12,5 & 1,0 & 129 & 3,2 & 3,2 & 412,8 \\
\hline 5 & 12,5 & 1,0 & 158 & 3,2 & 3,2 & 505,6 \\
\hline 4 & 12,5 & 1,0 & 193 & 3,2 & 3,2 & 617,6 \\
\hline 3 & 12,5 & 1,0 & 236 & 3,2 & 3,2 & 755,2 \\
\hline 2 & 16 & 1,6 & 286 & 3,2 & 5,1 & 1464,3 \\
\hline 1 & 16 & 1,6 & 344 & 3,2 & 5,1 & 1761,3 \\
\hline & &
\end{tabular}

De acordo com o orçamento de referência (base out/2010), os custos unitários de aço por diâmetro são:

- $\Theta=10 \mathrm{~mm}: 2,79$ reais $/ \mathrm{Kg}$;

- $\Theta=12,5 \mathrm{~mm}: 2,65$ reais $/ \mathrm{Kg}$;

- $\Theta=16 \mathrm{~mm}: 2,65$ reais $/ \mathrm{Kg}$;

Considerando a mesma perda do ED0 (de 3\%), as quantidades calculadas (para armadura horizontal e vertical) e os custos unitários, o custo total de aço do ED1 é de $\mathrm{R} \$ 29.210,70$, conforme mostra a Tabela 5.13. 
Tabela 5.13 - Custo de armação do ED1

\begin{tabular}{|c|c|c|c|c|c|c|}
\hline Armação & $\begin{array}{c}\text { Uni- } \\
\text { dade }\end{array}$ & $\begin{array}{c}\text { Custo } \\
\text { unitário } \\
(\mathrm{R} \$ / \mathrm{Kg}- \\
\text { out/2010) }\end{array}$ & $\begin{array}{c}\text { Peso sem } \\
\text { perda }\left(\mathrm{m}^{3}\right)\end{array}$ & $\begin{array}{c}\text { Perda } \\
(\%)\end{array}$ & $\begin{array}{c}\text { Peso com } \\
\text { perda }\left(\mathrm{m}^{3}\right)\end{array}$ & $\begin{array}{c}\text { Custo } \\
(\text { out/2010) }\end{array}$ \\
\hline $\begin{array}{c}\text { Armação }-\Theta \\
=10 \mathrm{~mm}\end{array}$ & $\mathrm{Kg}$ & 2,79 & $4.769,86$ & $3 \%$ & $4.912,95$ & $13.707,14$ \\
\hline $\begin{array}{c}\text { Armação }-\Theta \\
=12,5 \mathrm{~mm}\end{array}$ & $\mathrm{Kg}$ & 2,65 & $2.454,40$ & $3 \%$ & $2.528,03$ & $6.699,28$ \\
\hline $\begin{array}{c}\text { Armação }-\Theta \\
=16 \mathrm{~mm}\end{array}$ & $\mathrm{Kg}$ & 2,65 & $3.225,60$ & $3 \%$ & $3.322,37$ & $8.804,28$ \\
\hline \multicolumn{7}{|c|}{ TOTAL }
\end{tabular}

Sabendo que o edifício tem 10.434,76 $\mathrm{m}^{2}$ de área de alvenaria, o custo de armação para ED1 é:

- $29.210,70 / 10.434,76=2,80$ reais $/ \mathrm{m}^{2}$ de paredes estruturais.

Como o custo de armação do ED0 é de $R \$ 2,48 / \mathrm{m}^{2}$ de alvenaria (Quadro 5.4), a

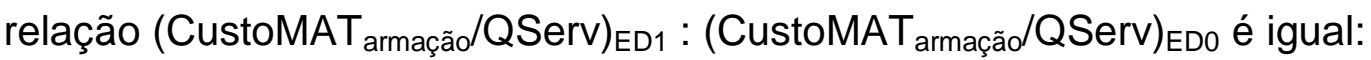

- $2,80 / 2,48=1,13$

O valor de 1,13 indica que o custo de aço/ $\mathrm{m}^{2}$ de parede estrutural do edifício a ter o custo estimado (ED1) é 13\% mais caro que o do empreendimento de referência (ED0). Esta variação se deve à maior quantidade de aço do ED1 $\left(1,00 \mathrm{Kg} / \mathrm{m}^{2}\right.$ de alvenaria) em relação ao $\operatorname{ED0}\left(0,86 \mathrm{Kg} / \mathrm{m}^{2}\right.$ de alvenaria). O maior consumo ocorre, principamente, devido à maior quantidade de pontos de graute do ED1, já que sua altura é maior e se devem absorver esforços de vento.

\subsubsection{CÁLCULO DO SUBFATOR LIGADO AOS MATERIAIS}

A Eq. 5.6 mostra o cálculo apresentado no Capítulo 3 para o subfator de custo unitário ligado aos materiais. 


$$
f M A T=\frac{\sum_{n}\left[\left(\frac{\text { CustoMAT }_{n}}{Q \operatorname{serv}}\right)_{E D 0} \times \frac{\left(\frac{\text { CustoMAT }_{n}}{Q M A T_{n}}\right)_{E D 1}}{\left(\frac{\text { UustoMAT }_{n}}{Q M A T_{n}}\right)_{E D 0}} \times \frac{\left(\frac{Q M A T_{n-\text { real }}}{Q S e r v}\right)_{E D 1}}{\left(\frac{Q M A T_{n-\text { real }}}{Q S e r v}\right)_{E D 0}}\right]}{\sum_{n}\left(\frac{\text { CustoMAT }}{Q \text { Serv }}\right)_{E D 0}}
$$

onde:

CustoMAT $_{n} /$ Qserv = custo do material $n$ para um dado serviço;

CustoMAT $n / \mathrm{QMAt}_{\mathrm{n}}=$ custo unitário do material $\mathrm{n}$;

$\mathrm{QMAT}_{\mathrm{n} \text {-real }} / \mathrm{Qserv}=$ consumo unitário de material $\mathrm{n}$ referente à quantidade de serviço;

ED1 = empreendimento a ter o custo da edificação prognosticado;

EDO = edificação de referência .

Sabendo que a alvenaria estrutural é composta por blocos, argamassa, graute e armação, o subfator é calculado através da seguinte expressão:

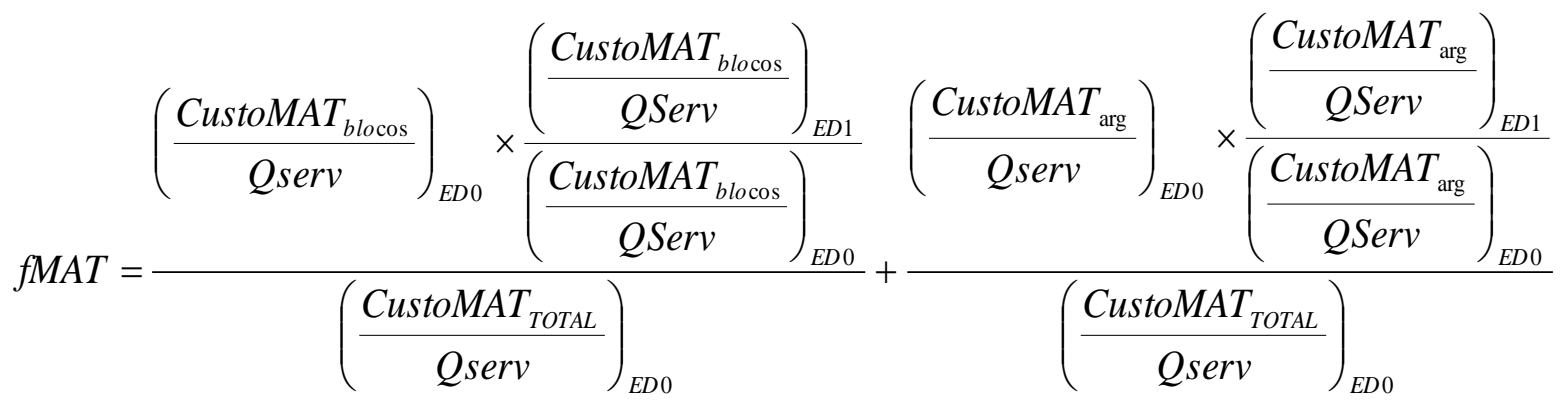

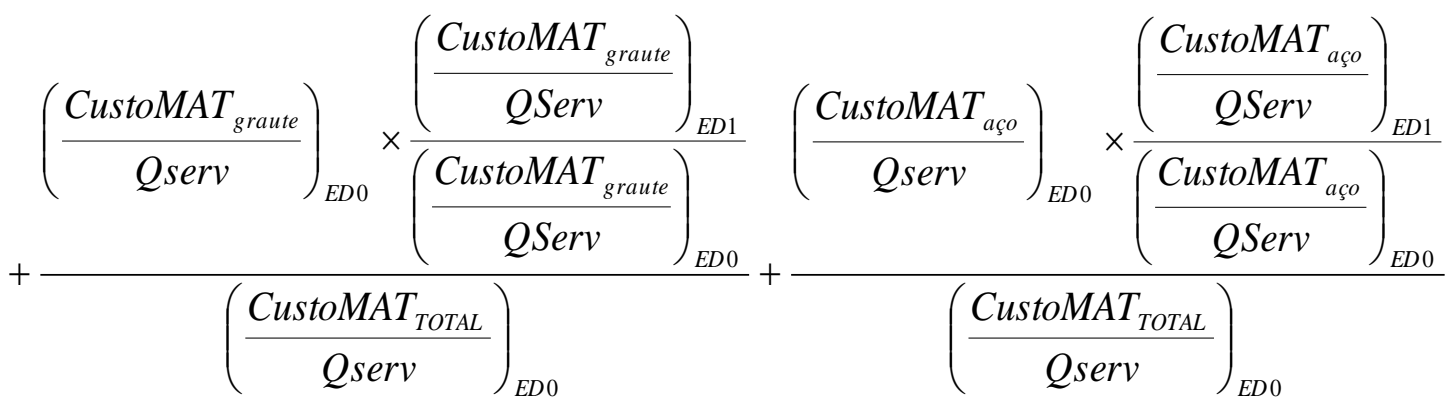


Considerando itens anteriores e os custos do Quadro 5.4, os valores das variáveis da expressão anterior são:

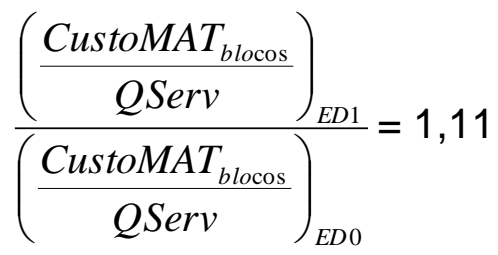

$$
\frac{\left(\frac{\text { CustoMAT }_{\mathrm{arg}}}{\text { QServ }}\right)_{E D 1}}{\left(\frac{\text { CustoMAT }_{\mathrm{arg}}}{Q S e r v}\right)_{E D 0}}=1,65
$$

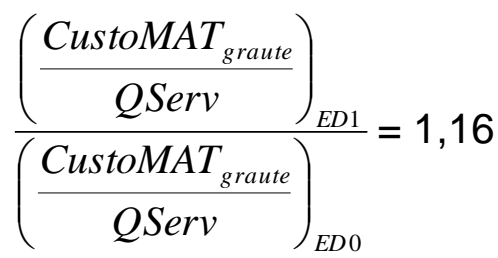

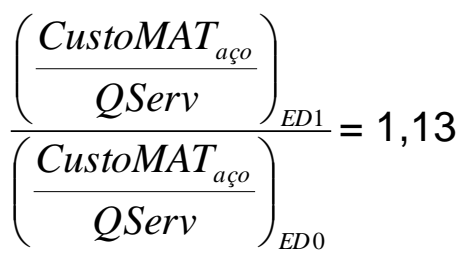$$
\left(\frac{\text { CustoMAT }_{\text {blocos }}}{\text { Qserv }}\right)_{E D 0}=29,73 \text { reais } / \mathrm{m}^{2} \text { parede esturtural (out/2010) }
$$

$\left(\frac{\text { CustoMAT }_{\text {arg }}}{\text { Qserv }}\right)_{E D 0}=2,27$ reais/ $\mathrm{m}^{2}$ parede esturtural (out/2010)

$$
\left(\frac{\text { CustoMAT } T_{\text {graute }}}{Q \operatorname{serv}}\right)_{E D 0}=2,95 \text { reais } / \mathrm{m}^{2} \text { parede esturtural (out/2010) }
$$

$\left(\frac{\text { CustoMAT }}{\text { aço }}\right)_{E D 0}=2,48$ reais $/ \mathrm{m}^{2}$ parede esturtural (out/2010)

$$
\left(\frac{\text { CustoMAT }}{\text { TOTAL }}\right)_{E D 0}=37,08 \text { reais } / \mathrm{m}^{2} \text { parede esturtural (out/2010) }
$$


Deste modo, o valor do subfator ligado aos materiais é:

$$
\begin{aligned}
& f M A T=\frac{29,38 \times 1,11+2,27 \times 1,65+2,95 \times 1,16+2,48 \times 1,13}{37,08} \\
& f M A T=1,15
\end{aligned}
$$

Com base no valor de fMAT, o custo de materiais por área de paredes estruturais do ED1 é $15 \%$ mais caro que o ED0.

\subsubsection{Subfator de custo unitário ligado à mão-de-obra}

O ED0 possui mão-de-obra terceirizada, com custo unitário igual a $R \$ 25,00$ por $\mathrm{m}^{2}$ de alvenaria (Quadro 5.4). De acordo com o Capítulo 3, o subfator de mão-de-obra deve ser calculado pela Eq. 5.7.

$$
\left.f M O_{\text {terceirizada }}=\frac{\left(\frac{\text { CustoMO }}{\text { terceirizada }}\right)}{\left(\frac{\text { CustoMO }}{\text { terceirizada }}\right)}\right)_{E D 1}
$$

onde:

$\mathrm{fMO}_{\text {terceirizada }}=$ subfator de mão-de-obra para o caso de terceirização;

$\left(\text { CustoMO } \text { terceirizada }_{\text {QServ }}\right)_{\mathrm{ED} 1}$ = custo de mão-de-obra por quantidade de serviço verificado para o empreendimento a ter o custo da edificação prognosticado;

$\left(\text { CustoMO } \text { terceirizada }_{\text {Q }} / \text { Serv }\right)_{\text {EDO }}=$ custo de mão-de-obra por quantidade de serviço da edificação de referência.

Considerando o mesmo custo de ED0 para a mão-de-obra do ED1, o subfator ligado a mão-de-obra é: 
- $\mathrm{fMO}=1$

\subsubsection{Cálculo do fator do custo unitário}

De acordo com o método apresentado no Capítulo 3, o cálculo do fator de custo unitário é dado pela Eq. 5.8.

$$
F C U n=\frac{f M A T \times\left(\frac{\text { CustoMAT }}{Q S e r v}\right)_{E D 0}+f M O \times\left(\frac{\text { CustoMO }}{Q S e r v}\right)_{E D 0}}{\left(\frac{\text { CustoMAT }}{Q S e r v}\right)_{E D 0}+\left(\frac{\text { CustoMO }}{Q S e r v}\right)_{E D 0}}
$$

onde:

FCUn = fator do custo unitário;

fMAT = subfator ligado ao custo de materiais;

CustoMAT/QServ = Custo de material por quantidade de serviço;

fMO = subfator ligado ao custo de mão-de-obra;

CustoMO/QServ = Custo de mão-de-obra por quantidade de serviço;

EDO = edificação de referência.

Considerando os subfatores calculados e os custos do Quadro 5.4, os valores das variáveis da Eq. 5.8 são:

$$
\begin{aligned}
& f M A T=1,15 \\
& f M O=1
\end{aligned}
$$


$\left(\frac{\text { CustoMAT }}{Q S e r v}\right)_{E D 0}=37,08$ reais $/ \mathrm{m}^{2}$ parede esturtural (out $\left./ 2010\right)$

$\left(\frac{\text { CustoMO }}{Q S e r v}\right)_{E D 0}=25,00$ reais $/ \mathrm{m}^{2}$ parede esturtural (out/2010)

Deste modo, o fator de custo unitário é dado por:

$$
F C U n=\frac{1,15 \times(37,08)+1 \times(25)}{37,08+25}=1,09
$$

De acordo com o valor de FCUn, o custo unitário do serviço de alvenaria estrutural do ED1 é $9 \%$ mais caro que o do ED0.

\subsection{Custo do serviço de alvenaria estrutural}

O custo de alvenaria estrutural estimado é dado pela Eq. 5.9.

$$
\left(\frac{\text { CustoServ }}{A}\right)_{E D 1}=\left(\frac{\text { CustoServ }}{A}\right)_{E D 0} \times F Q \operatorname{Serv} \times F C U n
$$

onde:

$(\text { CustoServ/A })_{E D 1}=$ custo de serviço por área de construção da edificação a ter custo prognosticado;

$(\text { CustoServ/A })_{\text {EDo }}=$ custo de serviço por área de construção da edificação com custo já definido e tomado como referência;

FQServ = fator de conversão relacionado com a quantidade de serviço;

FCUn = fator de conversão relacionado ao custo unitário do serviço;

Considerando os fatores calculados, o custo de alvenaria estrutural de ED1 por área construída, sem correção inflacionária, é dado por: 
$\left(\frac{\text { CustoServ }}{A}\right)_{E D 1}=\left(\frac{\text { CustoServ }}{A}\right)_{E D 0} \times 1,05 \times 1,09=\left(\frac{\text { CustoServ }}{A}\right)_{E D 0} \times 1,14$

$\left(\frac{\text { CustoServ }}{A}\right)_{E D 1}=105,36 \times 1,14$

$\left(\frac{\text { CustoServ }}{A}\right)_{E D 1}=119,94$ reais $/ \mathrm{m}^{2}$ de área construída [out/2010]

Considerando os cálculos feitos, pôde-se estimar o custo de alvenaria por área construída do ED1 em 119,94 reais, na base de out/2010.

Nota-se que ED1 terá alvenaria estrutural com custo $14 \%$ maior que o mesmo serviço de ED0.

\subsection{Atualização dos valores para maio de $\mathbf{2 0 1 2}$}

A fim de atualizar o valor para maio de 2012, utilizou-se o cálculo mostrado no Capítulo 3, conforme a Eq. 5.10.

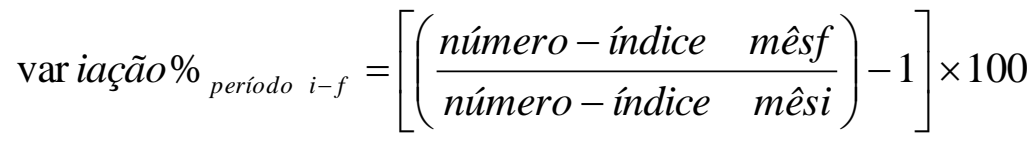

onde:

variação\% período i-f = variação em \% do valor do índice entre os meses i (início do período) ef (mês final do período);

número-índice mêsf= número índice relativo ao mês final do período;

número-índice mêsi= número índice relativo ao mês inicial do período. 
O índice utilizado foi o INCC-M (FGV-IBRE, 2012), sendo que os valores do mês i (outubro/2010) e do mês f (maio/2012) são:

- $\quad$ número-índice mês i (outubro/2010) = 1559,5411

- $\quad$ número-índice mês f (maio/2012) = 1755,4321

Deste modo, a variação do período foi de:

var iação\% $\%_{\text {periodo } i-f}=\left[\left(\frac{1755,4321}{1559,5411}\right)-1\right] \times 100=12,56 \%$

Com base no valor da variação, o fator de correção inflacionário (Finf) é dado por:

- $\quad$ Ffin $=1+0,1256=1,1256$

Atualizando o valor do custo de alvenaria estrutural de ED1 para maio de 2012, temse:

$\left(\frac{\text { CustoServ }}{A}\right)_{E D 1}=(119,94) \times 1,1256$

$\left(\frac{\text { CustoServ }}{A}\right)_{E D 1-\text { maio } / 2012}=135,00$ reais $/ \mathrm{m}^{2}$ de área construída 


\section{CONSIDERAÇÕES FINAIS}

\subsection{Cumprimento dos objetivos}

Este trabalho cumpriu o objetivo inicialmente proposto, qual seja a elaboração de um método para prognóstico de custos diretos de construção, com base no estudo preliminar de arquitetura, para dar apoio às tomadas de decisões visando atender o valor previsto no estudo de viabilidade de edificações. Tal cumprimento pode ser comprovado através do método apresentado no Capítulo 3, que teve aplicação demonstrada para o serviço de alvenaria estrutural, conforme mostraram os Capítulos 4 e 5.

No Capítulo 2, buscou-se, através da bibliografia existente, compreender o estudo de custos feito para empreendimentos de Construção Civil, bem como se procurou levantar e analisar as metodologias de estimativas de custos atualmente empregadas no Brasil e no exterior, a fim de se obterem subsídios para elaborar um método que pudesse ser atrativo, comparativamente às outras ferramentas existentes.

O desenvolvimento do método proposto foi feito através da análise dos fatores influenciadores do custo de alvenaria estrutural, buscando, através de revisão bibliográfica, definir as limitações, indicadores e especificações das partes constituintes do custo deste serviço, quais sejam: quantidade, custos unitários e eficiências.

O método apresentado possui diversos atributos que o tornam uma ferramenta de grande importância tanto para planejadores e orçamentistas (enquanto representantes da incorporação), quanto para projetistas, na avaliação de custos de diferentes partidos arquitetônicos, auxiliando-os a controlar os custos de modo a atender o valor previsto em estudo de viabilidade. 


\subsection{Avaliação crítica do método proposto}

Foram levantados, no Capítulo 2, os atributos que um bom método para a estimativa de custo deve ter. E avaliando-se tais pontos para o método proposto pode-se dizer:

- com relação à precisão: considera-se que o método proposto é preciso, na medida em que quebra o produto em partes e, racionalmente, compara as eficiências destas partes entre o edifício a ser analisado (ED1) e aquele tomado como referência (ED0); a base para isto é o Modelo dos Fatores, caminho já consagrado na avaliação da eficiência da produção;

- com relação à facilidade e rapidez na sua elaboração: imagina-se ter demonstrado, na aplicação à alvenaria estrutural (Capítulos 4 e 5), que o método teórico mostrado no Capítulo 3 possa ser desenvolvido para os outros subsistemas do edifício, tornando o caminho aqui proposto ainda mais abrangente e relevante para a previsão de custos;

- com relação à rapidez na utilização: o Capítulo 5, embora aparentemente prolixo, nasceu de poucas operações comparativas, de rápida aplicação; a própria redação do capítulo procura ser um guia para uso em alvenaria estrutural;

- com relação ao entendimento dos fatores: assim como as demais aplicações do Modelo dos Fatores, tem-se relações causa-efeito normalmente muito claras, deixando pouco espaço para questionamentos quanto aos fatores considerados; nasce um tipo de estimativa didática, na medida em que os fatores se ligam fortemente ao entendimento do que se está orçando;

- com relação à atualização do método: não demanda atualização a curto/ médio prazo caso não se altere o foco da empresa; porém, se isso acontecer, basta apenas 1 novo projeto como referência para viabilizar os prognósticos posteriores;

- com relação à utilização por diferentes empresas: na medida em que é comparativo e de fácil aplicação, cada empresa deveria eleger seu próprio 
ED0 para que os custos de seu novo empreendimento se relacione às suas próprias práticas;

- com relação à possibilidade de comparar diferentes projetos arquitetônicos: o método é extremamente útil para esta avaliação, já que a expectativa de custo do ED1 nasce fortemente da comparação de tipologias;

- com relação à avaliação de diferentes tecnologias: o método aqui desenvolvido é específico para a alvenaria estrutural; mas, em função dos comentários anteriores, é possível criar ferramentas semelhantes para outros métodos construtivos e, portanto, que possam gerar comparação de custos entre eles.

\subsection{Relevância do método apresentado}

Com base na aplicação do método ao serviço de alvenaria estrutural pôde-se verificar que, mesmo tendo características semelhantes (apartamentos destinados à baixa renda, com área privativa similar de $45 \mathrm{~m}^{2}$ ), o custo estimado deste serviço para o empreendimento em estudo (ED1) foi $14 \%$ maior que o valor do empreendimento de referência, por $\mathrm{m}^{2}$ de área construída.

Apesar de este serviço representar apenas $20 \%$ dos custos diretos de edificação, se tal análise for feita para todos os serviços e diferenças como esta forem constatadas em seus custos, a adoção de um método que apenas utiliza o custo do $\mathrm{m}^{2}$, de um empreendimento para outro semelhante, pode gerar imprecisões da ordem de 14\% do custo direto da obra, o que seria inaceitável no contexto de competição reinante no mercado atual

A aplicação do método mostrou, ainda, a geração de um custo estimado, de forma objetiva, mostrando cada variação de custo através dos fatores. Deste modo, o método tem grande importância para gestores, incorporadores e projetistas, na medida em que fornece valor preciso, compara diferentes soluções de produto e fornece subsídios para entender as variações de custos, auxiliando os agentes a organizar as informações de produto disponíveis e indicadores de consumo e 
eficiência que tenham praticado, para subsidiar uma estimativa de custo mais acurada.

\subsection{Sugestões para próximos trabalhos sobre o tema}

Melhorias do método proposto para alvenaria estrutural poderiam ser feitas para se avaliar os fatores influenciadores em perdas de graute e aço, bem como aqueles que fazem com que a produtividade da mão-de-obra varie.

O método proposto, apesar de desenvolvimento complexo, possibilita a análise comparativa de custos, fornecendo subsídios para avaliação de custos de diferentes produtos com precisão. Porém, não foi possível desenvolver o método para todos os serviços que formam um edifício. Deste modo, propõe-se, para dar prosseguimento ao trabalho, a determinação dos indicadores e parâmetros para os demais subsistemas de edificações de alvenaria estrutural, completando o método em termos da estimativa de custos diretos de um edifício como um todo.

Pode-se, ainda, sugerir a implementação do método proposto em trabalhos que utilizem modelagens em BIM ((Building Information Modeling), a fim de que se possa estimar custos diretos de construção durante a elaboração do modelo.

Outra sugestão é a análise de custos indiretos, definindo os fatores que os influenciam e determinando cálculos que auxiliem a determinar sua grandeza. Como exemplos de partes constituintes deste tipo de análise, podem-se citar: avaliação de custos de equipamentos, da mão-de-obra indireta, de implementação de canteiro, entre outros.

Por fim, tal método pode ser estendido, ainda, na direção da análise de custos de empreendimentos com diferentes métodos construtivos, tais como estrutura de concreto armado, estrutura em aço, paredes de concreto etc. 


\section{REFERÊNCIAS BIBLIOGRÁFICAS}

$\mathrm{ABCl}$ - Associação Brasileira da Construção Industrializada. Manual técnico de alvenaria. São Paulo: ABCl: Projeto, 1990. 280p.

ACCETI, K. M. Contribuições ao projeto estrutural de edifícios em alvenaria. 1998. 247 p. Dissertação (Mestrado) - Escola de Engenharia de São Carlos, Universidade de São Paulo, São Carlos, 1998.

ANDRADE, V. A. Modelagem dos custos para casas de classe média. 1996. 216 p. Dissertação (Mestrado) - Universidade Federal de Santa Catarina, Florianópolis, 1996.

ARAÚJO, L. O. C.; SOUZA, U. E. L. Produtividade da mão-de-obra na execução de alvenaria: detecção e quantificação de fatores influenciadores. Boletim Técnico da Escola Politécnica da USP, São Paulo, BT/PCC/269, 24 p, 2001.

ASSED, J. A. Construção civil: viabilidade, planejamento, controle. Rio de Janeiro: Livros Técnicos e Científicos, 1986. 95 p.

ASSOCIAÇÃO BRASILEIRA DE ESCRITÓRIOS DE ARQUITETURA. Manual de Escopo de Projetos e Serviço de Arquitetura e Urbanismo. Volume I. 2010. 131 p.

$<$ http://www.manuaisdeescopo.com.br/index.php?option=com docman\&ltemid=73\&li

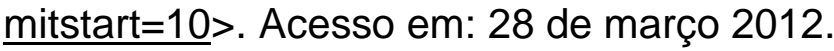

ASSOCIAÇÃO BRASILEIRA DE NORMAS TÉCNICAS. NBR 6136: Bloco vazado de concreto simples para alvenaria estrutural - Requisitos. Rio de Janeiro, 2006. 9 p.

NBR 10837: Cálculo de alvenaria estrutural de blocos vazados de concreto. Rio de Janeiro, 1989.

NBR 12721: Avaliação de custos unitários de construção para incorporação imobiliária e outras disposições para condomínios edilícios procedimento. Rio de Janeiro, 2006. 91 p.

NBR 13532: Elaboração de projetos de edificações Arquitetura. Rio de Janeiro, 1995. 8 p. 
ASSOCIAÇÃO BRASILEIRA DE NORMAS TÉCNICAS. NBR 15961: Alvenaria estrutural - Blocos de concreto. Parte 1: Projeto. Rio de Janeiro, 2011. 42 p.

NBR 15961: Alvenaria estrutural - Blocos de concreto. Parte 2: Execução e controle de obras. Rio de Janeiro, 2011. 35 p.

NBR 19530: Portas de madeira para edificações. Parte 2: Requisitos. Rio de Janeiro, 2011. 83 p.

NBR 6492: Representação de projetos de arquitetura. Rio

de Janeiro, 1994. $27 \mathrm{p}$.

ASSUMPÇÃO, J. F. P. FUGAZZA, A. E. C. Execução de orçamento por módulos para construção de edifícios. In: VIII Encontro Nacional de Tecnologia do Ambiente Construído, 2000, Salvador, Anais, p. 469-476.

BANSAL, V. K.; PAL, M. Potential of geographic information systems in building cost estimation and visualization. Automation in Construction, 16, p. 311- 322, 2007.

BARROS, M. M. S. B. Metodologia para implantacao de tecnologias construtivas racionalizadas na producao de edificios. 1996. 422p. Tese (Doutorado) -

BELCHIOR, M. V. et al. Análise das variáveis que influenciam na rentabilidade de empreendimentos residenciais: Estudo de Caso. In: V Simpósio Brasileiro de Gestão e Economia da Construção, 2007, CAMPINAS, Anais.

BERTO, R. M.; NAKANO, D. N. (1999). A produção científica nos anais do encontro nacional de engenharia de produção: um levantamento de métodos e tipos de pesquisa. Produção, São Paulo, volume 9, número 2, dezembro 1999.

BOTELHO, M. H. C.; MARCHETTI, O. Concreto armado: eu te amo. São Paulo: Edgard Blücher, 2004, 264 p.

CABRAL, E. C. C. Proposta de metodologia de orçamento operacional para obras de edificação. Florianópolis, SC. UFSC. 1988. 151p. Dissertação (Mestrado) - Universidade Federal de Santa Catarina, 1988. 
CAIXA ECONÔMICA FEDERAL. Demanda habitacional no Brasil / Caixa Econômica Federal. - Brasília: CAIXA, 2011. 170 p.

CAMACHO, J. S. Projeto de edifícios de alvenaria estrutural. Ilha Solteira, São Paulo: UNESP, 2006.

CARDOSO, F. F.; OVIEDO HAITO, R. J. J. Relatório contendo uma proposta de documentos referenciais regulatórios do PBQP-H voltados às empresas prestadoras de serviços especializados execução de obras para apoio à qualificação profissional. Projeto PNUD / MINCID / POLI, Contrato No. BRA108012/2009 (Não Publicado). 2011. 100 p.

CARDOSO, L. R. A.; ABIKO, A. K.. Meotodologia de avaliação de custos de inovações tecnológicas na produção de habitações de interesse social. BT/PCC/249, São Paulo, 2000. 22 p.

CARDOSO, R. S. Orçamento de obras em foco: Um novo olhar sobre a engenharia de custos. PINI. 2009. 480 p.

CARRARO, F. Produtividade da mão-de-obra no serviço de alvenaria. 1998. 226

p. Dissertação (Mestrado) - Escola Politécnica, Universidade de São Paulo, 1998.

CARVALHO, A. P. L. F. Redes neurais artificiais. Disponível em: $<$ http://www.icmc.usp.br/ andre/research/neural/>. Acesso em 13 nov. 2011.

CARVALHO, K. Orçamento. Revista Construção Mercado, São Paulo, n. 28, 2003. Disponível em: < http://www.piniweb.com.br/construcao/noticias/orcamento-799981.asp>. Acesso em: 26 de fev. 2009.

DORGAN, S. Z.; ARDITI, D.; GÜNAYDIN, H. M. Determining attribute weights in a CBR model for early cost prediction of structural systems. Journal of Construction Engineering and Management, v. 132, n. 10, p. 1092- 1098, 2006.

EASTMAN, C. et al. BIM handbook: a guide to building information modeling for owners, managers, designers, engineers and contractors. 2 ed. Hoboken, $\mathrm{NJ}$ : Wiley, $2011.626 \mathrm{p}$. 
ELHAG, T.M.S.; BOUSSABAINE, A.H.; BALLAL, T.M.A. Critical determinants of construction tendering costs: Quantity surveyors' standpoint. International Journal of Project Management. Vol. 23. Issue 7. P. 538-545, Octuber. 2005.

FARIA, R. Torres Econômicas. Capa. Téchne, IPT. Ed. 130. São Paulo. Janeiro, 2008.

FERRY, D. J.; BRANDON, P. S.; FERRY, J. D. Cost planning of buildings. $7^{\text {th }}$ ed. Malden, MA: Blackwell Science, 1999. 376 p.

FLANAGAN, R.; TATE, B. Cost Control in building design. Oxford: Blackwell Science, 1997. $322 \mathrm{p}$.

FREIRE, A. S. Indicadores de Projeto para Edifícios em Alvenaria Estrutural. 2007. 138 p. Dissertação (Mestrado) - Programa de Pós-Graduação em Construção Civil, Universidade Federal de São Carlos, São Carlos, 2007.

FUNDAÇÃO GETULIO VARGAS - IBRE. Índice Nacional de Custo da Construção - INCC. Rio de Janeiro. Disponível em: < http://portalibre.fgv.br/>. Acesso em: 20 mai. 2012.

FUNDAÇÃO GETULIO VARGAS - IBRE. Instituto Brasileiro de Economia. IGP-DI: Índice Geral de Preços - Disponibilidade Interna (Metodologia). Rio de Janeiro, 2010. 29 p.

FUNDAÇÃO JOÃO PINHEIRO; CENTRO DE ESTATÍSTICA E INFORMAÇÕES. Déficit habitacional no Brasil 2008. Ministério das Cidades, Secretaria Nacional da Habitação. Brasília, 2011, 140 p.

GIL, A. C. Como elaborar projetos de pesquisa. 4. ed .São Paulo: Atlas, 2008, 175 p.

GOLDMAN, P.; AMORIN, S. L. Estimativa orçamentária da construção: técnica paramétrica para utilização nos estudos de viabilidade de empreendimentos residenciais. In: VII Seminário Internacional do LARES, 2007, São Paulo, Anais.

GOMES, N.S. A resistência das paredes de alvenaria. 1983. 190p. Dissertação (Mestrado) - Escola Politécnica, Universidade de São Paulo, 1983. 
GONÇALVES, C. M. M. Método para gestão do custo da construção no processo de projeto de edificações. 2011. 182 p. Dissertação (Mestrado) - Escola Politécnica, Universidade de São Paulo, 2011.

GRAMA, A. S. Implementação computacional para projeto e cálculo de alvenaria estrutural. 2005. 152 p. Dissertação (Mestrado em Engenharia Civil) Universidade Federal de Uberlândia, Uberlândia, 2005.

Günaydin, H. M.; Dogan, S. Z. A neural network approach for early cost estimation of structural systems of buildings. International Journal of Project Management, v. 22, p. $595-602.2004$.

IBGE - Instituto Brasileiro de Geografia e Estatística. Indicadores IBGE: Sistema Nacional de Pesquisa de Custos e Índices da Construção Civil - SINAPI. Ministério do Planejamento, Orçamento e Gestão. abril, 2012. 38 p.

IBGE - Instituto Brasileiro de Geografia e Estatística. Pesquisa Anual da Indústria da Construção. Vol.19. Ministério do Planejamento, Orçamento e Gestão. 2009. 98 p.

INOUYE, K. P. Proposição de um método para subsidiar o prognóstico de custos de urbanização de conjuntos habitacionais horizontais com base em indicadores físicos. 2008. 300 p. Tese (Doutorado) - Escola Politécnica, Universidade de São Paulo, 2008.

ISAAC, S.; NAVON, R. Modeling building projects as a basis for change control. Automation in Construction, v. 18, p. 656-664, 2009.

JADID, M. N.; IDREES, M. M. Cost estimation of estructural skeleton using an interactive automation algorithm: a conceptual approach. Automation in Construction, 16, p. 797- 805, 2007.

JI, S. H.; PARK, M.; LEE, H. S. Cost estimation model for building projects using case-based reasoning. Canadian Journal of Civil Engineering, v. 38, p. $570-581$. 2011.

KAMARA, J. M.; ANUMBA, C. J.; EVBUOMWAN, N. F.O. Assessing the suitability of current briefing practices in construction within a concurrent engineering framework. International Journal of Project Management, v. 19, p. 337 - 351. 2001. 
KARSHENAS, S. Predesign Cost Estimating Method for Multistory Buildings. Journal os Construction Engineering and Management. Vol. 110. 79-86 p, March 1984.

KATO, C. S.; SOUZA, U. E. L. Comparação de métodos utilizados no prognóstico de custos de edifícios habitacionais: CUB e esimativa paramétrica. In: VI Simpósio Brasileiro de Gestão e Economia da Construção, 2009, João Pessoa, Anais.

KIM, G. H.; AN, S. H.; KANG, K. I. Comparison of construction cost estimating models based on regression analysis, neural networks, and case-based reasoning. Building and Environment, v. 39, p. 1235- 1242, 2004.

KIM, G. H.; SEO, D. S.; KANG, K. I. Hybrid models networks and genetic algorithms for predicting preliminary cost estimates. Journal of Computing in Civil Engineering, v. 19, n. 2, p. 208- 211, 2005.

LI, F.; XIANYI, G.; XIN, M. On reasons of uncontrollable construction cost based on the $A B C$ analysis method and the complete decomposition model. Systems Engineering Procedia, v. 4, p. 359 - 365, 2012.

LI, H.; SHEN, Q. P.; LOVE, P. E. D . Cost modeling of office buildings in Hong Kong: an exploratory study. Facilities, v. 23, p. 438 - 452, 2005.

LOSSO, I. R. Utilização das características geométricas da edificação na elaboração de estimativas preliminares de custos: estudo de caso em uma empresa de construção. 1995. 146 p. Dissertação (Mestrado) - Universidade Federal de Santa Catarina, Florianópolis, 1995.

LOVE, P. et al. Building design cost management. XVI. Oxford: Blackwell Science, 2002. $202 \mathrm{p}$.

LUCINI, H. C. Manual técnico de modulação de vãos de esquadrias. São Paulo : Pini, 2001. $101 \mathrm{p}$.

LYRIO FILHO, A. M.; AMORIN, S. L. Modelagem de empreendimentos imobiliários: um enfoque operacional. In: IV Simpósio Brasileiro de Gestão e Economia da Construção, 2005, Porto Alegre, Anais, p. 141-149. 
MAMEDE, F. C.; CORREA, M. R. S. Utilização de pré-moldados em edifícios de alvenaria estrutural. Cadernos de Engenharia de Estruturas (Online), v. 8, p. 1-27, 2006.

MARCHIORI, F. F. Desenvolvimento de um modelo de redes de composições de custo para orçamentação de obras de edificações. 2009. 235 p. Tese (Doutorado em Engenharia Civil) - Escola Politécnica da USP, São Paulo, 2009.

MARCONI, M. A.; LAKATOS, E. M. Técnicas de pesquisa: planejamento e execução de pesquisas, amostragens e técnicas de pesquisa, análise e interpretação de dados. $7^{\text {a }}$ Ed. São Paulo: Atlas, 2008. 277 p.

MASCARÓ, J. L. O custo das decisões arquitetônicas. $2^{\mathrm{a}}$ Ed. Revisão Ampliada. Porto Alegre: Sagra Luzzatto, 1998. 180 p.

MATTOS, A. D. Como preparar orçamentos de obras: dicas para orçamentos; estudos de casos; exemplos. São Paulo: Pini, 2007, 281 p.

MCT - Ministério da Ciência e Tecnologia. Necessidades de ações de desenvolvimento tecnológico na produção da construção civil e da construção habitacional, v.3, setembro 2000.

MELHADO, S. B. Qualidade do projeto na construção de edifícios: aplicação aocaso das empresas de incorporação e construção. 1994. Tese (Doutorado) Escola Politécnica, Universidade de São Paulo, São Paulo, 1994.

MELHADO, S. B.; AGOPYAN, V. O conceito de projeto na construção de edifícios: diretrizes para sua elaboração e controle. Boletim Técnico da Escola Politécnica da USP, São Paulo, BT/PCC/139, 19 p, 1995.

MONTEIRO FILHA, D. C. et al. Construção civil no Brasil: investimentos e desafios. In: TORRE, E.; PUGA, F.; MEIRELLES, B. Perspectivas do Investimento 20102013. $1^{\text {a }}$ Edição. Rio de Janeiro: BNDES, 2010. Capítulo 9, p. 300-356.

NETO, J. B. Projeto das estruturas de concreto armado para edifícios: diretrizes para garantia do desempenho, da qualidade, da exequibilidade e do custo final da estrutura/ edifício. São Paulo, 2003. 172 p. Dissertação (Mestrado) - Instituto de Pesquisas Tecnológicas do Estado de São Paulo, 2003. 
NETO, J. P. B.; FENSTERSEIFER, J. E.; FORMOSO, C. T. Os Critérios Competitivos da Produção: um Estudo Exploratório na Construção de Edificações. RAC, v. 7, n.1, Jan./ Mar. 2003: 67-85.

OLIVEIRA JÚNIOR, V. Recomendações para projeto de edifícios em alvenaria estrutural. 1992. 266 p. Dissertação (Mestrado) - Escola de Engenharia de São Carlos, Universidade de São Paulo, São Carlos, 1992.

OLIVEIRA, L. M.; PEREZ JR, J. H. Contabilidade de custos para não contadores. São Paulo, Atlas, 2000. 280 p.

OLIVEIRA, M. Caracterização de prédios habitacionais de Porto Alegre através de variáveis geométricas - uma proposta a partir das técnicas de estimativas preliminares de custo. 1990. 125 p. Dissertação (Mestrado) - Escola de Engenharia da Universidade Federal do Rio Grande do Sul, Porto Alegre, 1990.

OLIVEIRA, T. Custos. Revista Construção Mercado, São Paulo, fevereiro de 2006. Reportagens.

OTERO, J. A.; HEINECK, L. F. M. Análise paramétrica para estimativa de custos na construção de edifícios. In: X Encontro Nacional de Tecnologia do Ambiente Construído, 2004, São Paulo, Anais.

PALIARI, J. C. Método para prognóstico da produtividade da mão-de-obra e consumo unitário de materiais: sistemas prediais hidráulicos. São Paulo, 2008. 619p. Tese (Doutorado) - Escola Politécnica, Universidade de São Paulo.

PALIWAL, M.; KUMAR, U. A.. Neural networks and statistical techniques: A review of applications. Expert Systems with Applications, v. 36, p. 2 - 17, 2009.

POLI-ENCOL. Desenvolvimento de um novo processo construtivo em alvenaria estrutural não armada de blocos de concreto. Manual do Processo Construtivo POLI-ENCOL. Projeto. São Paulo, São Paulo: Relatório Técnico R5-25/91, Escola Politécnica da USP, 1991.

PROJECT MANAGEMENT INSTITUT - MG. PMBOK - Project Management Body of Knowledge. Belo Horiozonte, Brasil: PMBOK, 2002. 
PROVERBS, D. G.; HOLT, G. D.; OLOMOLAIYE, P. O. A method for estimating labour requirements and costs for international construction projects at inception. Building and Environment, v. 34, p. 43 - 48, 1999.

RIBA. Royal Institute of British Architects. Outline Plan of Work 2007. England, 2008. 3 p. Disponível em: <http://www.architecture.com>. Acesso em: 20 mar. 2012.

ROCHA LIMA, J. Especulação, Pânico e a Busca de Antídoto. Carta do NRE Poli. $\quad N^{\circ}$ 13-08. Departamento de Engenharia de Construção Civil, São Paulo. Dezembro, 2008.

ROCHA LIMA, J. Formação de modelos para analises econômico-financeiras na construção civil. 1985. Tese (Doutorado) - Escola Politécnica, Universidade de São Paulo, São Paulo, 1985.

ROCHA LIMA, J. Planejamento do produto no mercado habitacional. Boletim Técnico da Escola Politécnica da USP, São Paulo, BT/PCC/110, 26p, 1993.

SÃO PAULO (MUNICÍPIO). Decreto no 32.329, de 23 de setembro de 1992. Regulamenta a Lei 11.228, de 25 de junho de 1992 - Código de Obras e Edificações, e dá outras providências. São Paulo, 23 set. 1992.

SHEN, Z.; ISSA, R. R. A. Quantitative evaluation of the BIM - assisted construction detailed cost estimates. Journal of Information Technology in Constrction, v. 15, p. 234 - 257, 2010.

SILVA, L.L.R. Método de intervenção para a melhoria da eficiência na execução de revestimentos de argamassa de fachada. 2003. 199 p. Dissertação (Mestrado) - Escola Politécnica, Universidade de São Paulo, São Paulo, 2003.

SINDICATO DA INDÚSTRIA DA CONSTRUÇÃO CIVIL NO ESTADO DE MINAS GERAIS. Custo Unitário Básico $\left(\mathrm{CUB} / \mathrm{m}^{2}\right)$ : principais aspectos. Belo Horizonte: SINDUSCON- MG, 2007.112 p.

SINDICATO DA INDÚSTRIA DA CONSTRUÇÃO CIVIL NO ESTADO DE MINAS GERAIS. Número-Índice: Uma visão Geral. 2.ed. Belo Horizonte, SINDUSCON-MG, 2009. $72 \mathrm{p}$. 
SOLANO, S. R.; HEINECK, L. F. M. Caracterização geométrica e de consumo de mão-de-obra de edifícios de alto padrão em Porto Alegre: uma ferramenta auxiliar para a análise crítica de projetos e avaliação expedita de custos na fase preliminar do investimento. In: Workshop Nacional Gestão do Processo de Projeto na Construção de Edifícios, 2001, São Carlos. Anais.

SOUZA, J. C. S; SABBATINI, F. H. Metodologia de análise e seleção de inovações tecnológicas na construção de edifícios. BT/ PCC/ 370. São Paulo, 2004.

SOUZA, U. E. L. Método para a previsão da produtividade da mão-de-obra e do consumo unitário de materiais para os serviços de fôrmas, armação, concretagem, alvenaria, revestimentos com argamassa, contrapiso, revestimentos com gesso e revestimentos cerâmicos. 2001. 280 p. Tese (Livre Docência) - Escola Politécnica, Universidade de São Paulo, São Paulo, 2001.

STOY, C.; POLLALIS, S.; SCHALCHER, H. R. Drivers for Cost Estimating in Early Design: Case Study of Residential Construction. Journal of Construction Engineering and Management, v. 134, n. 1, p. 32 - 39, 2008.

STOY, C; SCHALCHER, H. R. Residencial Buildings Projects: Buildings Cost Indicators and Drivers. Journal of Construction Engineering and Management. Vol. 133, No 2. p. 139-145. February 2007.

TCPO: Tabelas de Composições de Preços para Orçamentos. 13ª Edição. São Paulo: Pini, 2003, 441 p.

THOMAS, H.R. et al. Modeling Construction Labor Productivity. Journal of Construction Engineering and Management. Vol. 116. $N^{\circ}$ 4. p 705- 726, December, 1990.

THOMAS, H.R.; YIAKOUMIS, I. Factor model of construction productivity. Journal of Construction Engineering and Management, v. 113, n. 4, p 623-39, 1987.

UNITED STATES OF AMERICA. Department of Defense. Parametric cost estimating handbook. 1995. 260 p. Disponível em: <http://cost.jsc.nasa.gov/pcehg.html>. Acesso em 20 nov. 2010.

YAU, N. J.; YANG, J. B. Case- based reasonig in construction management. Computer- Aided Civil and Infrastructure Engineering, 13, p. 143- 150, 1998. 
YEH, I. C. Quantify estimating of building with logarithm- neuron networks. Journal of Construction Engineering and Management, v. 124, n. 5, p. 374- 380, 1998. 


\section{APÊNDICE A - ENTREVISTA SEMI-ESTRUTURADA COM PROJETISTA DE ALVENARIA ESTRUTURAL}

A fim de se obterem mais subsídios para analisar os fatores que influenciam o consumo de materiais e suas especificações, no caso da alvenaria estrutural, foi proposta uma entrevista a um especialista desta área.

O entrevistado foi o Dr. Luiz Sérgio Franco que, além de lecionar a disciplina de Alvenaria Estrutural na Escola Politécnica da Universidade de São Paulo, atua como projetista e consultor de alvenaria estrutural na empresa ARCO.

A entrevista foi realizada em 24 de maio de 2012 e foi do tipo não estruturada, focalizada (MARCONI; LAKATOS, 2008).

A base de discussão foram indicadores que o próprio Professor tinha desenvolvido para análise de seus projetos.

Nos tópicos a seguir são retomadas as principais conclusões que foram utilizadas para a aplicação do método proposto nesta dissertação.

De acordo com Franco, estas estimativas foram feitas com base em parametrizações de resultados de projetos feitos em sua empresa. Para o projetista, as margens de erro que podem ocorrer nos valores estimados são da ordem de:

- $5 \%$ na quantidade de blocos;

- graute e armação horizontal: erro desprezível, mais ou menos igual à perda de material que pode ocorrer;

- graute e aço vertical: depende muito do local e projeto, podendo ter erro de até $20 \%$. 


\section{A.1 Estimativa e indicadores de blocos}

De acordo com Franco, a estimativa da resistência de blocos de alvenaria de 1 fbk por andar (com mínimo de $4 \mathrm{MPa}$ ) pode variar durante os cálculos de todos os esforços envolvidos em projeto executivo; porém, esta consideração em fase de viabilidade é usual e traz resultados satisfatórios.

Conforme discutido no item 4.2.1.1, a modulação de uma parede, em se utilizando blocos na coordenação modular de $20 \mathrm{~cm}$, necessita de blocos especiais. Verificando a distribuição de diferentes tipos de blocos em um pavimento tipo, projetado por ele, Franco considera as distribuições percentuais de referência mostradas no Quadro A.1, para os projetos que tem desenvolvido.

Quadro A.1: Distribuição percentual de componentes de blocos estruturais, incluindo canaletas

\begin{tabular}{|c|c|c|c|c|c|c|c|}
\hline Componente & Bloco 39 & $\begin{array}{c}\text { Meio } \\
\text { Bloco }\end{array}$ & $\begin{array}{c}\text { Bloco 34 } \\
\mathrm{cm}\end{array}$ & $\begin{array}{c}\text { bloco } 54 \\
\mathrm{~cm}\end{array}$ & $\begin{array}{c}\text { com 4 } \\
\mathrm{cm}\end{array}$ & $\begin{array}{c}\text { comp 9 } \\
\mathrm{cm}\end{array}$ & $\begin{array}{c}\text { canaleta } \\
39 \mathrm{~cm}\end{array}$ \\
\hline Dimensões & $\begin{array}{c}14 \times 39 x \\
19 \mathrm{~cm}\end{array}$ & $\begin{array}{c}14 \times 19 x \\
19 \mathrm{~cm}\end{array}$ & $\begin{array}{c}14 \times 34 \times \\
19 \mathrm{~cm}\end{array}$ & $\begin{array}{c}14 \times 54 x \\
19 \mathrm{~cm}\end{array}$ & $\begin{array}{c}14 \times 4 \times \\
19 \mathrm{~cm}\end{array}$ & $\begin{array}{c}14 \times 9 \times \\
19 \mathrm{~cm}\end{array}$ & $\begin{array}{c}14 \times 39 x \\
19 \mathrm{~cm}\end{array}$ \\
\hline $\begin{array}{c}\text { Área de um } \\
\text { bloco }\end{array}$ & 0,08 & 0,04 & 0,07 & 0,11 & 0,01 & 0,02 & 0,08 \\
\hline $\begin{array}{c}\% \text { na alvenaria } \\
\text { estrutural }\end{array}$ & $72 \%$ & $5 \%$ & $6 \%$ & $4 \%$ & $0,70 \%$ & $0,30 \%$ & $12 \%$ \\
\hline
\end{tabular}

Em se tendo uma planta base para levantamento de dados, pode-se fazer a estimativa da quantidade de blocos canaletas do seguinte modo:

- presença de canaletas em cinta superior (este projetista não utiliza cinta intermediária);

- presença de canaletas como verga e contra verga (em portas e janelas)

- medição linear de canaletas

- divisão da medição linear por $40 \mathrm{~cm}$ (bloco + junta), para se ter um referencial da quantidade deste tipo bloco. 
Com base na determinação da quantidade de canaletas, pode-se estimar a quantidade dos demais blocos trilhando os seguintes passos:

- cálculo da área líquida de paredes (dada pela quantidade linear de paredes multiplicada pelo pé-direito, subtraindo-se a área das esquadrias);

- cálculo da área total dos blocos canaletas;

- determinação da área de paredes sem canaletas, dada pela subtração da área de canaletas da área líquida de paredes;

- determinação da área total de cada tipo de bloco dada pela multiplicação da área de paredes sem canaletas pelo percentual de distribuição do Quadro A.2;

- estimativa da quantidade de blocos através da divisão da área total de cada tipo de bloco pela área de um único bloco (mostrada no Quadro A.2).

Quadro A.2: Distribuição percentual de componentes de blocos estruturais, sem considerar as canaletas

\begin{tabular}{|c|c|c|c|c|c|c|}
\hline Componente & Bloco 39 & $\begin{array}{c}\text { Meio } \\
\text { Bloco }\end{array}$ & $\begin{array}{c}\text { Bloco } 34 \\
\mathrm{~cm}\end{array}$ & $\begin{array}{c}\text { bloco } 54 \\
\mathrm{~cm}\end{array}$ & $\begin{array}{c}\text { com 4 } \\
\mathrm{cm}\end{array}$ & $\begin{array}{c}\text { comp } 9 \\
\mathrm{~cm}\end{array}$ \\
\hline Dimensões & $\begin{array}{c}14 \times 39 \times 19 \\
\mathrm{~cm}\end{array}$ & $\begin{array}{c}14 \times 19 \times 19 \\
\mathrm{~cm}\end{array}$ & $\begin{array}{c}14 \times 34 \times 19 \\
\mathrm{~cm}\end{array}$ & $\begin{array}{c}14 \times 54 \times 19 \\
\mathrm{~cm}\end{array}$ & $\begin{array}{c}14 \times 4 \times 19 \\
\mathrm{~cm}\end{array}$ & $\begin{array}{c}14 \times 9 \times 19 \\
\mathrm{~cm}\end{array}$ \\
\hline Área de um bloco & 0,08 & 0,04 & 0,07 & 0,11 & 0,01 & 0,02 \\
\hline $\begin{array}{c}\% \text { na alvenaria } \\
\text { estrutural }\end{array}$ & $81,8 \%$ & $5,7 \%$ & $6,8 \%$ & $4,6 \%$ & $0,8 \%$ & $0,3 \%$ \\
\hline
\end{tabular}

\section{A.2 Quantidade de graute}

De acordo com Franco, os blocos canaleta são utilizados para serem preenchidos com graute em reforços pontuais da parede; assim, a estimativa de graute horizontal pode ser feita multiplicando a quantidade linear de canaletas pela área de furo de sua seção vertical.

O grauteamento vertical é realizado, principalmente, devido principalmente, a dois fatores: 
- fator construtivo: há um mínimo de grauteamento para maior resistência do conjunto estrutural, que depende, principalmente, da quantidade de ligações entre paredes, esforços localizados e da altura da edificação;

- fator ligado a esforços horizontais de vento.

No primeiro caso, Franco forneceu indicadores de quantidades mínimas de pontos de graute, aqui chamados de Q0, apresentados no Quadro A.3.

Quadro A.3: Indicadores de quantidade de graute vertical Q0

\begin{tabular}{|c|c|}
\hline Pavimentos & $\begin{array}{c}\text { Q0 - Quantidade de grautes por } \\
\text { área construída }\left(\mathrm{un} / \mathrm{m}^{2}\right)\end{array}$ \\
\hline de 4 a 8 pavimentos & 0,065 \\
\hline de 9 a 12 pavimentos & 0,100 \\
\hline de 13 a 16 pavimentos & 0,120 \\
\hline
\end{tabular}

Para estimar a quantidade de graute devido a esforços de vento $(\mathrm{Qv})$, o projetista desenvolveu a Eq. A.1, que relaciona o vento, a rigidez do prédio (definida pelo projeto), a largura da fachada e altura da edificação. Esta quantidade deve ser aplicada apenas aos pavimentos abaixo de 8 andares (onde os esforços de vento serão significativos).

$$
Q_{v}=\frac{0,000007 \times V_{0}^{2} \times H^{3} \times L_{\text {Fachada }}}{\sum I}
$$

onde:

$Q_{v}=$ quantidade de grautes verticais devido a esforços de vento (em und.);

$\mathrm{V}_{0}=$ velocidade básica do vento em $\mathrm{m} / \mathrm{s}$ na região onde será implantado o edifício;

$\mathrm{H}=$ altura dos pavimentos acima do pavimento em questão, excluindo o ático do prédio (em m); 
$\Sigma I$ = somatória do momento de inércia das paredes estruturais para a direção principal do vento $\left(\mathrm{em} \mathrm{m}^{4}\right)$.

A Figura A.1 mostra, graficamente, a variação da quantidade de graute em edifícios. Nota-se que nos últimos 8 andares, há apenas Q0 pontos de graute e que nos andares abaixo, a quantidade de pontos de graute muda conforme o cálculo de Qv.

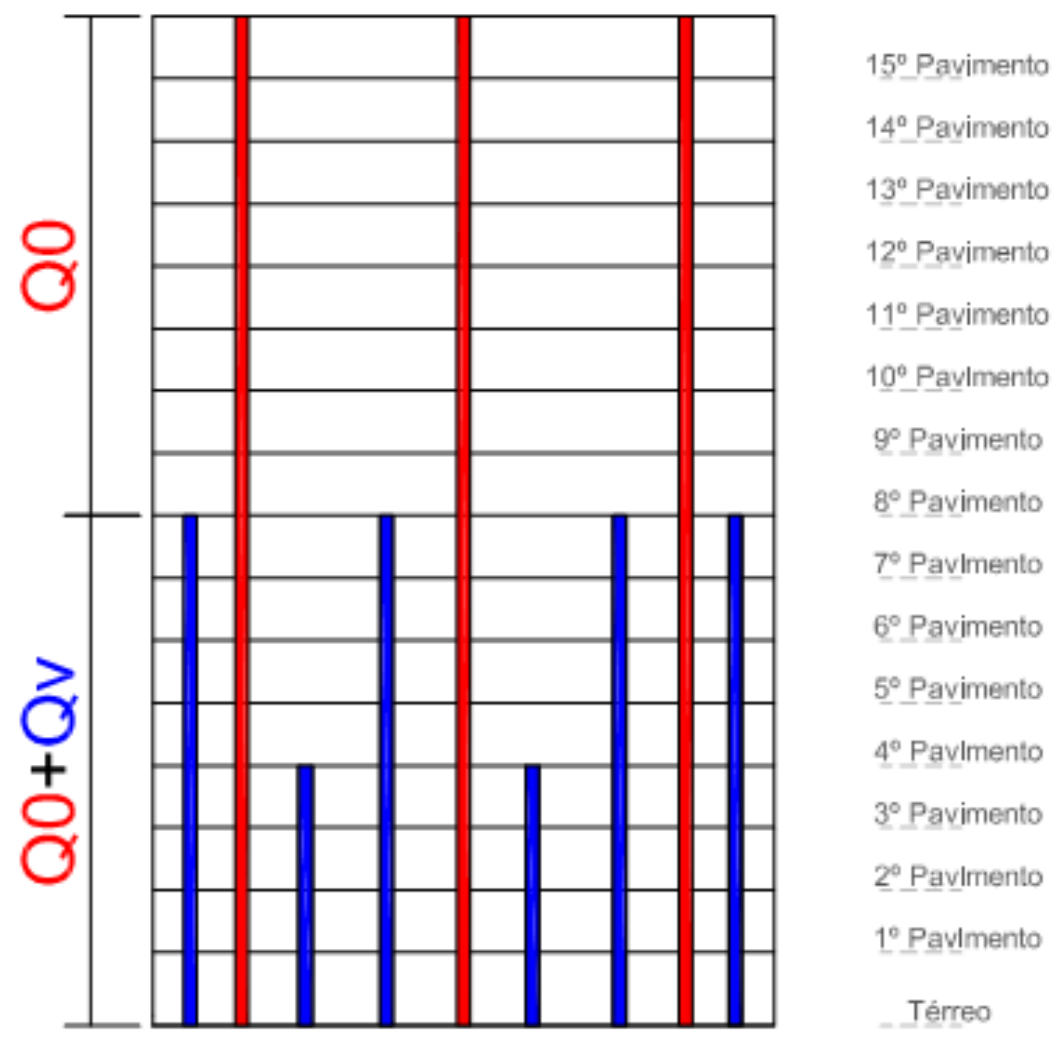

Figura A.1: Variação da quantidade de pontos de graute

\section{A.3 Quantidade de aço}

De acordo com Franco, o graute horizontal deve ser armado com $0,28 \mathrm{Kg} / \mathrm{bloco}$ canaleta (armação de uma barra de $10 \mathrm{~mm}$ nos blocos), o que, para o projetista, é adequado a maior parte das situações. 
Com relação à armação vertical, Franco prevê que todos os pontos grauteados verticalmente tenham armação. A estimativa feita por ele considera os seguintes indicadores:

- 4 primeiros andares: 1 barra de $16 \mathrm{~mm}(1,6 \mathrm{Kg} / \mathrm{ml})$; comprimento igual ao do pavimento $+60 \mathrm{~cm}$ de transpasse;

- 5 pavimentos acima: 1 barra de $12,5 \mathrm{~mm}$ ( $1 \mathrm{Kg} / \mathrm{ml})$; comprimento igual ao do pavimento $+60 \mathrm{~cm}$ de transpasse;

- restante (até 16 pavimentos): 1 barra de $10 \mathrm{~mm}(0,65 \mathrm{Kg} / \mathrm{ml})$; comprimento igual ao do pavimento $+60 \mathrm{~cm}$ de transpasse;

A Figura A.2 mostra, esquematicamente, a variação das bitolas das armações em relação à quantidade de pavimentos que o edifício possuir.

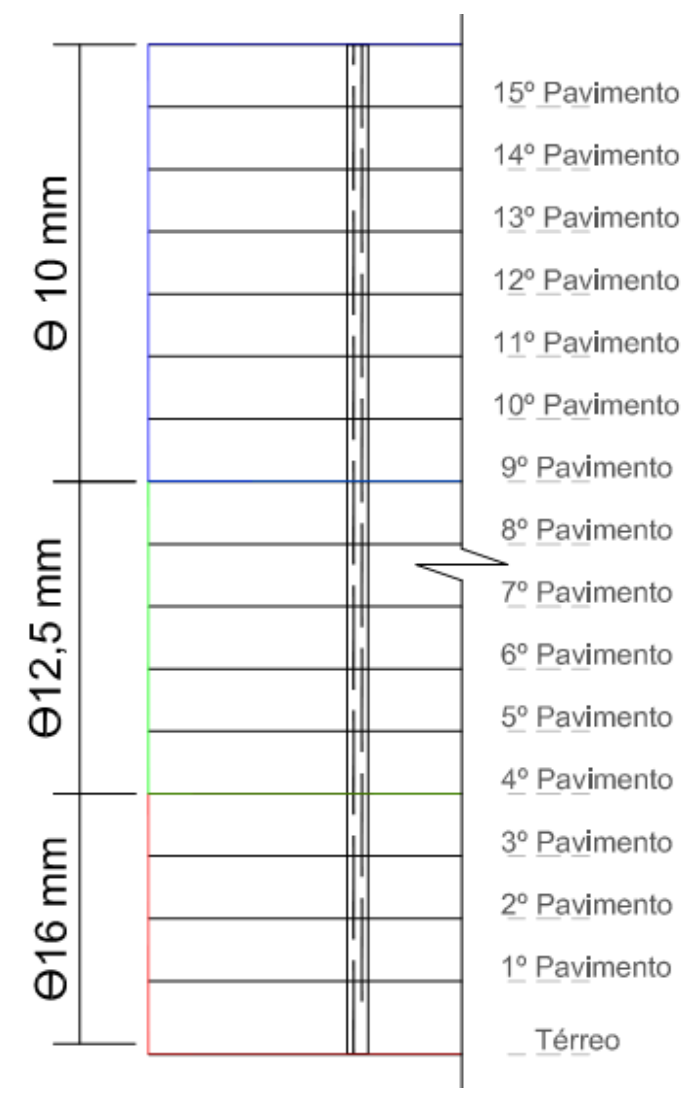

Figura A.2: Variação das bitolas de armação vertical por andar 